UNIVERSIDADE DE SÃO PAULO

FACULDADE DE ECONOMIA, ADMINISTRAÇÃO E CONTABILIDADE DEPARTAMENTO DE ADMINISTRAÇÃO

PROGRAMA DE PÓS-GRADUAÇÃo EM ADMINISTRAÇÃo

INOVAÇÃO E MELHORIA NAS FACILIDADES E DESEMPENHO OPERACIONAL

Robson Quinello

Orientador: Prof. Dr. Paulo Tromboni de Souza Nascimento

SÃo PAULO

2010 
Prof. Dr. João Grandino Rodas

Reitor da Universidade de São Paulo

Prof. Dr. Carlos Roberto Azzoni

Diretor da Faculdade de Economia, Administração e Contabilidade

Prof. Dr. Adalberto Américo Fischmann

Chefe do Departamento de Administração

Prof. Dr. Lindolfo Galvão de Albuquerque Coordenador do Programa de Pós-Graduação em Administração 
ROBSON QUINELLO

\title{
INOVAÇÃO E MELHORIA NAS FACILIDADES E DESEMPENHO OPERACIONAL
}

\begin{abstract}
Tese apresentada ao Departamento de Administração da Faculdade de Economia, Administração e Contabilidade da Universidade de São Paulo como requisito para a obtenção do título de Doutor em Administração.
\end{abstract}

Orientador: Prof. Dr. Paulo Tromboni de Souza Nascimento

SÃO PAULO

2010 


\section{FICHA CATALOGRÁFICA}

Elaborada pela Seção de Processamento Técnico do SBD/FEA/USP

Quinello, Robson

Inovação e melhoria nas facilidades e desempenho operacional /

Robson Quinello. -- São Paulo, 2010.

$240 \mathrm{p}$.

Tese (Doutorado) - Universidade de São Paulo, 2010.

Orientador: Paulo Tromboni de Souza Nascimento.

1. Desempenho organizacional 2. Ambiente organizacional

3. Criatividade I. Universidade de São Paulo. Faculdade de Economia, Administração e Contabilidade II. Título.

CDD -658.402 
A minha família e amigos, sempre presentes. 


\section{RESUMO}

Diversos autores apontam a inovação como uma atividade crítica para todas as empresas inseridas num contexto concorrencial, pois ela orienta a estratégica da empresa, direciona a alocação de recursos e influencia os indicadores de desempenho. Como os altos investimentos em P\&D não são suficientes para assegurar o sucesso de seus produtos, o diferencial competitivo das organizações não estaria relacionado apenas às grandes diferenças de conhecimento tecnológico, mas a maneira como cada uma delas aperfeiçoa os seus processos internos para implementar um novo produto. Esta condição reforça o papel das áreas funcionais periféricas, na construção de um ambiente inovador, não apenas modificando o desempenho da organização, mas também o impulsionando. Mas como será a participação dessas áreas, por exemplo, as de facilidades (termo traduzido do anglo-saxão facilities management), que estão fora do eixo tradicional de $\mathrm{P} \& \mathrm{D}$, nesse ambiente inovador? Elas inovam? Como suas inovações afetam o desempenho das empresas? O objeto de estudo da tese consistiu na caracterização das inovações e melhorias em facilidades e os impactos no desempenho das organizações. A hipótese principal foi que as inovações em facilidades afetariam diretamente a eficiência operacional e esta, por sua vez, os desempenhos financeiros, ou seja, as inovações em facilidades seriam intermediárias na obtenção dos resultados das operações. A pesquisa foi descritiva-relacional, quantitativa e qualitativa, utilizando triangulação metodológica. Os resultados foram obtidos por meio de casos coletados em campo durante a fase empírica, estudo de caso único e por questionários semiestruturados. Foram inquiridos 163 profissionais da área e analisadas 220 mudanças técnicas e organizacionais em facilidades, entre os anos de 2007 e 2010 . Esperou-se com essa tese aprofundar os estudos da dinâmica das inovações e melhorias em facilidades; estender a teoria da inovação por meio da investigação das em facilidades e avançar na discussão do papel delas no desempenho organizacional, dando um novo significado à gestão de facilidades dentro da área de Operações. Os resultados da tese apontaram que as mudanças técnicas e organizacionais nas facilidades constituem melhorias e inovações que impactam principalmente os fatores de eficiência operacional - produtividade e meio ambiente e, indiretamente, os financeiros - lucro. Todavia, numa análise fatorial, pode-se notar a formação de conglomerados específicos chamados aqui de inovações e melhorias em facilidades para apoio à produtividade, sustentabilidade, qualidade e rentabilidade. Esses grupos indicam que as melhorias e inovações geradas em facilidades são oriundas de intensa relação entre parceiros, busca contínua pela redução de custos e aumento do ciclo de vida dos ativos e das infraestruturas de apoio das organizações. Constataram-se diferenças na composição, na dinâmica e no propósito dessas inovações e melhorias, revelando assim que as estratégias e gestões para o desenvolvimento e implantação dessas mudanças, nesses ambientes, não são iguais aos recomendados pelas teorias correntes. As mudanças técnicas e organizacionais encontradas foram adotadas, na sua maioria, em caráter informal e tácito, gerando indiretamente novos serviços e produtos em facilidades, além de aprendizado infraestrutural. O grau de novidade variou de melhorias contínuas à inovações incrementais e raramente radicais.

Palavras-chave: Facilidades, Inovação, Melhoria Contínua, Desempenho Operacional 


\begin{abstract}
Several authors place the innovation as a critical activity for all companies included in a competitive environment because it supports the strategic direction of the company, directs the allocation of resources and influences the performance of the indicators. As the high investments in R \& D are not sufficient to ensure the success of its products, the competitive advantage of organizations would not be related only to large differences in technological knowledge, but how each one improves your internal processes to implement a new product. This condition strengthens the assumption that the role of peripheral functional areas, the construction of an innovative, can not just change the organization's performance, but also boost it. But how will the participation of these areas, for example, the facilities management, which are outside the traditional R \& D in this innovative environment? Do they innovate? How their innovations affect corporate performance? The subject of the thesis was the characterization of the innovations in facilities and its impacts on performance of organizations. The main hypothesis was that the innovations in facilities would directly affect operational efficiency and this, in turn, financial performance, in other words, the innovations in facilities would be intermediate in obtaining superior results in operations. The research was a descriptive-relational, quantitative and qualitative, using methodological triangulation. The results were obtained from cases collected in the field during the empirical phase and semi-structured questionnaires applied to 163 professionals and 220 innovations and improvements on facilities. It was expected that thesis with further study of the dynamics of innovation in facilities; extend the theory of innovation through research in the facilities and advance the discussion of their role in organizational performance, giving new meaning to the facilities management within Operations field. The results of the thesis showed that the changes and organizational in facilities producing improvements and innovations that impact primarily the factors of operational efficiency: productivity and environment and, indirectly, the financial markets: profit. However, a factor analysis, one could note the formation of specific clusters called here, innovations and improvements in facilities to support the productivity, sustainability, quality and profitability. These groups indicate that improvements and innovations generated by the facilities are artifacts coming from a close relationship between partners, continuous search for lower costs and increase the life cycle of assets and infrastructure in support of the organizations. There were differences in the nature, composition, dynamics and purpose of innovations and improvements, thus revealing that the strategies and management activities for the development and deployment these changes, these environments are not exactly the same as recommended by current theories. The technical and organizational changes found were adopted, mostly in an informal and tacit way, indirectly generating new services and products in facilities, and infrastructural learning. The degree of novelty varied from the continuous improvements to the incremental innovations, and, rarely, to radical.
\end{abstract}

Keywords: Facilities, Innovation, Continuous Improvement, Operational Performance 



\section{SUMÁRIO}

LISTA DE QUADROS 3

LISTA DE FIGURAS

LISTA DE TABELAS

LISTA DE GRÁFICOS

1 INTRODUÇÃO

1.1 O que são facilidades e gestão de facilidades 11

1.2 Por que caracterizar as inovações e melhorias em facilidades e seus impactos 13

$\begin{array}{lll}1.3 & \text { Problema de pesquisa } & 15\end{array}$

$\begin{array}{lll}1.4 & \text { Objetivos da pesquisa } & 15\end{array}$

1.5 A mudança técnica e organizacional em facilidades e seus impactos 16

$\begin{array}{lll}1.6 & \text { Justificativas teórica e prática do estudo } & 20\end{array}$

1.7 Contribuições esperadas do estudo das inovações e melhorias em

$\begin{array}{ll}\text { facilidades } & 21\end{array}$

$\begin{array}{lll}1.8 & \text { Estrutura utilizada na tese } & 22\end{array}$

2 FACILIDADES, INOVAÇÃO E MELHORIAS CONTÍNUAS 24

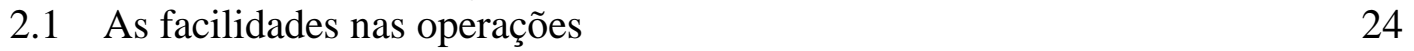

2.2.1 Inovações e melhorias em facilidades 26

2.2 Conceitos gerais sobre as inovações e melhorias contínuas 27

2.3 Tipos de inovação tradicionais 33

2.4 Inovações com foco em serviços 38

2.5 Inovações com foco em processos e melhorias 40

$\begin{array}{ll}2.6 & \text { Inovações organizacionais }\end{array}$

2.7 Síntese da fundamentação teórica 49

3 MODELO RELACIONAL DO IMPACTO DAS INOVAÇÕES E
ELHORIAS

3.1 A relação da inovação e melhorias com os resultados das organizações 56

3.2 Especificações iniciais do modelo relacional: conteúdo e estrutura 61

3.3 Caracterização das dimensões do modelo relacional 62

3.1.1 Testes de hipóteses do modelo de investigação 66

3.4 Limitações do modelo relacional proposto na tese 68

4 METODOLOGIA DA PESQUISA

4.1 Tipos de pesquisa utilizados na tese: qualitativos e quantitativos $\quad 70$

$\begin{array}{lll}4.2 & \text { Amostragem } & 73\end{array}$

$\begin{array}{lll}4.3 & \text { Levantamento dos dados } & 74\end{array}$

$\begin{array}{lll}4.4 & \text { Estratégias para análise dos dados } & 80\end{array}$

4.1.1 Técnicas estatísticas usadas na pesquisa $\quad 80$

$\begin{array}{lll}4.5 & \text { Confiabilidade dos dados coletados } & 81\end{array}$

4.6 Síntese dos aspectos metodológicos $\quad 82$

5 O IMPACTO DAS INOVAÇÕES E MELHORIAS NAS FACILIDADES 84

5.1 Levantamento de casos de inovações e melhorias em facilidades 84

5.1.1 $1^{\text {a }}$. etapa: primeiras evidências das inovações em facilidades $\quad 84$

5.1.2 2a $2^{\mathrm{a}}$. etapa: indícios da relação entre inovações, melhorias e

desempenhos $\quad 89$

5.1.3 $3^{\text {a }}$. etapa: inovações e melhorias e seus impactos nos desempenhos 94

5.1.4 Convergindo as inovações e melhorias em facilidades 98

5.2 Estudo de caso único: as inovações e melhorias em facilidades geradas em 
sistemas tecnológicos complexos $\quad 102$

$\begin{array}{lll}\text { 5.2.1 O contexto do caso } & 104\end{array}$

5.2.2 Unidade de análise: um parque de torres de resfriamento 105

5.2.3 Nível de análise: os componentes, subsistemas e sistemas $\quad 107$

5.2.4 Mecanismos causais e a aprendizagem infraestrutural 114

5.2.5 Sequência temporal: as etapas da implantação da inovação 117

$\begin{array}{lll}5.3 & \text { Survey } & 122\end{array}$

5.3.1 Fases pilotos para elaboração do survey 122

$\begin{array}{ll}\text { 5.3.2 Aplicação do survey } & 124\end{array}$

5.3.2.1 Perfil das empresas $\quad 125$

5.3.2.2 Perfil dos respondentes 128

5.3.2.3 Características gerais das inovações e melhorias $\quad 130$

5.3.2.4 Impactos nas eficiências operacionais 136

5.3.2.5 Correlações e testes de significância da amostra 138

5.3.2.6 Análise fatorial e testes de hipóteses: novas categorias $\quad 145$

6 CONTRIBUIÇÕES DO ESTUDO, LIMITAÇÕES E CONCLUSÕES 153

$\begin{array}{ll}\text { 6.1 Respondendo a questão geral da tese } & 153\end{array}$

6.2 Respondendo as questões específicas da tese 154

$\begin{array}{ll}6.3 \text { Implicações gerenciais } & 157\end{array}$

6.4 Limitações da tese 159

6.5 Contribuições teóricas e novas pesquisas $\quad 160$

7 REFERÊNCIAS BIBLIOGRÁFICAS

8 LISTA DE APÊNDICES 


\section{LISTA DE QUADROS}

Quadro 1 - Sequência lógica do estudo

Quadro 2 - Etapas para delineamento do modelo da tese

Quadro 3 - Comparativo entre as inovações da literatura e dos casos empíricos

Quadro 4 - Evolução da manufatura

Quadro 5 - Dimensões e hipóteses da pesquisa

Quadro 6 - Diferenças entre pesquisa quantitativa e qualitativa 71

Quadro 7 - Explicações das dimensões pesquisadas 75

Quadro 8 - Síntese metodológica $\quad 82$

Quadro 9 - Características gerais das inovações e melhorias 94

Quadro 10 - Pleitropia de uma inovação em facilidades 111

Quadro 11 - Nível, mudança e grau de novidadade do caso 113

Quadro 12 - Características gerais das inovações e melhorias 130

Quadro 13 - Testes de hipóteses de igualdade entre as variáveis 140

Quadro 14 - Dimensões e hipóteses testadas 148 


\section{LISTA DE FIGURAS}

Figura 1 - Inovações e melhorias em facilidades: modelo preliminar conceitual $\quad 10$

$\begin{array}{ll}\text { Figura } 2 \text { - Dimensões que geram a gestão de facilidades } & 13\end{array}$

Figura 3 - Localização e escopo de I/M F e I/M P 16

Figura 4 - Objeto de estudo da tese: uma inovação no parque de torres de resfriamento 17

Figura 5 - Posicionamento das atividades de facilidades 25

Figura 6 - Tipos de inovações e inter-relações 33

Figura 7 - O modelo da dinâmica das inovações 43

Figura 8 - Passo e tempo das inovações em processos e melhorias $\quad 47$

Figura 9 - Modelo de investigação relacional preliminar das inovações 64

Figura 10 - Modelo relacional para testes de hipóteses $\quad 67$

$\begin{array}{ll}\text { Figura } 11 \text { - Triangulação metodológica utilizada na tese } & 72\end{array}$

Figura 12 - Intensidade das inovações e melhorias em facilidades $\quad 86$

Figura 13 - Relações das inovações em facilidades $\quad 88$

Figura 14 - Modelo preliminar das inovações e seus impactos operacionais 93

Figura 15 - Modelo interpretativo das inovações, melhorias e desempenhos $\quad 97$

Figura 16 - A coexistência entre novas e antigas tecnologias 103

Figura 17 - Tipos de torres de resfriamento de água 105

Figura 18 - Níveis de análise da tecnologia de insfraestrutura para resfriamento $\quad 109$

$\begin{array}{ll}\text { Figura } 19 \text { - Principais eventos do caso analisado } & 118\end{array}$

Figura 20 - O modelo da dinâmicas das inovações reformulado 120

Figura 21 - O cronograma da implantação e recursos do caso 122

Figura 22 - Resultado da análise fatorial $\quad 146$

Figura 23 - O modelo de hipóteses testado $\quad 147$

Figura 24 - Combinações possíveis para as melhorias em facilidades $\quad 150$ 


\section{LISTA DE TABELAS}

Tabela 1 - Componentes da complexidade das famílias de produtos

Tabela 2 - Principais dimensões afetadas pelas mudanças

Tabela 3 - Diferenças estatísticas entre as dimensões das empresas

Tabela 4 - Testes de significância dos fatores de desempenho e financeiro 


\section{LISTA DE GRÁFICOS}

Gráfico 1 - Produção acadêmica sobre inovação entre 1900 a 2005

Gráfico 2 - Características gerais da convergência das fases empíricas 99

Gráfico 3 - Gráfico do porte das empresas e dos tipos de inovações 101

Gráfico 4 - Origem e tamanho das organizações 126

Gráfico 5 - Setor, perfil e atividades das organizações $\quad 127$

Gráfico 6 - Experiência e formação dos respondentes 128

Gráfico 7 - Cargo e nível hierárquico dos respondentes 129

Gráfico 8 - Análise léxica das respostas 131

Gráfico 9 - Tipo, localização e intensidade das inovações e melhorias 132

Gráfico 10 - Centralidade das inovações e melhorias e perfil das empresas $\quad 132$

Gráfico 11 - Motivação e obstáculos para as inovações e melhorias 133

Gráfico 12 - Tipo de inovações e melhorias e os obstáculos 134

Gráfico 13 - Tempo e custo das inovações e melhorias 134

Gráfico 14 - Fonte de ideias e conhecimentos utilizados $\quad 135$

Gráfico 15 - Posição e tipo de inovações e melhorias 136

Gráfico 16 - Impactos das mudanças nos desempenhos 137

Gráfico 17 - Peso dos impactos das mudanças 138

Gráfico 18 - Diferenças estatísticas entre posicionamento e impactos 141

Gráfico 19 - Diferenças estatísticas entre motivação e impactos 142

Gráfico 20 - Diferenças estatísticas entre conhecimentos e impactos 143

Gráfico 21 - Diferenças estatísticas entre tamanho e impactos 144

Gráfico 22 - Diferenças estatísticas entre cargo, experiência e impactos 144 


\section{INTRODUÇÃO}

Diversos autores colocam a inovação como uma atividade crítica para todas as empresas inseridas num contexto concorrencial, pois ela orienta a estratégica da empresa, direciona a alocação de recursos e influencia os indicadores de desempenho. Indústrias submetidas a ambientes de forte concorrência e acelerado crescimento e presentes nos países emergentes como o Brasil, têm voltado sua atenção não só para seus próprios produtos em si, mas também para o aperfeiçoamento de seus processos internos. Altos investimentos em P\&D não são suficientes para assegurar o sucesso de novos produtos, sendo assim o diferencial competitivo das organizações não estaria relacionado apenas às grandes diferenças de conhecimento tecnológico, mas pela maneira como cada uma delas aperfeiçoa os seus processos internos para implementar um novo produto (QUINELLO; CASTRO, 2007). Esta condição reforça que o papel das áreas funcionais centrais e também as periféricas, na construção de um ambiente inovador, pode não apenas modificar o desempenho da organização, mas também impulsioná-lo. Mas, como será a participação de áreas periféricas, por exemplo, as responsáveis pelas infraestruturas internas conhecidas como facilidades (termo técnico traduzido do anglo-saxão facilities management), que estão fora do eixo tradicional de P\&D (Marketing-Manufatura-Engenharia), nesse ambiente inovador? Elas inovam? Como suas inovações afetam o desempenho das empresas? O termo técnico facilities management foi traduzido livremente para gestão de facilidades, pois a amplitude das funções da área é maior do que faz pensar a tradução tradicional - gestão das instalações.

De acordo com Becheikh et al (2006) a literatura científica, especificamente a relacionada às inovações em processos ("parentes" próximas das em facilidades), é, em comparação àquela em produtos, reduzida. Segundo o autor, em parte devido à dificuldade em conceituá-la, isolála, mensurá-la e descrevê-la. Como as inovações em serviços, recentemente incluídas no rol das pesquisas acadêmicas, os trabalhos das inovações em processos ainda são poucos. Não se pode pensar em produtos com escala de vendas sem os processos, por mais rudimentares que sejam e nem em processos sem as inúmeras inovações e melhorias, ocorridas no dia a dia, nas facilidades. Sob o ponto de vista acadêmico, um desafio intelectual seria analisar este fenômeno, seja do ponto de vista descritivo, isto é, como ele ocorre, ou do ponto de vista prescritivo, como deveria ser feito. 
Um agravante maior é a escassez de trabalhos e pesquisas acadêmicas que desvendem substratos ainda mais tênues e profundos das inovações em processos: parte delas é composta por melhorias contínuas (improvement innovation) como ajustes, aperfeiçoamentos, adaptações, correções, outras, pejorativamente classificadas como "gambiarras" ou kluge (denominação dada por engenheiros americanos), ocorridas frequentemente nas infraestruturas internas das organizações e por vezes desprezadas. Marcus (2008) denomina esses kluges de soluções não elegantes para um problema. Eles impactam direta ou indiretamente nos desempenhos das organizações? Como? Aqui foram definidos todos estes sinônimos, a princípio conceitualmente, como inovações e melhorias em facilidades e os indicadores por eles afetados, como fatores de desempenho operacional.

A escassez de pesquisas neste tipo de inovação se agrava por outro fator: falta de estatísticas oficiais. Esforços sistemáticos de mensuração das inovações, como o da Pesquisa Industrial de Inovação Tecnológica (PINTEC, p. 18, 2005), claramente descartam tais inovações: “[...] sendo excluídas as mudanças: pequenas ou rotineiras nos processos produtivos existentes, e aquelas puramente administrativas ou organizacionais". Seriam pequenas ou rotineiras mudanças insignificantes para os desempenhos organizacionais? Não seriam estas inovações descartadas melhorias contínuas?

São pertinentes algumas conceituações preliminares dos termos inovação e melhorias contínuas em facilidades e fatores de desempenho operacional. As inovações e as melhorias em facilidades seriam artefatos técnicos ou processos organizacionais modificados, oriundos de ações e intervenções de indivíduos ou grupos de profissionais, sem necessariamente uma gestão formalizada, nas infraestruturas operacionais periféricas (instalações, máquinas, equipamentos, sistemas e utilidades em geral), necessárias para as operações centrais das organizações. Essas modificações técnicas ou organizacionais, na grande maioria, não são pensadas com o intuito ou lógica de mercado, mas para resolver problemas, ou seja, características que fogem dos conceitos tradicionais de inovação. As modificações em facilidades, pelas primeiras investigações de campo conduzidas na tese, mostram-se muito próximas àquelas ocorridas em processos e às organizacionais, próximas das em serviços e distantes das em produtos, lembrando uma escala de parentesco, como pode ser notada na Figura 1. 
Os fatores de desempenho operacional, tratados nesta tese, foram reduzidos à eficiência operacional apontada por diversos autores como fundamental e devidamente aprofundada na seção de fundamentação teórica. A eficiência operacional já foi utilizada por Skinner (1996), Slack (1993) e Nakajima (1988) a partir da década de 1970, referindo-se a um conjunto de critérios operacionais que traduziriam ganhos em disponibilidade, qualidade e desempenhos internos. Aqui se pressupõe que as inovações e melhorias em facilidades afetam principalmente os fatores internos (eficiência) e não os financeiros. Os financeiros (lucro, participação de mercado e retorno sobre os investimentos) foram utilizados para se contrapor aos de eficiência operacional.

Na Figura 1, uma primeira abstração, formulada a partir de pesquisas de campo, preliminares à tese, com 125 mudanças técnicas e organizacionais geradas por departamentos de facilidades de empresas de diversos setores no Estado de São Paulo, nota-se que as inovações e melhorias em facilidades (os círculos) estariam limitadas ao ambiente interno e particular das organizações, não sendo diretamente visíveis ou captadas pelo ambiente externo (clientes e concorrentes). Elas possuem intensidade de novidade entre mínima e média, ou seja, entre melhorias contínuas e inovações incrementais (apenas uma inovação citada poderia ser considerada radical - a implantação de um parque industrial com novas tecnologias). Não obstante, ajudariam a expandir (setas) e aperfeiçoar internamente as capacidades, reduzir as restrições operacionais e impulsionar as inovações em processos ou as organizacionais (os quadrados) e estas impulsionariam o desempenho final materializado pelos produtos e ou serviços. Qual é a força desta relação? 


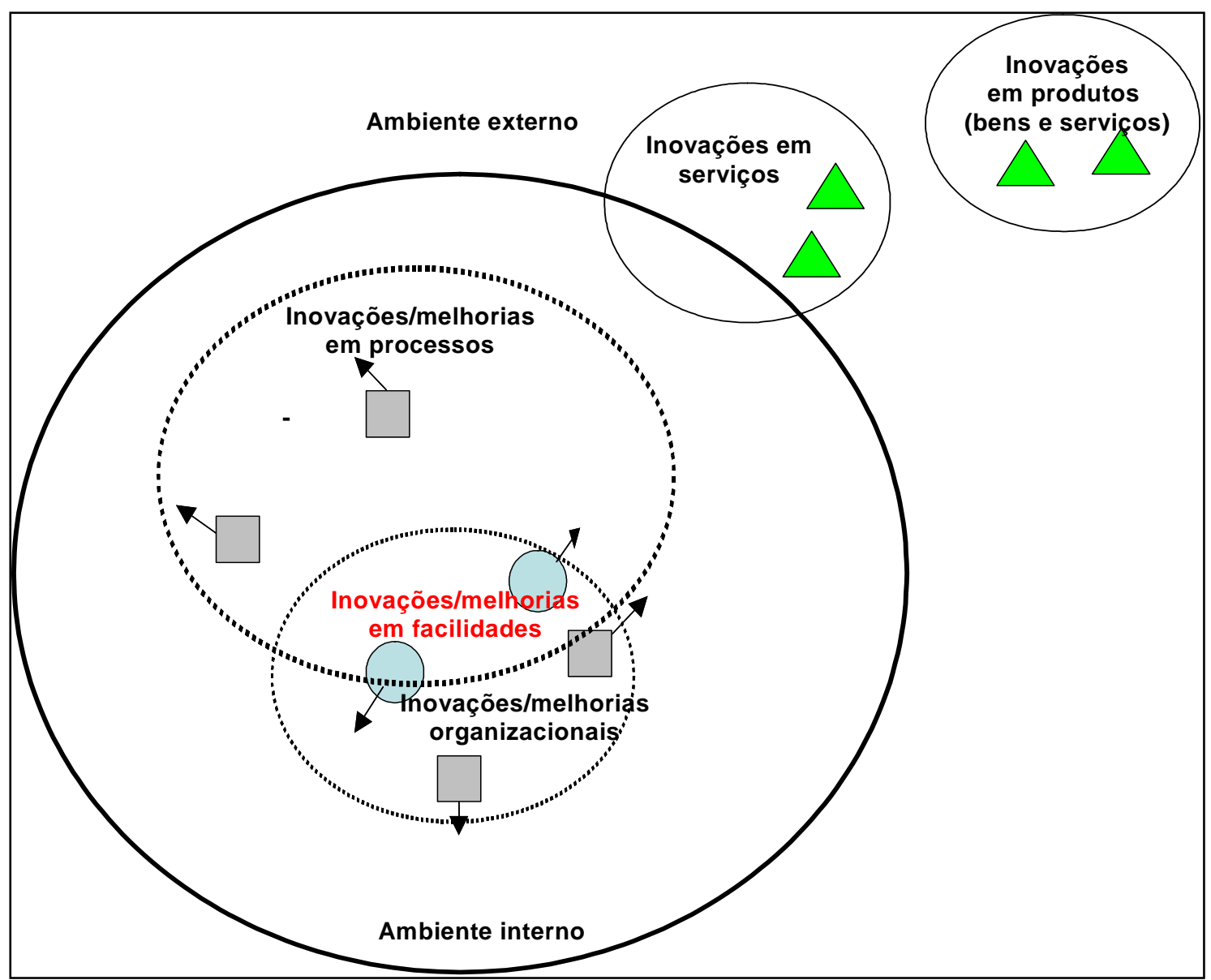

Figura 1 - Inovações e melhorias em facilidades: modelo preliminar conceitual

$\mathrm{Na}$ parte externa da Figura 1 estão os produtos ou serviços (triângulos) das inovações (radicais ou incrementais) observáveis e adquiridas pelos clientes externos. No ambiente interno, estariam as inovações e melhorias em processos e as organizacionais (quadrados), e na intersecção (círculos), as em facilidades. Nessa primeira investigação não foi possível distinguir categoricamente as diferenças taxonômicas e as intensidades de novidade entre melhorias e inovações em facilidades, dada a proximidade entre ambas. A dinâmica dessa relação foi explorada no exemplo da seção 1.4, onde pôde-se verificar que as mudanças em facilidades, por vezes, fazem surgir novas demandas de serviços técnicos especializados e estes, por sua vez, geram novas melhorias e inovações. A relação das mudanças em facilidades com inovações em produtos (bens ou serviços), ainda nessa fase preliminar, se mostrou fraca, possivelmente indicando que mudanças na esfera das infraestruturas operacionais periféricas não impactam profundamente nos novos bens e serviços desenvolvidos pelas organizações, quiçá gerando restrições. Como as mudanças radicais nas 
infraestrutras periféricas necessitam de altos investimentos, presume-se que as organizações se limitem a investir o mínimo necessário nessas áreas, limitando-as a desenvolverem soluções de baixos investimentos e complexidades (QUINELLO; CASTRO, 2007).

\subsection{O que são facilidades e gestão das facilidades.}

A palavra facilidades ou facilities (no termo anglo-saxão) sempre esteve ligada à idéia de instalações, ou seja, uma das preocupações iniciais das organizações era a busca por equipamentos, máquinas e arranjos físicos que facilitassem a produção de seus produtos, como podemos notar no trabalho de Ross (1896) ainda no século XIX. Facilidades, nesse sentido restrito, se referem às partes estruturais físicas necessárias para uma organização atingir seus propósitos. De acordo com Maia et al (2005) e Clark e Johnston (2010, p.332) as estruturas de uma operação incluiriam as instalações, os prédios e sua localização, "[...] a vista ou o ambiente físico criado pelas instalações visíveis aos clientes e funcionários". Já as infraestruturas de uma organização compreenderiam as decisões e a gestão do modo como essa estrutura é utilizada (organização, planejamento, controle, melhoria dos processos e desempenhos). Dá-se aqui a diferença entre facilidades - partes estruturais e estáticas das organizações e gestão de facilidades (GF) - partes infraestruturais e dinâmicas.

As atividades de localizar espaços e arranjar máquinas e equipamentos tiveram seu apogeu nas manufaturas americanas, na metade do século XX, dentro das chamadas estratégias de operações, ainda a cargo das engenharias de produção ou engenharias de instalações (HEGARU, 2008). O viés, naquele período, fortemente industrial e endógeno, era direcionado a gestão operacional das fábricas.

Novas demandas e pressões externas, a partir da década de 1950, como o advento das terceirizações em massa nos setores de serviços bancários nos E.U.A.; os estudos de cunhos sociológico e psicológico nas organizações, iniciado com a Escola das Relações Humanas, onde o indivíduo passa a ser reconhecido como agente na dinâmica organizacional; instauração de órgãos governamentais como a Organização Mundial do Trabalho, provendo novas leis e regulamentações; informatização dos escritórios; downsizing das organizações, período caracterizado por um profundo processo de cortes de pessoal, culminando com terceirizações e disseminação do conceito das atividades centrais e não centrais nas empresas, fortaleceriam o surgimento e formalização da GF (QUINELLO; NASCIMENTO, 2008b). 
Já em Tompkins e White (1984, p.2) GF tem um objetivo claro "[...] determinar como um ativo fixo tangível de uma atividade pode melhor suportar os objetivos dessa atividade". Ainda segundo os autores, como o assunto GF, nas estratégias operacionais, é complexo, amplo e cruza uma infinidade de disciplinas especializadas, faz-se fundamental um corte setorial que diferencie o escopo analisado. Segundo Lord et al. (2001), o termo gestão de facilidades originou-se por volta de 1960, nos Estados Unidos da América, para descrever o crescimento de práticas de terceirização dos serviços bancários, responsáveis pelo processamento de cartões de créditos e outras transações. De acordo com os mesmos autores, sua definição é controversa tanto na Inglaterra como nos EUA - países pioneiros nas práticas de gestão de facilidades - pois poderia abranger uma série de atividades, dependendo da complexidade do negócio envolvido.

Com novos papéis e responsabilidades, GF não estaria centrada apenas nos ambientes fabris, mas por todo o espaço corporativo. A expansão da atividade se confirma com o advento, após a década de 1980, das associações profissionais como a NFMA - National Facility Management Association, nos EUA, futuramente a IFMA - International Facilities Management Association, abrindo caminho para outras em diversos países, como no Brasil, em 2004, a ABRAFAC - Associação Brasileira de Facilities.

A Figura 2, elaborada por Williams (1996), pressupõe que GF nasceria da intersecção de três construtos - homem, com suas habilidades e necessidades; artefatos, sendo os meios tecnológicos para obtenção de um benefício; e os significados que esses ambientes emitem. 


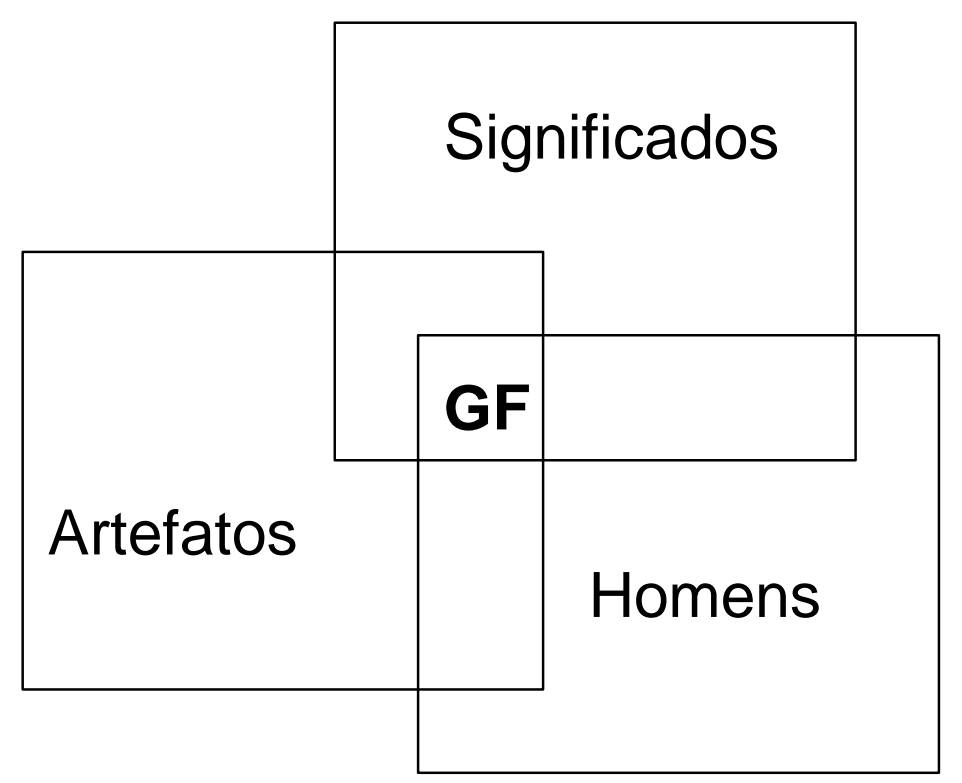

Figura 2 - Dimensões que geram a GF

Fonte: Extraído de Williams (1996, p. 28).

Pela definição do IFMA, gestão de facilidades é uma atividade que engloba múltiplas disciplinas, assegurando a funcionalidade e a produtividade ambiente laboral, por meio da integração de pessoas, locais, processos e tecnologia. Algumas atividades administradas pela GF são: a gestão do patrimônio, instalações prediais, manutenção de equipamentos e construções, alterações e planejamento de layout (arquitetura corporativa), jardinagem, limpeza, segurança, utilidades (energia elétrica, água, ar comprimido e vapor), serviços de suporte aos negócios (arquivamento, foto-cópias, papelaria, correio, portaria, transportes, viagens, mobílias, etc.), serviços de suporte ao staff (restaurante, academia de ginástica, serviço de saúde ocupacional, gerenciamento de helpdesk etc.) e serviços de segurança, saúde e meio ambiente. Para a ABRAFAC, as atividades de GF podem ser classificadas em prestadoras de serviços (empresas terceirizadas fornecendo serviços especializados, tendo GF como atividade central) e em tomadoras de serviços (empresas contratantes onde a atividade de facilidades pode não ser a central).

\subsection{Por que caracterizar as inovações e melhorias em facilidades e seus impactos}

O objeto de estudo desta tese consiste na caracterização das inovações e melhorias contínuas em facilidades e os impactos na eficiência operacional das organizações. A definição operacional prévia das inovações e melhorias em facilidades é: artefatos técnicos ou 
organizacionais oriundos de ações e de intervenções de indivíduos ou grupos de profissionais, sem obrigatoriamente uma estrutura ou gestão formalizada nas infraestruturas operacionais periféricas (máquinas, equipamentos, sistemas e utilidades em geral) necessárias para as operações das organizações. Por artefatos técnicos entende-se dispositivos, equipamentos, máquinas e hardwares que compõem as infraestruturas, já os organizacionais seriam as estruturas organizacionais, contratos e modelos de negócios. A hipótese principal é que as inovações e melhorias em facilidades afetam diretamente a eficiência operacional e esta, por sua vez, os desempenhos financeiros. As inovações e melhorias em facilidades seriam intermediárias na obtenção de resultados superiores nas operações.

A inspiração sobre o tema surgiu por duas vias que correram paralelamente por meio das pesquisas empíricas e da revisão de literatura. Nas pesquisas de campo, aprofundadas nas próximas seções da tese e realizadas nas fases preliminares da construção do modelo teórico relacional, observou-se, empiricamente, que as inovações em facilidades não afetavam diretamente os indicadores de desempenho típicos das empresas investigadas, como os de rentabilidade, de preço, de participação de mercado, de lucro, de crescimento, entre outros. $\mathrm{O}$ que se pôde notar é que afetavam indicadores operacionais internos como a disponibilidade, confiabilidade e eficiência das infraestruturas operacionais. Entretanto, como ressaltam Neely et al (2005), dada a quantidade e diversidade de medidores de desempenho e ao contexto operacional, optou-se pelos critérios de eficiência de Nakajima (1988). Os trabalhos de Nakajima, principalmente aqueles orientados para o TPM - total productive maintenance, enfatizavam a importância das práticas de qualidade (melhorias contínuas) do chão-de-fábrica no desempenho das organizações. Essas práticas, definidas em critérios de eficiência, aderem a pesquisa empreendida nessa tese.

É preciso destacar também que as chamadas melhorias contínuas, com características próximas das inovações em facilidades, são discutidas na literatura de Qualidade Total como destacam Ehigie e McAndrew (2005), Kaynak (2003) e Hoang e Igel (2005). Contudo a ênfase é dada na gestão e na filosofia dos movimentos da qualidade como o TQM (total quality management) ou TPM (total productive maintenance), na conformidade, nos controles estatísticos e nas especificações dos produtos e na satisfação dos clientes. A materialização das ações desses movimentos, digam-se artefatos técnicos ou processos organizacionais modificados, é tratada como co-adjuvante desse processo e não sendo objeto de investigação 
usual. McKobe et al (2001) inclusive apontam que o estudo do impacto do TPM nos desempenhos organizacionais ainda é assunto não esgotado.

Segundo Lager e Horte (2002), os fatores de sucesso das inovações em produtos não são os mesmos das em processos, fortalecendo a hipótese que as inovações em facilidades podem funcionar diferentemente nos desempenhos das empresas. Para Lin e Chen (2007), quatro são as abordagens mais utilizadas quando se estuda inovação: i) aquelas preocupadas com tipologias; ii) as que buscam os antecedentes e determinates da inovação; iii) as centradas nos resultados dos esforços da inovação e iv) as atentas à difusão e a fontes da inovação. Conjugaram-se as abordagens i e iii, isto é, estudo de tipologia (inovação e melhoria em facilidades) e seus resultados (eficiência operacional), mas sob a perspectiva - o da inovação per se e não apenas da gestão.

\subsection{Problema de pesquisa}

O problema central da pesquisa é definido da seguinte forma: o que são as inovações e as melhorias contínuas em facilidades e como elas impactam na eficiência operacional e financeira das organizações.

\subsection{Objetivos da pesquisa}

\section{Objetivo geral da tese:}

Consiste na investigação do impacto das inovações e melhorias em facilidades no desempenho operacional. Essa análise pretende obter mais informações sobre quais as características dessas mudanças e os fatores de desempenho afetados (eficiência operacional e financeira).

\section{Objetivos específicos:}

1. Caracterizar as inovações e melhorias em facilidades;

2. Analisar como elas afetam a eficiência operacional das organizações;

3. Demonstrar as diferenças do impacto nas eficiências operacionais e nos fatores de desempenho financeiro. 


\subsection{A mudança técnica e organizacional em facilidades e seus impactos}

Duas diferenciações fundamentais entre inovações e melhorias em facilidades e outras são o escopo e a localização da mudança. A inovação ou melhoria em facilidades surge como artefatos técnicos ou processos organizacionais periféricos modificados para atender, sobretudo, as infraestruturas das operações centrais. Está vinculada às chamadas decisões estruturais das organizações. Exemplos: implantações, modificações, manutenções ou descomissionamento nas instalações de equipamentos de suporte ao processo produtivo, nos sistemas de utilidades (compressores de ar, subestações elétricas, parque de torres de resfriamento ou aquecimento de água de processos), nas construções civis, nas estações de tratamento de efluentes, nos escritórios e propriedades, nos sistemas de combate a incêndio, nos serviços compartilhados especializados (manutenção, limpeza, alimentação), entre outros. Já as inovações e melhorias em processos ocorrem diretamente nas operações centrais das empresas, variando de acordo com os negócios das mesmas. A Figura 3 faz uma alusão e distinção nos espaços e escopos onde as inovações ou melhorias em facilidades - IMF e as inovações ou melhorias em processos - IMP ocorrem.

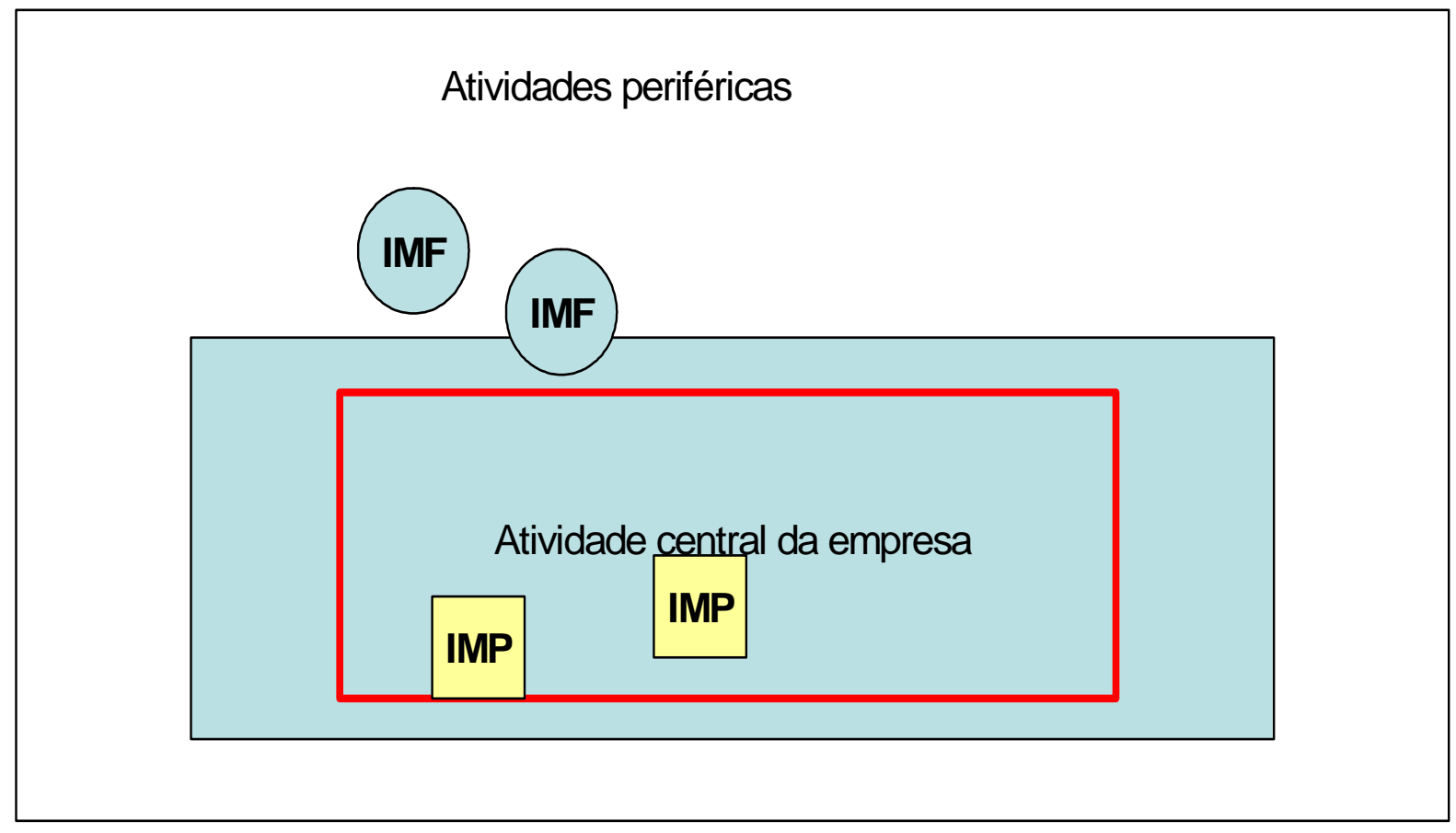

Figura 3 - Localização e escopo das I/M F e I/M P 
A lógica da Figura 3 só se inverte quando se analisa a inovação ou melhoria sob a ótica do prestador de serviços de facilidades. Para eles, sendo GF a atividade central da empresa, as inovações e melhorias em facilidades passam a orbitar próximas à região central da figura.

Para materializar e expandir o objeto de estudo da tese foi exemplificado, na Figura 4, um caso - uma inovação em facilidades ocorrida no departamento de manutenção da Ford Motor, planta situada no Grande ABC, nos anos de 2008 e 2009.

Para que o funcionamento dos robôs da linha de montagem ocorra satisfatoriamente, faz-se necessário um eficiente sistema de geração de ar comprimido (que moverá as articulações dos dispositivos) e, para que este tenha um ótimo desempenho, suas torres de resfriamento de água de processo devem fornecer água resfriada a uma determinada temperatura de operação. Seria o mundo ideal, se não fosse o desgaste do tempo.

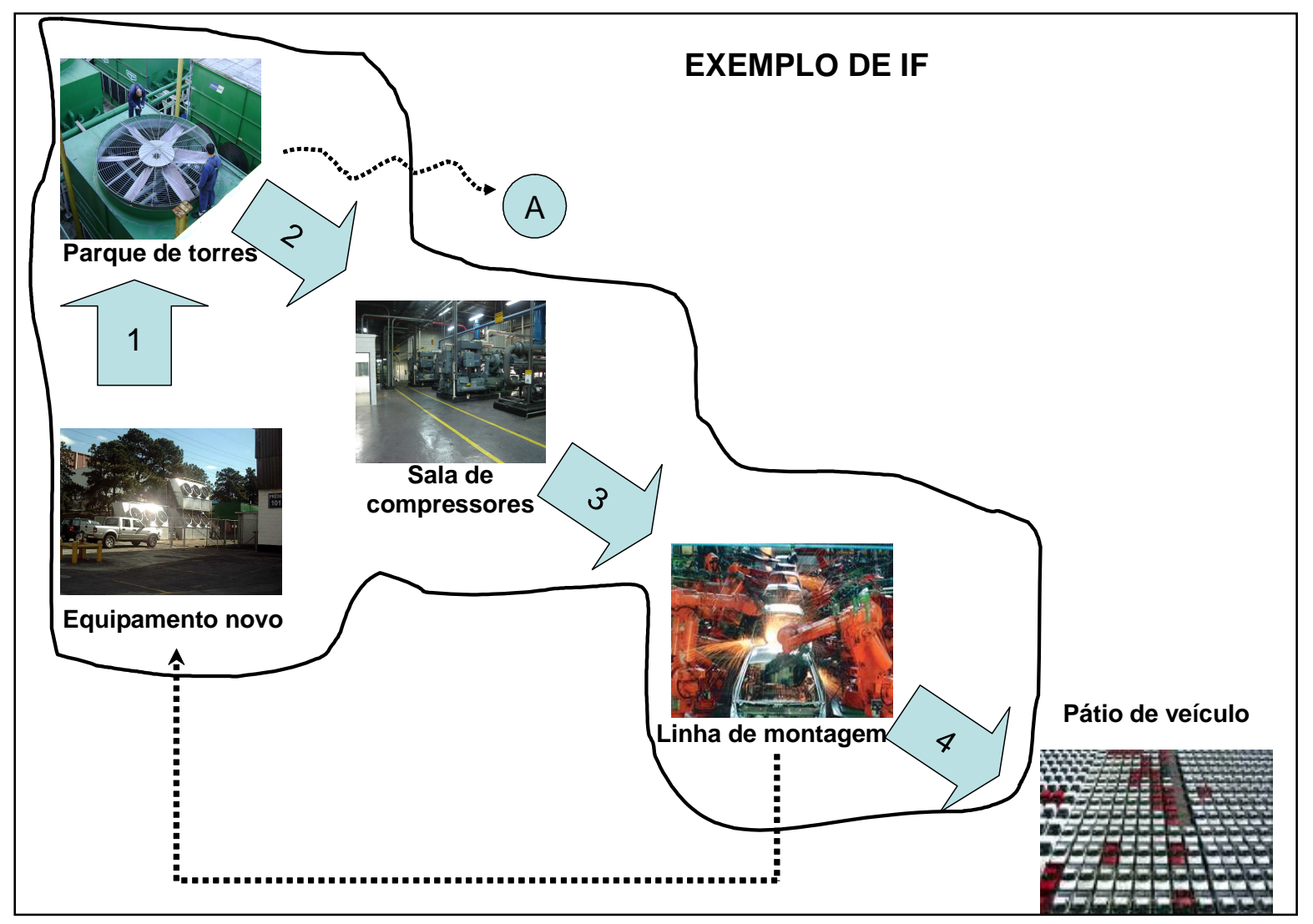

Figura 4 - Exemplo do objeto de estudo da tese: inovação no parque de torres de resfriamento

Com o uso intensivo de uma planta industrial, alguns sistemas, como o parque de torres de resfriamento, perdem sua eficiência e provocam impactos em série, uma vez que a água aquecida reduz o desempenho das torres e compressores e, consequentemente afetam os 
robôs. Assim sendo, o time de manutenção da empresa, por meio de parceria com um fornecedor local, introduziu um novo módulo de resfriamento (seta 1) no antigo parque de torres de resfriamento. Esse módulo, já existente no mercado, é tecnologicamente superior aos encontrados nesse parque e traz uma série de benefícios, tais como: baixo consumo de energia elétrica, de consumo de água, de insumos e produtos químicos, baixa manutenção e novo design, além de custos de implantação reduzidos, uma vez que não há necessidade da troca de todo o parque. É oportuno ressaltar que as inovações e melhorias em facilidades não ocorrem somente por meio de parcerias, mas também há casos de esforços individuais ou coletivos, sem a participação externa.

Uma vez inserido o novo equipamento no parque atual, o sistema como um todo produzirá a redução ideal de temperatura da água para o sistema de compressores de ar (seta 2). A água resfriada ajuda também na troca de calor que ocorre na parte interna dos compressores, ou seja, seu desempenho ainda é afetado por esta condição. Os compressores necessitam de estabilidade operacional durante todo o tempo produtivo da planta, pois alimentam as articulações dos robôs-ponteadores, responsáveis por parte do processo de soldagem da carroceria do veículo (seta 3). Outros ganhos, além dos técnicos, fazem-se presentes e são discutidos ao longo da pesquisa como o aumento das competências técnicas, arquiteturais, sensoriais e recombinatórias, fortalecimento das alianças com fornecedores na busca de melhorias contínuas, revitalização operacional com baixo custo e redução de impactos ambientais. Todos estes ganhos são frutos da inserção de um novo equipamento num sistema velho. É importante ressaltar que esse arranjo tem funcionalidade dentro de um contexto específico, já que se implementado em outro parque de uma empresa distinta, certamente necessitará de diferentes ajustes e poderá produzir outros resultados.

É necessário destacar as externalidades geradas pelas inovações em facilidades no parque de torres de resfriamento (círculo A). Elas podem surgir nesse processo na forma de aumento da vulnerabilidade e do risco operacionais e no encarecimento dos serviços especializados, uma vez que o equipamento transplantado torna o sistema mais sofisticado, por conseguinte, mais sensível. As deficiências (ou fracassos) também fariam parte do aprendizado visto que colocariam os técnicos frente a novas soluções. Uma observação adicional com relação ao objeto de pesquisa é relacionada ao escopo: ele é intraorganizacional, porque essas só são perceptíveis para os operadores e clientes internos, porque afeta as infraestruturas operacionais limitadas às fronteiras internas da planta industrial. 
A inserção de uma inovação ou melhoria nesse sistema (novo equipamento) não impacta apenas nos resultados operacionais internos, como ainda indiretamente na pontualidade, nos custos e na velocidade final da empresa, isto é, no caso Ford, entregam-se os veículos certos na hora certa, traduzindo-se em ganhos de desempenho (seta 4) e na retroalimentação de informações para novas soluções (seta pontilhada). Ressalta-se que assim como os resultados finais da empresa, geralmente expressos em lucros, há também os internos, sinalizadores dos ganhos operacionais. Em relação às competências e aprendizados adquiridos ou reforçados, notadamente, alguns técnicos que participaram desta inovação comentaram que seriam capazes de "sentir" o desempenho do sistema por meio de técnicas preditivas sensoriais (a "vibração", a "temperatura" e o "som" do sistema). Para esses experientes profissionais um sistema de medição convencional (termômetro, manômetros etc.) seria apenas um complemento do conhecimento sensorial e tácito que adquiriram ao longo da carreira (durante o acompanhamento da implantação desta inovação era comum os profissionais colocarem as mãos na torre para "senti-la", buscando o melhor ajuste). Entretanto, verificando-se o esquema da Figura 4, surgem novas questões: onde, como e quando ocorre essa inovação ou melhoria?

Somado às dúvidas relatadas nos parágrafos anteriores, ainda há uma observação quanto ao objetivo final de uma inovação ou melhoria em facilidades: ele difere de forma sutil das inovações de processos e de produtos. Enquanto que o foco está na sustentação e na ampliação do ciclo de vida da infraestrutura, por meio de adaptações, aperfeiçoamentos ou ajustes de dispositivos, equipamentos, hardwares, softwares ou práticas organizacionais em ciclos pequenos e constantes (indo de um grau de novidade extremamente pequeno ao incremental) nas operações de apoio; na inovação em processos ocorrem modificações mais acentuadas, às vezes com saltos tecnológicos (indo do incremental ao radical), nas operações centrais e tendo o resultado final atrelado à otimização operacional. Em relação às inovações em produtos, o objetivo geralmente está relacionado ao crescimento e a rentabilidade dos negócios, expressos em novos bens ou serviços.

Não são objetos de estudo as inovações em produtos e outros fatores de desempenho que não os de eficiências operacionais e de mercado. Esses cortes, além da limitação teórica, são propositais e práticos na medida que focam a investigação. No entanto, dado o desafio da pesquisa, a amostra não foi limitada em relação ao setor, idade, tamanho ou nacionalidades das empresas. Uma condição importante é que para inovar, na definição do objeto desta tese, 
faz-se necessário algo implementado (artefato tangível ou organizacional) como a introdução de equipamentos, dispositivos, hardwares, recombinações, modelo de gestão, softwares ajustados ou adaptados para melhoria das operações em quaisquer intensidades. LeonardBarton (1998) ressalta que uma inovação se dá inclusive na implementação, pois a introdução pura e simples de um dispositivo num processo já existente carece, muitas vezes, de adaptações e ajustes diversos, disseminando-se novos conhecimentos e mais inovações ao longo da implementação.

Com relação às dimensões que foram utilizadas, estão excluídas quaisquer medições quantitativas de desempenho das organizações, entendendo-se que os profissionais, frequentemente, não têm acesso pleno aos resultados das empresas e até porque a padronização de tais resultados exigiria novas pesquisas. Dessa forma, os impactos das inovações e melhorias são analisados qualitativamente, sob a perspectiva e percepção do respondente do questionário que foi aplicado (APÊNDICE A). Também não se questionam, na tese, quais são os melhores indicadores para se medir o desempenho. Eles foram selecionados por meio da fundamentação teórica e empírica, como os mais relevantes para o contexto analisado (o operacional).

\subsection{Justificativas teórica e prática do estudo}

Indubitavelmente, o tema inovação vem sendo objeto de estudo acadêmico por parte de inúmeros pesquisadores e vários resultados já foram alcançados e muito ainda existe para ser investigado. O desafio intelectual sobre o tema, inovações e melhorias em facilidades, ainda está lançado e passível de maior exploração. Pela natureza verificada nos estudos empíricos preliminares, percebe-se que as inovações e melhorias em facilidades têm proximidade de natureza com as em processos, as organizacionais e em serviços mas são de escopos distintos.

Como justificativa teórica para o presente estudo, é importante destacar os seguintes pontos: os estudos sobre inovações em processos, próximas das em facilidades, têm limitações bem significativas - a do viés econômico, nas quais inovações que efetivamente não têm intuito mercadológico, ou seja, não diretamente vendáveis, são consideradas melhorias não significativas (visão amplamente amparada pela vertente schumpeteriana e reforçada no Manual de Oslo) e a do viés teórico, pois boa parte da literatura corrente ou trata da inovação em produtos como variável independente ou em produtos e processos como variáveis 
interdependentes, como no modelo clássico da dinâmica da inovação formulado por Abernathy na década de 1970 (ABERNATHY e CLARK, 1985), dificultando a análise isolada dos impactos dessas inovações e melhorias nos fatores de desempenho das organizações. Nesta tese, a inovação ou melhoria em facilidades é considerada uma subcategoria da inovação em processos e organizacional, próxima da em serviços, porém afastada da em produtos. Esse distanciamento só se desfaz quando o papel da área de facilidades se modifica de tomador para provedor ou prestador de serviços, tornando-se atividade fim da empresa, por exemplo, as de consultoria e de projetos de facilidades. As inovações, nesse caso, são produtos ou serviços oferecidos para os clientes externos.

Revendo-se a literatura acadêmica sobre estudos empíricos de inovação nos setores manufatureiros ingleses, entre os anos de 1993 e 2003, Becheikh et al (2006) conclui-se que apenas $1 \%$ das pesquisas focou suas investigações sobre inovações em processos. Em contrapartida, 37\%, $43 \%$ e $9 \%$, respectivamente, foram em produtos, produtos e processos juntos e outros tipos. Não há como se estimar a porcentagem de estudos das chamadas inovações em facilidades, mas certamente é menor que $1 \%$. Sendo assim, existe espaço na literatura para uma pesquisa que investigue e amplie a teoria existente.

Além das justificativas teóricas supracitadas, existem as práticas: os profissionais e o próprio mercado têm aguardado pelo debate, como se pôde verificar no $1^{\circ}$ Encontro Nacional da Associação Brasileira de Facilities realizado em São Paulo em 2006, repetindo o fórum internacional do IFMA intitulado "Facilities Managment 2005: A provocative exploration into the Facility Manager's future", que tratou de temas como profissão, mercado, tecnologias e inovações. Os tópicos discutidos no encontro brasileiro foram a inovação e a criatividade na gestão de facilidades. Destaca-se também a introdução de uma disciplina de tecnologia e inovação no curso de pós-graduação em Gestão de Facilidades da Escola Politécnica da Universidade de São Paulo. No âmbito internacional, a British Institute of Facilities Management criou o BIFM Award for Innovation nas categorias inovação em tecnologia, sistemas e serviços, em produtos e em serviços aos clientes desde 2006.

\subsection{Contribuições esperadas do estudo das inovações e melhorias em facilidades}

Do ponto de vista acadêmico e de implicações gerenciais, destacam-se as seguintes contribuições: 
1) A presente investigação pretende aprofundar os estudos da dinâmica das inovações e melhorias em facilidades, procurando analisar integralmente a visão dos agentes envolvidos, buscando a caracterização das mesmas e os impactos sobre os desempenhos operacionais das organizações.

2) Estender a teoria da inovação por meio da investigação das em facilidades e avançar na discussão do papel delas nos desempenhos organizacionais;

3) Identificar se alguns tipos de empresas ou pessoas estão mais aptos a inovarem em facilidades;

4) Dar um novo significado à gestão de facilidades dentro da área de Operações. Esforços, nesse sentido têm sido feitos mundialmente com a formação de associações profissionais nos EUA e Inglaterra, fundação de mestrados e doutorados e a existência de periódicos científicos como o Facilities e o Journal of Facilities Management. No Brasil, o fenômeno está em curso.

\subsection{Estrutura utilizada na tese}

O presente trabalho está estruturado em seis capítulos: 1) Introdução; 2) Fundamentação teórica; 3) Modelo relacional da tese; 4) Metodologia de pesquisa, abordando como ocorreu o experimento; 5) Resultados; 6) Conclusões, com as considerações finais, limitações do estudo e proposição de novas pesquisas na área. O Quadro 1 apresenta a sequência lógica do estudo.

\section{Quadro 1 - Sequência lógica do estudo}

\begin{tabular}{|l|l|}
\hline CAPÍTULO 1 & $\begin{array}{l}\text { Introdução ao tema, definição de facilidades e gestão de facilidades, objeto de estudo - as } \\
\text { inovações e melhorias em facilidades e seus impactos, problemas de pesquisa, objetivos da } \\
\text { pesquisa, exemplificação de uma mudança em facilidades, justificativas téoricas e práticas, }\end{array}$ \\
\hline CAPÍTULO 2 & $\begin{array}{l}\text { Revisão da literatura sobre as bases teóricas, principais vertentes, tipos e escolas do tema } \\
\text { inovação. Síntese da fundamentação teórica, resgatando os principais elementos que } \\
\text { sustentarão a construção do modelo relacional da tese. }\end{array}$ \\
\hline CAPÍTULO 3 & Apresentação do modelo relacional da tese e as hipóteses de pesquisa. \\
\hline CAPÍTULO 4 & Aspectos metodológicos da pesquisa empírica: método de pesquisa, amostragem, \\
\hline
\end{tabular}




\begin{tabular}{|l|l|}
\hline & levantamento de dados, estratégias para análise de dados, confiabilidade e validade. \\
\hline CAPÍTULO 5 & Análise dos dados: verificação das hipóteses do estudo. \\
\hline CAPÍTULO 6 & Conclusões, limitações e proposições de novos estudos. \\
\hline
\end{tabular}




\section{FACILIDADADES, INOVAÇÃO E MELHORIAS CONTÍNUAS}

A fundamentação teórica desta pesquisa envolve um tema central com subdivisões, sendo relacionada às pesquisas acadêmicas sobre teoria da inovação. Subdivide-se em:

a) as facilidades nas operações e suas inovações e melhorias;

b) conceitos e tipologias das inovações e melhorias contínuas;

c) principais correntes teóricas sobre inovação e melhorias;

d) impacto das inovações e melhorias no desempenho das organizações.

Como a amostra se deu em ambientes operacionais de empresas principalmente industriais e o foco estará nas áreas de facilidades, fez-se necessário aprofundar as inovações em produtos, processos e serviços a fim de buscar a proximidade e o afastamento destas em relação às em facilidades. A parte final do capítulo busca sintetizar toda a fundamentação teórica com o objetivo de subsidiar a caracterização da inovação e melhorias em facilidades, construção do modelo conceitual da tese e da elaboração das hipóteses do estudo. É importante lembrar que as pesquisas de campo do autor apontaram similaridades com as inovações em processos e as chamadas melhorias contínuas.

\subsection{Facilidades nas operações e suas inovações e melhorias}

Facilidades, numa definição ampla, para Hegaru (2008), são espaços construídos onde pessoas, materiais e máquinas são direcionadas conjuntamente para um determinado propósito. Nas chamadas estratégias de operações ou produção, a área de GF - gestão de facilidades não está explicitamente representada, mas aparece na chamada área de decisão estrutural, isto é, aquela responsável por capacidade, equipamentos e tecnologias necessários para o processo produtivo (MAIA et al, 2005). Em Tompkins e White (1984, p.2) as áreas de facilidades seriam responsáveis por etapas bem definidas no ciclo de vida de um ativo: na determinação da localização de uma empresa, a definição do layout funcional, da manutenção do ativo e, ainda que não mencionado pelos autores, do descomissionamento e reuso desse ativo. As decisões sobre as facilidades de uma organização também geram inércia na tomada de decisão, pois após a escolha sobre um determinado desenho de facilidades, esse perdurará por um longo período, aumentando os riscos e as incertezas caso tenha sido equivocado. 
Já em Ferreira (2005, p.37) é utilizada a seguinte definição: gestão de facilidades é o gerenciamento estratégico de pessoas, espaços, processos de trabalho e investimentos dentro de um ambiente organizacional destacando a operação e manutenção de seus sistemas e subsistemas prediais. A definição, ainda que ampla, não estabelece claramente os limites de atuação dentro de Operações, como apresentado na Figura 5. Nela se observa que as atividades de facilidades (quadrados) estão à margem ou à periferia das atividades centrais das empresas (círculos), não importando se são prestadas por pessoal próprio ou terceirizado. Dada a dificuldade para as definições de centralidade e de periferia das atividades de facilidades, podem-se utilizar os conceitos de Hamel e Prahalad (1994), como advogam Correia e Correia (2005), pela qual a centralidade estaria ligada à combinação de três características: valor percebido para o cliente, diferenciação sobre a concorrência (por meio da competência) e a extendabilidade (opotunidades de novos negócios através da competência central). Quão mais distantes estão as atividades dessa combinação, mais periféricas seriam.

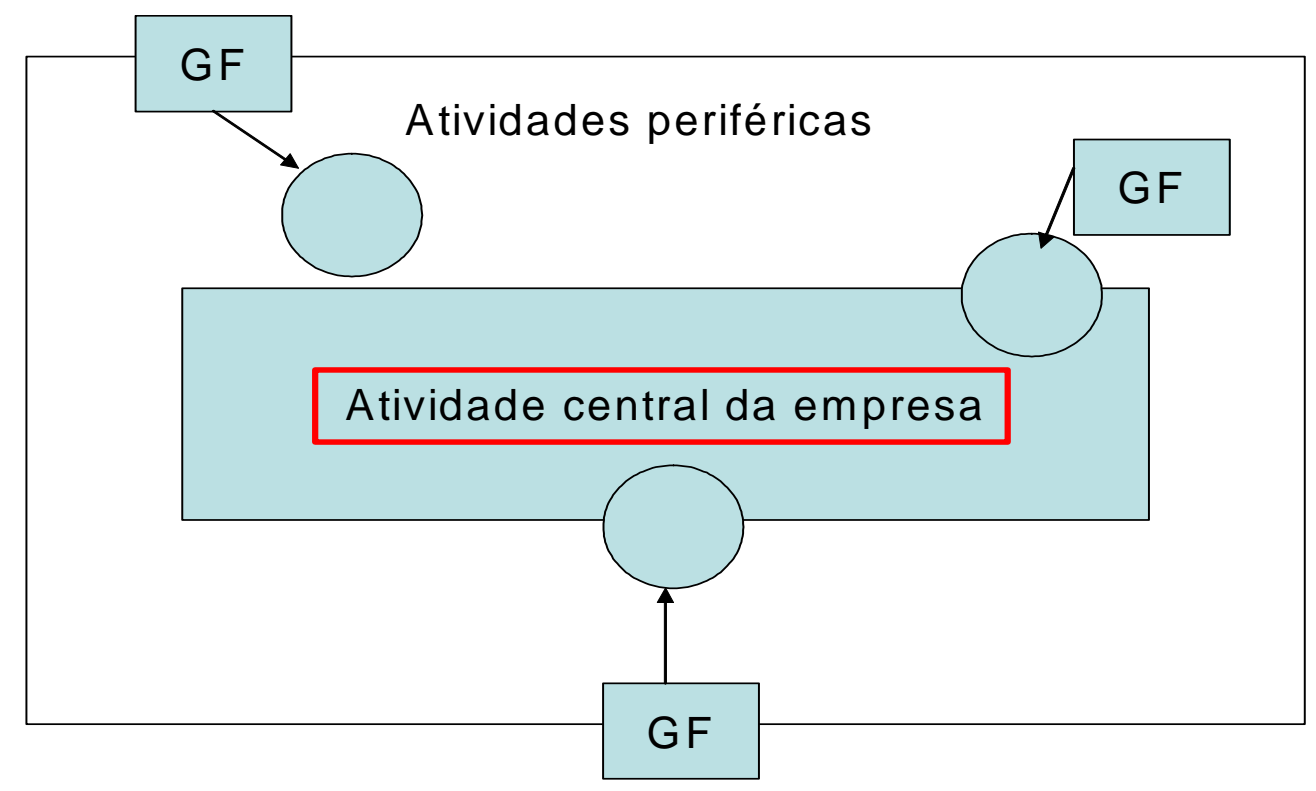

Figura 5 - Posicionamento das atividades de facilidades

No Brasil, o assunto facilidades é relativamente novo e controverso dentro da gestão de operações e serviços. A dificuldade para consolidação talvez se dê pela ausência de pesquisadores na área, falta de associações profissionais consolidadas (a British Institute of Facilities Management - BIFM foi fundada em 1993 e a Associação Brasileira de Facilities ABRAFAC em 2004), de profissionais interessados em relatar suas experiências, generalização do termo, da não normatização da atividade, dos altos custos envolvidos ou até dos próprios profissionais de facilidades atuando nas organizações sem formalização da 
atividade (QUINELLO e NICOLETTI, 2006; ALEXANDER, 1996). Shohet e Lavy (2004) chamam a atenção para três paradoxos encontrados na literatura internacional: GF é reconhecida como estratégica nas organizações, mas seus profissionais atuam nos níveis operacionais; se deseja estar na posição vital das organizações, porém muitos dos serviços são terceirizados; e, aspira-se gerenciar mudanças dentro dos organizações, enquanto que em muitos casos é uma atividade reativa.

As empresas, indiferente o setor de atuação, gastam tempo e recursos projetando e reprojetando suas facilidades. Um projeto pobre custa às organizações um volume significativo de recursos e riscos para o atendimento das operações, das necessidades dos funcionários, clientes e comunidade. Em termos de recursos, de acordo com Weise et al. (2008), o setor de facilities movimenta aproximadamente $\mathrm{R} \$ 100$ bilhões ao ano no Brasil.

\subsubsection{As inovações e melhorias em facilidades}

Quanto as origens das inovações em facilidades, Nutt (1999) ressalta que elas ocorreriam por meio das tarefas e operações, problemas e técnicas, idéias e conceitos ou escopo e contexto. Mansharamani (2005), propõe que estas áreas teriam dois tipos básicos de inovações: a demand-side, caracterizada como inovações em produtos de serviços focadas no atendimento dos requerimentos dos clientes e que aumentariam a rentabilidade das organizações e a supply-side, tratando das inovações em processos e preocupada no aumento da eficiência produtiva e das margens operacionais. Discutem-se pouco as inovações e melhorias cujas preocupações não estariam exatamente centradas no sucesso de mercado. Poderíamos, sob este ângulo, trazer um novo grupo, o self-side, ou seja, inovações ou melhorias internas não preocupadas com mercados externos (saída) ou suas origens (entrada) e sim como facilitadoras das atividades internas (meio).

Em um dos poucos trabalhos sobre inovações em facilidades, Goyal e Pitt (2007), numa pesquisa com empresas britânicas, detectaram diversas inovações e melhorias, principalmente em processos e gestão, frutos da integração, cooperação e relação destas empresas com extensas redes de contatos e multi-contratos (fornecedores, parceiros, contratados e subcontratados). Para Iansiti (1995) as inovações podem surgir entre as rotinas de especificações (parâmetros técnicos iniciais dos projetos) e as de execução (obras/atividades físicas). Outra pesquisa empreendida por Cardellino e Finch (2006), tendo como objetivo a 
identificação do processo de inovação em facilidades de 11 organizações britânicas, identificou-se que as inovações raramente seguem um esquema formal e prática sistemática. Ocorrem subitamente nos primeiros estágios dos projetos e são tipicamente associadas a softwares. Quanto a natureza estariam muito próximas das inovações em serviços.

O caso apresentado na seção 1.5 - novo parque de torres de resfriamento na Ford, mostrou que mesmo sob ambientes informais e tácitos, a simples introdução de um novo equipamento faz movimentar o "dínamo" da criatividade, materializado por inovações e melhorias nos mais diversos graus de novidade, complexidades e tipos. Esse caso registra a dificuldade em se classificar categoricamente uma inovação ou melhoria no ambiente de facilidades. Se fossem seguidas as recomendações do Manual de Oslo, a introdução da nova torre poderia ser classificada como inovação em processos. Mas analisando-a sob a perspectiva de facilidades, encontrar-se-iam múltiplas inovações e melhorias: em produtos (inovação no design das hélices), em processos (melhoria do desempenho com os aspersores de água introduzidos nas torres), em serviços (melhoria da manutenção especializada para esse tipo de torre), em implantação (inovação no novo layout operacional proposto ao longo do projeto), nas competências e aprendizagens adquiridas e utilizadas (novo conceito infraestrutural) e outras melhorias contínuas (como as bacias para captação e reciclagem de água, introduzidas após a implantação da torre). Para cada tipo pode-se aferir graus de novidades e complexidades também diferentes, aumentando a riqueza de detalhes que não seria alcançada com a aplicação de uma tabela classificatória tradicional, como a do Manual de Oslo.

\subsection{Conceitos gerais sobre inovação e melhorias contínuas}

Como lembram Moreira e Queiroz (2007), uma das dificuldades das ciências sociais aplicadas, no caso da Administração, é a sistematização dos seus objetos de estudo. Geralmente há mais de uma visão, ora consensual, ora conflitante. Entretanto, ao contrário do que poderia evocar - um desânimo generalizado - ocorre justamente o inverso - espaço para mais estudos e investigações que aperfeiçoem esses objetos. Nesta tese a inovação é uma dessas situações onde as dúvidas começam pelo conceito. Enquanto que para uns a inovação é "algo novo" (SLAPPENDEL, 1996) para outros não há um acordo sobre o que poderia ser considerado "novo" (JOHANNESSEN, OLSEN, LUMPKIN, 2001). Em Drucker (1986) vêse a importância da figura do empreendedor, como aquele apto a utilizar ferramentas específicas para explorar mudanças (inovações), como oportunidades para diferentes serviços 
ou negócios (e estas inovações podem ser apresentadas como uma disciplina e serem aprendidas e praticadas).

Dentro desta perspectiva, a da divergência de conceitos, nem todas as idéias, práticas ou objetos serão considerados uma inovação. Para alguns, a chave da distinção do que é ou não uma inovação é a novidade, e para outros, é a sua percepção (SLAPPENDEL, ibid). Além disso, conforme destaca Zaltman et al (1973), a percepção da novidade serve para diferenciar inovação de mudança ou modificação. Todas as inovações implicam em modificações, mas nem todas as modificações serão inovações, pois elas nem sempre são percebidas pelos agentes. A percepção é de quem ou para quem? É intencional ou casual? Assim, as dificuldades vão aumentando. Há também um problema relacionado à classificação, apesar de que alguns tipos já são amplamente aceitos pelos pesquisadores, como a inovação técnica ou tecnológica ou, para os economistas, os estudos direcionados para um setor ou nação. Moreira e Queiroz (ibid) acrescentam o desafio do "mapeamento mental" do campo da inovação, onde o escopo de análise (por exemplo, o da empresa) não tem respostas prontas ou consenso das variáveis-chave que a descreva.

É necessário destacar a diferença entre desenvolvimento de produto e o tecnológico. Enquanto que o primeiro está intimamente relacionado com algo vendável, com riscos e incertezas de mercado, o segundo está mais centrado na técnica, ou em parte de um produto ou processo (NASCIMENTO, YU, 2008).

Apesar de todas as dificuldades citadas nos parágrafos anteriores, a inovação tem despertado o interesse crescente dos pesquisadores. Em busca realizada no banco de dados acadêmico ISI - Web of Knowledge (utilizando a palavra-chave "innovation”), verificaram-se alguns resultados interessantes, ainda que precários, apontando tendências: 


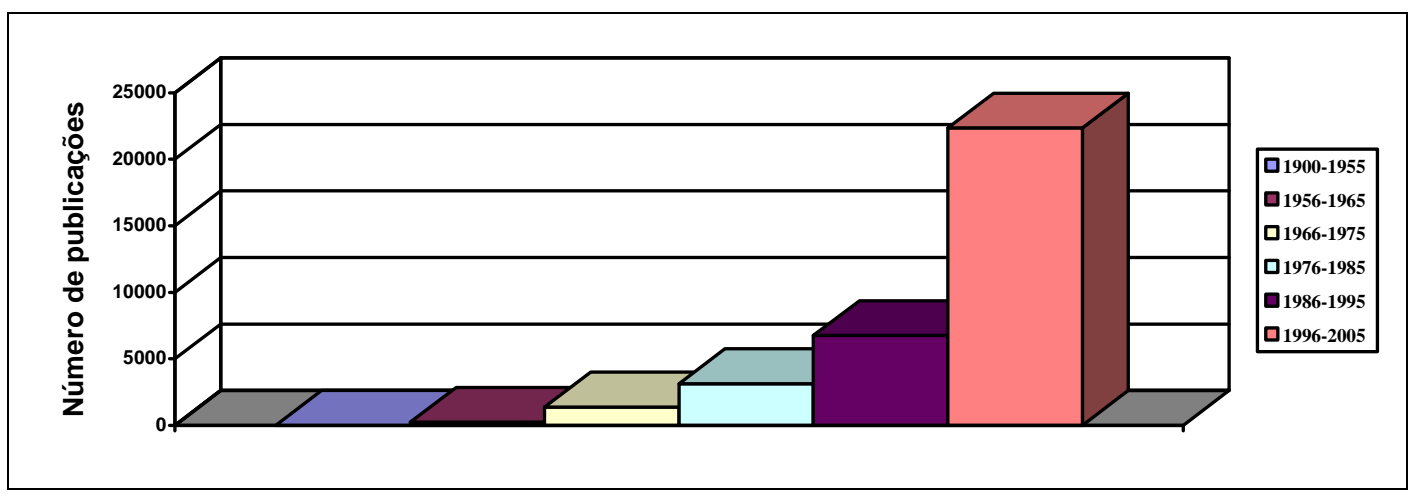

Gráfico 1 - Produção acadêmica sobre inovação entre 1900 a 2005

Fonte: ISI Web of knowledge (novembro 2008)

No Gráfico 1, elaborado a partir de pesquisa no banco de dados da ISI, observa-se que de 1900 a 1955 foram apresentados nove trabalhos acadêmico sobre inovação. Este cenário ganha um salto quantitativo significativo entre 1960 e 1970, provavelmente refletindo os esforços dos teóricos, entre eles Schumpeter, ainda nas décadas anteriores, apresentando uma teoria da inovação. A partir de 1980, o assunto ganhou notoriedade com o crescente aumento de publicações, quintuplicando-se em relação a 1970 e, assim, sucessivamente. Dessas publicações, 35\% são dos EUA, $11 \%$ da Grã-Bretanha, 6\% da China (participação mais recente) e 4\% Canadá. Do total das publicações, 54\% são artigos, 22\% papers e 9\% revisões de livros. Dentre os dez autores mais citados, cinco são chineses, mostrando uma nova faceta do assunto. Em relação às instituições, em primeiro está Harvard, seguida do MIT, da Universidade da Pensilvânia, Berkeley e Stanford. Os campos que tratam da inovação são administração com $21 \%$, negócios $14 \%$, economia $11 \%$, operações $7 \%$ e engenharia 7\%. As principais revistas são Research Policy, Technovation, International Journal of Technology Management, R\&D Management e Journal of Product Innovation Management. Quando o assunto é inovação ainda há um forte viés ocidental norteamericano, que pode mudar a longo prazo. Este levantamento ajudou a ampliar o foco da revisão bibliográfica, sintonizando o "radar teórico" para novas tendências, como os trabalhos chineses.

Bolwijn e Kumpe (1990) acreditam que a mudança no foco das empresas nas últimas décadas (no caso as manufatureiras) propiciou novas posturas das mesmas. Se na década de 1960 o objetivo principal era eficiência, na de 1990 foi a inovação. Conclui-se que o aumento significativo de trabalhos acadêmicos neste campo de conhecimento acompanhou a transformação das organizações. 
Apesar de o assunto ganhar impulso nas últimas duas décadas, o conceito de inovação está muito ligado aos trabalhos de Joseph Schumpeter, economista austríaco, considerado por muitos como o principal formulador deste conceito na década de 1930. Schumpeter (1961) acreditava que longas ondas dos ciclos de desenvolvimento no capitalismo eram resultados da combinação de inovações, que criavam um setor líder na economia ou um novo paradigma, que passava a impulsionar o rápido crescimento dessa economia. A teoria de desenvolvimento econômico de Schumpeter trata de cinco tipos de atividades que envolvem o processo de inovação (SCHUMPETER, 1961):

- Introdução de um produto novo ou uma mudança qualitativa em um produto existente;

- Novo processo de produção na indústria (que não precisa envolver um conhecimento inédito);

- A abertura de um mercado novo, em que uma área específica da indústria ainda não se tenha penetrado, independentemente do fato do mercado existir antes ou não;

- Desenvolvimento de novas fontes de provisão para matérias-primas ou outras contribuições, independentemente do fato da fonte existir antes ou não;

- Mudança organizacional.

As inovações, de acordo com Schumpeter (ibid), constituem o motor do processo de mudança que caracteriza o desenvolvimento capitalista e resultam da iniciativa dos agentes econômicos. Mesmo partindo de objetivos individuais, os efeitos da inovação são amplos e levam à reorganização da atividade econômica, garantindo o aspecto instável e evolutivo do sistema capitalista. Dessa forma, o desenvolvimento é definido pela realização de inovações que se caracterizam pela introdução de novas combinações produtivas ou mudanças nas funções de produção. São percepções fortemente ligadas ao período vivido pelo autor, cidadão de uma época de intensa industrialização e grandes descobertas científicas. Neste sentido, a definição de inovação deve ser contextualizada.

Para Schumpeter (ibid), as mudanças significativas e radicais, consideradas as verdadeiras inovações, são as que provocam rupturas sócio-econômicas. Surgem não necessariamente do desejo dos clientes (considerado pelo autor um participante passivo) e sim do próprio produtor por meio de modificações no produto e processo. Ele não destaca as inovações menos radicais, como as incrementais. 
Em contrapartida, perto da Áustria, havia um uzbequistanês atento aos estudos de invenções e criatividade. Genrich S. Altshuller, em 1946, iniciaria pesquisa em 40.000 patentes na antiga URSS (YANG e EL-HAIK, 2008). Ele concluiu que grande parte das inovações era constituída de pequenas melhorias de sistemas existentes, geralmente com pequenos ajustes. Concluiu também que o universo das grandes descobertas e desenvolvimento de nova ciência representavam cerca de $1 \%$ dos trabalhos desenvolvidos. Entre esses dois extremos têm-se as inovações aparentes ou convencionais, invenções substanciais dentro da tecnologia e fora dela. A seguir, cada uma das cinco classificações de Altshuller, em ordem decrescente de ocorrência (YANG e EL-HAIK , ibid):

- $45 \%$ - pequena invenção significando melhorias em sistemas existentes, geralmente com alguma adaptação ou ajuste. Esse tipo de solução geralmente é resultado de centenas de ações de tentativa e erro, requerendo o conhecimento de apenas um campo da tecnologia. O sistema existente é ligeiramente alterado e inclui novas características que levam às melhorias definitivas. Exemplos: introdução de mais graus de ajustes na altura ou no grau de inclinação de uma poltrona, de dispositivo de variação de velocidade em motores elétricos para melhor controle de equipamentos e alteração de coxim de borracha para diminuir vibração entre o motor e a estrutura ou o chassi do equipamento;

- $32 \%$ - solução aparente ou convencional, utilizando métodos bem conhecidos dentro de sua especialidade. Esta, na verdade, é um tipo de melhoria onde uma característica particular é enfatizada ou reforçada. Geralmente é composta de acanhadas extensões, devido a necessidade de o sistema ser ajustado à situação proposta, aplicação ou utilização.Exemplos: aumento da espessura da película de tinta para maior proteção contra corrosão, aumento da camada de borracha no para-choque para diminuir os efeitos da colisão e aumento do isolamento acústico da sala para diminuir o ruído;

- $18 \%$ - invenção substancial dentro da tecnologia, com melhoria essencial de um sistema existente. Essa invenção traz uma melhora significativa no sistema existente, geralmente pela introdução de algum elemento completamente novo. Normalmente, este elemento novo provém de uma área de conhecimento diferente daquela do sistema original, onde surgiu o problema da invenção. A solução resultante costuma causar uma mudança de paradigma no interior da indústria. Exemplos: introdução de acionamento com embreagem em uma batedeira de bolo, de sistemas de resfriamento ("coolers") em 
embalagens especiais e de motor elétrico acionado por rádio-freqüência nas rodas da mala de viagem;

- $4 \%$ - invenção fora da tecnologia, nova geração de projetos utilizando a ciência. Neste caso, os saltos inovadores são encontrados na ciência e não na tecnologia, geralmente utilizando efeitos físicos e fenômenos anteriormente desconhecidos ou não aplicados na área. Exemplos: certos materiais possuem memória térmica de tal maneira que retornam a suas formas originais após esfriarem ou após serem aquecidos, novos polímeros termoelétricos poderão ter várias aplicações graças à sua flexibilidade, que permite que eles sejam utilizados para a fabricação de peças em qualquer formato e espessura. $\mathrm{O}$ capacete próativo é uma criação do designer industrial norueguês Tore C. B. Storholmen (2008), onde a camada externa do capacete detecta o impacto de um objeto qualquer, o material interno, macio e confortável em condições normais, transforma-se rapidamente em um material resistente e capaz de absorver o choque;

- $1 \%$ - grande descoberta e nova ciência. As grandes descobertas representam cerca de $1 \%$ dos trabalhos de inovação e costumam requerer vidas de dedicação. Soluções desse tipo ocorrem quando um novo fenômeno é descoberto e aplicado ao problema da invenção. Uma vez que essa descoberta se torna conhecida, as aplicações ou invenções subsequentes ocorrem em um dos quatro níveis anteriores. Exemplos: os transistores que revolucionaram a eletrônica nos anos 1950 são utilizados rotineiramente em brinquedos infantis e o laser. A inovação tecnológica dos anos 1960 agora é utilizada em ponteiro luminoso de palestrantes.

Verifica-se, pelo paradigma schumpeteriano, muitas inovações ficariam fora da análise. O descarte de boa parte dessas inovações de baixa complexidade e novidade ocorreu, certamente, devido ao uso do foco macroeconômico dado por Schumpeter na formulação da sua teoria - preocupada com os grandes saltos ou ciclos econômicos.

Por outro lado, autores como Freeman (1974) diferem a inovação da invenção, sendo esta, fruto de uma idéia, esboço ou modelo de algo novo ou aprimorado. Não obstante, a diferenciação entre inovação e invenção é muito sutil e para Fagerberg (2003) pertencem a um processo contínuo e intrínseco. A inovação, num sentido econômico, precisa estar acompanhada da primeira transação comercial, ou seja, precisa estar disponível para os clientes. Porém, os mesmos autores argumentam que o termo inovação é utilizado para todo o processo criativo, seja ele uma invenção, uma inovação ou difusões tecnológicas, 
distanciando-se dos pressupostos de Schumpeter. Andrade (2005) classifica Freeman como um neoschumpeteriano e responsável pelo perfil corporativo atual da inovação.

Deixando um pouco do foco econômico, Moreira e Queiroz (2007, p.9) relembram que alguns autores tendem a conceituar a inovação "não como um objeto externo e que sua novidade seja decidida pela percepção da unidade social que a adota”. Sob esta perspectiva, uma prática pode ser uma inovação para uma empresa e não para outra. Tornatzky e Fleisher (1990) alertam que a novidade é uma qualidade situacional, isto é, ela relaciona-se ao tempo e ao espaço. Algo é novo por certo período de tempo e em determinado ambiente, então ainda há divergência de conceitos.

\subsection{Tipos de inovação tradicionais}

$\mathrm{O}$ ato de tipificar as inovações parece ser infindável, tamanha a gama de possibilidades. Por outro lado, é a forma de não excluirmos a diversidade de opções, tratando-as não de modo reducionista, mas "inclusionista", não descartando qualquer oportunidade. A busca por taxonomias vem desde a formulação de teorias da inovação. Para Damanpour (1991), argüindo sobre a tipificação das inovações, pode-se compreender seus comportamentos e determinantes, isto é, podemos geri-las mais eficientemente dentro das suas especificidades. Uma maneira simples e inicial de pensar nesta tipificação, classificação ou categorização é posicionarmos a inovação (independente do grau de novidade) no modelo da Figura 3, baseado no Manual de Oslo (2005) e Knight (1967):

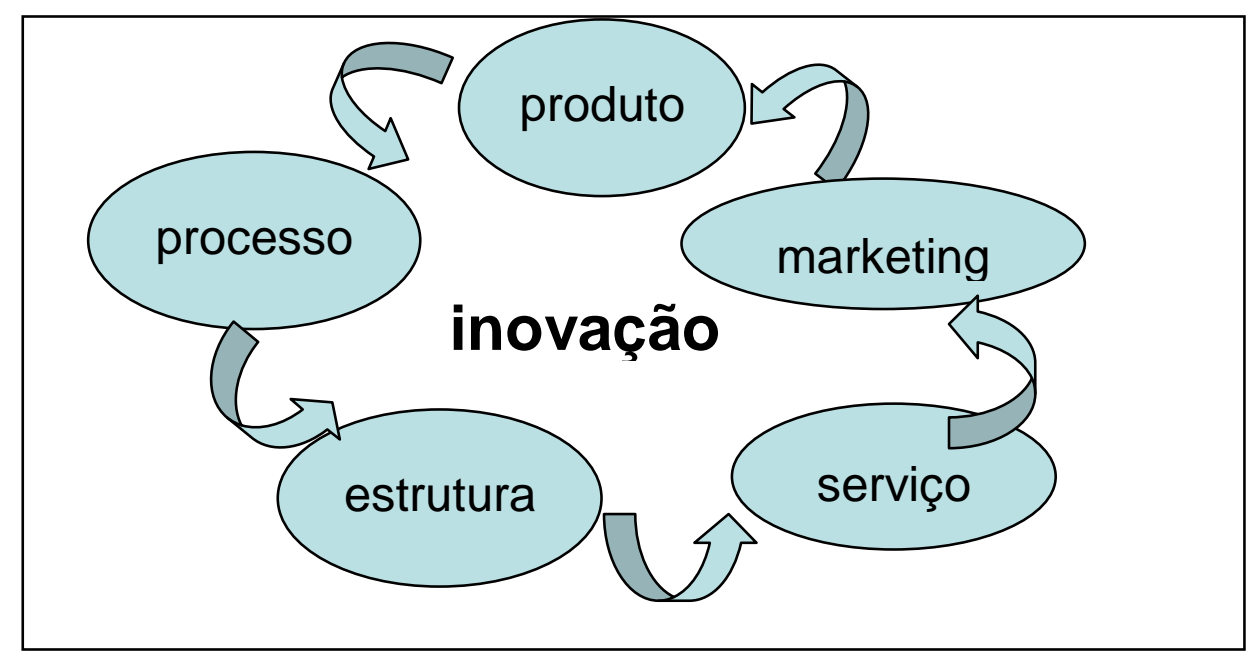

Figura 6 - Tipos de inovações e inter-relações 
Encontram-se, na Figura 6, ainda que parcialmente, inovações em cada uma das atividades, ou nas quatro simultaneamente, porém não é possível inferir o grau de intensidade dos relacionamentos. Geralmente é a inovação em produto a mais evidente dentro e fora de uma organização, afinal é ela que faz a ponte entre a empresa e o mercado. Porém, não menos importante, temos as inovações em processos, geralmente atreladas à produção ou operações, a de serviços (recentemente introduzida na literatura) e a de estrutura organizacional, quando novas práticas modificam a relação entre as pessoas e o ambiente.

Por vezes estas inovações se confundem numa só processo. Por exemplo: na indústria automobilística a busca por materiais mais ecológicos levou a criação de tintas à base de água para a pintura dos veículos. Esta inovação de produto é radical, uma vez que as outras tintas eram à base de solventes. Esta inovação está posicionada em produto, mas impactou em mudanças radicais também no processo, pois os robôs que pintam as carrocerias necessitam de ajustes para receber o novo produto. Consequentemente, essa mudança no processo levou à criação de novos serviços especializados, porque os técnicos de manutenção estão diante de novos equipamentos robotizados. Essas modificações geraram uma nova estrutura organizacional, com a introdução de um especialista em produtos à base de água no organograma do departamento de engenharia da pintura. Em relação a inovação em marketing, a empresa pode ofertar o veículo com o apelo ecológico por não causar impactos ao meio ambiente durante sua fabricação. Esta atitude pode influenciar um nicho específico de mercado e ganhar competitividade.

Outro caso, ainda no setor automotivo, é a introdução de um compressor de ar com tecnologia mais avançada (com partidas elétricas mais suaves e eficientes). Este novo equipamento, uma inovação em processos, não gerará necessariamente um novo produto - veículo, mas impactará nos serviços de manutenção, pois a tecnologia é nova, demandando novas competências.

Os exemplos relatados nos revelam que num ambiente dinâmico, uma inovação, seja em produto, processo, marketing, estrutura ou serviços, impacta de diversos graus e formas em toda a cadeia. Se olharmos com uma lente restrita, podemos perder as nuances e os ganhos advindos desta relação. 
De acordo com o Manual de Oslo (2005), concebido pelos países membros da Organização para a Cooperação e o Desenvolvimento Econômico - OCDE para coleta de dados sobre inovações, já na terceira revisão do manual, foram classificados quatro tipos principais de inovação: de produto, de processo, organizacional, e em marketing.

- Inovação de Produto: introdução de um bem ou serviço que é novo ou significativamente melhorado, como, por exemplo, especificações técnicas, componentes, materiais, softwares incorporados e características funcionais.

- Inovação de Processo: é a implementação de uma nova ou significativamente melhor produção ou método de entrega. Temos como exemplos, as mudanças técnicas, as modificações em equipamentos e os softwares.

- Inovação Organizacional: é uma implementação de um novo método organizacional nas práticas de negócios, ambiente de trabalho ou relações externas. Podemos citar as técnicas de Total Quality Management - TQM nas décadas de 1980 e 1990, como lembram Mônaco e Guimarães (2007) analisando a relação entre os círculos da qualidade e os aumentos de produtividade e qualidade.

- Inovação em Marketing: é um novo método de marketing envolvendo mudanças significativas no projeto ou embalagem dos produtos, a forma de apresentação/disposição, promoções e precificação destes.

Contudo, o Manual de Oslo alerta para aquilo que não é considerado inovação: cessar o uso de um processo de marketing, organizacional ou de um mercado de determinado produto; simples reposição de capital ou extensão (no caso de simples reabilitação de equipamentos); mudanças resultantes em função de alterações no preço; customizações; mudanças sazonais ou cíclicas e trading de produto novo ou significativamente melhorado (por exemplo, alguns processos de transportes ou distribuição).

Um importante passo nos estudos das inovações em serviços foi a inclusão, na última revisão do Manual de Oslo em 2005, das palavras "bens" e "serviços", indicando preocupação com uma atividade pouco explorada na versão anterior. Ainda no manual, faz-se distinção entre inovações tecnológicas de produtos ou processos (bens ou serviços) - TPP e as inovações não tecnológicas. A primeira apontando uma mudança tecnologicamente nova ou modificada para melhoria do desempenho, a segunda puramente gerencial ou organizacional. Todavia, o manual alerta que as duas podem estar ligadas, beneficiando-se mutuamente. 
Quanto ao aspecto de novidade da inovação, pode-se partir do máximo (novo para o mundo), passando pelo médio (novo para uma região ou país) até o mínimo (novo para uma empresa). Quando não há mudanças significativas, ou não há novidade ou apenas melhorias criativas, o Manual de Oslo as classifica como não inovação. Não seria o caso de uma investigação neste espectro dada a gama de novas possibilidades?

Os pesquisadores Henderson e Clark (1990), ampliando o leque taxonômico, verificaram que até então os estudos focavam-se, sobretudo, em inovações incrementais (poucas modificações) e radicais (grandes mudanças). O primeiro tipo era comum em firmas estabelecidas e o segundo podendo ser base de sucesso das empresas novas ou inovadoras. Ambas têm consequências diferentes sobre as competências organizacionais: as incrementais reforçam aquelas já estabelecidas, enquanto que as radicais demandam novas habilidades, questionamentos, perfis técnicos e comerciais, novas abordagens para resolução de problemas.

A evolução do conhecimento arquitetural e dos componentes, parte de um projeto dominante. Para Henderson e Clark (1990), a inovação arquitetural modifica o modo que os componentes se recombinam, sem modificar o conceito central (dominante) do desenho. Estes projetos dominantes possuem produtos tecnológicos que emergem de evolução técnica e experimentação e as competências e conhecimentos organizacionais surgem ao redor das tarefas recorrentes destes projetos. Outro destaque dado nos estudos destes autores é com relação ao aprendizado, por meio de resolução de problemas, que no conceito de architectural innovation, está no refinamento e elaboração da idealização dos componentes existentes inseridos num esquema de conhecimento já estabelecido.

Sanderson e Uzumeri (1995), numa pesquisa feita com empresas de áudio, depararam-se com produtos reengenheirados (exemplo o walkman e suas constantes miniaturizações) dando vida a novas plataformas (chamaram-nas de plataformas generacionais), fortemente ligadas aos desenhos dominantes e criadoras de novas subfamílias. Argumentam que não se trata de uma ruptura tecnológica, apesar das modificações. Além destas plataformas, encontraram o que chamaram de não plataformas: inovações incrementais e topológicas. As primeiras não necessitam de grandes mudanças nas gerações, já as topológicas são apenas "cosméticas" (85\% dos produtos pesquisados eram simples rearranjos, como por exemplo, a modificação da cor dos rádios). 
Haustein e Maier (1979) trazem outro conceito, o da pseudoinovação. Para esses autores existem algumas inovações que são apropriadas para atingir os objetivos de sistemas ou subsistemas sócioeconômicos. Porém, elas apresentam uma influência negativa nestes sistemas com o passar do tempo, como se emitissem externalidades (emprestando o termo de Milton Friedman (2008), para quem externalidade é o efeito de uma transação para um terceiro que não havia consentindo em participar da realização da mesma). Naveh e Erez (2004), analisando a introdução da ISO 9000 em quatro plantas de manufaturas, constataram que apesar de ela afetar positivamente a atenção dos agentes e da cultura a detalhes qualitativos e procedimentais, impactou negativamente a cultura das inovações. Esta situação se deu devido a forte atenção dada a burocratização interna em detrimento de um ambiente dinâmico.

Outro exemplo dos efeitos das pseudoinovações é a modificação de um processo que resulta em danos ambientais. A tinta atualmente utilizada para proteger e pintar os veículos contra ferrugem é um produto inovador, mas também produz emissões atmosféricas poluentes, que, por sua vez, prejudicam o meio ambiente. O cliente paga pela tinta, mas não pelo dano causado à sociedade. Hoje, estuda-se a queima destes gases voláteis, no entanto o consumo elétrico do equipamento necessário agride o meio-ambiente do mesmo modo, num ciclo constante onde os trade-offs da inovação deveriam ser equacionados.

Nesse sentido, o de inovar por meio do desenvolvimento de produtos, Wheelwright e Clark (1992, p. 49) apresentam uma classificação de projetos comum nos setores de bens de capital e bens de consumo duráveis:

- Projetos radicais (breakthrough): envolvem significativas modificações no projeto do produto ou do processo existente, podendo criar uma nova categoria ou família de produtos para a empresa. Como neles são incorporadas novas tecnologias e materiais, eles normalmente requerem um processo de manufatura também inovador.

- Projetos de plataforma ou próxima geração: normalmente representam alterações significativas no projeto do produto e/ou processo, sem a introdução de novas tecnologias ou materiais, mas representando um novo sistema de soluções para o cliente. Este sistema pode representar uma próxima geração de um produto ou de uma família destes anteriormente existentes. Também pode representar o projeto de uma estrutura básica do bem que seria comum entre os diversos modelos que compõem uma 
família. Para funcionar como plataforma, um projeto deve suportar toda uma geração de produto (ou de processo) e ter ligação com as gerações anteriores e posteriores destes.

- Projetos incrementais ou derivados: envolvem aqueles que criam produtos e processos que são derivados híbridos ou com pequenas modificações em relação aos já existentes. Incluem versões de redução de custo de um produto e de inovações incrementais, requerem menos recursos, pois partem dos já existentes, estendendo a sua aplicabilidade e ciclo de vida.

Outro importante trabalho de identificação de inovações foi o de Nascimento et al. (2005) no mercado de produtos populares. Para os autores, apesar das classes C e D demandarem produtos simples de consumo rápido, não são descartadas estratégias e produtos inovadores. Para este público haveria uma estratégia específica de atuação por parte das organizações, que na visão de Castro (apud Nascimento et al., 2005) poderíamos chamá-la de "grandes saltos para baixo", isto é, com inovações direcionadas, as empresas teriam grandes oportunidades de negócios.

Ainda na linha de Nascimento et al, Prochnik e Araújo (2005) investigaram empresas com baixa inovação tecnológica (BIT) e, ao contrário do senso comum, verificaram inúmeras inovações em processos advindas principalmente da aquisição de máquinas e equipamentos, ou seja, tecnologias incorporadas [estas empresas são denominadas por Pavitt (1984) como firmas dominadas pelos fornecedores]. Como não estão centradas nas inovações em produtos (mais quantificáveis), a taxa de inovação destas, geralmente, fica de fora das estatísticas tradicionais.

\subsection{Inovações com foco em serviços}

Com as constantes mudanças econômicas das últimas décadas, observou-se um crescimento dos setores de serviços em detrimento dos industriais. Neste cenário, Gadrey e Gallouj (1995) ressaltam que as teorias econômicas da inovação tendem a ignorar as áreas de serviços, considerando-as mais como adaptações daquelas encontradas nas indústrias. Todavia, destacam possibilidades de contribuições mútuas (indústria e serviços) na formulação de novas discussões a respeito do fenômeno inovação. Esta lacuna, ainda de acordo com Gadrey e Gallouj (ibid), deve-se a interpretação econômica que considera as 
atividades industriais como centrais e as de serviços como periféricas, dando menor importância a segunda. Shostack (1982) estabelece diferenças marcantes, não apenas semânticas, para as duas entidades na geração de inovações. Enquanto produto é um objeto tangível e existe no tempo e no espaço, serviços consistem apenas de atos e processos no tempo. Isto tem colocado áreas centradas em serviços às margens das principais pesquisas sobre o tema (exemplo no Manual de Oslo, nas versões anteriores à terceira), com classificações frequentemente genéricas (KLEMENTI, 2007).

No entanto, uma mesma inovação pode conter no seu elemento dominante características tangíveis (produto) e intangíveis (serviço) (SHOSTACK, ibid), abrindo um campo fértil para exploração de novas tipologias de inovações.

Gallouj (2007) propõe um esforço de aproximação das taxonomias encontradas no segmento industrial para as áreas de serviços e adverte que estas novas propostas colocariam a inovação não mais como um resultado, mas como um processo gerado pela combinação de competências diretas do prestador $(\mathrm{C})$, competências do cliente $\left(\mathrm{C}^{\prime}\right)$, características técnicas materiais e imateriais $(\mathrm{T})$ e finais ou do serviço $(\mathrm{Y})$.

- Inovação radical - descrevendo a criação de um novo conjunto de características C, C', T e Y (mesmo se Y for mantido);

- Inovação pela melhoria - reforçando as qualidades ou características de C, C', T e Y, pelo acúmulo de aprendizado sem modificações das estruturas do sistema;

- Inovação incremental - descrevendo a adjunção, supressão ou substituição de características $\mathrm{C}, \mathrm{C}^{\prime}$, T e Y modificados marginalmente;

- Inovação "ad hoc" - soluções para problemas específicos dos clientes que envolvem um conjunto de alternativas de ordem organizacional, estratégica, social, humana, técnica etc., em face de um problema (em parte inédita);

- Inovação pela recombinação - muita próxima da inovação incremental, esta modalidade se baseia na associação e dissociação de características finais e técnicas, Y e T para novas soluções;

- Inovação pela formalização ou pela objetivação - responsável pela materialização, formatação e padronização das características finais de um serviço $\mathrm{Y}$ (como a introdução de um sistema técnico, métodos, gestão etc.). 
Quanto as especificidades da inovação em serviços, Gallouj (2007) propõe quatro tipos de inovação (numa perspectiva shumpeteriana):

- Inovação do produto-serviço - numa escala suficientemente larga para contemplar produtos materiais e imateriais (exemplo uma nova fórmula);

- Inovação em processo - englobando sistemas técnicos ou de processos não materiais (como um novo método);

- Inovação organizacional (interna) - envolvendo modificações na estrutura de atendimento das atividades e processos;

- Inovação de relação externa - caracterizando novas formas de relações entre os stakeholders.

Além da inovação em serviços como tema emergente na literatura, outras pesquisas, como as de Abernathy e Clark (1985), têm definido a inovação como produto de uma sequência de atividades envolvendo a aquisição, transferência e utilização de informação, dando um caráter mais gerencial ao tema. Esta linha, o de transformá-la em algo gerenciável ou mensurável, vem ao encontro com estudos mais abrangentes, como o do Manual de Oslo (2005). Este relaciona a inovação à evolução da economia baseada no conhecimento. Conforme o manual, as nações que desenvolvem e gerenciam efetivamente seus ativos de conhecimento têm melhor desempenho que as outras. $\mathrm{O}$ investimento em conhecimento propicia inovação tecnológica, e esta resulta de atividades inovadoras, incluindo os gastos em $\mathrm{P} \& \mathrm{D}$, criando oportunidades para maior aporte de recursos em processos para melhoria da capacidade produtiva com qualidade, o que, a longo prazo, gera empregos e rendas adicionais.

Nota-se que a inovação não pode restringir-se a setores sofisticados que recebem altos investimentos em P\&D. Ao contrário, há espaço para a inserção em novos mercados (mesmo os populares). Se estes produtos populares são menos complexos, talvez demandem soluções tecnológicas simples em seus processos, ratificando a necessidade de estudos das atividades não P\&D no grande dínamo da inovação.

\subsection{Inovações com foco em processos e melhorias contínuas}

Podem ser definidas como novos elementos introduzidos nos serviços ou nas operações das organizações (podendo ser por meio de materiais, tarefas específicas, mecanismos de fluxo 
da informação e equipamentos usados para produzir ou entegar um produto ou serviço). Têm como objetivo, segundo Utterback (1996) e Adner et al (2001), reduzir custos e/ou aumentar a qualidade, impactando diretamente na produtividade da organização. Em Deming (1988), já havia um forte discurso em prol da produtividade aumentada por meio de melhorias da qualidade (o que ele chamaria de inovações de engenharia, apoiadas, sobretudo, por forte controle estatístico do processo). Drucker (1986) as chamaria de inovações sistemáticas baseadas nas necessidades dos processos.

Tidd et al (2008) ressaltam que estas inovações (em processos) são típicas das firmas dominadas pelos fornecedores. Reichstein e Salter (2006) destacam que as histórias de mudanças técnicas têm mostrado que as inovações em processos possuem uma profunda ligação com o desenvolvimento industrial e é um dos principais direcionadores da competitividade sustentável, que, de acordo com Porter (1985), traz melhorias não só nos processos como na curva de aprendizagem, que também auxilia a otimização do uso de recursos, alvancando a economia de escala.

Alguns autores sugerem que haja uma separação entre inovações em processos das organizacionais. A primeira é relativa a tecnologias paupáveis e a segunda a elementos não tecnológicos. Entretanto, esta argumentação não se sustenta, pois muitas inovações em processos têm íntima ligação com novos modelos de gestão, por exemplo, o lean manufacturing que une inovações não só tecnológicas, como também de novas práticas organizacionais ou com as inovações em produtos (WOMACK, 1992).

No clássico livro de Utterback (1996) "Mastering the dynamics of innovation", o autor recorda do modelo das dinâmicas da inovação, proposto por ele e Abernathy na década de 1970, cujas inovações de maiores vultos seguem um padrão ao longo do tempo (em três fases), alternando as inovações em produto e processo como que numa onda entrelaçada. Essa visão, da estreita ligação entre inovação de produto e de processo como um fluxo contínuo interdependente, tem sido a tônica da maioria dos trabalhos acadêmicos. Nesse modelo (Figura 7), a introdução de novos produtos na indústria ocorre nos primeiros anos de sua formação, chamados de fase fluidez. As inovações em processos, neste período, são mínimas. Na fase seguinte, a transicional, há um assentamento delas em produtos dando espaço para as inovações em processos (em busca da redução de custos e ineficiências, por exemplo). Na última etapa, algumas empresas entram na chamada fase específica, cujas 
inovações tanto em produto como em processo se reduzem. As empresas estariam nesta fase totalmente centradas em custos, volume e capacidade, e as inovações são pequenas aparecendo em forma incremental.

Apesar de o ambiente ser o industrial, o trabalho de Utterback e Abernathy (UTTERBACK, ibid) e Dosi (1982) foram fundamentalis para traçar na linha do tempo as trajetórias tecnológicas possíveis das organizações inseridas neste segmento. Para os autores, na fase fluidez, as mudanças em produtos são constantes e maiores, tipicamente geradas por indústrias onde os processos de produção são flexíveis, porém ineficientes. Os equipamentos requerem mão de obra qualificada, as plantas industriais são de pequena escala, os custos são baixos para mudanças nos processos e o controle organizacional é informal. Estas orientações se modificam na fase transicional. Neste momento as mudanças maiores são em processos, tendo como fonte de inovação as manufaturas e seus usuários. Os procedimentos são rígidos, surgem as automações com mão de obra mais especializada por função ou subárea, os custos para mudanças nos processos são moderados e o controle organizacional é por projetos ou grupos de tarefas. Na última fase específica, frequentemente gerada por fornecedores, as inovações são de melhorias e incrementais (focadas em produtividade e qualidade), com equipamentos de monitoramento (resultado da automoção da fase anterior), com custos de mudanças nos processos altos e com o controle organizacional estruturado por regras e metas. Dosi (1982) argumenta que as mudanças tecnológicas são geralmente atreladas às trajetórias tecnológicas, definidas pelos paradigmas tecnológicos, ou seja, a mudança tem algo de contextual e histórico. 


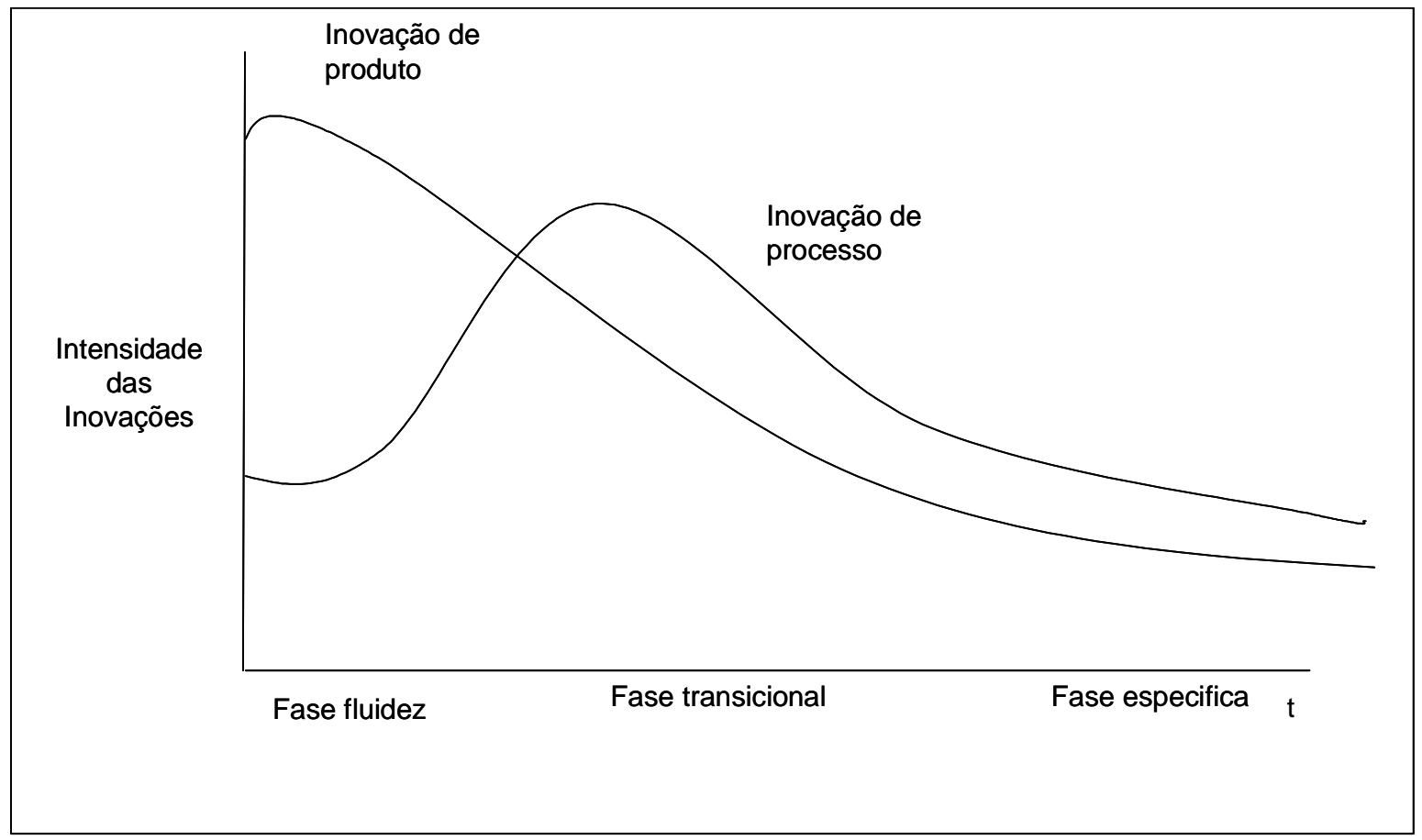

Figura 7 - O modelo da dinâmica das inovações

Fonte: Adaptado de Utterback (1996)

Ratificando esta linha, em revisão da literatura acadêmica sobre estudos empíricos de inovação nos setores manufatureiros, entre os anos de 1993 e 2003, Becheikh et al (2006) concluem que apenas $1 \%$ das pesquisas analisadas focou as inovações em processos como um fenômeno independente. Em contrapartida, 37\%, 43\% e 9\%, respectivamente, foram em produtos, produtos e processos juntos e outros tipos. Li et al (2007) reforçam a tese de que inovações em processos são contínuas com riscos menores do que as em produtos. Afirmam que ambas têm interdependência variável ao longo do tempo, ou seja, ora próximas, ora distantes.

Em termos de participação das áreas de processos dentro da dinâmica da inovação, Yu et al (2008), analisando os componentes da complexidade das famílias de produtos, verificaram que os gastos em investimentos nos processos variam de segmento para segmento. Nas empresas onde os processos são inerentes ao negócio-chave, como no setor alimentício, os investimentos são mais expressivos, demonstrando que a intensidade das inovações em processos varia. 


\begin{tabular}{|c|c|c|c|c|}
\hline \multirow[b]{2}{*}{ Empresa } & \multicolumn{4}{|c|}{ Investimentos em novas famílias de produtos } \\
\hline & P\&D e engenharia & $\begin{array}{l}\text { Processo (facilities, } \\
\text { ferramentas, } \\
\text { equipmentos) }\end{array}$ & Marketing & Total \\
\hline Embraer & $66 \%$ & $33 \%$ & $1 \%$ & $100 \%$ \\
\hline Sadia & $8 \%$ & $38 \%$ & $54 \%$ & $100 \%$ \\
\hline Caloi & $20 \%$ & $19 \%$ & $61 \%$ & $100 \%$ \\
\hline
\end{tabular}

Tabela 1 - Componentes da complexidade das famílias de produtos Fonte: Traduzido de Yu et al (2008)

Nesse sentido, a inovação em processos assume um papel de destaque no sucesso das organizações. No entanto, o efeito dela depende do nível da inovação em produtos, quanto mais radical uma, também a outra (KOTABE e MURRAY, 1990). Esses autores concluem que aliando inovações em processos com produtos, o desempenho da firma é afetado positivamente.

Mas, afinal, quais são os fatores motivadores para a inovação dos processos? Em um trabalho sobre reestruturação de empresas (ou "reengenharia", como muitos a chamam), publicado por Morris e Brandon (1994), encontram-se algumas respostas:

- Redirecionar a produção: concentrar a atenção na eficiência, flexibilidade e qualidade. Eliminar operações ou processos redundantes, melhorar o fluxo das informações, das operações, e dos processos de apoio à atividade principal (central).

- Reduzir custos: basicamente, a redução de custo abrange três componentes: materiais, mão-de-obra e informação. Quanto aos materiais, procuram-se diminuir os custos de aquisição, armazenamento e transporte, envolvendo a cadeia de suprimento da empresa. Em relação à mão de obra, busca-se a redução de atividades redundantes ou desnecessárias. Quanto às informações, buscam-se reduzir os custos de armazenamento, transmissão de voz e dados, relatórios e outros mecanismos de difusão de informações para a tomada de decisão.

- Melhorar a qualidade: reduzir retrabalhos, desperdícios, perdas de tempo e de materiais, aumentar a confiabilidade operacional e de atendimento ao cliente.

- Aumentar a receita: seja por meio de redução de custos e, consequentemente, maior venda e produção, ou por meio da redução do ciclo de fabricação ou do aumento da velocidade da inovação em produtos ou serviços. 
- Melhorar o atendimento ao cliente: saber identificar adequadamente as expectativas dos clientes e de seus grupos, como também ser capaz de fornecer produtos ou serviços compatíveis com essas exigências ou expectativas a um preço final adequado ao nível de atendimento.

- Aumentar a lucratividade: é uma consequência da redução de custos, do aumento da receita e da melhoria da satisfação dos usuários.

Reichstein e Salter (2006), analisando as fontes das inovações em processos de manufaturas da Grã-Bretanha como variáveis interdependentes, encontraram subtipos envolvendo a introdução de máquinas e equipamentos $(47,9 \%)$, mudanças nos processos de produção $(16,6 \%)$, utilização de tecnologia da informação (15\%), novos modelos de práticas gerenciais $(8,8 \%)$ e outros $(8,8 \%)$, abrindo caminho para análises em substratos menores dentro da inovação em processos. Esta análise (a de Reichstein e Salter, ibid) permite concluir que mesmo as inovações em processos podem ser subcategorizadas em inovações tecnológicas ou não tecnológicas. Com relação a inovações por melhorias contínuas, Baba (1989) relembra que foram os japoneses, inicialmente com produtos eletrônicos e depois com a indústria automobilística, um dos primeiros a colocarem em práticas as pequenas melhorias técnicas como uma das soluções para competitividade sustentada.

As inovações em processos criam conhecimentos específicos nos agentes. Gopalakrishnan et al (1999) encontraram, por meio da análise de 31 inovações, que as mesmas tendiam a incorporarem mais conhecimento complexo e sistêmico do que as inovações em produtos, mas ambas apresentavam dimensões tácitas parecidas. Esses conhecimentos se formavam internamente e apesar de custosos eram mais perceptíveis aos agentes.

Já Imai (1987) argumenta que uma mudança pode ser contínua ou descontínua e as melhorias categorizadas como pequenas e incrementais (kaizen) ou inovativas (reengenharia). No caso das inovações pequenas (small innovations), o autor a caracteriza como problemas operativos do chão de fábrica (bottom-up) na busca de soluções operativas, geralmente espontâneas. Surgem naturalmente em produções de pequena escala, por meio do conhecimento íntimo dos operadores nas pequenas partes dos sistemas, com baixo custo e fora do campo de controle gerencial, com efeito agregador mas fragmentadas. Imai (ibid) aponta as melhorias contínuas, assim como boa parte do movimento da qualidade total, como a base do kaizen. Este é responsável pela alavancagem na qualidade e confiabilidade 
dos produtos e serviços, redução dos custos operacionais, aumento do envolvimento e comprometimento dos funcionários, da satisfação e integração dos clientes, da segurança e moral dos funcionários. Choi (1995) aponta a cultura orientada a redução de desperdícios, a experimentação, a processos e a métodos sistemáticos como elemento chave nas melhorias contínuas. Em Tushman e Henderson (1986) surge o conceito de inovação por melhoria, onde determinadas características de um bem ou serviços são alteradas sem mudanças da estrutura do sistema (por meio do melhoramento das competências ou características técnicas). Para eles, esse tipo de inovação ocorre pelo acúmulo de competências e aprendizado. Entretanto estas melhorias são raramente investigadas dentro da literatura corrente da teoria da inovação.

Davenport (1993) infere que as chamadas melhorias em processos estão focadas em qualidade, tempo e custos operacionais, com "passo" da mudança rápido e tático. Ele ainda alerta que diferentes abordagens podem surgir quando se fala em inovação e melhorias em processos. Pisano (1996) encontrou subtipos das inovações em processos como as advindas de novas máquinas ou equipamentos, as de mudanças de processos de produção e aquelas surgidas com a introdução de novas tecnologias da informação, propondo que novas tipologias ou subtipologias diferentes das tradicionais são possíveis. 


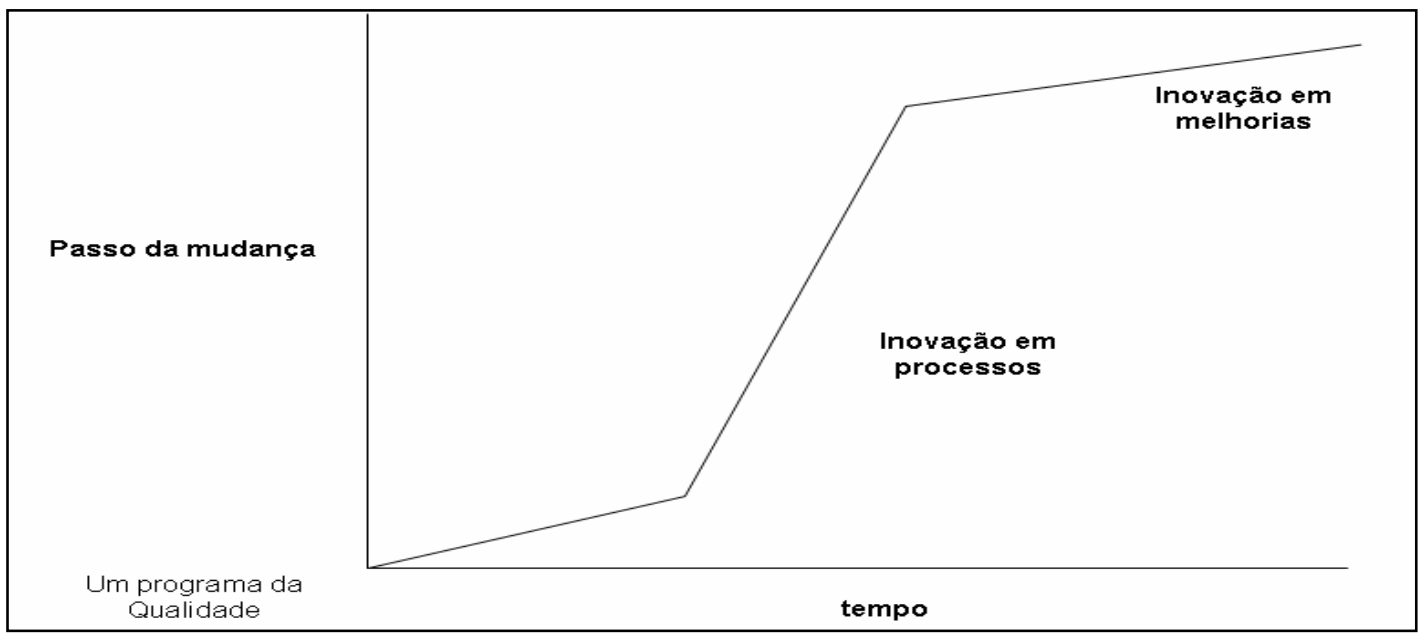

Figura 8 - Passo e tempo das inovações em processos e melhorias Fonte: Davenport (1993)

Na Figura 8, observa-se que o passo da mudança e o tempo das inovações em processos e melhorias são distintos. Na primeira ocorre num espaço de tempo menor, mas com o passo mais intenso e rápido (muito em função dos altos investimentos nelas alocados). Na segunda acontece o inverso: o passo é menos intenso e o tempo é maior (tipicamente melhorias contínuas de baixo custo). O terceiro passo, o da inovação em melhorias, o tempo é longo e contínuo com passo de mudança muito curto, típicos de ações de aperfeiçoamento ou ajustes sistemáticos em processos. Em Davenport (ibid) há um traço histórico e qualitativo no desenvolvimento das melhorias contínuas. Elas teriam nascido das inspeções no início do século XX em ambientes manufatureiros, passado pelos controles da qualidade, a partir da década de 1930, e culminado nas inovações em processos já nos anos 1980. Doravante o autor não estende a "régua" histórica e deixa uma lacuna no tempo.

\subsection{Inovações organizacionais}

Na definição sucinta de Hage (1999) as inovações organizacionais são adoções de novas idéias e comportamentos nas empresas. A fonte dessas inovações surgiria, fundamentalmente, das divisões complexas do trabalho, das estruturas organizacionais e das estratégias das empresas. Incluiriam ainda as "[...] mudanças nas relações de autoridade, nas alocações do trabalho, nos sistemas de remuneração, nos sistemas de comunicação e em outros aspectos da interação formal entre as pessoas". São interdependentes às inovações técnicas ou tecnológicas, na medida em que "a inovação tecnológica é uma parte significativa da função de renovação das organizações sociais”. (MOREIRA e QUEIROZ, 2007, pp 9-10). 
Na visão de Teece et al (1997), esse tipo de inovação, influenciada pelas ações individuais e estruturais, portanto, de difícil mensuração, foi justamente um dos elementos centrais, juntamente com as modificações tecnológicas, na criação de riqueza dos setores privados ao longo das décadas. Essas inovações, como novas estruturas, práticas e processos gerenciais e administrativos, complementariam e suportariam as atividades produtivas. A introdução de um simples equipamento ou máquina num sistema produtivo pode demandar novas competências e habilidades das pessoas (modificando inclusive a relação de poder via profissionalização), novas estruturas organizacionais (como a criação de um departamento de assistência técnica especializada), novas remunerações (devido ao novo grau de especialização), ou seja, uma mudança técnica provoca uma transformação organizacional e vice-versa (a criação de uma área técnica ou a modificação no desenho da estação de trabalho também demandará novas aquisições, competências e recursos).

Lynch (2007) conduzindo um survey longitudinal em empresas manufatureiras e não manufatureiras nos anos de 1990, nos EUA, verificou que os resultados dessas empresas estavam relacionados também à utilização de novas práticas organizacionais como a adoção de novas tecnologias da informação, desenhos dos fluxos e processos do ambiente de trabalho, job rotation, políticas junto aos sindicatos, investimento em capital humano por meio de treinamentos ou recompensas. Notadamente, as empresas não sindicalizadas eram mais receptíveis às inovações organizacionais, devido, provavelmente, à baixa resistência sindical às mudanças nas relações trabalhistas que algumas inovações demandavam (no processo de reengenharia, por exemplo, postos de trabalho podem ser cortados ou nos círculos da qualidade os funcionários exercerem um leque mais amplo de atividades sem necessariamente serem remunerados de maneira diferenciada). Para as empresas com foco mais externo (internacionalizadas) notou-se mais investimentos em novas práticas gerenciais através de benchmarking junto aos fornecedores. A difusão dessas inovações seria parte da explicação do crescimento da produtividade das empresas americanas nas últimas décadas, ainda que a mesma venha apresentando declínio nos últimos anos.

Lynch (2007) conclui que alguns fatores já preexistentes contribuíram para as diferenças nos resultados das empresas manufatureiras e não manufatureiras que adotaram alguma inovação organizacional: a qualificação da mão de obra, a sindicalização, a rentabilidade das operações, o foco externo da liderança e os investimentos em tecnologia da informação. Esses resultados indicam que os ambientes internos e externos das empresas influenciam no sucesso desse tipo 
de inovação. É preciso lembrar que determinadas estruturas organizacionais favorecem diferentes perfis para inovar. Mintzberg (1979), no seu arquétipo de estruturas organizacionais, já apontava que diferentes estruturas geram determinados tipos de inovações.

\subsection{Síntese da fundamentação teórica}

Da fundamentação teórica referida nesta seção, algumas conclusões foram tiradas e ajudaram a refinar a questão central da pesquisa. Existem muitos estudos e pesquisas acerca das inovações (principalmente em produtos), porém poucos caracterizando as inovações e melhorias em facilidades no Brasil. Os motivos, alguns descritos na seção anterior, estão relacionados à precocidade da profissão e da área enquanto campo de pesquisa, à falta de estatísticas ou levantamentos de casos e à dificuldade no corte e na diferenciação das suas características. Entretanto, entidades como o SEBRAE e a Comunidade Européia (por meio do projeto piloto PIM - Project Innovation Management, realizado com empresas pequenas e médias da República Checa, Hungria, Polônia, Romênia e Eslovênia) estão atentas a importância destas novas categorias para suas economias, permitindo concluir que são objetos de estudos promissores.

A literatura tem tratado do tema inovação, majoritariamente, como um produto ou serviço novo ou parcialmente novo que, necessariamente, deva ser introduzido no mercado. Esta visão reducionista e econômica acaba ofuscando muitas iniciativas internas às organizações (que não chegam ao mercado), colocando em segundo plano todo um esforço que contribuirá para a movimentação do ambiente inovador necessário para a fecundação das inovações e melhorias desejadas, e falando-se principalmente das em facilidades.

Na questão das melhorias contínuas, se destaca o papel dos movimentos da qualidade nos anos de 1970, como, por exemplo, o TQM e TPM (Total Quality Management e Total Productive Maintenance) ricamente explorado pelas empresas orientais. No entanto, percebe-se que o foco primordial dado pelas manufaturas ocidentais, quando na implementação de tais práticas, foi a busca pela redução de custos e erros e, conseqüentemente, a melhoria da qualidade. Esta postura não significou necessariamente uma abertura para que os funcionários praticassem as inovações. Como relembra Nakajima (1988), um dos introdutores das práticas da qualidade americana no Japão, esses movimentos foram os meios pelos quais áreas como as de manutenção puderam contribuir 
com um ambiente mais dinâmico, participativo e inovador, adotando melhorias sistemáticas nos processos, nas máquinas, nos equipamentos e nos sistemas. Também contribuíram para a elevação do conhecimento e da especialização dos funcionários das empresas.

Sendo assim, as inovações em facilidades não devem ser encaradas como um assunto a parte nos negócios empresariais. O estabelecimento de um ambiente favorável nas empresas é fator vital para o encorajamento da inovação (OECD, 2006). Além disso, a difusão dela ocorre quando se é capaz de transformar o conhecimento e aplicá-lo nas tecnologias, independente da amplitude e complexidade.

Sintetizando, a partir da fundamentação teórica da pesquisa, destacam-se alguns pontos, tanto de conteúdo como de estrutura e metodologia no campo da teoria da inovação:

- Não se deu, dentro da literatura corrente pesquisada, a devida importância para as inovações ou melhorias em facilidades. Raras são as pesquisas que as caracterizem ou descrevam;

- Poucos são os trabalhos que demonstram as correlações entre os subtipos encontrados na investigação empírica e os fatores de desempenho das organizações;

- Os poucos instrumentos de mensuração encontrados foram desenhados a partir de metodologias diversas, parte focada no sujeito (empresa) parte no objeto (inovação);

- As pesquisas são predominantemente quantitativas, de caráter longitudinal;

- Não há consenso sobre quais são os fatores determinantes para explicar o sucesso das empresas via inovações. É necessário considerar que se trata de um fenômeno heterogêneo e contextual;

- Várias abordagens são utilizadas em separado. Dentre elas as que tratam das tipologias, das difusões, dos resultados e dos antecedentes/determinantes. Foram unidas as abordagens de tipologia (por meio da etapa descritiva da pesquisa) e a dos resultados (na etapa causal);

- Frequentemente, os agentes inquiridos nas pesquisas sobre inovação são do nível estratégico das organizações. A proposta desta tese é investigar o fenômeno também sob o olhar operacional;

- Foram utilizadas áreas periféricas (suporte às operações) como unidades de análise, por exemplo, os departamentos de facilities, o que é raro na literatura corrente. 
- Futuras pesquisas, segundo Ittner e Larcker (1998), poderiam prover evidências das influências dos indicadores não financeiros na avaliação das empresas. 


\section{MODELO RELACIONAL DO IMPACTO DAS INOVAÇÕES E MELHORIAS EM FACILIDADES}

Para a elaboração final do modelo relacional da tese, é necessário relembrar, ainda que superficialmente nessa seção, o percurso percorrido em campo durante os anos de 2007 e 2009. No decorrer desse tempo, surgiram novas questões, novidades e aperfeiçoamentos do modelo final a ser testado na tese. Foram obtidas, paralelamente às pesquisas teórica, 170 inovações e melhorias em facilidades apontadas por 113 profissionais da área. Contou ainda com duas fases pilotos, uma ocorrida antes da qualificação da tese e rodada com 30 inovações e outra após a banca com 15 inovações. Todas as etapas subsidiaram não só o estudo do fenômeno e delineamento do modelo conceitual, como também auxiliaram a formatação dos instrumentos de coleta de dados.

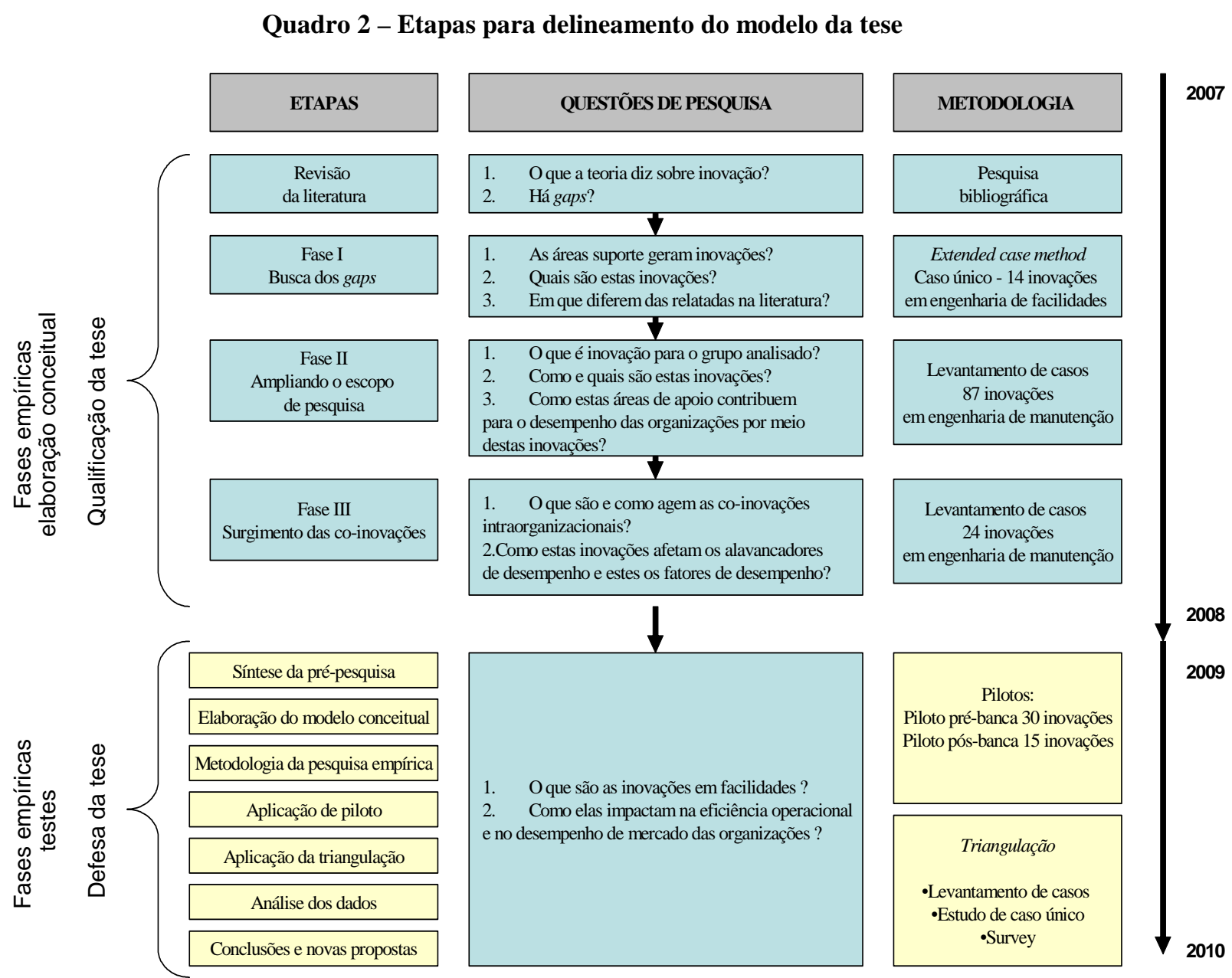

- A primeira etapa envolveu uma revisão bibliográfica a respeito de aspectos pertinentes à inovação. Nesta fase, investigou-se as literaturas tradicionais e correntes na busca de subsídios para fundamentação teórica e gaps. Estes registros foram selecionados em 
bases de dados como o ProQuest, EBSCO e ISI Web of Knowledge sempre dando preferência aos trabalhos mais relevantes ou citados no assunto tratado nesta tese;

- A segunda, paralelamente a revisão bibliográfica, ocorreu por meio de pesquisa de campo com 14 inovações e melhorias relatadas por 10 profissionais da área de facilidades da multinacional Ford Motor Company, localizada no Estado de São Paulo, apontando que as inovações e melhorias em facilidades são próximas às de processos e serviços e distantes das de produtos. Essa descoberta mostrou que uma possível subcategoria poderia ser explorada;

- Uma vez demonstrada a existência de subtipos das inovações tradicionais, na terceira etapa, iniciou-se a caracterização preliminar das inovações em facilidades, apontando que as mesmas afetavam determinados fatores de desempenho em detrimento de outros. Essa constatação, por meio da análise de 87 inovações relatadas por 34 profissionais da área de manutenção de várias empresas localizadas no Estado de São Paulo (participantes do curso noturno de pós-graduação em gestão da manutenção de uma IES), forneceu alguns subsídios para a formulação da questão de pesquisa dessa tese;

- Na quarta etapa, outra pesquisa de campo efetuada com um grupo de estudantes do curso de pós-graduação de gestão de manutenção de uma IES, foram levantadas 24 inovações e melhorias, testando-se as correlações das inovações em facilidades com os desempenhos operacionais das empresas, resultando no surgimento de fatores mais e outros menos afetados, não sendo o comportamento uniforme;

- A última etapa, por meio do aperfeiçoamento das fases anteriores, produziu-se um questionário piloto (antes da qualificação da tese) a fim de testá-lo e delineá-lo para aplicação do survey. Esse piloto contou com 30 profissionais (participantes do curso noturno de pós-graduação em gestão da manutenção de uma IES). Após a qualificação da tese e as considerações da banca, realizada em 20 de julho de 2009, o instrumento de coleta foi corrigido e reaplicado num teste-piloto com mais 15 participantes chegando-se ao modelo de hipóteses e o instrumento de coleta da etapa do survey.

As etapas supracitadas foram abordadas superficialmente nessa seção para demonstrar que paralela à pesquisa teórica, ocorreu uma empírica. Elas foram profundamente exploradas no capítulo 5 - análise dos dados. 
A revisão teórica foi confrontada com a empírica, permitindo diferenciar as nuances entre as inovações em processos, serviços e produtos (a primeira com similaridade mais próxima das em facilidades). Essa diferenciação não só destacou as peculiaridades de ambas, como também ajudou na definição operacional do termo "inovação e melhorias em facilidades". Percebeu-se, ainda, a gama de fatores e indicadores afetados pelas inovações tradicionais, mas com carência de aprofundamento nas em facilidades.

A primeira constatação apontada no Quadro 3 é que as características técnicas da inovação e melhorias em facilidades são muito similares das em processos (não diferindo em natureza), indicando, uma provável sublinhagem. Isso ficou claro durante o levantamento dos casos empíricos onde foram apontadas várias inovações relacionadas à introdução de novos dispositivos, maquinários e equipamentos de apoio aos processos produtivos dessas organizações, seguidos ou não de mudanças e inovações organizacionais. Entretanto, as diferenças entre as inovações em processos e facilidades estão relacionadas ao espaço (localização), ao tempo, a participação dos clientes e as competências exigidas: dão-se nas atividades periféricas, são pontuais, têm participação contínua dos clientes na implantação e demandam conhecimentos tácitos e sensoriais diferenciados. Essas características que as diferem serão retomadas ao longo do capítulo cinco, na análise do caso.

Juntas, pesquisas empíricas e bibliográficas, ajudaram a vislumbrar um fenômeno pouco explorado sob a ótica da teoria da inovação, que são as inovações e melhorias em facilidades com suas características peculiares, ainda que próximas das em processos, das organizacionais e em serviços.

Quadro 3 - Comparativo entre as inovações da literatura e dos casos empíricos

\begin{tabular}{|l|l|l|}
\hline Dimensões & $\begin{array}{l}\text { Inovações tradicionais em } \\
\text { processos } \\
\text { (revisão de literatura) }\end{array}$ & $\begin{array}{l}\text { Inovações e melhorias em } \\
\text { facilidades }\end{array}$ \\
\hline $\begin{array}{l}\text { Relação com os produtos e/ou } \\
\text { serviços finais da empresa }\end{array}$ & Alta & $\begin{array}{l}\text { campo) } \\
\text { (dados empíricos coletados em }\end{array}$ \\
\hline Custos & Altos (> US\$ 1 milhão) & Baixa \\
\hline Frequência da mudança & Longa e pontual & Baixos (<US\$ 1 milhão) \\
\hline Tempo requerido para & Longo & Curta e contínua \\
\hline
\end{tabular}




\begin{tabular}{|c|c|c|}
\hline implantação & & \\
\hline Ponto de início & $\begin{array}{l}\text { Desenvolvimento de uma operação } \\
\text { central }\end{array}$ & $\begin{array}{l}\text { Resolução de problemas/restrições } \\
\text { nas operações de apoio }\end{array}$ \\
\hline Agentes envolvidos & $\begin{array}{l}\text { Engenharia, Fornecedores (top- } \\
\text { down) }\end{array}$ & $\begin{array}{l}\text { Engenharia, Fornecedores, Chão-de- } \\
\text { fábrica (top-down + bottom-up) }\end{array}$ \\
\hline Participação do cliente & Pontual (especificações e entregas) & $\begin{array}{l}\text { Contínua (especificações, execuções } \\
\text { e entregas) }\end{array}$ \\
\hline Tipo de gestão & Formal & Informal \\
\hline Modificações (complexidade) & Média-Alta & Baixa-Média \\
\hline Nível da mudança & Incremental a Radical & Melhorias a Incremental \\
\hline Tipo da inovação (similaridade) & $\begin{array}{l}\text { Processos necessários para a } \\
\text { produção do bem ou serviço (ex: } \\
\text { linha de produção) }\end{array}$ & $\begin{array}{l}\text { Processos , Organizacionais e } \\
\text { Serviços }\end{array}$ \\
\hline Escopo & $\begin{array}{l}\text { Amplo, cross-functional e processos } \\
\text { centrais }\end{array}$ & $\begin{array}{l}\text { Focado, funcional e processos } \\
\text { periféricos }\end{array}$ \\
\hline Risco & Alto & Moderado \\
\hline Pressões & Internas ou Externas & Internas \\
\hline Conhecimento utilizado & Técnico-formal & Empírico-informal \\
\hline Conhecimento adquirido & Sistêmico & Infraestrutural \\
\hline Indicadores afetados & $\begin{array}{l}\text { Fatores de desempenho operacional } \\
\text { e financeiro }\end{array}$ & Fatores de desempenho operacional \\
\hline Intuito mercadológico & Médio & Baixo \\
\hline Passo da mudança & Intenso & Moderado \\
\hline Exemplo de inovação & $\begin{array}{l}\text { Grandes mudanças em processos e } \\
\text { sistemas }\end{array}$ & $\begin{array}{l}\text { Dispositivos, hardware, software, } \\
\text { política e competências de apoio aos } \\
\text { processos ou sistemas centrais. }\end{array}$ \\
\hline Termos técnicos & $\begin{array}{l}\text { Aprimoramento de algo existente ou } \\
\text { completamente novo para a empresa }\end{array}$ & Aprimoramento de algo existente \\
\hline Nível de experiência dos agentes & Médio- Alto & Alto \\
\hline
\end{tabular}

Fonte: Elaborado pelo autor

Os parágrafos anteriores apresentaram o raciocínio para a construção do modelo conceitual da tese. Para tanto, a próxima seção será dividida nos seguintes tópicos:

- Especificações iniciais do modelo, tanto do ponto de vista do conteúdo como da estrutura a ser analisada na tese, e com o qual a pesquisa foi conduzida;

- O modelo conceitual que foi utilizado para a formulação das hipóteses de pesquisa; 
- Ao término desta seção, serão apresentadas as principais contribuições esperadas pelo presente estudo.

O modelo e hipóteses construídos são testados, posteriormente, com a metodologia apresentada no capítulo 4.

\subsection{A relação da inovação e melhoria com os resultados das organizações}

Na revisão de literatura, verificou-se que não há consenso acadêmico sobre quais seriam os melhores indicadores de desempenho das organizações, mas há concordância sobre a influência (positiva ou não) das inovações ou melhorias sobre os resultados das mesmas e que mensurá-los ainda é uma importante ferramenta de gestão. Kaplan e Norton (1996), na apresentação do conceito de balanced scorecard, indicaram a necessidade de medir o desempenho dos negócios de forma balanceada, por meio de um leque de indicadores representativos pelos quais as empresas estariam inseridas, capazes de não só mensurarem, mas sustentarem os negócios ("para dentro e para fora"). Para isso identificaram quatro perspectivas: financeira, dos clientes, processos internos e crescimento/aprendizagem. Elas seriam as dimensões pelas quais cada organização deveria avaliar, os indicadores mais significativos dentro do seu contexto empresarial (na busca de eficiência operacional e ampliação da rentabilidade). Mas qual seria a relação entre as inovações e essas perspectivas? Para Kaplan e Norton (ibid, p.97) "innovation is a critical internal process. Being effective, efficient and timely in innovation processes is, for many companies, even more important than excellence in....day-to-day operating processes". Já Melnyk et al (2004) veem o controle, a comunicação e as melhorias contínuas como as principais funções do ato de se medir as operações.

$\mathrm{Na}$ análise de melhores práticas para medidas de desempenho das organizações, leia-se indicadores de desempenho, Ittner e Larcker (1998) verificaram que são três as vias mais correntes: as que utilizam indicadores econômicos/financeiros, as que optam pelos indicadores não financeiros como os operacionais e as que fazem uso de medidas de desempenho de agências governamentais. Apesar de uma parte significativa das empresas investigadas ainda opte pelos métodos tradicionais (financeiros) na hora de verificarem ganhos, há uma corrente preocupada com o reducionismo desta ação e propõe o uso de medidas de desempenho operacionais, principalmente ligados às eficiências. No entanto, 
quando se pensa na qualidade destas medidas, há pouca preocupação dos gestores em qualificá-las. Ainda em Ittner e Larcker (ibid), os motivadores para os que adotam outros indicadores que não os tradicionais são: i) percepção da limitação dos indicadores financeiros tradicionais, pois eles só olham para trás, ou seja, não são previsíveis para explicar o desempenho futuro, reconhecem apenas ações de curto prazo, não captando as mudanças nos negócios, são muito restritos para as ações gerenciais, refletem funções e não os processos matriciais e não medem os ativos intangíveis; ii) pressão competitiva para novas formas de medir, gerenciar e controlar; iii) agregam novas iniciativas como TQM. Esta condição é atingida quando se equaliza as medidas de desempenho tradicionais ou não, embora, como reconhecem os autores, seja difícil relacionar as saídas destas medidas com os resultados das empresas. Na linha da relação entre inovações e desempenho, destacam-se trabalhos de Slack (1993), Skinner (1996) e Nakajima (1988) quando os mesmos relacionam vantagens operacionais como justificativa das operações nas organizações. Com enfoque mais operacional e utilizando fatores como eficiência, velocidade, qualidade, custos, pontualidade e confiabilidade, tais trabalhos demonstraram que esforços internos tendem a expandirem os ganhos externos, numa espécie de trade-off.

A Ernest \& Young (ITTNER e LARCKER, ibid) realizou pesquisas durante seis anos em 584 empresas de manufaturas e serviços dos EUA sobre os indicadores de desempenho utilizados e, especificamente, os de desempenhos operacionais (e que podem medir as melhorias em processos). Os resultados apontaram que as prioridades eram alteradas ao longo deste tempo. Em 1988, as duas principais medidas utilizadas para analisar o desempenho operacional foram custos e reclamação de clientes. Em 1991, eram reclamações de clientes e custos (inverteram-se as prioridades). Já em 1994, esperava-se que a ordem fosse: reclamações de clientes e erros/defeitos. Este trabalho longitudinal demonstra a importância da repriorização dos indicadores na linha do tempo e do espaço.

Medidas de desempenho são mecanismos que os gestores utilizam para acompanhar melhorias em produtos e processos organizacionais, reforçando atividades que são mais significativas para as empresas (BOND, 1999). Bond aponta que essas melhorias contínuas, assim como o TQM - total quality management, são o caminho da vida corporativa sustentável. Na mesma visão de Prajogo (2003) que encontrou correlação positiva com o TQM e inovações em processos, consideradas pré-requisitos para a vantagem competitiva e Wechsler e Nascimento (2008), na investigação de práticas em processo de desenvolvimento 
de novos produtos, encontrando o uso de TPM - total productive maintenance como prática de otimização dos processos internos. Contudo, Wechsler e Nascimento (ibid) ressaltam que apesar da literatura tratar do TPM, principalmente após 1990 (pós-advento do TQM), ainda há escassez de estudos empíricos no assunto.

Kotabe e Murray (1990) verificaram, em análise de algumas multinacionais, que aquelas que aliaram inovações em processos com produtos tiveram seus desempenhos potencializados positivamente. Não obstante, os resultados das empresas advindos de produtos e processos são distintos na visão de Koellinger (2008), Cordero (1990), Vicent et al (2004). Frequentemente, processos estão atrelados a eficiências operacionais e produtividade, ou seja, aspectos internos das organizações. Já os produtos têm ligação mais direta com o crescimento, a rentabilidade, o desempenho financeiro.

Tidd et al (2008) apontam várias vantagens estratégicas geradas pelas inovações, entre elas: novidade na oferta de produto ou serviço; novidade no processo; complexidade; proteção legal; alteração dos fatores competitivos como preço, qualidade, variedade; lead time; desenvolvimento de plataformas; reescritura de regras; reconfiguração de partes do processo e transferência de conhecimentos. Já para mensurar estas inovações, eles indicam algumas possibilidades: mensurações pelos resultados de saída (vendas ou lucros); pelos operacionais ou dos processos (flexibilidade, eficiência e qualidade); pelos comparativos entre setores; pelos estratégicos (receita, lucratividade, participação no mercado). No caso das inovações em processos, recomendam o uso de mensurações das melhorias contínuas (acúmulo de economias, número de resolução de problemas, sugestão/funcionário).

A pesquisa de Lin e Chen (2007), com pequenas e médias empresas de Taiwan, indicou que havia forte correlação positiva entre o tamanho da empresa, a internacionalização e as alianças com os resultados de vendas, beneficiadas por muitas inovações organizacionais e as de pequenas complexidades. Neste ponto os autores chamam a atenção para as diferenças da trajetória oriental (focada nas pequenas melhorias) para com a ocidental (na busca de grandes saltos). Ambas têm seus méritos. Bhaskaran (2006) acrescenta que as inovações incrementais, mesmo pequenas, analisadas em pequenas e médias empresas australianas, foram responsáveis por aumentos significativos das vantagens competitivas destas firmas. Para Freel e Robson (2004) os impactos das inovações em produtos e processos se diferenciam no segmento de atuação da empresa. Analisando empresas pequenas e médias 
da Escócia e Inglaterra, concluíram que os resultados das manufatureiras eram diferentes das de serviços. Enquanto as primeiras tinham correlações positivas entre produtos novos ou incrementais no crescimento do emprego e correlações negativas com vendas e produtividade, nas empresas de serviços os processos incrementais tiveram correlações positivas com crescimento em vendas e produtividade.

Em Kemp (2003), constata-se que políticas de inovação governamentais afetam as chamadas entradas da inovação (como porcentagem de tempo utilizado pelas pessoas para inovar nas empresas), mas não as saídas (participação nas vendas), embora a inovação, nesta pesquisa, tenha efeito positivo no crescimento e na geração de empregos e pouco na produtividade e rentabilidade. Isso demontra que os incentivos nem sempre afetam os resultados finais das organizações.

Como já visto, produtos e processos, em alguns trabalhos, não geram os mesmos desempenhos. Vicent et al (ibid) mostraram em suas pesquisas que não só eram diferentes, como deveriam ser analisados em separado, concluindo que o tamanho, recursos e diversificação das empresas influenciaram os resultados financeiros das mesmas, mas não a idade. As inovações em produtos aumentaram o desempenho financeiro da empresa. Enfim, recomendam uma análise em separado dos impactos de processos e produtos nos resultados financeiros. Salomo et al (2008) investigaram mediadores dos desempenhos das inovações. $\mathrm{O}$ estudo mostrou que uma carteira de projetos em produtos bem estruturada alavancou, indiretamente, os resultados das empresas analisadas.

No Brasil, a dificuldade em se inovar é um fato, mas será que as estatísticas captam tipologias realmente importantes para o país? Uma pesquisa realizada no ano de 2008 pelo Serviço de Apoio às Micro e Pequenas Empresas de São Paulo (SEBRAE-SP), com 450 empresas sediadas no Estado de São Paulo dos setores da indústria, comércio e serviços, revelou que $47 \%$ das micro e pequenas empresas paulistas raramente introduzem inovações em seus processos ou negócios. Por outro lado, as outras 53\% afirmaram ter realizado alguma melhoria ou novidade no seu negócio. Porém, quanto a frequência no desenvolvimento de inovações, somente $14 \%$ dos empreendimentos têm o hábito de realizálas. Quanto ao tipo de inovação, a pesquisa revelou (para aquelas que inovam):

- $28 \%$ das empresas introduziram um novo produto ou serviço no mercado; 
- $22 \%$ delas implantaram novos processos;

- $15 \%$ conquistaram novos mercados.

Especificamente em relação às inovações em processos ou métodos, 5\% dessas MPE's introduziram alguma tecnologia da informação nos negócios, 3\% novas ações de marketing, $2 \%$ adquiriram novas máquinas e equipamentos, $1 \%$ modificou seu modelo de gestão, $1 \%$ mudou o layout e o restante foi diluído em outras pequenas melhorias. Os investimentos médios foram de $\mathrm{R} \$ 7.877,00$ e o tempo de desenvolvimento em torno de 4 meses. As fontes para as inovações foram os proprietários $(8 \%)$ ou os próprios funcionários $(6 \%)$. Mesmo introduzindo pequenas melhorias, $22 \%$ inovaram em processos, $74 \%$ tiveram de aumento na produtividade, $49 \%$ aumentaram a receita, 35\% reduziram os custos, $19 \%$ substituíram insumos, $17 \%$ reduziram impactos ambientais. Será que estas pequenas melhorias também não possuem impactos nas empresas de médio e grande porte?

O relatório da PINTEC (2005) demonstrou que 80,3\% das empresas brasileiras inovaram via aquisição de máquinas ou equipamentos. Por último, paradoxalmente, apenas 4,6\% inovou via $P \& D$. Verificou-se que as inovações em produtos são frutos de esforços internos e que as em processos vêm por meio de fornecedores (também considerados as principais fontes de informação para inovações). Em termos de impactos, melhoria da participação dos empregados e na qualidade dos produtos e serviços foram, respectivamente, os mais citados. Os maiores obstáculos, em ordem de importância verificados por estas empresas, foram custos da inovação, riscos econômicos e pessoal desqualificado.

Em Bolwijn e Kumpe (1990) percebe-se uma preocupação em relacionar demandas do mercado, critérios de desempenho e tipo ideal de firma para explicar a transição no tempo entre as empresas eficientes e as inovadoras (num contexto manufatureiro). Partindo de um mercado preocupado com preço, na década de 1960 até os anos 1990, quando o foco deixa de ser o preço, nota-se uma mudança significativa no perfil da firma, como destacado no Quadro 4: 
Quadro 4 - Evolução da manufatura

\begin{tabular}{|r|l|l|l|}
\hline \multicolumn{1}{|c|}{ Tempo } & \multicolumn{1}{|c|}{$\begin{array}{c}\text { Requerimentos do } \\
\text { mercado }\end{array}$} & \multicolumn{1}{|c|}{ Critérios de desempenho } & \multicolumn{1}{|c|}{ Firma (tipo ideal) } \\
\hline 1960 & Preço & Eficiência & A firma eficiente \\
\hline 1970 & Preço, qualidade. & Eficiência + qualidade & A firma com qualidade \\
\hline 1980 & $\begin{array}{l}\text { Preço, qualidade, linha } \\
\text { de produtos. }\end{array}$ & Eficiência + qualidade +flexibilidade & A firma flexível \\
\hline 1990 & $\begin{array}{l}\text { Preço, qualidade, linha } \\
\text { de produtos, } \\
\text { exclusividade. }\end{array}$ & $\begin{array}{l}\text { Eficiência + qualidade +flexibilidade + } \\
\text { habilidade para inovar }\end{array}$ & A firma inovadora \\
\hline
\end{tabular}

Fonte: Traduzido de Bolwijn e Kumpe (1990)

Verifica-se que eficiência, mesmo passadas quatro décadas, ainda é um dos objetivos centrais das organizações.

\subsection{Especificações iniciais do modelo relacional: conteúdo e estrutura}

Este item trata das especificações iniciais da tese em termos de conteúdo e estrutura, dos aspectos levantados na fundamentação teórica e das hipóteses de pesquisa que farão parte desta. Encontrou-se uma analogia nos trabalhos de Wolff e Pett (2006) no direcionamento desta tese, realizados com 855 pequenas e médias empresas de manufatura nos EUA. O objetivo era compreender as relações entre os fatores antecedentes (hostilidade ambiental, tamanho de firma, capacidade de inovação e internacionalização), as melhorias em processos e produtos e as dimensões de desempenho (crescimento e rentabilidade). Observou-se forte correlação entre as variáveis - capacidade para inovação e internacionalização, atuando tanto nas inovações em produtos como nas em processos. Não foi o caso encontrado para as variáveis - tamanho da firma e hostilidade ambiental, com correlações fracas (porém, afetaram diretamente o crescimento).

Neste modelo de Wolff e Pett (ibid), conclui-se que para as organizações testadas, enquanto as inovações em produtos apresentam forte correlação com o crescimento, as melhorias em processos atuam como coadjuvantes. Por que as chamadas inovações de melhorias em processos têm uma participação insignificante nos resultados das organizações? Será que esta 
neutralidade se dá em função da atuação de fatores intermediários? Essas foram as questões levantadas por Wolff e Pett que, analogamente, estimularam as questões da tese.

Por motivos de conveniência e metodologia, a abordagem foi sobre o objeto (inovações e melhorias em facilidades - IMF) e o sujeito (a empresa), seguindo orientações do Manual de Oslo (2005). A tese realizará uma análise profunda da IMF com alguns fatores de desempenho operacional, pois se verificou, ao longo da fundamentação teórica, de forma mais explícita no trabalho de revisão da literatura efetuada por Becheikh et al (2006), a predominância de estudos em inovações em produtos ou produtos e processos interdependentes. Com isso, procura-se contribuir para a pesquisa acadêmica por meio da investigação das inovações e melhorias em facilidades - IMF, bem como suas relações com os desempenhos operacionais das organizações.

A tese foi de natureza descritiva, mas procurará estabelecer após análise de seus principais resultados, algumas prescrições pertinentes ao seu modelo de pesquisa, que utilizará questionários semiestruturados (APÊNDICE A) aplicados nos profissionais de facilidades para condução do estudo, captação da percepção dos profissionais, coleta dos dados e teste de hipóteses, somados a estudos de casos de IMF em facilidades relatados na fase empírica. Os profissionais participantes foram tanto do nível operacional como do estratégico, ligados diretamente na implantação das inovações averiguadas. A opção por envolver os profissionais operacionais é porque os mesmos estão diretamente envolvidos na implantação das inovações e melhorias em facilidades. Difere-se das pesquisas tradicionais em inovação, onde os principais interlocutores são gestores ou líderes da alta direção, frequentemente, oriundos de áreas centrais como os de Marketing, P\&D ou Engenharias Avançadas.

\subsection{Caracterização das dimensões do modelo relacional}

Dentro da revisão de literatura, pôde-se verificar a pequena quantidade de trabalhos que incorporam, com tratamento empírico, as inovações com características próximas as em facilidades com os desempenhos operacionais. Mesmo quando analisadas sob a perspectiva dos movimentos da qualidade total, pouca atenção se deu aos papéis e às relações que estas têm com a teoria da inovação ou com os resultados organizacionais no âmbito operacional. Majoritariamente, e isto pode ser notado na revisão de Kaynak (1999), os estudos focam a relação entre a gestão da qualidade das organizações com alguns indicadores 
multidimensionais de desempenhos operacional, financeiro e/ou de mercado. Pouco se refere aos artefatos (inovações) gerados pelas áreas periféricas e suas relações com os desempenhos operacionais, menos ainda com os externos.

Esta pouca discussão se deve em parte a dificuldade de estreitar a lente de observação dos pesquisadores em ambientes industriais pouco explorados. Esta foi a conclusão e dificuldade de Coobs et al (1996), analisando 951 inovações de empresas baseadas na Inglaterra. Eles identificaram que apenas $1 \%$ era em processos, mas a baixa participação se devia, sobretudo, a falta de relato e acesso às informações de tais inovações. As áreas periféricas, de apoio às operações, são extremamente dinâmicas e tácitas, criando obstáculos adicionais nos trabalhos de pesquisas. A redução desta dificuldade inicial, nesta tese, foi reduzida com as quatro fases empíricas apresentadas anteriormente, onde o pesquisador pode limitar as fronteiras do fenômeno. Outros trabalhos como os de Wolff e Pett (2006) e Li et al (2007) ajudaram na abstração inicial para a construção do modelo teórico apresentado na Figura 9. Esses autores propõem modelos de causalidade entre inovações de produtos e processos com resultados organizacionais, concluindo que as últimas são afetadas em diferentes graus de intensidade pelas primeiras.

Porém, ainda dentro literatura científica, é possível afirmar que os resultados operacionais das organizações são influenciados pelas inovações e essas por um vasto conjunto de fatores internos e externos. Autores como Bhaskaran (2006), Wolff e Pett (2006), Lin e Chen (2007), Ferreira et al (2007) e Avermaete et al (2003) têm demonstrado que fatores intrínsecos às organizações como idade, tamanho, setor, número de empregados, estilo de profissional, participação regional e ciclo de vida impactam diferentemente na geração de tipos de inovações e estas nos resultados econômicos das empresas.

Partindo das constatações empíricas e teóricas, foram utilizadas as dimensões classificatórias ou categóricas para se caracterizarem o sujeito (perfil da empresa e respondentes) e o objeto (IMF - inovações ou melhorias em facilidades), e as assertivas para se investigarem as relações dessas com a eficiência operacional e desempenho financeiro. Não foram estabelecidas características prévias dos objetos, pois na análise dos resultados pode-se encontrar subtipos das IMF em função das características dos respondentes e das próprias inovações. 
Pressupõe-se que essas inovações ou melhorias teriam relações significativas com a dimensão da eficiência operacional e não ocorrendo o mesmo com a de desempenho financeiro. Contudo, as de eficiência e de desempenho financeiro teriam relações indiretas. A inclusão da dimensão - desempenho financeiro é para que se possa contrastar e posicionar os impactos das inovações em facilidades em diferentes níveis. Para esta tese, estas inovações são artefatos mediadores dos resultados finais das organizações, pois eles criam, por meio das eficiências operacionais, condições de expansão das capacidades internas. Essa afirmação será refutada ou confirmada nessa tese e para isso, desenhou-se um modelo de investigação preliminar, conforme Figura 9, onde as linhas apontariam a força da relação (linha cheia representa relação forte, linha tracejada fraca):

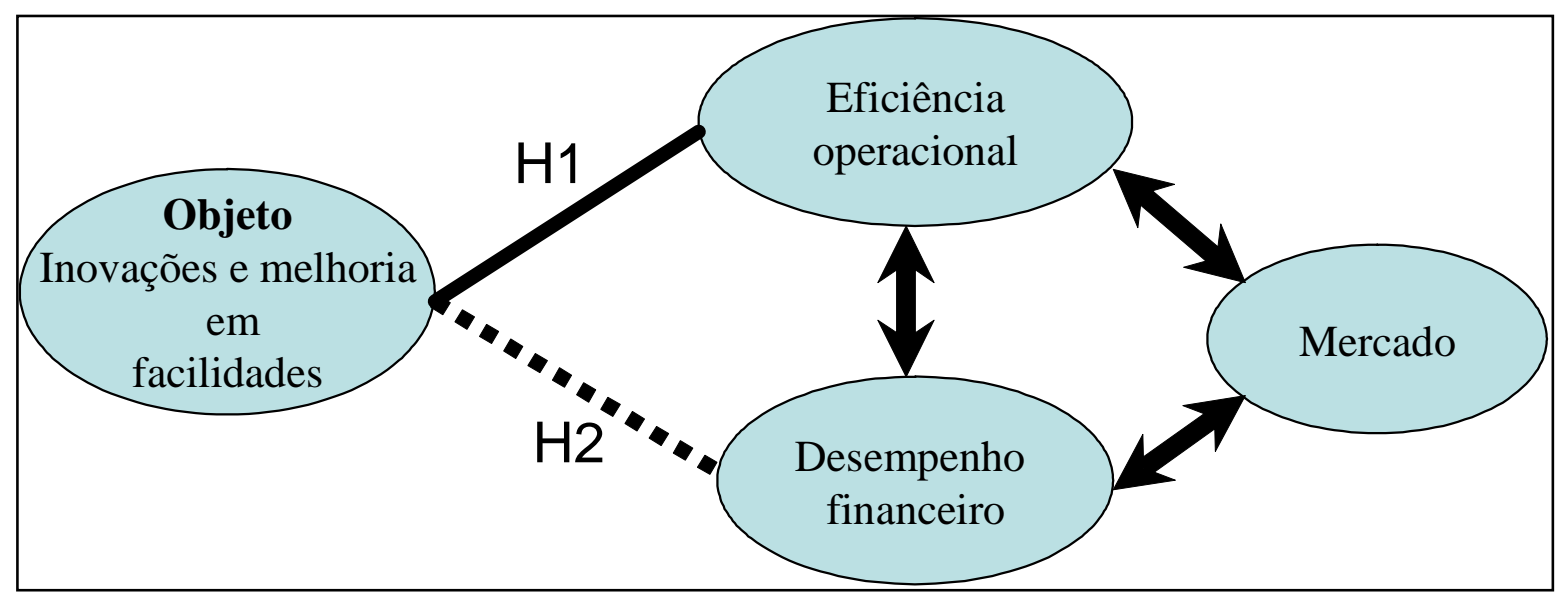

Figura 9 - Modelo de investigação relacional preliminar das inovações e melhorias

O modelo da Figura 9 possui relações já conhecidas pela literatura (linhas com setas), por isso foram descartadas as correlações ou testes de hipóteses das mesmas. Slack (1993) no seu modelo de desempenho, ressaltaria que os fatores de desempenho (eficiência) afetam e são afetados pelos financeiros, gerando inclusive trade-offs. Uma inovação pode melhorar a qualidade dos produtos ou serviços, mas também pode aumentar os custos internos com inspeções e controles da qualidade, por exemplo. Essa dinâmica é também influenciada pelas variáveis ambientais, como o mercado, relação esta apresentada por Brown e Eisenhardt (1995) na explicação dos fatores de sucesso no desenvolvimento de produtos. Para elas, o mercado, via tamanho, crescimento ou concorrência, interfere diretamente nos desempenhos financeiros das organizações. Nessa análise, curiosamente, o mercado não afetaria diretamente os desempenhos operacionais e estes, por sua vez, não seriam afetados pelos desempenhos financeiros (numa relação de causa e efeito). Apesar de não discutirem 
causalidade no modelo proposto, a direção dada pelas autoras é que o desempenho operacional e o mercado são causas diretas dos desempenhos financeiros (estes, então, os efeitos).

Vários estudos evidenciaram a influência das inovações nos resultados das organizações e uma forma de captá-la é por meio de fatores de desempenho. Como cada organização pode ter diversos e diferentes objetivos ou indicadores. Optou-se por um conjunto que contemplasse os aspectos mais significativos para as operações de uma empresa. Thompson (1976) ressalta que as organizações são multidimensionais e buscam, quando possuidoras de tecnologias apropriadas e um ambiente operacional estável, eficiências para a sua sobrevivência. Neste sentido, os seis critérios propostos por Nakajima (1988), também utilizados parcialmente por Slack (1993), Da Silveira e Slack (2001) e Kaplan e Norton (1996), definem que os fatores operacionais internos como qualidade, velocidade e flexibilidade podem gerar execução superior e, consequentemente, eficiência operacional. Da Silveira e Slack (ibid) os chamam de “objetivos competitivos". Também se alinham às de Bolwijn e Kumpe (1990) que argumentam ser a flexibilidade, a qualidade, a eficiência e a capacidade em inovar as dimensões-chave da manufatura moderna.

A escolha pelos critérios de Nakajima se deveu principalmente a aderência deste em relação ao contexto de investigação - o operacional. Nakajima (1988) apresentou os primeiros esboços do que viria a ser conhecido com Total Productive Maintenance, na década de 1970. Para ele, o sucesso de uma empresa se dava em pequenas melhorias sistemáticas adotadas pelos agentes de todos os níveis das organizações, reforçando a premissa que inovações são práticas do dia a dia que modificam, mesmo em pequena escala, o patamar de desempenho das empresas. Contrasta com a percepção ocidental de inovação advinda de grandes saltos tecnológicos. Nakajima (ibid) apontou que a eficiência de uma empresa era obtida pela busca de seis grandes dimensões - produtividade, qualidade, custos, entrega, segurança/meio ambiente e moral. Cada uma com um rol de indicadores adequados com o contexto. Ainda em relação a eficiência, Churchman (1968) a define como a idéia de "o melhor caminho a ser seguido". Por exemplo: se o objetivo de uma empresa é montar um produto, então a abordagem da eficiência consistirá, entre outras coisas, em minimizar o tempo dessa montagem, resultando em eficiência. 
Para os chamados desempenhos financeiros, haveria uma infinidade de dimensões utilizadas e testadas na literatura científica. Como o intuito da tese é o de verificar diferenças de impactos das inovações em facilidades nas dimensões internas (eficiência operacional) e externas (desempenhos financeiros) optou-se pelo uso parcial do modelo utilizado por Douglas e Judge (2001). Esses autores investigaram o impacto nas dimensões financeiras (lucro, participação de mercado e retorno sobre investimentos) percebidas pelos adotantes de práticas do Total Quality Management - TQM, essas profundamente relacionadas com a teoria e o ambiente de pesquisa de Nakajima.

Após definição do modelo preliminar de investigação, elaborou-se o modelo teórico para os testes de hipóteses que responderá uma parte da questão central da tese: como as inovações e melhorias impactam a eficiência operacional e no desempenho financeiro das organizações.

\subsubsection{Testes de hipóteses do modelo de investigação}

Nesta seção serão apresentadas as hipóteses do modelo a ser testado na tese. O modelo está representado na Figura 10 e é composto por vinte dimensões classificatórias acerca da empresa, do respondente e da IMF - inovação/melhoria em facilidades e nove assertivas (seis critérios para detectar a eficiência operacional e três para o desempenho financeiro).

A primeira etapa consiste em identificar possíveis diferenças estatísticas significativas entre os sujeitos e objetos. A hipótese de nulidade (H0) é que não haja diferenças entre as amostras a um nível de significância 0,05. A hipótese alternativa (HA), sendo a definição operacional ou predição presumida da teoria que está sendo comprovada (SEIGEL, 1975), é que haja diferenças estatísticas significativas entre as amostras. Supõe-se que diferentes sujeitos (empresa e respondente) geram diferentes características nos objetos (inovações em facilidades). Essa constatação, se comprovada, pode indicar subcategorias dentro dessas IMF que necessitarão de análises em separado dos grupos encontrados.

Em seguida, têm-se as outras hipóteses de pesquisa relacionando o objeto com a eficiência operacional (H1), o objeto com o desempenho financeiro (H2). As IMF se relacionariam significativamente com a eficiência operacional e nem tanto com os de desempenho financeiro. A relação entre as duas dimensões (eficiência operacional e desempenho financeiro), supõe-se que seja relativa. Como se utilizará uma escala Likert (variando de 1, 
para impacto muito negativo, a 5, muito positivo), as forças das relações foram testadas por meio das modas.

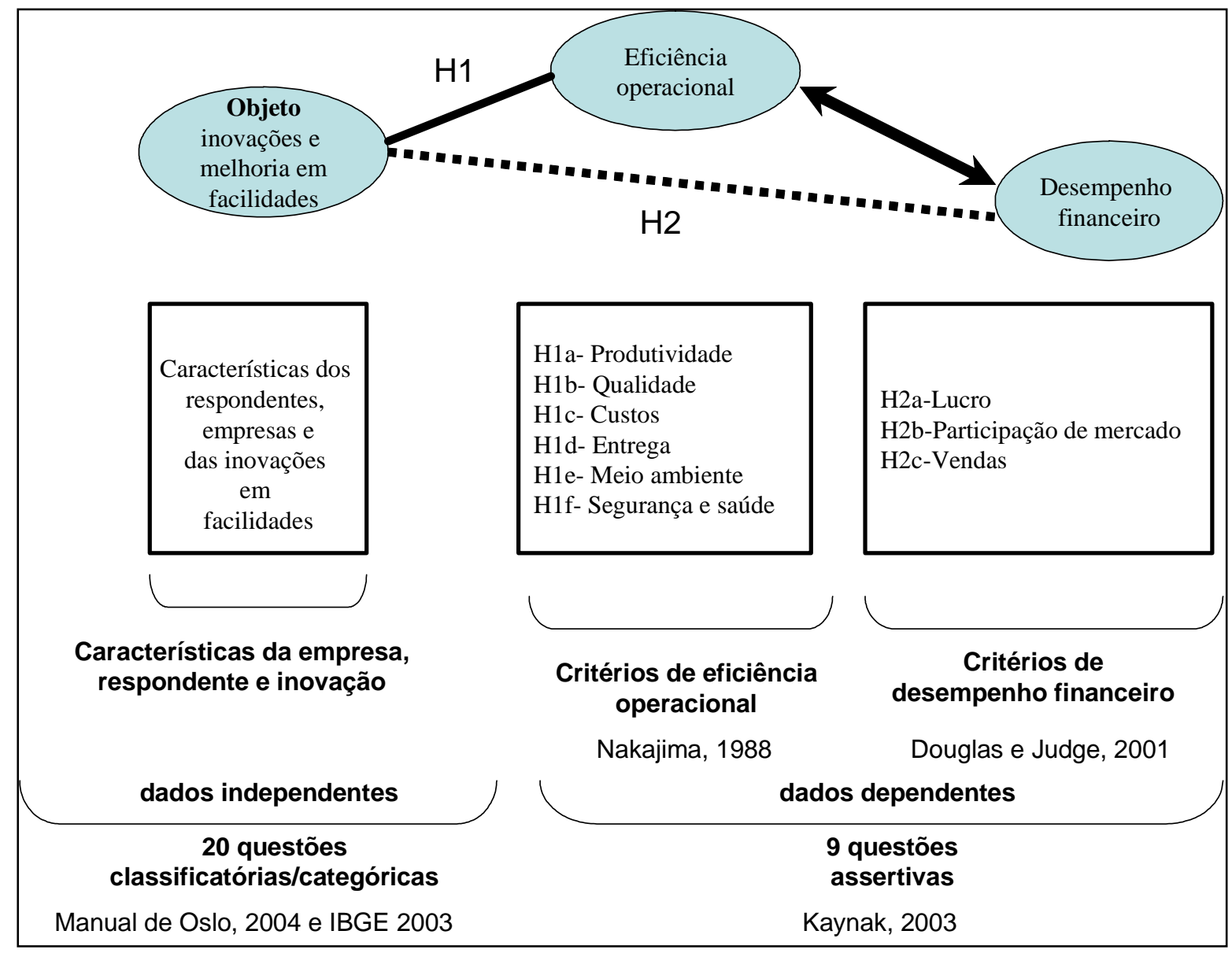

Figura 10 - Modelo relacional para testes de hipóteses 
O Quadro 5 explica cada uma das dimensões testadas, as hipóteses principais e as de investigação.

Quadro 5 - Dimensões e hipóteses da pesquisa

\begin{tabular}{|c|c|c|}
\hline Dimensão & $\begin{array}{c}\text { Hipóteses } \\
\text { principais de } \\
\text { pesquisa }\end{array}$ & Hipóteses secundárias de pesquisa \\
\hline $\begin{array}{l}\text { Inovação/melhoria } \\
\text { e eficiência } \\
\text { operacional }\end{array}$ & $\begin{array}{l}\text { H1: as IMF } \\
\text { impactam } \\
\text { significativamente } \\
\text { na eficiência } \\
\text { operacional }\end{array}$ & $\begin{array}{l}\text { H1a: as IMF impactam significativamente a produtividade das empresas } \\
\text { H1b: as IMF impactam significativamente a qualidade das empresas } \\
\text { H1c: as IMF impactam significativamente os custos das empresas } \\
\text { H1d: as IMF impactam significativamente a entrega das empresas } \\
\text { H1e: as IMF impactam significativamente o meio-ambiente das empresas } \\
\text { H1f: as IMF impactam significativamente a segurança e saúde das empresas }\end{array}$ \\
\hline \begin{tabular}{|l|} 
Inovação/melhoria \\
e desempenho \\
financeiro
\end{tabular} & $\begin{array}{l}\text { H2: as IMF não } \\
\text { impactam } \\
\text { significativamente o } \\
\text { desempenho } \\
\text { financeiro }\end{array}$ & $\begin{array}{l}\text { H2a: as IMF não impactam significativamente os lucros das empresas } \\
\text { H2b: as IMF não impactam significativamente a participação de mercado das } \\
\text { empresas } \\
\text { H2c: as IMF não impactam significativamente nas vendas das empresas }\end{array}$ \\
\hline
\end{tabular}

Fonte: Elaborado pelo autor

A questão central de pesquisa da tese consiste em: o que são as inovações e melhorias em facilidades e como elas impactam na eficiência operacional e no desempenho financeiro das organizações.

Nota-se que para responder a questão principal da tese, foram percorridos dois passos macros explicados no capítulo de metodologia: um tratamento estatístico descritivo/indutivo nas variáveis independentes (classificatórias) para determinar o que são as inovações e melhorias e outro para examinar como elas impactam os desempenhos das organizações por meio das variáveis dependentes (assertivas).

\subsection{Limitações do modelo relacional proposto na tese}

Dificilmente um único modelo conseguiria contemplar todos os fatores de desempenho das organizações. Prova disso foi o resultado apontado nas seções anteriores, onde a gama de 
indicadores já experimentados em outras pesquisas demonstra a heterogeneidade de opções, ou seja, as informações quantitativas ou qualitativas, medidoras dos resultados das organizações, são frutos do contexto. Por conseguinte, como primeira limitação do modelo, surge o corte dado a esses fatores. Procurou-se na fundamentação teórica e pesquisas empíricas os que melhor se ajustavam a realidade investigada na tese (contexto operacional), mas se assume que nem todos estarão presentes, logo se explorará parte desta realidade. Outra limitação é a causalidade entre a eficiência operacional, o desempenho financeiro e as inovações em facilidades. Quem afeta quem primeiro? Esta questão não foi discutida nesta tese, mas o quanto uma afeta a outra. A terceira limitação ocorre na interpretação dos resultados das organizações: eles foram indicados qualitativamente por meio da percepção dos respondentes e não pela utilização de indicadores quantitativos, o que implica interpretar os dados com a lente do inquirido. 


\section{METODOLOGIA DA PESQUISA}

O objetivo desta seção é explicitar a opção metodológica adotada e o procedimento de pesquisa empírica, visando à reprodutibilidade do estudo e considerando os itens: tipos de pesquisa, experimentos, amostragem, levantamento dos dados, instrumentos para coleta de dados, técnicas estatísticas, validação interna/externa e limitações da metodologia de pesquisa.

\subsection{Tipos de pesquisa utilizados na tese: quantitativos e qualitativos}

A pesquisa foi do tipo descritiva-relacional, quantitativa e qualitativa, utilizando abordagem metodológica do extended case method. Essa opção é detalhada ao longo desta seção.

A escolha de um tipo de pesquisa depende do objetivo do estudo. Selltiz (1974, p.59) descreve alguns dos principais tipos e seus objetivos:

- Estudos Descritivos: para apresentar, de forma precisa, as características de uma determinada situação, verificar a freqüência de sua ocorrência e formular modelos. A pesquisa descritiva necessita da formulação prévia de hipóteses específicas, utilizando, para coleta de dados, método de inquérito (ou survey), painéis e observação.

- Estudos relacionais: para verificar as relações entre fatores ou dimensões por meio de agrupamentos de um fator com outro, ou outros (MARTINS, 2002). Utilizar-se-ão técnicas de análise multivariada para a busca das associações entre os fatores.

Outra forma de classificar os tipos de pesquisa é a metodologia utilizada para a obtenção dos dados. Os primários podem ser qualitativos ou quantitativos quanto à sua natureza. A metodologia para a obtenção destes dados qualitativos costuma ser chamada de pesquisa qualitativa e a de dados quantitativos, pesquisa quantitativa.

A pesquisa qualitativa, como apresentado pelo Quadro 6, é uma metodologia não estruturada, exploratória, que proporciona reflexões e compreensão do contexto do problema. As informações podem ser obtidas a partir da análise do discurso do entrevistado, mas se considera sua postura global diante das questões colocadas. Sem preocupação estatística, esse método é utilizado para casos pelos quais se quer explorar um problema e seus dados podem ser considerados conclusivos, mas não generalizáveis à população-alvo. Ela foi utilizada na 
Fase I da pesquisa empírica dessa tese e aplicada na análise dos casos descritos brevemente pelos respondentes.

A pesquisa quantitativa tem por objetivo quantificar os dados e generalizar os resultados da amostra para a população-alvo, utilizando um número de casos significativos, com amostras representativas, coleta de dados estruturada e análise estatística dos dados. Observa-se que a Fase IV da pesquisa empírica foi conduzida pela metodologia quantitativa.

\section{Quadro 6 - Diferenças entre pesquisa quantitativa e qualitativa}

\begin{tabular}{|c|c|c|}
\hline Metodologia & Qualitativa & Quantitativa \\
\hline Objetivo & $\begin{array}{c}\text { Obter compreensão qualitativa das razões } \\
\text { e motivações envolvidas }\end{array}$ & $\begin{array}{l}\text { Quantificar os dados e generalizar os } \\
\text { resultados da amostra para a população-alvo }\end{array}$ \\
\hline 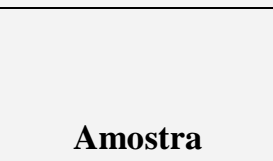 & Alguns casos & Grande número de casos \\
\hline 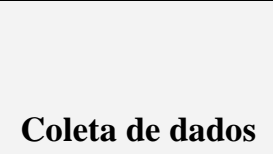 & Não estruturada & Estruturada \\
\hline Análise de dados & Não estatística & Estatística \\
\hline Resultado & Compreensão do problema & Recomenda um curso final de ação \\
\hline
\end{tabular}

Fonte: Malhotra (2001, p.156)

Yin (2005) relembra que é possível, inclusive benéfico, o uso da triangulação (dos dados, dos pesquisadores, da teoria ou da metodologia) nas pesquisas, principalmente para a validação de constructos. A construção do modelo a ser testado (Figura 10) passou pela triangulação de dados (obtidos na fase empírica e teórica) e de metodologias (das várias utilizadas até o amadurecimento do desenho). Easterby-Smith et al $(1999$, p. 133) ressaltam que a mistura de métodos de pesquisa é saudável, pois "a força de qualquer medida é falha de uma forma ou de outra, portanto, as concepções e estratégias de pesquisa podem ser compensadas entre si". O uso de medidas múltiplas, mas independentes, é chamado de triangulação. Como foram 
utilizados questionários semiestruturados e análise qualitativa dos casos para obtenção das melhoras respostas das questões de pesquisas formuladas, a metodologia mesclará os enfoques quantitativos e qualitativos, logo, triangulados.

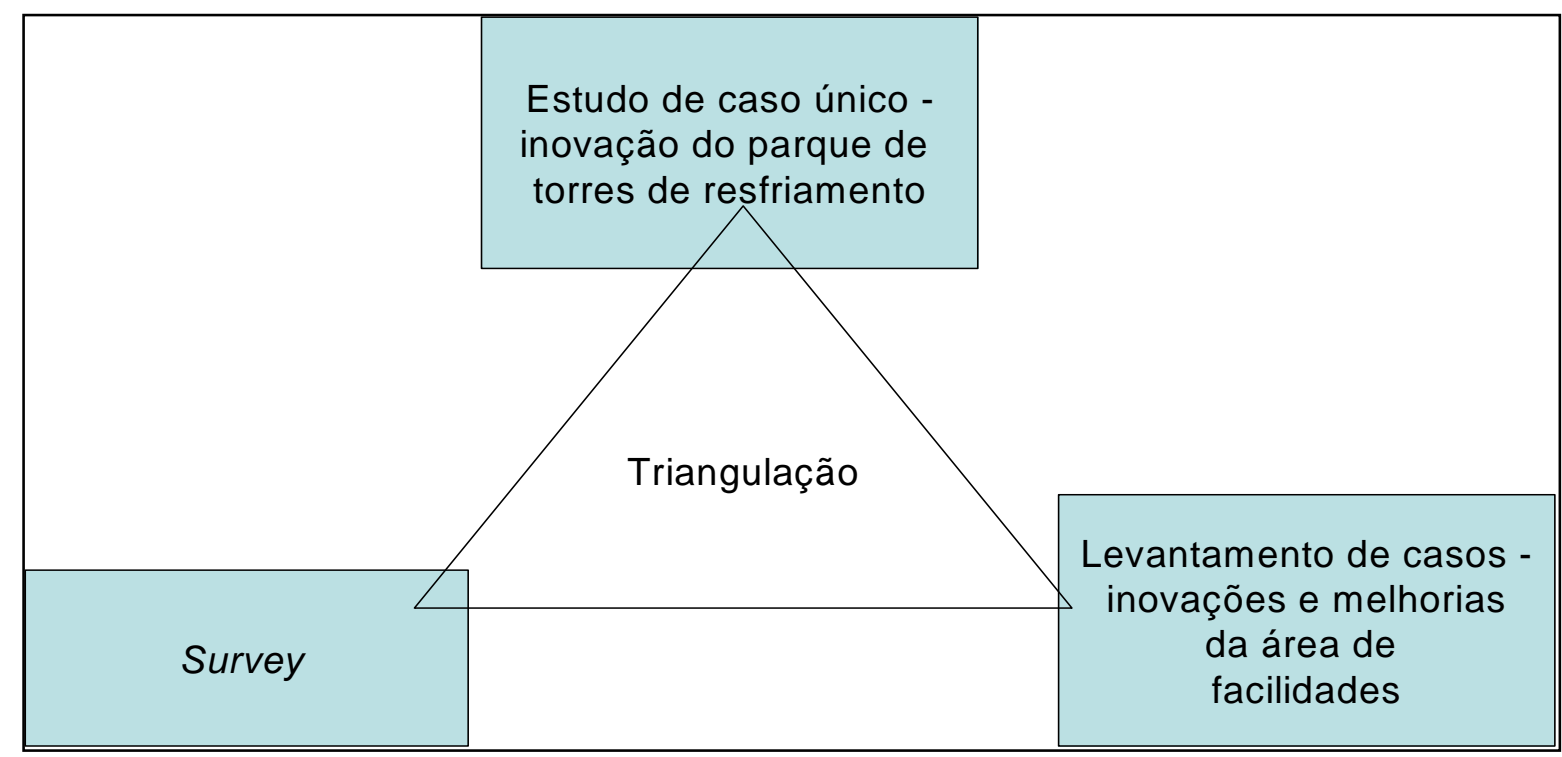

Figura 11 - Triangulação metodológica utilizada na tese

- O levantamento de casos, para Gil (2009), está enquadrado na categoria estudos exploratórios uma vez que envolvem, sem muita profundidade, a análise de exemplos que estimulam a compreensão do fenômeno por meio de informações a respeito de um grupo, organização ou comunidade. Também tem o objetivo de descrever a incidência ou predominância desse fenômeno.

- O estudo de caso único (YIN, 2005) envolve, além do aprofundamento do fenômeno, a observação direta dos acontecimentos que estão sendo estudados e as entrevistas das pessoas neles envolvidas.

- Uma das maneiras para se reunir dados primários, analisá-los e compará-los é por meio de questionários autoadministrado, também chamado de survey (COOPER e SCHINDLER, 2003). Ele pode ser supervisionado ou não. Possui inúmeros benefícios como o acesso e respostas rápidas e desvantagens, como baixo índice de respostas e impossibilidade de intervenção do entrevistador.

Recentemente, outra abordagem metodológica utilizada para responder desafios, como os propostos neste trabalho, tem sido a extended case method. Este é um tipo de pesquisa chamada por Burawoy (2003) de etnografia reflexiva que usa dados empíricos confrontados com fundamentos teóricos. Quatro são as dimensões afetadas por esta abordagem: 1) a do 
observador como participante do processo; 2) a da busca pela integração e extensão de uma teoria existente; 3) a da verificação dos processos internos do fenômeno (microanálise) e 4) a da observação dos fatores externos do fenômeno (macroanálise). Essa abordagem se difere da grounded theory (STRAUSS e CORBIN, 1990), pois se pretende contribuir com uma teoria corrente e não em construir uma nova. Esta metodologia foi utilizada por Danneels (2002) para descrever como a inovação em produtos ajudava na renovação da firma.

Antes da aplicação do questionário final, foi conduzido um teste-piloto com profissionais das áreas de facilities industriais, alunos de pós-graduação de gestão da manutenção de uma IES Instituição de Ensino Superior - da cidade de São Paulo e, validado o questionário, utilizarse-á um banco de dados com profissionais de facilities do Brasil, assinantes da revista INFRA (especializada no tema de facilidades) ao longo do ano de 2009.

\subsection{Amostragem}

A amostra é não probabilística e por conveniência (COOPER e SCHINDLER, 2003), devido ao acesso do pesquisador como professor de uma disciplina na pós-graduação da IES (UNIFEI) e também como membro da ABRAFAC - Associação Brasileira de Facilities (patrocinadora da revista INFRA). Ela também é conhecida como não casual (LEVIN, 1987) e baseia-se na escolha dos sujeitos que convém à pesquisa, geralmente advinda de questionários preenchidos. Essa opção também auxilia no filtro das inovações pesquisadas, garantindo que as mesmas possuam características típicas das em facilidades (Quadro 4) ou ao menos sejam aproximadas, evitando falha na seleção do objeto (inovação).

Os tamanhos das populações-alvo $(\mathrm{N})$ foram de 45 profissionais na fase piloto [Cooper e Schindler (ibid), recomendam de 25 a 100 pessoas] e aproximadamente 10.000 na segunda etapa. Uma diferenciação que se pretende estabelecer com estas amostras é o de ressaltar o papel da tecnoestrutura (MINTZBERG, 2003), ou seja, dos técnicos, engenheiros e analistas na implantação das inovações, diferentemente das pesquisas tradicionais, onde o papel da alta liderança é o mais destacado. 


\subsection{Levantamento dos dados}

Não foram descartados os dados qualitativos previamente levantados na fase empírica que totalizaram 170 inovações. Essas informações ajudarão na triangulação pretendida, principalmente na caracterização de tais inovações.

Os dados do survey foram coletados ao longo segundo semestre de 2009. Foi solicitado aos respondentes o preenchimento de um questionário semiestruturado, desenhado através do modelo de hipóteses, via Internet (APÊNDICE A). Este recurso não só agilizou as respostas como facilitou a coleta dos dados, pois o processo foi automático, não necessitando de transcrição dos dados para a planilha e também auxiliará na correção do mesmo na etapa de validação. Foram solicitados aos profissionais de facilidades que apresentassem uma inovação significativa ocorrida nos últimos dois anos na empresa onde trabalham e da qual tenham participado. A partir de então, as perguntas elaboradas remeteram à inovação citada.

A elaboração do questionário foi adaptada do Manual de Oslo (2005), de Kaynak (2003), de Nakajima (1988) e de Douglas e Judge (2001), pois se entende que são instrumentos de coleta legitimados e testados. Também serviram de referências para a elaboração do mesmo as fases piloto já descritas no início desse capítulo. A seguir (QUADRO 7), as dimensões que foram analisadas na tese para responder as questões de pesquisa: 
Quadro 7 - Explicações das dimensões pesquisadas

\begin{tabular}{|c|c|c|c|c|}
\hline 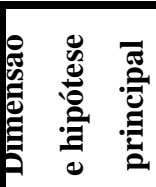 & Detalhamento da questão & Respostas & $\begin{array}{l}\text { Hipótese } \\
\text { testada }\end{array}$ & 离 \\
\hline \multirow[b]{4}{*}{ שّٓ } & 1) Nome do respondente & & & \multirow{4}{*}{ 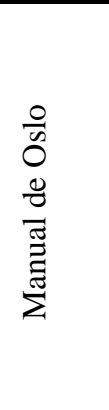 } \\
\hline & 2) e-mail para contato & & & \\
\hline & 3) Nome da empresa (razão social) & & & \\
\hline & $\begin{array}{l}\text { 4) Descreva, brevemente, a inovação mais importante } \\
\text { implantada nos últimos } 2 \text { anos, pelo seu departamento, e } \\
\text { da qual você tenha participado no desenvolvimento e } \\
\text { implantação. }\end{array}$ & & & \\
\hline \multirow{6}{*}{$\Xi$} & $\begin{array}{l}\text { 5) } \mathrm{O} \text { impacto dessa inovação na produtividade das } \\
\text { operações pelas quais ela foi implantada. }\end{array}$ & $\square$ muito negativo $\square$ negativo $\square$ neutro $\square$ positivo $\square$ muito positivo & H1a & \multirow{6}{*}{ 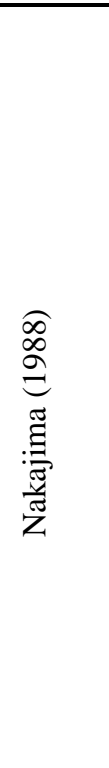 } \\
\hline & $\begin{array}{l}\text { 6) O impacto dessa inovação na qualidade dos produtos } \\
\text { ou serviços oferecidos pela empresa. }\end{array}$ & $\square$ muito negativo $\square$ negativo $\square$ neutro $\square$ positivo $\square$ muito positivo & H1b & \\
\hline & $\begin{array}{l}\text { 7) O impacto dessa inovação nos custos das operações } \\
\text { pelas quais ela foi implantada. }\end{array}$ & $\square$ muito negativo $\square$ negativo $\square$ neutro $\square$ positivo $\square$ muito positivo & H1c & \\
\hline & $\begin{array}{l}\text { 8) O impacto dessa inovação na entrega dos produtos ou } \\
\text { serviços oferecidos pela empresa. }\end{array}$ & $\square$ muito negativo $\square$ negativo $\square$ neutro $\square$ positivo $\square$ muito positivo & H1d & \\
\hline & $\begin{array}{l}\text { 9) O impacto dessa inovação no meio ambiente } \\
\text { (incluindo o consumo de energia, água, geração de } \\
\text { resíduos etc). }\end{array}$ & $\square$ muito negativo $\square$ negativo $\square$ neutro $\square$ positivo $\square$ muito positivo & H1e & \\
\hline & $\begin{array}{l}\text { 10) O impacto dessa inovação na segurança e saúde dos } \\
\text { funcionários. }\end{array}$ & $\square$ muito negativo $\square$ negativo $\square$ neutro $\square$ positivo $\square$ muito positivo & H1f & \\
\hline
\end{tabular}


76

\begin{tabular}{|c|c|c|c|c|}
\hline \multirow{3}{*}{ 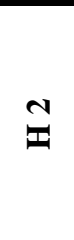 } & 11) O impacto dessa inovação nos lucros da empresa. & $\square$ muito negativo $\square$ negativo $\square$ neutro $\square$ positivo $\square$ muito positivo & $\mathrm{H} 2 \mathrm{a}$ & \multirow{3}{*}{ 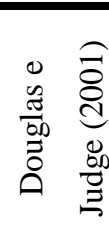 } \\
\hline & $\begin{array}{l}\text { 12) O impacto dessa inovação na participação de } \\
\text { mercado da empresa. }\end{array}$ & $\square$ muito negativo $\square$ negativo $\square$ neutro $\square$ positivo $\square$ muito positivo & $\mathrm{H} 2 \mathrm{~b}$ & \\
\hline & 13) O impacto dessa inovação nas vendas da empresa. & $\square$ muito negativo $\square$ negativo $\square$ neutro $\square$ positivo $\square$ muito positivo & $\mathrm{H} 2 \mathrm{c}$ & \\
\hline \multirow{5}{*}{ 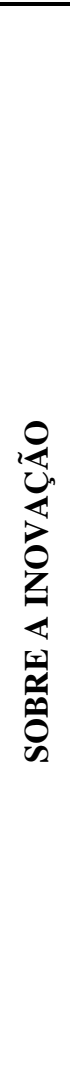 } & 14) Essa inovação ocorreu principalmente: & $\begin{array}{l}\square \text { nos produtos da empresa } \square \text { nos equipamentos, máquinas, } \\
\text { dispositivos de apoio às operações } \square \text { nos software, sistemas, programas } \\
\square \text { nas competências, especialização da mão de obra } \square \text { nos modelo de } \\
\text { negócios, estruturas, gestão, práticas de trabalho } \square \text { nas formas de entrega } \\
\text { ou prestação de serviços } \square \text { nas formas de apresentação, marketing dos } \\
\text { produtos ou serviços } \square \text { outros }\end{array}$ & & \multirow{5}{*}{ 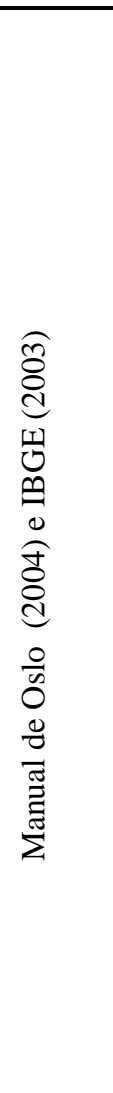 } \\
\hline & 15) Onde se localiza a inovação: & $\begin{array}{l}\square \text { principalmente na empresa } \square \text { principalmente outra empresa do grupo } \\
\square \text { principalmente a empresa em cooperação com outras empresas ou } \\
\text { institutos } \square \text { principalmente outras empresas ou institutos }\end{array}$ & & \\
\hline & 16) Aponte qual a intensidade da inovação: & $\begin{array}{l}\square \text { nova para o departamento, mas já existe na empresa } \square \text { nova para a } \\
\text { empresa, mas já existe no mercado nacional } \square \text { nova para o mercado } \\
\text { nacional, mas já existe no mercado mundial } \square \text { nova para o mercado } \\
\text { mundial }\end{array}$ & & \\
\hline & 17) Qual foi o custo para implantação da inovação $(\mathrm{R} \$)$ ? & $\begin{array}{l}\square \text { até } 50 \text { mil } \square 51 \text { a } 200 \text { mil } \square 201 \text { a } 500 \text { mil } \square 501 \text { a } 1 \text { milhão } \square \\
\text { mais de } 1 \text { milhão }\end{array}$ & & \\
\hline & 18) Qual a principal motivação para a inovação? & $\begin{array}{l}\square \text { resolução de problemas } \square \text { expansão de mercado } \square \text { concorrência } \square \\
\text { outra_ }\end{array}$ & & \\
\hline
\end{tabular}




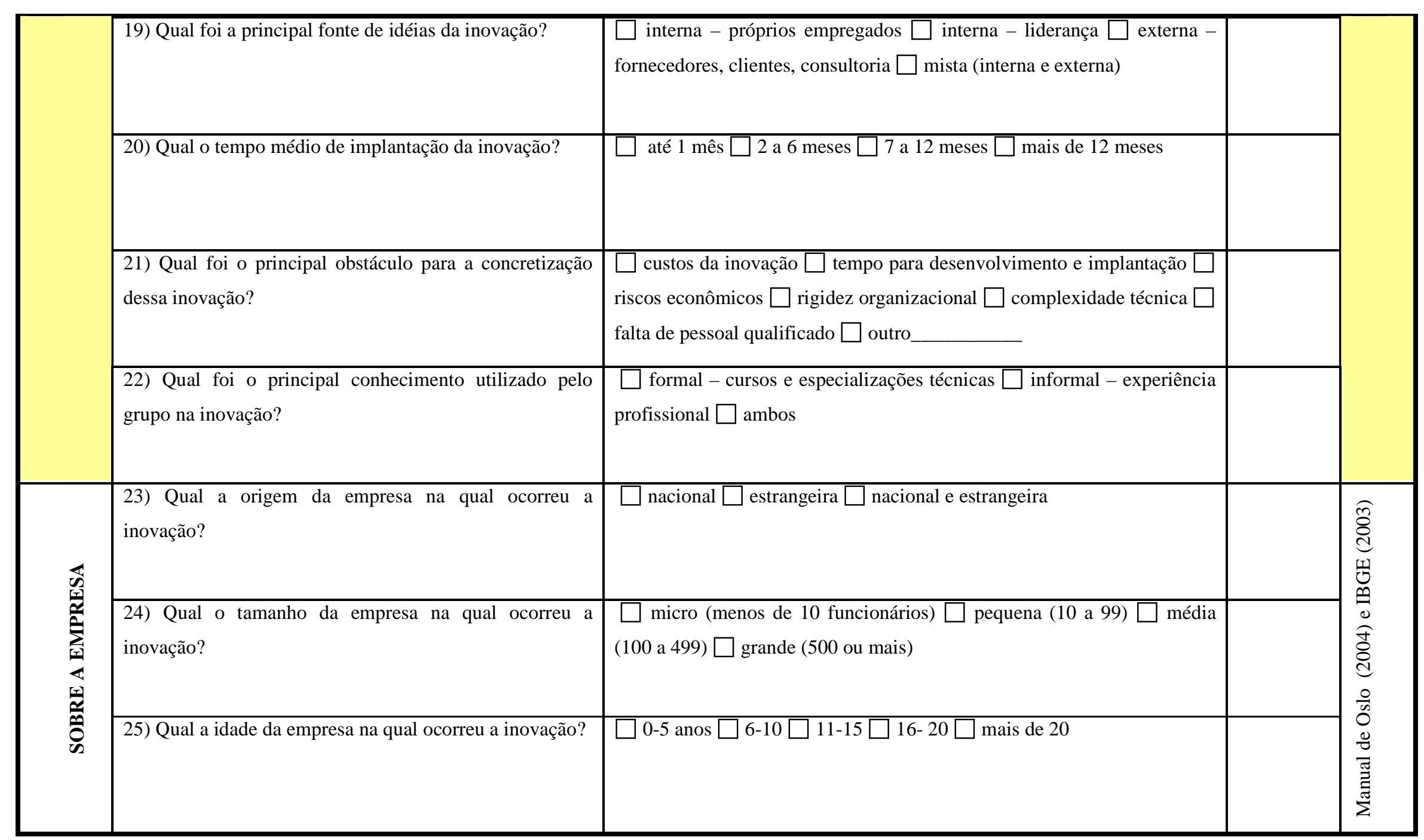




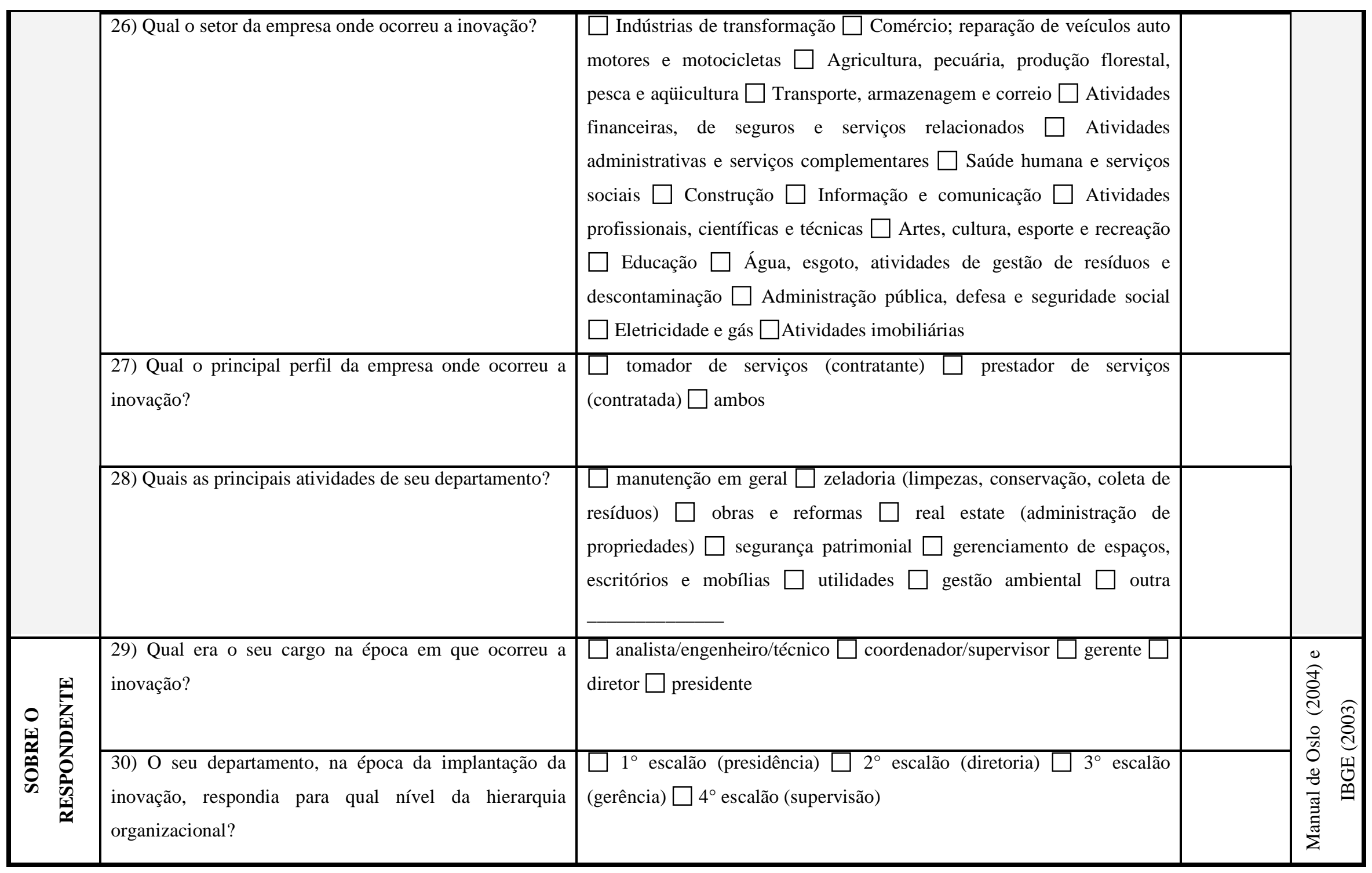




\begin{tabular}{|l|l|l|l|}
\hline $\begin{array}{l}\text { 31) Qual era sua experiência profissional (em anos) na } \\
\text { época em que ocorreu a inovação? }\end{array}$ & $\square$ 0-5 anos $\square$ 6-10 $\square$ 11-15 $\square$ 16-20 $\square$ mais de 20 \\
& $\begin{array}{l}\text { 32) Qual era o seu grau de formação acadêmica na época } \\
\text { em que ocorreu a inovação? }\end{array}$ & $\begin{array}{l}\square \text { técnico } \square \text { graduação } \square \text { pós-graduação (especialização) } \square \text { mestrado } \\
\square \text { doutorado }\end{array}$ & \\
\hline
\end{tabular}


Mencionou-se anteriormente que, o Manual de Oslo (2005) recomenda duas maneiras de coligir dados sobre inovações: coletas baseadas no sujeito e no objeto. A primeira preocupada em verificar inovações em empresas que inovam ou não. A segunda em obter informações sobre inovações específicas ou peculiares. Optou-se pelas duas abordagens, mas com foco no objeto.

O APÊNDICE A é o desenho do questionário a ser aplicado no público-alvo já mencionado. Está estratificado em blocos similares ao modelo estrutural da tese e tem como objetivo apontar, na fase descritiva da pesquisa, o perfil das empresas e dos respondentes, as principais características das inovações apresentadas e, na fase indutiva, testar as relações com e entre as dimensões de eficiência e desempenho financeiro.

\subsection{Estratégias para análise dos dados}

O estudo recorreu ao auxílio das seguintes técnicas estatísticas: análise descritiva (uni e bivariada), de variância, fatorial e de correlação múltipla. Os dados que foram coletados por meio dos questionários são do tipo não métricos e qualitativos e as escalas do tipo nominal (para as questões classificatórias) e ordinal (para as questões assertivas). Em função das limitações dos tipos de dados, das escalas e da quantidade esperada de respostas (menos de 5\% do total), diversos autores (SIEGEL, 1975; LEVIN, 1987; COOPER e SCHINDLER, 2003) recomendam as provas estatísticas não paramétricas.

\subsubsection{Técnicas estatísticas usadas na pesquisa}

- Análise descritiva e de variância

A análise descritiva caracterizou o perfil da amostra, por meio da verificação da média, moda, desvio-padrão, coeficiente de variação, máximo e mínimo de cada item pesquisado. Usada também para descrever os fenômenos associados a uma população ou parte dela com certas características (COOPER e SCHINDLER, 2003). O primeiro passo é verificar se a quantidade de dados permitirá a utilização ou não de estatística paramétrica. Essa etapa ocorre na averiguação das questões classificatórias do instrumento de coleta de dados. Com isso, foi possível não só caracterizar a amostra como um todo, como também as subamostras (no caso de se encontrar diferenças estatísticas significativas entre as mesmas). As diferenças estatísticas entre amostras são obtidas com testes de significância (qui-quadrado). Levin 
(1987) aponta que a variação total de um conjunto de escores busca a variação dentro e entre os grupos (utilizando as distâncias das médias, no caso de paramétricos, e modas, para os não paramétricos).

Ainda nessa etapa pode-se encontrar subamostras que poderão ser agrupadas por análise de conglomerados ou clusters. A análise de cluster é um procedimento exploratório multivariado (pertencente à família da análise multivariada) que serve para detectar grupos homogêneos nos dados, podendo ser constituídos de variáveis ou casos (PESTANA e GAGEIRO, 2005).

- Análise de correlação múltipla e fatorial

Compreende o estudo causal da tese que checará a associação entre as variáveis do modelo proposto. Tem a finalidade exploratória de verificação de fortes e fracas associações dentro do painel de dimensões do modelo de pesquisa. O conceito de causalidade é baseado na lógica do teste de hipóteses que, por sua vez, produz conclusões indutivas, contudo são probabilidades e não podem ser demonstradas com certeza (COOPER e SCHINDLER, ibid). A análise de correlação múltipla acontecerá na interceptação dos dados obtidos das questões assertivas do instrumento de coleta de dados. Como regra geral, de acordo com Cooper e Schindler (ibid), necessita-se de no mínimo cinco vezes mais observações do que o número de variáveis, portanto, espera-se que para as 9 categorias analisadas, que compõem as dimensões eficiência operacional e desempenho financeiro, tenha-se uma amostra mínima de 45 observações. Essa pesquisa obteve dados não métricos (qualitativos) em função da natureza das escalas utilizadas, ou seja, o tratamento estatístico foi não paramétrico. Para a obtenção das relações causais em amostras independentes e com nível de mensuração no mínimo ordinal, Levin (1987) recomendada a prova de Kruskal-Wallis. A análise fatorial é, para Corrar et al (2007), uma das técnicas multivariadas de interdependência em que todas as variáveis são simultaneamente consideradas, a fim de estudar as inter-relações e sumarização das mesmas. Utilizou-se essa técnica para análise dos impactos (eficiência e financeiro) e suas relações.

\subsection{Confiabilidade dos dados coletados}

Realizar-se-á uma avaliação da consistência interna dos construtos utilizados para a medição das correlações, por meio do coeficiente Alpha de Cronbach (mais apropriado para escalas multiitens), buscando valores superiores a 0,60 (ideais para pesquisas exploratórias, de acordo 
com HAIR et al, 2005). Essa etapa mede o grau em que os itens do instrumento (questionário) são homogêneos e refletem o mesmo constructo implícito.

\subsection{Síntese dos aspectos metodológicos}

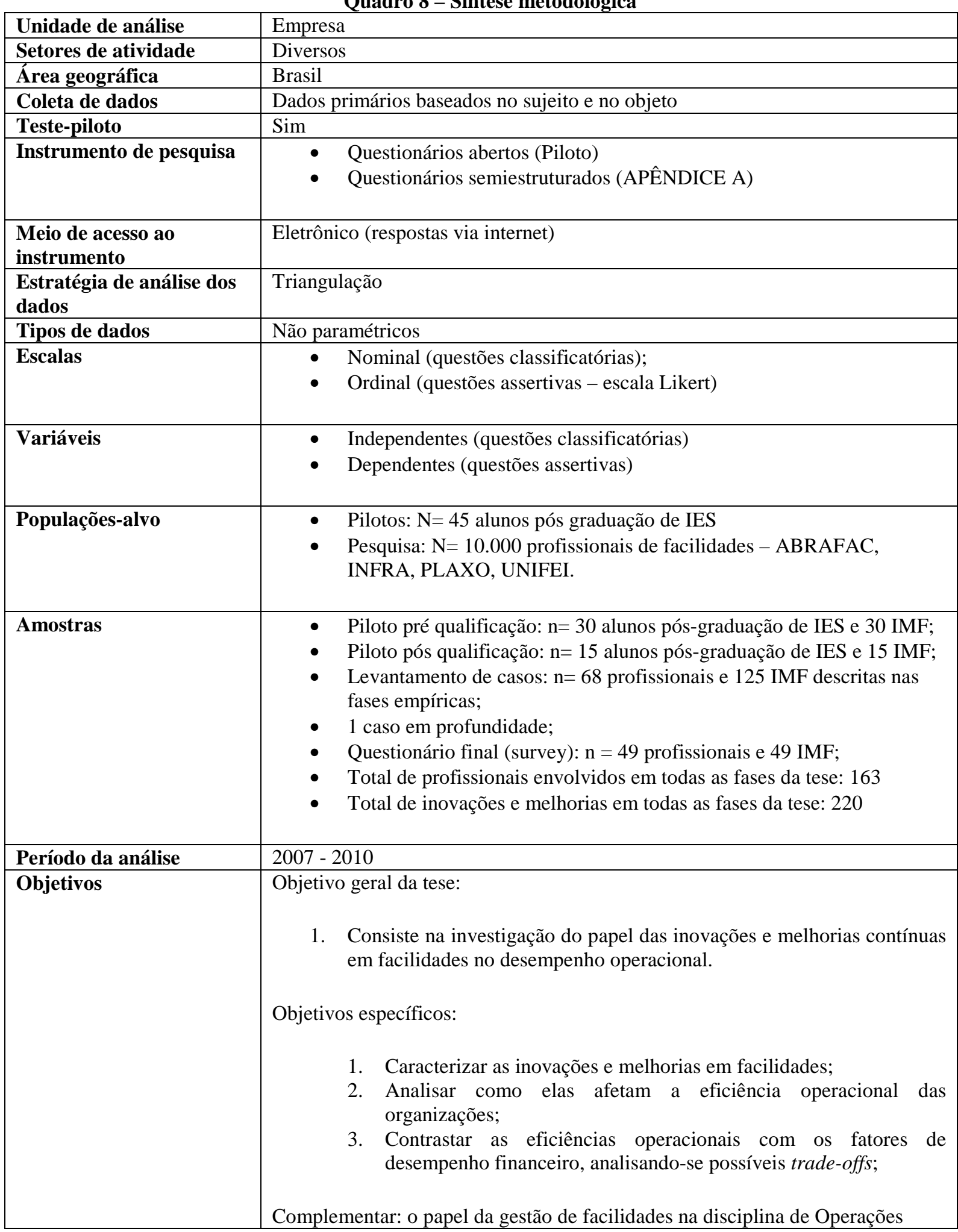




\begin{tabular}{|c|c|}
\hline $\begin{array}{l}\text { Questões centrais de } \\
\text { investigação }\end{array}$ & $\begin{array}{l}\text { 1. } \begin{array}{l}\text { O que são as inovações e melhorias em facilidades e como elas } \\
\text { impactam a eficiência operacional e no desempenho financeiro das } \\
\text { organizações? }\end{array} \\
\text { Questão suplementar: } \\
\text { 2. As inovações e melhorias em facilidades formam subcategorias ou são } \\
\text { homogêneas? Se heterogêneas impactariam diferentemente nos } \\
\text { desempenhos? }\end{array}$ \\
\hline Hipóteses de investigação & $\begin{array}{l}\text { H1: as inovações/melhorias em facilidades impactam significativamente a } \\
\text { eficiência operacional } \\
\text { H2: as inovações/melhorias em facilidades não impactam significativamente o } \\
\text { desempenho financeiro }\end{array}$ \\
\hline $\begin{array}{l}\text { Análise de dados (provas } \\
\text { estatísticas) }\end{array}$ & $\begin{array}{l}\text { - Análise exploratória de dados (questões de investigação) - Qui- } \\
\text { quadrado (para testar a independência de duas ou mais variáveis não } \\
\text { paramétricas no nível nominal) e análise fatorial para investigação de } \\
\text { subcategorias. } \\
\text { Inferências estatísticas (hipóteses de investigação) - Kruskal-Wallis } \\
\text { (correlação não paramétrica para duas ou mais variáveis no nível } \\
\text { ordinal), medidas de tendência central (moda) para averiguar a força } \\
\text { das relações e análise fatorial para investigar formação de } \\
\text { conglomerados . } \\
\text { - Levantamento de casos - análise de conteúdo dos breves relatos dos } \\
\text { questionários pré-survey. } \\
\text { Estudo de caso único em profundidade. }\end{array}$ \\
\hline Confiabilidade interna & Alpha de Cronbach \\
\hline Softwares utilizados & Minitab e SPSS \\
\hline Resultados esperados & $\begin{array}{l}\text { O que são as inovações e melhorias em facilidades no Brasil e como elas } \\
\text { impactam a eficiência operacional e o desempenho financeiro das organizações. }\end{array}$ \\
\hline
\end{tabular}




\section{O IMPACTO DAS INOVAÇÕES E MELHORIAS NAS FACILIDADES}

A análise dos dados obedecerá a divisão estabelecida na triangulação metodológica onde foram definidos três delineamentos:

- Levantamento de casos, com a participação de 113 profissionais e 170 inovações e melhorias;

- Estudo de caso único, com um profissional entrevistado em profundidade;

- Survey, com 49 profissionais e 49 inovações/melhorias em facilidades. .

Juntos, os três delineamentos contaram com 163 profissionais e 220 inovações e melhorias investigadas entre os anos de 2007 e 2010.

\subsection{Levantamento de casos de inovações e melhorias}

Essa fase ocorreu entre os anos 2007 e 2009, contanto com 113 profissionais e 170 inovações e melhorias descritas em quatro etapas. Essa seção foi subdividida de acordo com a cronologia dessas pesquisas de campo.

\subsubsection{Primeira etapa: as primeiras evidências das inovações e melhorias em facilidades}

O levantamento de casos foi iniciado no segundo semestre de 2007 com a seguinte pergunta: dada a ampla gama de inovações relatadas pela literatura científica, elas existiriam na área de facilidades? Essa primeira indagação justificou uma pesquisa de campo no departamento de facilidades da Ford Motor Company Brasil, localizada no Grande ABC (QUINELLO e NASCIMENTO, 2008). Solicitou-se, via e-mail, que 10 profissionais seniores (engenheiros e analistas) relatassem livremente possíveis inovações dentro dos seus campos de atuação. Nesse momento, numa fase totalmente exploratória, não houve preocupação com definições ou taxonomias a respeito das inovações. Esperavam-se apenas relatos, sem estruturas préestabelecidas que favorecessem os depoimentos (APÊNDICE B).

Nas entrevistas informais com os respondentes, notou-se que não há preocupação ou entendimento de como, onde ou porque ocorre a inovação, ou seja, não há uma gestão formal para a inovação, corroborando com os achados de Cardellino e Finch (2004). Muitos nomeiam inovação como melhoria, ideia, ajuste, correção, "gambiarra", adaptação, entre outros, demonstrando que a realidade empírica está distante da teórica, pelo menos na 
epistemologia e semântica. De qualquer maneira, os relatos informais puderam dar pistas de onde, como, para que e porque ocorreram essas inovações.

Elas eram, geralmente, atreladas aos objetivos típicos de uma área de engenharia, ou seja, surgiram para resolver problemas dos clientes internos (processos) ou externos (órgãos governamentais ou comunidade). No entanto, como destacado por Iansiti (1995), as soluções apareciam antes, durante ou após a execução de uma tarefa, reunião formal ou informal, isto é, entre as rotinas de especificações preliminares e as rotinas de execução. Não foi encontrado um processo formalizado e sistemático, mas tácito e aparentemente desordenado.

Das 14 inovações e melhorias listadas, 5 eram originadas na manutenção, 10 geradas por forças internas e $2 / 3$ produzidas em parceira com fornecedores, demonstrando a participação pluralista na geração de inovações, ratificando as descobertas de Goyal e Pitt (2007) em relação a importância da extensão da rede de contato para as inovações. Sendo a origem dessas inovações as áreas de manutenção, suspeita-se que a aproximação com equipamentos, dispositivos e sistemas de apoio ao processo produtivo facilita e encoraja tais tipos de inovações. Notou-se que as inovações e melhorias nesse ambiente possuíam, em parte, algumas características peculiares das regularmente citadas nas literaturas:

- A origem das inovações e melhorias não tinha um ponto determinado no tempo e no espaço, ora nascendo da necessidade do cliente, no decorrer das atividades ou para correções de desvios encontrados após a entrega dos serviços. Algumas delas, segundo entrevistados, vieram de inspirações coletivas após reuniões de grupos autônomos. Eram, na maior parte do tempo, do tipo supply-side, utilizando a expressão de Mansharamani (2005), sendo inovações que facilitam a entrega final dos serviços e focadas, sobretudo, na busca de eficiência operacional;

- O foco do problema, frequentemente, estava atrelado não só às questões internas como às externas à organização. Por exemplo, meio-ambiente, saúde e segurança da comunidade e novas políticas, corroborando com as observações de Flikkema et al (2007) para os quais as inovações ultrapassam os limites internos das organizações;

- Eram resultados de relações intensas de parceiras entre os funcionários próprios, terceiros ou ambos; 
- Não tinham ligação com o mercado, pelo menos para os tomadores de serviços, pois não eram "pensadas" com intuito comercial ou econômico, como se espera de uma inovação típica, e sim para o aumento da eficiência operacional;

- Apesar de utilizarem conhecimentos adquiridos ao longo dos anos sobre os processos e equipamentos, os funcionários envolvidos possuíam formação formal e especializada. Esse conhecimento tácito permitiria ajustes e correções quando da introdução de novos equipamentos em sistema já existente;

- De acordo com os relatos, percebeu-se que a intensidade das inovações é maior nas extremidades do ciclo de vida dos equipamentos (curva $U$ da Figura 12), máquinas e dispositivos: na etapa de implantação ou start-up, onde ajustes são necessários, e na etapa de obsolescência ou envelhecimento, para a sobrevida dos mesmos. Nessas fases, a complexidade e a amplitude da mudança são maiores dos que as encontradas durante a vida útil dos ativos (nesse caso ocorreram mais as chamadas melhorias contínuas).

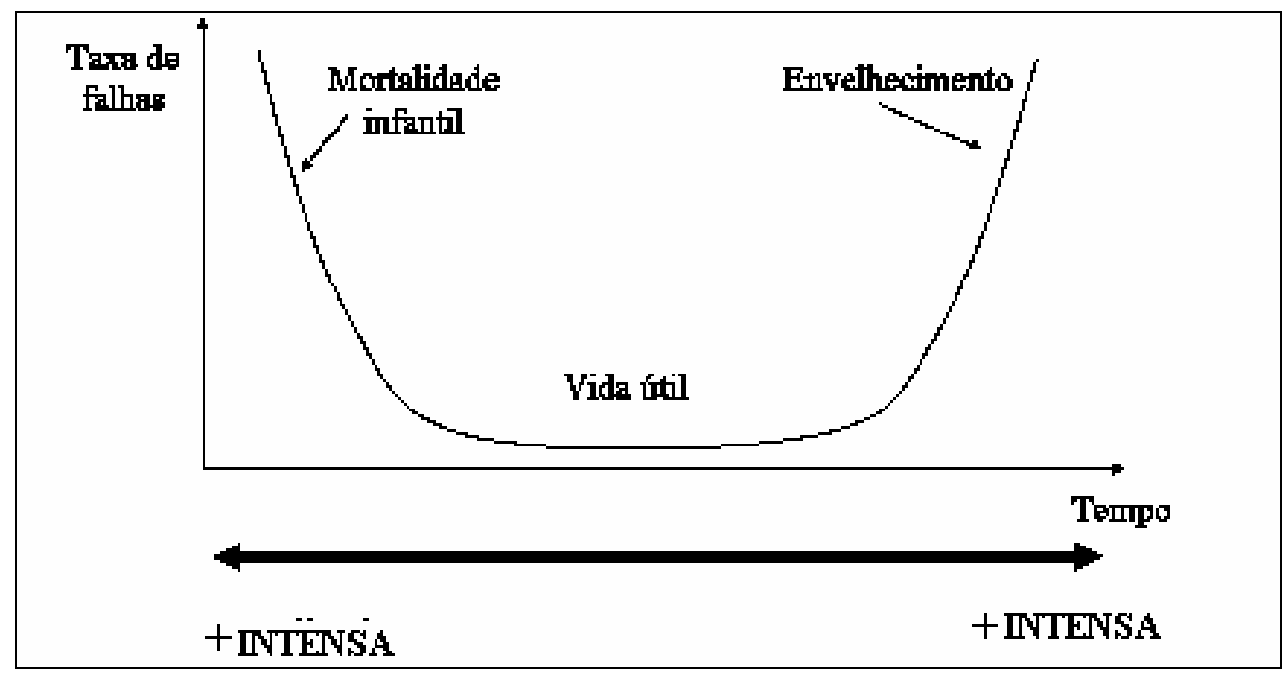

Figura 12 - Intensidade das inovações e melhorias em facilidades

Fonte: Quinello e Nascimento (2009)

Dois exemplos de inovações em facilidades, extraídos dessa etapa de pesquisa, ilustram as intensidades, as complexidades e o espaço-tempo discutidos nos parágrafos anteriores: a da instalação de amortecedores das prensas e a dos queimadores de gases voláteis chamados de RTO - regenerative thermal oxidizer (APÊNDICE I). As duas inovações estão localizadas em equipamentos de apoio ao processo produtivo: a primeira na área de estamparia e a segunda na área de pintura, configurando as chamadas inovações em facilidades. 
A instalação de amortecedores ocorreu no ano de 2008 em função de reclamações da comunidade local, devido a ruídos e vibrações emitidas pelas prensas (dispostas próximas a um conjunto residencial). Como a estamparia possuía mais de dez prensas instaladas há mais de vinte anos num prédio fabril bem localizado, não era economicamente viável transferi-la para outro local. Sendo assim, foi contratada uma empresa especializada em ruídos para desenvolver nichos especiais (amortecedores) que seriam postos embaixo dos pés de apoio das prensas, minimizando os efeitos sonoros emitidos durante as prensagens. A segunda inovação, ocorrida em 2009, a instalação de queimadores de gases voláteis, era um novo equipamento com nova tecnologia desenvolvida por empresas parceiras para atendimento de normas ambientais da CETESB - Companhia Ambiental do Estado de São Paulo. A área da pintura, durante seu processo, gera resíduos voláteis para a atmosfera e estes são responsáveis pela redução da camada de ozônio. Esse queimador tem a função de eliminar os particulados pesados presentes nos gases emitidos pelas chaminés.

As duas inovações, de alta complexidade, foram desenvolvidas por empresas parceiras de engenharia e instaladas pelas equipes internas da Ford, num processo de alta interatividade. Embora existissem equipamentos similares no mercado, as configurações atuais dos processos produtivos eram únicas, fazendo desses artefatos peças únicas. A singularidade das inovações em facilidades acaba por dar-lhes formatos de baixa transferibilidade, uma vez que para outro processo produtivo ou sistema, podem não se adaptar. Há também ausência de transferência de direito de propriedade, afinal os artefatos tecnológicos finais foram frutos de amplas parcerias (sejam nos anteprojetos, nos componentes, nas instalações ou nos testes finais), impossibilitando o estabelecimento de um único proprietário. Outra peculiaridade é o envolvimento total dos clientes nas inovações desde a concepção, passando pela implantação e pelo uso.

Outro achado na pesquisa foi o posicionamento das inovações em facilidades, conforme Figura 13, que remete à uma abstração da proximidade da área de facilidades (GF) com processos (Ps), serviços (S) e produtos (Po). A relação estabelecida com as áreas operacionais, principalmente processos produtivos, gera novos serviços que, por sua vez, geram novas soluções de infraestrutura. Por exemplo: quando uma nova lei de emissão atmosférica pressiona a instalação de um equipamento como o RTO (inovação puxada), facilidades não só inovarão no apoio ao processo produtivo, como gerarão novos serviços técnicos de análises físico-químicas dos gases emitidos, além de manutenção especializada no 
equipamento (inovação empurrada). Esse ciclo contínuo faz da área uma ponte entre processos e serviços no suporte às inovações em produtos (visto que os veículos produzidos atenderão às normas ambientais). Uma observação adicional é que para o parceiro (fornecedor da solução) a inovação em facilidades pode ser considerada uma inovação em produto, pois para a empresa prestadora essa é sua atividade fim. De qualquer maneira o objetivo da solução continua sendo o mesmo: apoio e suporte das infraestruturas aos processos produtivos.

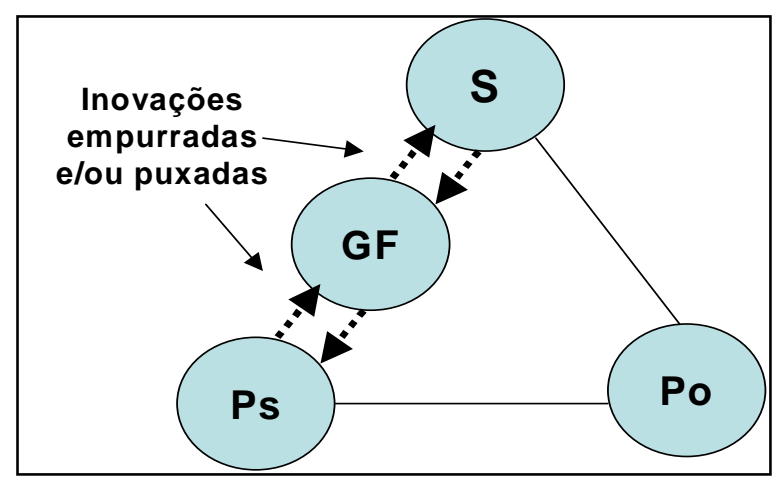

Figura 13 - Relações das inovações em facilidades

Os resultados dessa etapa de pesquisa, ainda exploratória, indicaram coerências com outros trabalhos, entre eles Mansharamani (2005) e Gallouj (2007), quando os autores advertem sobre as dificuldades relacionadas às especificidades destas inovações (interatividade, heterogeneidade e intangibilidade). Os graus destas especificidades não foram avaliados, indicando a necessidade de novas pesquisas para mensuração destas variáveis.

SINOPSE 1a: inovações e melhorias em facilidades, nesta etapa de pesquisa de campo, mostraram ser o elo intermediário no melhoramento de partes ou do todo de um produto, processo ou serviço (tangível ou não), nas infraestruturas de apoio às operações, resultante da ação adaptativa, simultânea e interativa entre tomador e prestador de serviços, sem necessariamente ter um objetivo econômico ou de mercado. O objetivo principal é o de resolver problemas nas operações.

SINOPSE 1b: a implantação das inovações e melhorias em facilidades, no geral, não possui uma gestão formalizada, nascendo da necessidade dos clientes internos, no decorrer das 
próprias atividades de facilidades ou para correções de desvios encontrados após a entrega dos serviços.

SINOPSE 1c: em facilidades, as mudanças são mais intensas e complexas nas extremidades da curva $\mathrm{U}$, indicando que as fases de comissionamento e descomissionamento das infraestruturas são mais propícias para o surgimento de inovações. Por outro lado, na fase intermediária da curva, ocorreriam as chamadas melhorias contínuas, menos intensas na complexidade e impactos gerados nas operações.

\subsubsection{Segunda etapa: os indícios da relação entre inovações e melhorias em facilidades nos desempenhos organizacionais.}

Uma vez demonstrada a existência de subtipos das inovações tradicionais - denominadas inovações e e melhorias em facilidades, iniciaram-se novas indagações sobre a caracterização preliminar delas e seus possíveis impactos nos fatores de desempenho. Os resultados dessa etapa, obtidos por meio da análise de 87 inovações e melhorias relatadas por 34 profissionais (APÊNDICE D) da área de manutenção de várias empresas localizadas no Estado de São Paulo, no primeiro semestre de 2008, forneceram subsídios para a formulação de parte das questões de pesquisa desta tese (QUINELLO e NICOLETTI, 2009). Utilizou-se um questionário semiestruturado como instrumento de coleta de dados (APÊNDICE C), constituído de questões classificatórias e assertivas.

Em relação aos dados classificatórios, a amostra foi composta majoritariamente por empresas nacionais $(47,1 \%)$, de grande porte $(58,8 \%)$ e do setor industrial $(55,9 \%)$. Os respondentes eram formados basicamente por engenheiros e analistas (50\%). Seguindo a classificação do ISIC (Classificação Industrial Internacional Padronizada), estratificaram-se mais detalhadamente os setores e constatou-se que as empresas pertenciam às atividades ligadas a químicos $(14,7 \%)$, a borrachas e plásticos (12\%), a alimentício/bebidas $(8,8 \%)$ e ao comércio em geral $(14,8 \%)$, mostrando a diversidade da amostra.

Quando inquiridos sobre o que seriam as inovações nas suas áreas, assim como na primeira etapa da fase empírica, os respondentes informaram que as palavras mais próximas seriam "adaptações", "mudanças de rotinas", "melhorias", "fazer diferente", "ajustes e correções operacionais" entre outras. Essas afirmações, dado o contexto industrial e fabril da amostra, 
aproximam-se daquilo que Leonard-Barton (1992) chamariam de "fábricas como laboratório de aprendizagem". Oriundas de pressões internas e para resolução de problemas, essas inovações seriam meios (e não apenas fins) para as áreas operacionais buscarem respostas aos gargalos técnicos impostos pelas operações. Para a autora, esses seriam ambientes orgânicos complexos que estimulariam, ainda que por vezes isolados, as inovações contínuas por meio de experimentações e de conhecimentos mútuos (parcerias internas e externas).

Sobre as inovações e melhorias indicadas, pôde-se verificar que as mesmas eram de naturezas distintas. Uma pequena parte foi formada por inovações em processos para apoio à produção e a maioria vinculada à categoria intitulada pelo Manual de Oslo (2005) de não inovações. Seriam pequenas mudanças técnicas ou organizacionais que estariam mais próximas às chamadas melhorias contínuas ou às inovações não tecnológicas. Em relação aos dados assertivos, conclui-se que:

- A pressão para inovar partia dos clientes internos, geralmente as áreas de produção (61\%), demonstrando a forte participação dos respondentes em melhorias relacionadas aos processos operacionais. Essas inovações ou melhorias são feitas e pensadas "para dentro" das empresas, os clientes externos não as veem;

- Os agentes que participam destas mudanças são majoritariamente o próprio pessoal interno da organização (53\%), com raras participações estritamente externas (fornecedores ou terceiros). Por outro lado a coparceria é intensa (41\%) entre grupos internos e externos até pela proximidade entre os engenheiros e as empresas contratas para serviços especializados (vale lembrar que as áreas de manutenção foram intensivamente expostas aos processos de terceirização e reengenharia nos últimos anos);

- As principais barreiras para as inovações e melhorias foram: resistência a mudanças (20\%), baixa qualificação profissional dos funcionários internos (16\%) e curto prazo exigido pelas áreas solicitantes (11\%). Tem-se, no ambiente interno destas organizações, o reflexo da realidade nacional: baixa qualificação profissional nas áreas operacionais, somada a falta de reciclagem dos mesmos (PINTEC, 2005) resultando nas barreiras citadas;

- Quanto aos tipos de inovações encontradas verificaram-se dois grandes blocos: as inovações e as não inovações, de acordo com as tipologias do Manual de Oslo: i) 
inovações em processos de produção com mínima novidade (21\%) e ii) não inovações em processos de produção (20\%), não inovações em processos de entrega (12\%) e não inovações organizacionais $(30 \%)$ com mínima novidade. Estas não inovações somam $62 \%$ do total encontrado e são, frequentemente, de ordem organizacional e sem nenhuma modificação significativa, mas que geram mudanças no ambiente da área, fundamentais para impulsionar outras inovações. Exemplos delas são: introdução de softwares e novos modelos de gestão, essenciais, segundo os respondentes, para as transformações organizacionais atuais das suas empresas;

- Vencidas as barreiras supracitadas, os respondentes afirmaram que diversos ganhos foram alcançados. Pelos fatores de desempenho apontados por Slack (1994), foi possível notar que $25 \%$ estão relacionados à redução de custos, $20 \%$ à flexibilidade operacional, $30 \%$ à melhoria da qualidade dos produtos ou serviços e $20 \%$ outras contribuições não cobertas pelo modelo de Slack - foram aqui chamadas de fatores de desempenho interno, pois não afetam diretamente os fatores de Slack, mas contribuem indiretamente para seu atendimento (no entanto, dado o instrumento de coleta dessa etapa, não foi possível quantificar a intensidade desta relação). Entre esses fatores estão: eficiência operacional, redução de impacto ambiental, aceleração na tomada de decisão, aumento do conhecimento e competências técnicas, aumento da autoestima do time, melhoria na segurança operacional, disponibilidade de máquinas, aceleração do fluxo de informações, melhoria na imagem, fortalecimento da integração dos times, aumento de confiabilidade, manutenabilidade e alteração de aspectos ergonômicos. Todos estes ganhos adicionais não são influenciadores diretos dos produtos ou serviços finais das empresas pesquisadas, contudo são intermediários dos ganhos de desempenho finais;

- Quanto à descrição das inovações e melhorias, dividiram-se basicamente em aquisição de softwares para gestão, novos dispositivos para o processo produtivo, formação de novas competências, criação de novas estruturas organizacionais e formulação de novas estratégias.

Como os dados extraídos do questionário (semiestruturado) não estavam pareados e não geraram uma amostra com distribuição normal, não foi possível uma análise multivariada ou fatorial para detectar-se a correlação entre as variáveis classificatórias e as assertivas. Optouse, portanto, por um diagrama de interrelacionamento entre as variáveis: tipo de inovação, 
barreiras e ganhos, de acordo com os setores (ISIC) de cada caso. Notou-se o intenso relacionamento entre as inovações em processos de apoio à produção com redução de custos. Nas não inovações (melhorias) em processos de apoio à produção há forte relação com redução de custos e fatores internos de desempenho; já a não inovação em processos de entrega encontrou significativa relação com redução de custos, melhoria na flexibilidade e qualidade. Por fim, nas não inovações organizacionais, há intensa relação com redução de custos, melhorias na flexibilidade e qualidade, porém intermediados pelos fatores de desempenho interno.

Após a busca pelas relações estabelecidas entre as variáveis - tipos e ganhos, modelou-se um quadro síntese dos resultados finais, demonstrado na Figura 14. Nele observam-se as pressões internas forçando os agentes na busca de soluções para problemas operacionais. Esses agentes, formados por funcionários internos e empresas parceiras, deparam-se com barreiras frequentemente culturais e de competências. Superados esses principais obstáculos, obtêm-se dois tipos macros de inovações: as inovações para apoio aos processos de produção, com impactos principalmente em custos, e as melhorias contínuas (bloco hachurado) com impactos em custos, qualidade e flexibilidade, porém em alguns casos (não inovações em processos de produção e não inovações organizacionais) ocorreram a intermediação dos fatores de desempenho interno. 


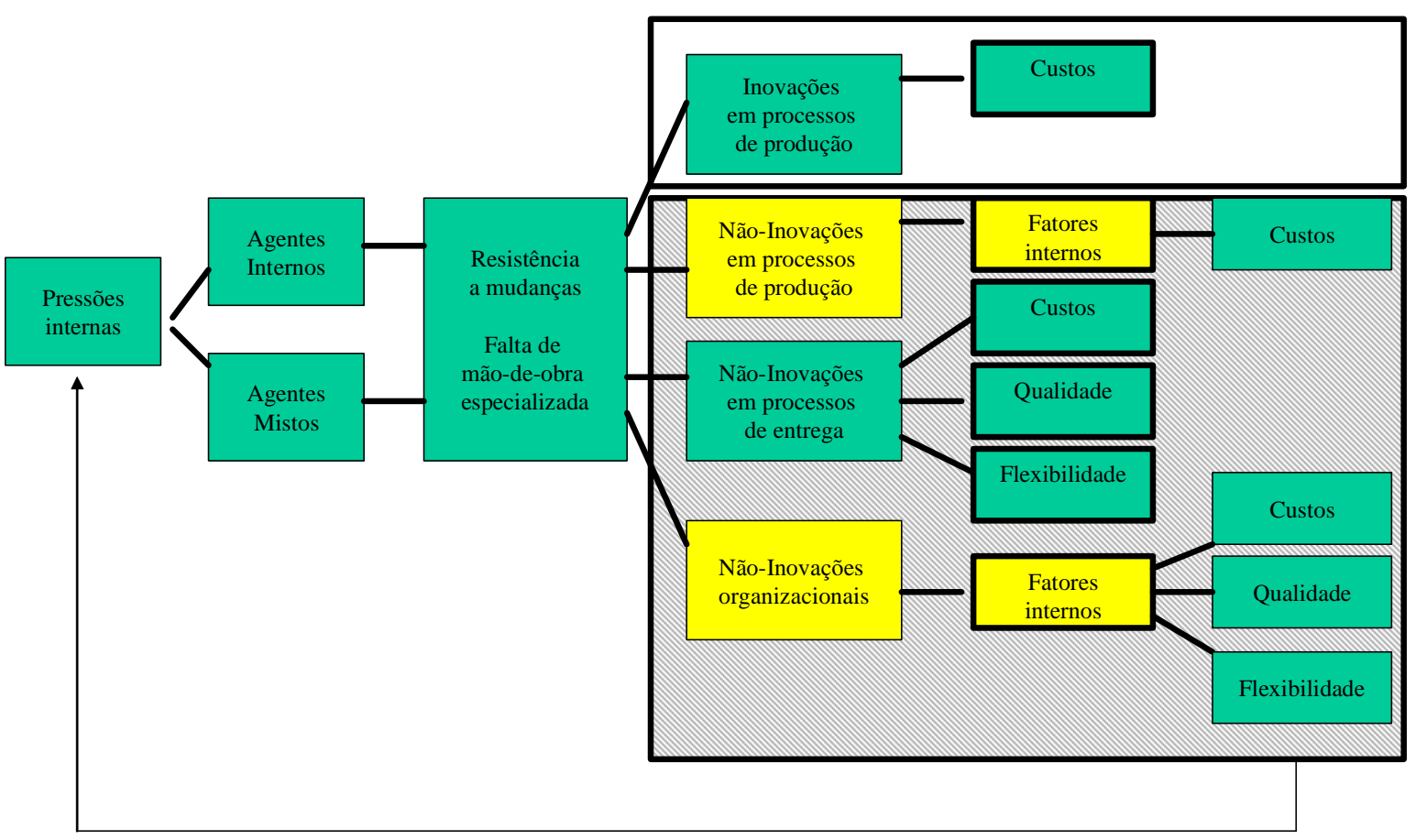

Figura 14 - Modelo preliminar das inovações e melhorias e seus impactos operacionais Fonte: Quinello e Nascimento (2009); Quinello e Nicoletti (2009)

Os fatores de desempenho internos podem ser demonstrados por indicadores operacionais das organizações como o OEE - overall equipment efficiency, o MTTR - mean time to repair e o MTBF - mean time between failure. Esses indicadores, os mais citados na pesquisa, surgiram principalmente após o advento dos movimentos da qualidade (por exemplo, TQM - Total Quality Management e o TPM - Total Productive Maintenance) e seriam essenciais para o movimento de expansão das capacidades internas e essas para os resultados externos das organizações.

SINOPSE 2: as mudanças técnicas e organizacionais ocorridas nas infraestruturas periféricas de apoio podem surgir sob a forma de inovações ou de melhorias. Elas são colaboradoras dos fatores de desempenho gerais (como os definidos por Slack) e específicos (aqui chamados de fatores de desempenho interno). 


\subsubsection{Terceira etapa: as inovações e melhorias em facilidades e seus impactos nos desempenhos}

Nessa etapa, em outra pesquisa de campo efetuada com um grupo de estudantes do curso de pós-graduação de gestão de manutenção no segundo semestre de 2008, foram levantadas, por meio de questionário estruturado (APÊNDICE E), 24 inovações, buscando as correlações destas com os desempenhos operacionais das empresas, o que resultou no surgimento de fatores mais e outros menos afetados, ou seja, o comportamento observado não era uniforme, ratificando os achados da etapa anterior.

Sobre a amostra analisada: a) origem - 54,2\% eram de empresas nacionais, 41,7\% estrangeiras e $4.2 \%$ mistas; b) porte - $50 \%$ grande, $41,7 \%$ médio e $8,3 \%$ pequeno; c) cargo - $12,5 \%$ eram engenheiros, $50 \%$ supervisores e $12,5 \%$ gerentes; d) setor - 58,3\% pertenciam a indústria, $25 \%$ a serviços e $12,5 \%$ ao comércio e $4,5 \%$ a agricultura e social. Verifica-se que a amostra foi formada por supervisores de empresas, majoritariamente, nacionais de grande porte do setor industrial e muito semelhante com a segunda etapa da fase empírica. As inovações e melhorias apresentaram as seguintes características:

Quadro 9 - Características gerais das inovações e melhorias

\begin{tabular}{|c|c|}
\hline Características analisadas & Principais considerações \\
\hline $\begin{array}{l}\text { Como são conhecidas as } \\
\text { inovações em facilidades e } \\
\text { quais os similares mais } \\
\text { próximos }\end{array}$ & $\begin{array}{l}\text { As inovações apontadas pelos respondentes como as mais importantes dos } \\
\text { últimos dois anos, são também conhecidas como melhorias contínuas, ou seja, } \\
\text { os respondentes reconhecem que mudanças técnicas ocorrem nos seus } \\
\text { ambientes de trabalho em diferentes intensidades. Estas mudanças são em sua } \\
\text { maioria em processos }(62 \%) \text {, seguida pelas organizacionais }(29 \%)\end{array}$ \\
\hline Grau de novidade & $\begin{array}{l}\text { São de baixa novidade ( } 87 \%) \text { para o departamento ou para a empresa e fruto de } \\
\text { aprimoramento de algo existente }(70 \%) \text {, configurando o que é chamado de } \\
\text { melhoria contínua ou inovação por melhorias. }\end{array}$ \\
\hline Escopo & $\begin{array}{l}\text { Elas são "pensadas" para dentro, ou seja, intraorganizacionais. Surgem por } \\
\text { pressões internas das áreas }(83 \%)\end{array}$ \\
\hline Tempo e custo & $\begin{array}{l}\text { São implantadas em curto período, em torno de um ano, e custam } \\
\text { aproximadamente } \mathrm{R} \$ 270.000,00 \text {. }\end{array}$ \\
\hline Agentes env.vidos & $\begin{array}{l}\text { São resultados de intensas relações entre funcionários operacionais e } \\
\text { fornecedores, numa espécie de parceria. }\end{array}$ \\
\hline
\end{tabular}




\begin{tabular}{|l|l|}
\hline Barreiras & $\begin{array}{l}\text { As principais barreiras para as inovações e melhorias são os custos envolvidos, } \\
\text { resistência interna e falta de pessoal especializado. }\end{array}$ \\
\hline Tipo de gestão & Não há modelo formal de gestão da inovação. \\
\hline Tamanho do grupo & As inovações/melhorias reúnem times de até 10 pessoas. \\
\hline Fonte de informação & $\begin{array}{l}\text { As informações são obtidas com os próprios empregados das empresas ou } \\
\text { fornecedores. }\end{array}$ \\
\hline Fatores afetados & $\begin{array}{l}\text { Afetam significativamente os fatores de desempenho intraorganizacionais } \\
\text { (confiabilidade, manutenabilidade, agilidade e eficiências operacionais) e } \\
\text { indiretamente os fatores de desempenho extraorganizacionais (pontualidade e } \\
\text { velocidade). }\end{array}$ \\
\hline
\end{tabular}

Nessa fase evidenciou-se que as mudanças proporcionadas por facilidades podem gerar tanto inovações como melhorias contínuas nas infraestruturas de apoio. Essa conclusão foi obtida quando os respondentes foram arguidos sobre o grau da novidade e complexidade da mudança e mais de $80 \%$ informou que as mudanças ocorridas eram de baixa novidade em algo já existente com investimentos em torno de $\mathrm{R} \$ 270.000,00$. Como destacado na revisão de literatura, a diferenciação entre melhoria contínua e inovação tem sido debatida, contudo sem grandes avanços. Para Terziovski e Sohal (2000) uma melhoria pode ser dividida em duas: contínuas, sendo aquela obtida por esforços contínuos (Kaizen) por meio de pequenos melhoramentos no status quo e sem grandes investimentos. Por outro lado, a melhoria pode ser uma inovação, e essa envolveria saltos de melhoramentos como resultado de altos investimentos em tecnologia e equipamentos. Ainda assim a definição é polêmica, pois grandes investimentos para uma empresa pode ser pequenos para outra.

As principais mudanças encontradas foram obtidas pela introdução de equipamentos (50\%), novos recursos, modelos ou técnicas de gestão (37,5\%) e softwares (12,5\%). Também se observou que uma inovação pode gerar outra, por exemplo, quando um equipamento era inserido num sistema existente, as habilidades e competências dos agentes foram alteradas, exigindo modelos de gestão mais sofisticados como o TPM - total productive maintenance e este, num ciclo contínuo, pressionaria novas melhorias dos grupos de trabalho.

Ainda em relação a análise descritiva, pode-se verificar que os cinco fatores de Slack (1993) mais afetados pelas inovações foram, em ordem de importância: qualidade, flexibilidade, 
pontualidade, custos e eficiência. Porém, na etapa de análise de regressão, as ordens foram alteradas em função das correlações encontradas.

\begin{tabular}{l|l|l|l}
\hline Fatores & Mean & $\begin{array}{l}\text { Std. } \\
\text { Deviation }\end{array}$ & Analysis N \\
\hline INDQUAL & $\mathbf{4 . 1 6 6 7}$ & $\mathbf{1 . 0 9 0 1}$ & $\mathbf{2 4}$ \\
\hline INDFLE & $\mathbf{3 . 7 9 1 7}$ & $\mathbf{1 . 3 8 2 5}$ & $\mathbf{2 4}$ \\
\hline INDPONT & $\mathbf{3 . 7 5 0 0}$ & $\mathbf{1 . 3 5 9 3}$ & $\mathbf{2 4}$ \\
\hline INDCUST & $\mathbf{3 . 7 0 8 3}$ & $\mathbf{1 . 4 2 8 9}$ & $\mathbf{2 4}$ \\
\hline INDEFIC & $\mathbf{3 . 7 0 8 3}$ & $\mathbf{1 . 4 5 9 0}$ & $\mathbf{2 4}$ \\
\hline INDVEL & 3.6667 & 1.4039 & 24 \\
\hline INDCAP & 3.5417 & 1.5030 & 24 \\
\hline INDCONF & 3.4167 & 1.3805 & 24 \\
\hline INDCOMP & 3.4167 & 1.4421 & 24 \\
\hline INDDISP & 3.2917 & 1.6011 & 24 \\
\hline INDAGIL & 3.2500 & 1.5948 & 24 \\
\hline INDMANU & 3.2083 & 1.5030 & 24 \\
\hline INDMEIO & 3.0417 & 1.6545 & 24 \\
\hline INDERGO & 3.0000 & 1.5323 & 24 \\
\hline INDUTIL & 2.7917 & 1.5874 & 24
\end{tabular}

Tabela 2 - Principais dimensões afetadas pelas mudanças

As inovações e melhorias dessa etapa de investigação se correlacionam, otimizando os fatores internos e estes os externos. Após análise das estatísticas descritivas, sumarizadas nos parágrafos anteriores, utilizaram-se as questões assertivas para os testes de correlações e análise de regressão. Inicialmente a confiabilidade interna das respostas foi testada (alpha de Conbrach), sendo satisfatória $(0,86)$. Depois da análise da confiabilidade interna, analisaramse as correlações entre os fatores de desempenho operacionais e as inovações relatadas pelos entrevistados. Sendo a amostra inferior a 30, utilizou-se o teste de correlação não paramétrica - Kruskal Wallis, obtendo-se as principais correlações. Posteriormente, eliminaram-se as variáveis menos significativas (por meio da análise de regressão múltipla, com rotação Varimax). Após duas rodadas, chegou-se a um KMO maior que 0,5 (responsável pelo teste de proporção da variância, causada pelos fatores implícitos, no qual se o valor exceder 0,5, se justifica-se a análise de fatores), com $\mathrm{r}^{2}$ de 0,72 (fator de explicação razoável), resultados que suportam e justificam o modelo reduzido (LEVIN, 1987).

O modelo reduzido, Figura 15, aponta os principais fatores internos afetados pelas inovações e melhorias (com $\mathrm{r}^{2}$ maiores que 0,55), denominados de fatores de desempenho interno. Estes indicadores são potencializadores que juntos, ao menos nessa pesquisa, auxiliam indiretamente os resultados gerais das organizações (esses mais perceptíveis pelos clientes externos). Os aglomerados que se formaram são produtos do contexto, ou seja, pode ser que para outras amostras em outras condições, os fatores se unam em formatos e intensidades 
diferentes. Também se avaliou a correlação inversa e anti-imagem para descartar erros na relação causal entre as variáveis e eliminar as menos significativas.

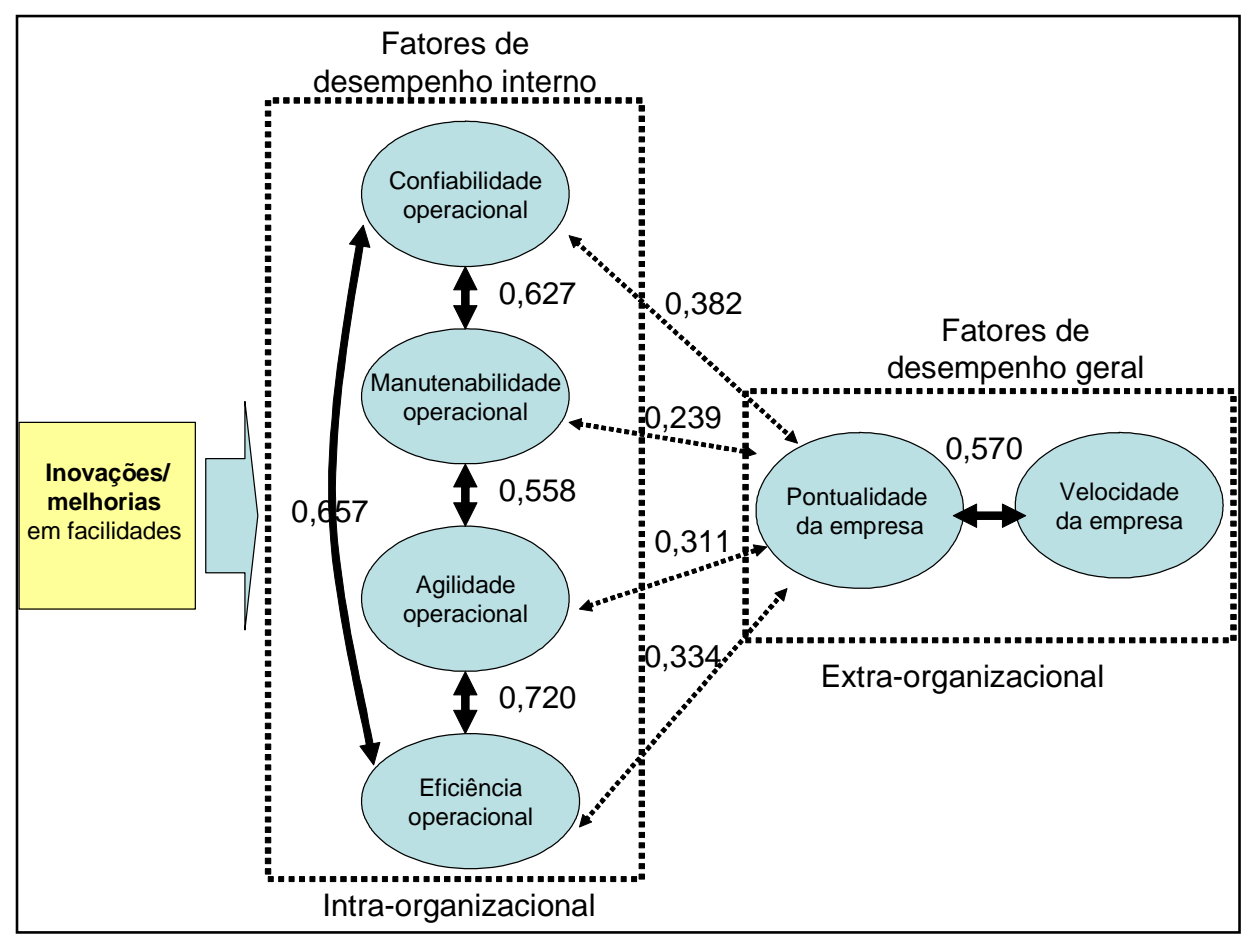

Figura 15 - Modelo interpretativo das inovações e melhorias em facilidades e os desempenhos das organizações

Fonte: Quinello e Nascimento (2009)

O modelo da Figura 15 mostra os principais fatores encontrados e suas correlações, a saber:

- A confiabilidade operacional, segundo Smith (1976), é a probabilidade de um equipamento ou de um sistema operar sem falhas quando colocado em serviço, geralmente expresso pela fórmula $R(t)=e-\square . t(t>=0)$ sendo: $R(t)$ a chance de sobrevivência além do tempo t; e $\square$ a taxa de falha. A manutenabilidade ou manutenibilidade operacional é relativa às facilidades que um processo propicia para sua manutenção, isto é, quanto tempo e de que forma um dispositivo é facilmente corrigido no caso de parada ou manutenção. Ele pode ser expresso em MTTR (mean time to repair), sendo o tempo total entre a chamada de uma solicitação até seu funcionamento. A agilidade operacional está relacionada as melhorias que tornam as operações mais simples, incluindo a própria manutenção. Pode-se medi-la por ciclos ou tempo entre operações (etapas). Já a eficiência operacional O.E.E - overall equipment efficiency, é o resultado da multiplicação entre disponibilidade, qualidade e rendimento operacionais, demonstrando o quanto o ativo está sendo efetivamente 
utilizado. Já os fatores pontualidade e velocidade formaram um cluster separado do conjunto de fatores internos, mostrando que a expansão de dimensões operacionais internas podem afetar positivamente, porém indiretamente, os desempenhos finais das organizações.

Há inovações e melhorias em facilidades que surgem da relação estabelecida com as áreas operacionais, principalmente com os processos produtivos, pois esses produzem novas demandas e requerimentos que, por sua vez, geram novas soluções de infraestrutura, em outras palavras, são dependentes entre si. De qualquer forma, constatou-se a importância do reconhecimento da área dentro das Operações, uma vez que o crescimento do mercado não acompanha, necessariamente, investimentos em ativos, forçando os gestores a prolongarem o ciclo de vida das infraestruturas operacionais. A restrição a recursos parece ser uma das impulsionadoras no desenvolvimento de soluções e alternativas nessas áreas.

SINOPSE 3: as inovações e as melhorias em facilidades têm papel não só na manutenção dos processos produtivos, mas também na alavancagem dos resultados das organizações. Essa alavancagem não é homogênea, podendo surgir impactos de diferentes intensidades e formatos, principalmente nas eficiências operacionais.

\subsubsection{Convergindo as inovações e melhorias em facilidades}

Na convergência de todas as fases empíricas e pilotos reunidos antes da aplicação do survey, obtiveram-se 156 inovações e melhorias em facilidades - IMF apontadas por 103 profissionais (APÊNDICE H). Elas são oriundas das fases II (34 profissionais e 87 IMF), III (24 profissionais e $24 \mathrm{IMF}$ ), pré piloto (30 profissionais e $30 \mathrm{IMF}$ ) e pós piloto (15 profissionais e 15 IMF). A fase I, que continha 14 inovações identificadas por 10 profissionais, foi descartada, pois o instrumento de coleta era um questionário aberto e não estruturado, o que dificultaria a convergência quantitativa das demais coletas (essas advindas de questionários semiestruturados). Nessa etapa pretende-se aproveitar todos os levantamentos realizados entre os anos de 2007 e 2009, auxiliando as próximas etapas da triangulação.

Pelo Gráfico 2, observa-se que a amostra é formada com mais frequência por empresas de grande porte $(56,4 \%)$, nacionais $(53,2 \%)$ e do setor industrial $(57,7 \%)$. Em relação às 
inovações e melhorias produzidas; 40,4\% são voltadas para processos produtivos como melhorias de máquinas, dispositivos e equipamentos de apoio; 30,1\% nas mudanças organizacionais como introdução de modelos da qualidade, grupos de trabalho autônomos, mudança de turnos e novas estruturas organizacionais; 18,6\% foram direcionados para inovações ou melhorias em softwares para gerenciamento ou controles de máquinas. Essas mudanças operadas pelas áreas de facilidades são de baixa e média novidade, possuem características mais próximas às chamadas melhorias contínuas ou inovações por melhorias $(39,8 \%)$. Uma pequena parcela pode ser tratada como inovações incrementais ou radicais $(4,5 \%)$. Os dados apontam, assim como na literatura corrente sobre inovação, que em facilidades também há uma graduação, ainda que discreta, na novidade das mudanças técnicas ou organizacionais.

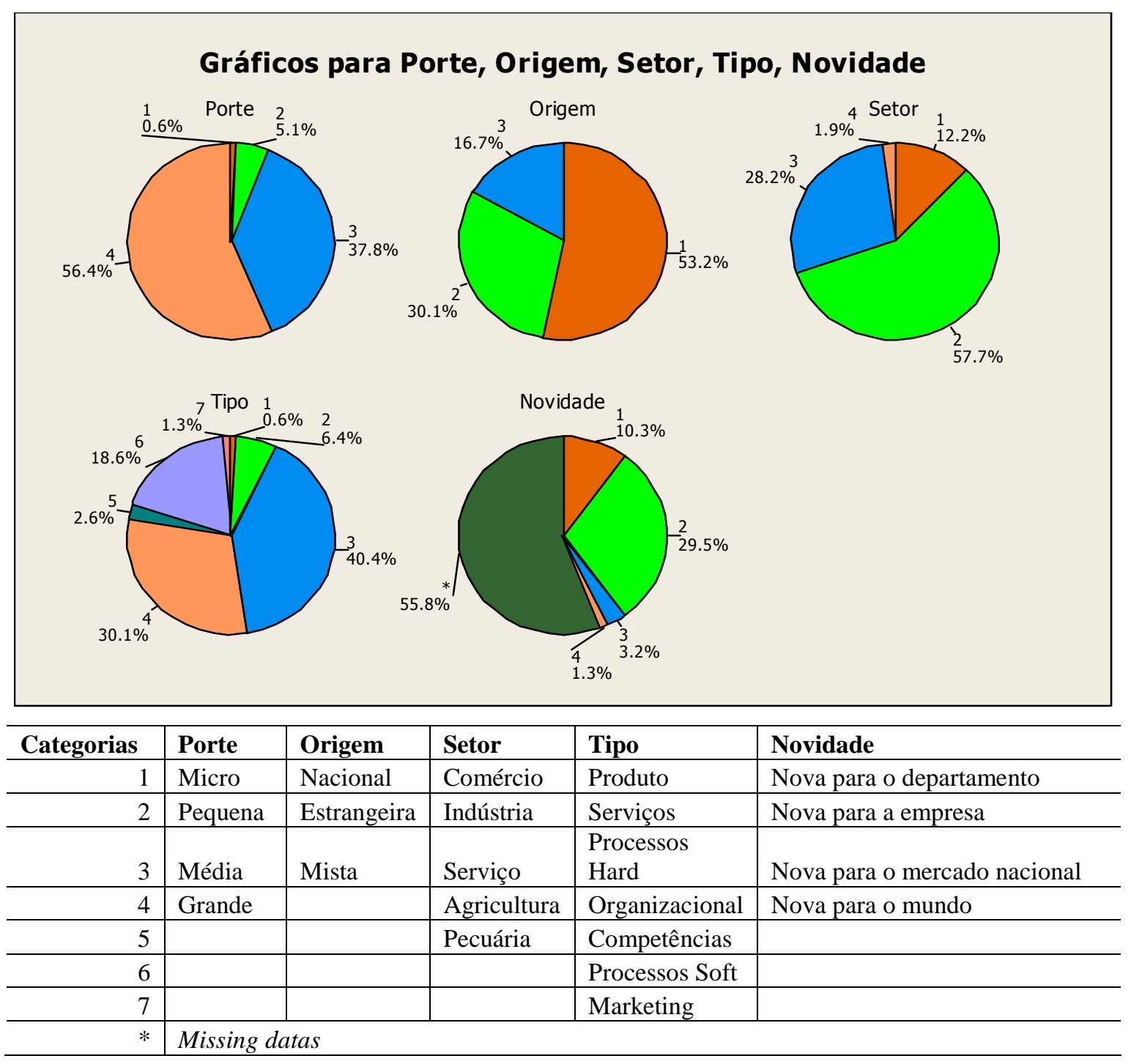

Gráfico 2 - Características gerais da convergência das fases empíricas 
As variáveis que mantiveram as mesmas escalas em todas as etapas empíricas foram as classificatórias (PORTE, ORIGEM e SETOR) e as assertivas (TIPO E NOVIDADE). Aplicou-se um teste de hipóteses não paramétrico (Kruskal-Wallis) para determinar se haveriam diferenças estatísticas significativas entre essas variáveis categóricas em relação às assertivas:

- H0: não há diferenças entre as amostras

- H1: há diferenças em pelo menos duas amostras

Os resultados encontrados estão na Tabela 3 e apontam diferenças estatísticas significativas (p-value < 0,05 rejeitando H0) entre as variáveis PORTE e TIPO. Uma das explicações, para Wolff e Pett (2006), é que as empresas pequenas possuem restrições de recursos, ao passo que as grandes teriam inúmeras opções que as fariam mais aptas a inovar. No entanto, os resultados encontrados, divergem da pesquisa de Wolff e Pett (ibid), em empresas americanas de manufaturas, onde o porte das mesmas não teve correlações com o tipo de inovação gerada (processo ou produto). Para eles, outras variáveis como internacionalização e capacidade para inovar foram mais decisivas na configuração das inovações.

\begin{tabular}{l|r|r}
\hline $\begin{array}{l}\text { Sig. }(\boldsymbol{p} \text { - } \\
\text { value })\end{array}$ & \multicolumn{1}{|c|}{ Tipo } & Novidade \\
\hline Porte & $\mathbf{0 . 0 3 1}$ & 0.164 \\
\hline Origem & 0.504 & 0.115 \\
\hline Setor & 0.743 & 0.325 \\
\hline
\end{tabular}

Tabela 3 - Diferenças estatísticas entre as dimensões das empresas

Nessa tese, as empresas de grande porte, aparentemente possuidoras de mais recursos, optam por desenvolverem, em sua maioria, inovações em facilidades ligadas aos processos produtivos. Essas inovações podem ser consideradas tecnicamente mais dispendiosas, por envolverem soluções técnicas complexas e mão-de-obra especializada. Em contrapartida, as chamadas inovações organizacionais foram as mais constantes nas empresas de médio porte. Nota-se que há uma inversão das inovações focadas em processos e as organizacionais nos portes médio e grande, sugerindo um movimento cíclico no desenvolvimento das infraestruturas, isto é, esforços iniciais estariam concentrados nas inovações e melhorias organizacionais e a medida que recursos são disponibilizados, aumentam as em processos, tecnicamente mais complexas. 


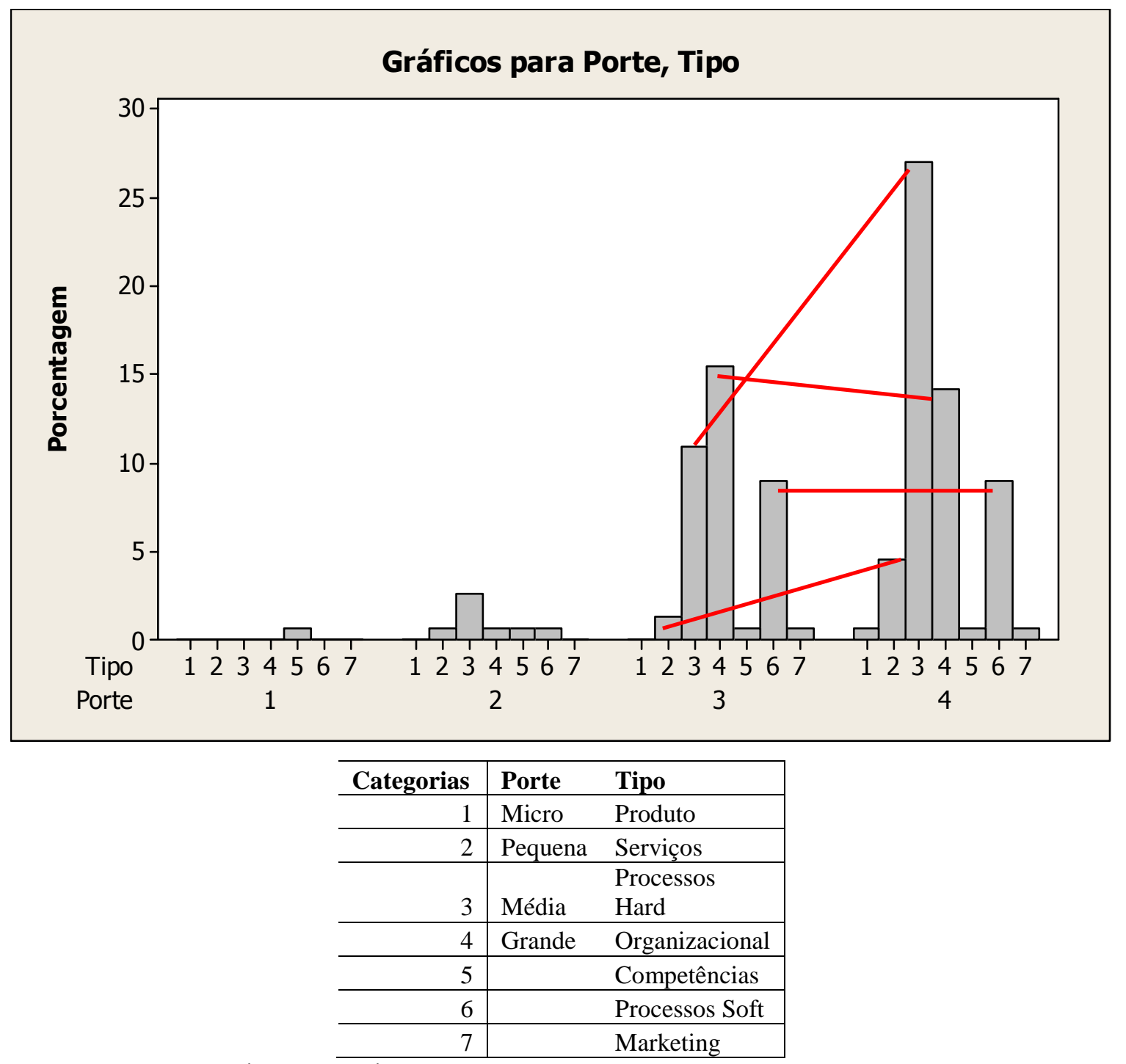

Gráfico 3 - Gráfico do porte das empresas e do tipo de inovações

Outra possível interpretação para a inversão das inovações e melhorias em relação ao porte, é que as mudanças organizacionais poderiam, inicialmente, preparar as bases para o desenvolvimento das inovações em processos, como os movimentos da qualidade e as novas técnicas de gestão, diversas vezes apontados nas fases empíricas e ratificando o trabalho de Prajogo (2003), em empresas australianas, encontrou uma relação positiva entre as empresas que adotaram o TQM e as inovações em processos nelas desenvolvidas. Essa relação sugere que em ambiente onde a gestão é mais formalizada e profissionalizada, muitas vezes frutos das inovações organizacionais, haja um estímulo extra para as inovações.

Por outro lado, como demonstrado no Gráfico 3, as mudanças oriundas desse estímulo seriam muito mais do tipo melhorias ou inovações incrementais do que as chamadas inovações radicais, possivelmente porque em ambientes industriais formalizados e padronizados, como 
aqueles influenciados pelos movimentos da qualidade, as mudanças ocorram muito mais em função de resolução de problemas ou ajustes técnicos do que para o desenvolvimento de produtos completamente novos para o mercado.

SINOPSE 4: as inovações e melhorias contínuas em facilidades podem variar de acordo com as características das organizações, como o porte. Isso sugere que elas podem ser incentivadas pelo acesso das organizações às práticas de qualidade, pelo ciclo de vida das infraestruturas e pelas restrições dos recursos disponíveis.

\subsection{Estudo de caso único: as inovações e melhorias das facilidades geradas em sistemas tecnológicos complexos.}

A infraestrutura física de uma planta produtiva é um sistema tecnológico complexo, hierarquizado e adaptativo. Sistemas complexos, para Simon (1962), envolvem incertezas técnicas, pois mesmo pequenas mudanças nos projetos dos artefatos (equipamentos, dispositivos, sistemas) podem causar diversas consequências funcionais para os mesmos em função das múltiplas interações, por isso, uma vez implantada uma instalação (como uma planta industrial), essa tende a se manter constante por décadas, gerando inércia organizacional. Ainda em Simon (ibid) há a ideia de que a complexidade é geralmente hieráquica porque sistemas hierárquicos evoluem mais rapidamente do que sistemas não hierárquicos. E sistemas complexos adaptativos, na concepção de Holland (1995), seriam sistemas que dependem de condições exógenas, alterando o seu comportamento para ajustarse a certas mudanças no ambiente que o circunda, possibilitando ou facilitando o alcance dos seus objetivos. $\mathrm{O}$ autor advoga também que as mudanças nos sistemas complexos adaptativos poderiam surgir por meio de agregação, interação, adaptação ou aprendizado.

Dessa forma, também não seria incorreto pensar na infraestrutura de uma dada organização como que uma tecnologia dominante para aquele contexto, valendo-se do termo utilizado por Abernathy e Utterback (1978) para definirem projetos específicos que se tornam padronizados e legitimados pelos agentes, passando a gerar isomorfismo no setor de atuação.

Independente da referência operacional utilizada pode-se afirmar que uma instalação industrial, em função dos recursos alocados e da complexidade técnica exigida, formatará, por um longo período, a trajetória tecnológica de uma planta industrial, dando uma falsa aparência de inércia. As facilidades de uma organização também podem moldar ou restringir os 
produtos ali desenvolvidos, como é o caso das montadoras, que produzem veículos não apenas em função dos desejos dos consumidores ou mercados locais, como também das infraestruturas já existentes. É justamente nesse cenário industrial, aparentemente pouco dinâmico, que se deu o estudo de caso analisado nessa seção. Trata-se do desenvolvimento e implantação de uma nova torre de resfriamento de água de processo para compressores de ar comprimido e ponteadeiras, na planta industrial da Ford Motor Company, localizada no Grande ABC - Estado de São Paulo. Essa torre faz parte da infraestrutura de abastecimento de utilidades da planta industrial.

Os objetivos desse estudo de caso são elucidar as características das inovações e melhorias em facilidades e entender os seus impactos no desempenho dessa organização. Para isso, contouse com entrevistas em profundidade com o coordenador do projeto. Trabalharam na implantação da torre aproximadamente quatro funcionários da empresa contratante (um coordenador e três técnicos em elétrica, mecânica e hidráulica) e seis da contratada (dois engenheiros mecânicos e elétricos e quatro técnicos mecânicos e elétricos), num total de 1119 horas. Os custos para implantação foram de $\mathrm{R} \$ 300.000,00$ e havia expectativa de uma economia em torno de $\mathrm{R} \$ 100.000,00$ a.a. (referentes a redução de consumo de água, material para tratamento químico, manutenção e reparos e energia elétrica), ou seja, o retorno sobre o investimento ocorreria em três anos de operação. Os trechos das entrevistas foram inseridos na transcrição do caso, de acordo com a temática tratada ao longo das seções. A Figura 16 ilustra, a esquerda, as antigas torres do tipo evaporativas e, a direita a nova, os hidrocoolers ${ }^{\circledR}$. O desafio da equipe foi adaptar uma nova tecnologia num sistema em plena operação.

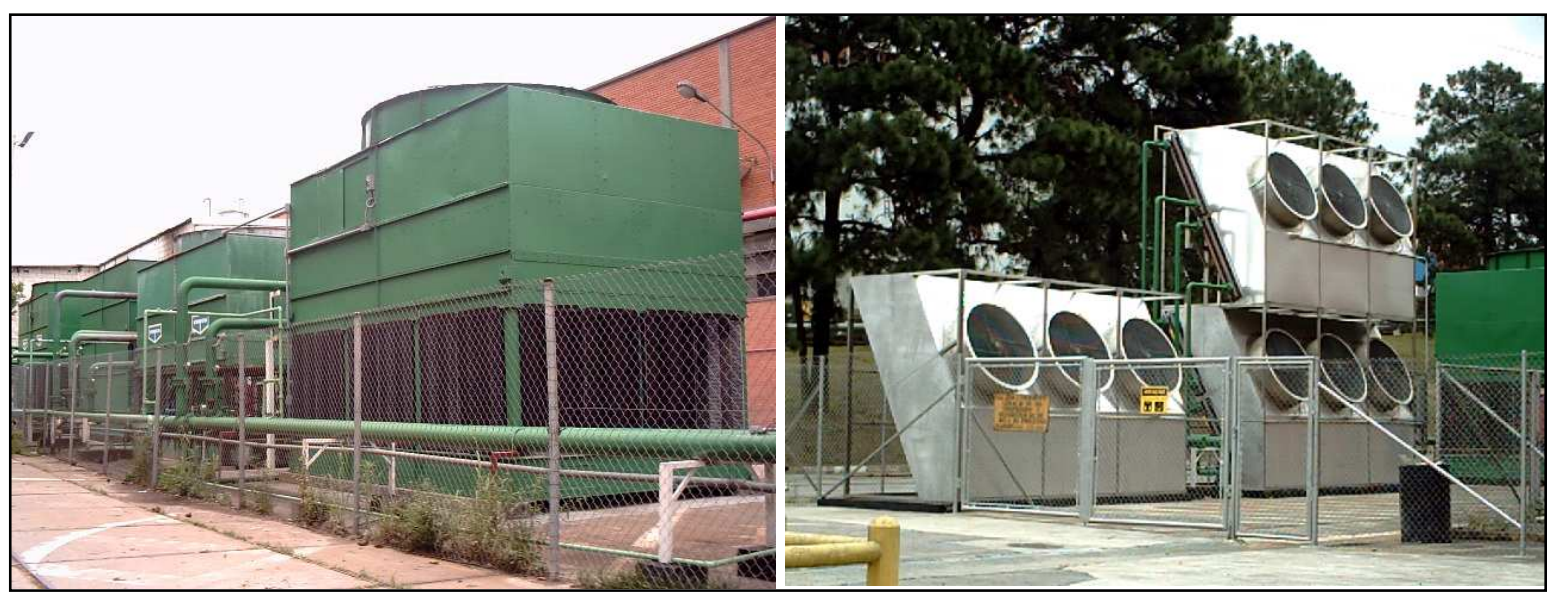

Figura 16 - A coexistência entre novas e antigas tecnologias Fonte: Quinello e Nascimento (2009) 


\subsubsection{O contexto do caso}

A Ford Motor Company tem uma de suas plantas industriais localizada na região do Grande ABC, Estado de São Paulo, inaugurada na década de 1950. Atualmente, esse complexo industrial possui aproximadamente 6.000 funcionários, produzindo carros leves (250 unidades dias) e pesados (300 unidades dia) para os mercados interno e externo. Desde a década de 1990, a unidade vem introduzindo os conceitos do FPS (Ford Production System), uma espécie de práticas da qualidade composta por várias ferramentas e metodologia de trabalho como o lean manufacturing, seis sigma, quality production system (QPS), ISO 9000 e 14000, kaizen, mapeamento da cadeia de valores, entre outros.

A área de facilidades é responsável pela manutenção e engenharia das infraestruturas de utilidades, manutenção predial, zeladoria, meio-ambiente, gerenciamento de espaços, real estate e reformas e obras civis. É composta por 50 funcionários diretos e 150 indiretos (estes basicamente oriundos de empresas terceirizadas) com um orçamento anual de US\$ 20 milhões e subordinada à diretoria de manufatura avançada.

Dentre os vários sistemas de infraestruturas de utilidades existentes nessa planta (instalações de rede de energia elétrica, gás e ar comprimido), há o de água resfriada para os processos produtivos. Esse sistema é formado por uma rede de parques de torres de resfriamento, conectadas por mais de $9 \mathrm{Km}$ de tubulações por toda a planta e responsáveis pela troca de calor gerada pelos compressores de ar comprimido e equipamentos de soldagem. Os parques possuem idades distintas que vão da década de 1960 ao parque mais recente implantado na década de 1990 durante o projeto FIESTA. O objeto de análise do estudo de caso é uma nova torre de resfriamento comprada em 2008 e implantada em 2009, contando com a participação da engenharia de facilidades e parceiros externos.

Nas seções subsequentes, são utilizados os conceitos e as estratificações operacionais de Murmann e Frenken (2006), que recomendam a hierarquização dos artefatos tecnológicos, ainda que essas categorizações sejam por vezes subjetivas e informais. A subjetividade e a informalidade ocorreriam porque os limites dessas categorias dependem das limitações e percepções humanas, tornando-as frequentemente arbitrárias e confusas. Todavia, essa estratégia analítica poderia ampliar e aprofundar o caso sobre a unidade, os níveis, os mecanismos causais e a sequência temporal das inovações e melhorias em facilidades, pois 
elas ocorrem em espaços, intensidades e tempos distintos das inovações tradicionais. Nessa análise não foram abordados os ciclos de desenvolvimento de cada artefato, dada a escassez de informações e incompatibilidade com o foco de pesquisa.

\subsubsection{Unidade de análise: um parque de torres de resfriamento}

Para a grande maioria dos processos industriais se faz necessário o resfriamento dos equipamentos, dispositivos e maquinarias em geral, pois eles são geradores de calor durante as operações. Um dos fluídos utilizados para a dissipação do calor é a água, devido a baixa viscosidade, alta condutibilidade térmica e alta densidade, além da fácil obtenção e atoxidade (OMNI, 2009). Essa água pode ser reaproveitada para um sistema de resfriamento aberto ou semifechado e, na maioria dos casos, utilizam-se as chamadas torres de resfriamento de água, equipamentos que usam processos de evaporação e transferência de calor. Dentro os tipos mais comuns, destacam-se os de tiragem de ar natural ou mecânico com seus subtipos, de acordo com Figura 17.

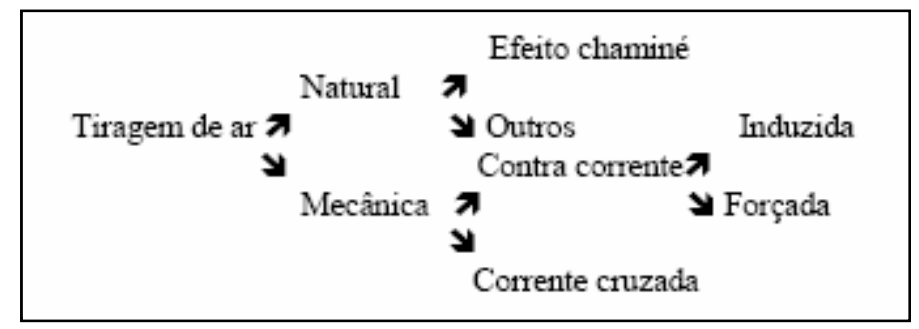

Figura 17 - Tipos de torres de resfriamento de água Fonte: Extraído de OMNI (2009)

$\mathrm{O}$ antigo parque de torres de resfriamento de água analisado foi importado dos EUA e é composto por torres do tipo tiragem de ar mecânico de contra corrente induzida, com circuito aberto (conhecido como sistemas evaporativos). Esse parque é responsável, dentro das infraestruturas da planta, pelo resfriamento da água de processo utilizada tanto nos compressores de ar comprimido, que necessitam de resfriamento interno, como nas pinças ponteadeiras dos robôs soldadores. São equipamentos que operam 24 horas por dia acompanhando a produção. A nova torre instalada é nacional com a mesma função, porém com circuito fechado (uma das inovações propostas para o sistema atual, também chamada de hidro-cooler $\left.{ }^{\circledR}\right)$. O circuito fechado reduz um dos grandes desafios que até poucas décadas atrás não era tão importante - o impacto ambiental gerado pelo consumo de energia, água e descarte de produtos químicos. 
Nos sistemas antigos, os de circuitos abertos, a renovação de água necessária para o adequado resfriamento consume grandes volumes de recursos hídricos, produtos químicos para o tratamento da água, altos custos de manutenção, além de serem fontes de contaminação por bactérias como as da Legionella, elevando assim os custos e riscos operacionais do sistema. Como destacou o especialista que coordenou o projeto:

\footnotetext{
"[...] primeiro veio a necessidade da aquisição de um equipamento para substituir o atual que já se mostrava bem deficiente, junto com esta necessidade operacional veio também a questão ambiental a qual (o novo equipamento ) traz grandes vantagens no tocante a economia de água e energia. Se podemos ser bem objetivos: custo operacional e de manutenção e aspecto ambiental foram os ganhos da inovação".
}

Ainda buscando o entendimento do porquê da necessidade se introduzir uma torre com tecnologia diferente da atual, abrem-se outras inferências pouco comentadas na literatura de inovação: a falta de gerência e recursos sobre os ativos das organizações como estimuladores de novas soluções. Frequentemente, as pesquisas como as de Henderson e Clark (1990), apontam a resolução de problemas como um dos propulsores das inovações (muito comuns nos círculos da qualidade). Mas o que estimularia a resolução de problemas no caso analisado? Perguntado sobre como se chegou na necessidade de instalação da nova torre, o especialista entrevistado confirmou que a política de manutenção da organização é falha, ou seja, possivelmente a alocação de recursos para a manutenção do ciclo de vida dos ativos é frágil e não acompanhou o processo de obsoletismo dos equipamentos ao longo das suas duas décadas de vida, resultando em um sistema pouco eficiente. A baixa eficiência do sistema de resfriamento de água pode comprometer a vida útil dos equipamentos de geração de ar comprimido como também reduzir a qualidade das soldas dos veículos. Outro motivador, além da obsolescência das torres, foi a inexistência de peças para reposição, visto que o parque de torres foi importado dos E.U.A, dificultando a substituição dos seus componentes.

Conclui-se que foram a degradação do sistema, o isomorfismo tecnológico, a ingerência (inércia) e a restrição de recursos, e não especificamente as prática de melhorias contínuas, os principais impulsionadores dessa inovação. Essa constatação pode ser notada na resposta do especialista, quando perguntado sobre as barreiras para a implantação da nova torre:

“[...] desconfiança do novo (a mudança de tecnologia, assim como qualquer outra mudança deixa as pessoas com medo), além da resistência em evoluir o processo (renovação tecnológica) junto a alta administração. [...] quebra de paradigmas para conseguir fazer com que os envolvidos aceitassem esta nova tecnologia". 
O desenvolvimento da torre foi em parceria com fornecedores locais. A equipe interna de manutenção contatou uma empresa nacional especializada em transferência de calor e solicitou uma tecnologia ecológica, econômica e funcional que pudesse ser agregada ao sistema já existente. $\mathrm{O}$ coordenador indagou que com as barreiras enfrentadas para renovação do parque de torres, o objetivo da implantação da nova torre era, paradoxalmente, a redução dos efeitos da degradação do tempo e não a busca por máxima eficiência, já que esta estava longe de ocorrer (em função dos recursos escassos).

SINOPSE 5: as inovações e melhorias contínuas em facilidades podem ser estimuladas pela inércia organizacional, isomorfismo tecnológico, degradação dos ativos, ingerências e restrição de recursos, levando os grupos autônomos a buscarem soluções tecnológicas em parcerias que ampliem o ciclo de vida das instalações e reduzam os gargalos operacionais, na busca de aumento da eficiência mínima.

\subsubsection{Nível de análise: os componentes, subsistemas e sistemas da torre de resfriamento}

Seguindo a classificação de Murmann e Frenken (2006), os artefatos tecnológicos podem ser analisados em diferentes níveis ou granularidades - no nível dos componentes, subsistemas e sistemas como um todo. Esse detalhamento ajudaria a entender os esforços $\mathrm{e}$ as complexidades exigidas em cada "parte" da inovação, uma vez que a mesma poderia ser composta por diferentes tecnologias com fases de desenvolvimento ou aperfeiçoamento distintos. A própria classificação da intensidade da novidade é facilitada quando o artefato é dividido em níveis: uma mesma inovação pode ser radical na implantação, arquitetural no subsistema e incremental nos componentes ou vice-versa (HENDERSON e CLARK, 1990). Segundo Murmann e Frenken (ibid), pode ser radical nos antecedentes (escopo de conhecimento utilizados ou adquiridos) ou nas consequências e efeitos (nos desempenhos obtidos), como ainda radical para o prestador de serviços e incremental para o tomador.

A Figura 16 apresenta a infraestrutura para refrigeração de água de processos como uma tecnologia dominante local e hierarquizada, composta por um conjunto de torres de resfriamento de água espalhadas pela planta industrial (sistema), parques descentralizados de torres de resfriamento (subsistemas de primeira ordem), torres de resfriamento (subsistemas de segunda ordem) e equipamentos e dispositivos que constituem as torres (componentes). Esses artefatos ora são centrais, ora periféricos. A definição de centralidade e periferia remete 
à relação entre a alteração de um dos níveis do artefato com o impacto por ele causado ao sistema como um todo. Geralmente, como indicam os trabalhos de Henderson e Clark (ibid) e Murmann e Frenken (ibid), mudanças ocorridas nos níveis dos componentes que alteram drasticamente (positiva ou negativamente) os resultados desses artefatos tecnológicos, tornam-as mais centrais; as mudanças implementadas nos componentes menos críticos, dado seu reduzido efeito sobre o sistema como um todo, deixam-os mais periféricos.

Juntamente com os conceitos de centralidade e perifericidade em artefatos complexos, Murmann e Frenken (ibid) evocam os modelos analíticos de pleitropia para explicar o porquê uma dada tecnologia será dominante. O termo pleitropia vem dos estudos da biologia sobre os fenótipos e genótipos e indica como determinadas mutações têm alta ou baixa probabilidade de sucesso. Analogamente ao modelo biológico, características técnicas dos componentes seriam os genótipos de uma tecnologia e as características dos serviços ou atributos da tecnologia, os fenótipos. Enquanto as características técnicas são alteradas pelos técnicos, as de serviços se ajustam aos olhos dos usuários. Se um componente tem uma característica técnica capaz de alterar inúmeros atributos, diz-se que ele possui alta pleitropia e vice-versa. A alta pleitropia de um componente, subsistema ou sistema, explicaria sua dominância devido, sobretudo, a implicação que sua mudança causaria ao artefato. A dificuldade da mudança não estaria apenas ligada às questões de complexidade técnica, como também às de cunho institucional (político, comercial e econômico), afinal uma infraestrutura de instalações industriais pode funcionar num dado contexto e não em outro. 


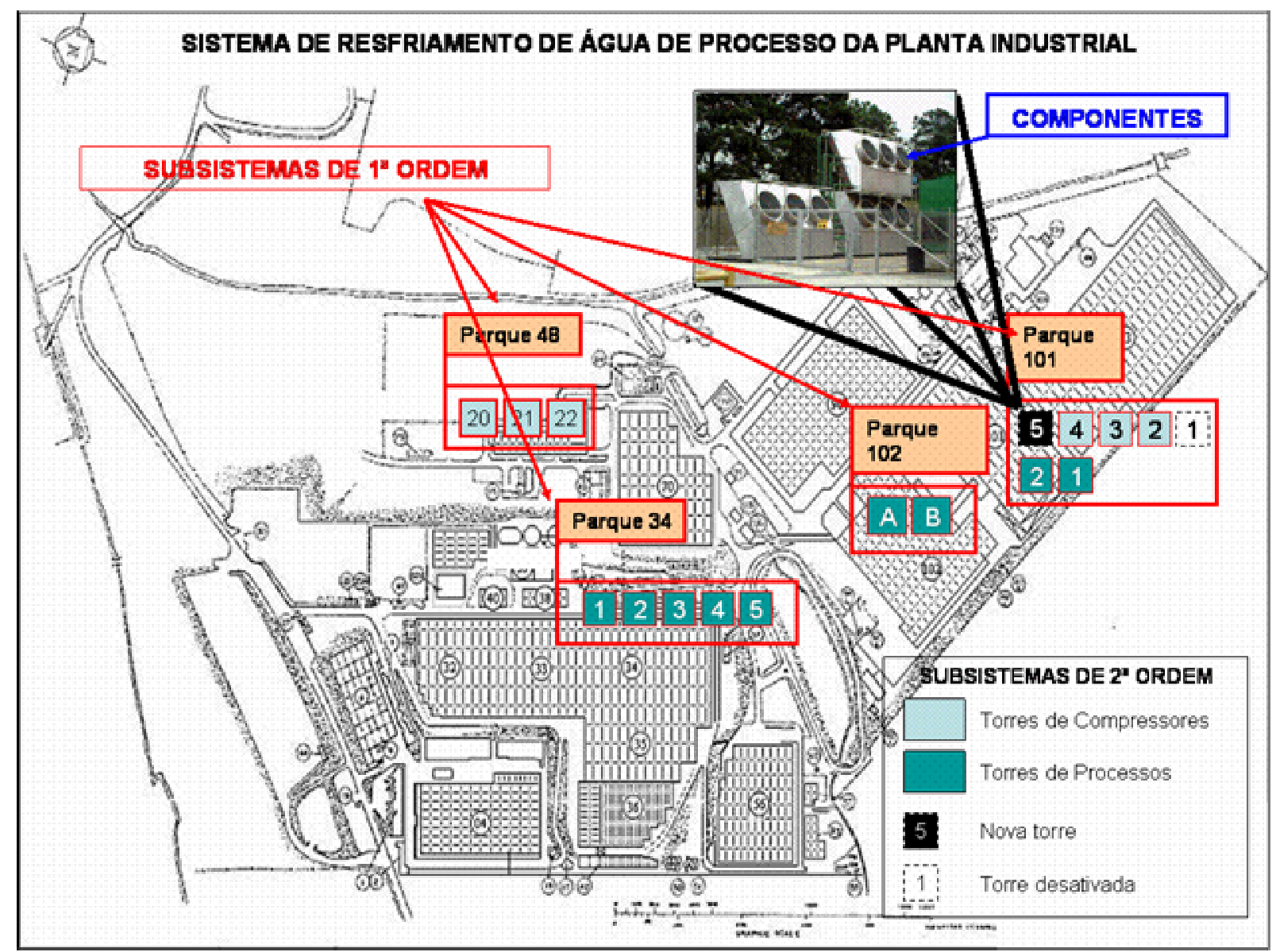

Figura 18 - Níveis de análise da tecnologia de infraestrutura para resfriamento de água de processo

A implantação da inovação ocorreu, inicialmente, pela simples troca de uma torre desativada pela nova. Segundo a empresa fornecedora da inovação, as vantagens técnicas da nova torre seriam:

- Limitaria o consumo de água há poucas horas durante o ano e de forma intermitente somente em condições ambientais extremas;

- Proporcionaria economia de energia elétrica com o gerenciamento do funcionamento dos ventiladores pelo Softronic-Control®;

- Único sistema de resfriamento de água industrial que atenderia completamente às normas da ISO 14000;

- Dispensaria a troca da água em circulação quando operado adequadamente;

- Pela substituição do processo tradicional de resfriamento da água industrial através da torre evaporativa seria eliminada a precipitação e, consequentemente, a incrustação interna das tubulações; 
- Reduziria drasticamente a necessidade de manutenção dos trocadores de calor;

- Não requereria tratamento químico da água, dispensando a parada periódica para limpeza dos trocadores de calor e reservatórios, reduzindo os custos operacionais;

- Proporcionaria estabilização das características físico-químicas dos fluidos em circulação;

- Evitaria a contaminação do fluido por algas, bactérias e fungos, mantendo o sistema constantemente limpo;

- Conferiria estabilidade e precisão aos processos, pois mantém a temperatura do fluido de arrefecimento constante;

- De concepção modular, permitiria expansões da planta em etapas, com simplicidade e economia.

Entretanto, um subsistema de infraestrutura de segunda ordem (a torre) é um artefato tecnológico central com alta pleitropia. Essa condição se deve aos altos riscos que sua substituição ou desativação induz ao subsistema de primeira ordem (o parque) e, consequentemente, ao sistema da planta como um todo. Os técnicos das empresas esperavam que pequenos ajustes seriam suficientes para a total inserção e encaixe dos equipamentos, mas os primeiros resultados não foram animadores, como destacado pelo coordenador do projeto:

\footnotetext{
"[...] embora tendo resultado no mercado, o fornecedor também teve dificuldades de ajustar o modelo de equipamento para as nossas necessidades [...] na implantação (da nova torre) tivemos alguns contratempos; local de instalação (não apropriado para o equipamento), modelo do equipamento entregue na primeira versão não atendeu o escopo contratado, tendo que sofrer grandes alterações, apesar que tudo estava sendo um aprendizado mútuo".
}

Os riscos só não foram maiores porque, para instalações interconectadas, percebeu-se que as redundâncias operacionais amortecem os impactos da alta pleitropia, ou seja, subsistemas considerados, a princípio, centrais e com alta pleitropia, quando devidamente replicados, podem adquirir características periféricas de baixa pleitropia, não aumentando nem diminuindo os ganhos operacionais, mas reduzindo os riscos operacionais. Essa condição se dá porque um dos subsistemas pode ficar em espera, liberando sua réplica para as devidas modificações. Na empresa analisada, os atributos de desempenho (ganhos) da torre eram a desempenho - o quanto a temperatura da água de saída é reduzida, a qualidade - da água resfriada que circulará nos equipamentos, e a disponibilidade - o quão apta está a torre quando acionada para as operações, atributos também conhecidos como OEE - overall equipment effectiveness (cujo objetivo é de $85 \%$ ). 
Numa segunda etapa, agora quanto aos componentes, os projetistas apresentaram as mudanças que a torre sofreria, como a modernização das hélices (aerodinâmica mais simples e eficiente), do material da estrutura (em alumínio), dos aspersores externos (que ajudam a resfriar o sistema em dias excessivamente quentes) e do circuito interno (fechado com consumo mínimo de água). Esperava-se uma redução de no mínimo $6^{\circ}$ Celsius (delta de temperatura ideal), porém se chegou no máximo a $3^{\circ} \mathrm{C}$ de redução. Mais uma vez, a dificuldade da mudança pode ser explicada pelas características dos componentes da inovação, seus atributos e suas pleitropias, conforme Quadro 10 (modelado de acordo com os relatos do entrevistado e informações técnicas das torres):

\begin{tabular}{|c|c|c|c|c|c|}
\hline $\begin{array}{r}\text { Dimensões técnicas } \\
\text { alteradas }\end{array}$ & 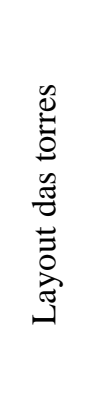 & 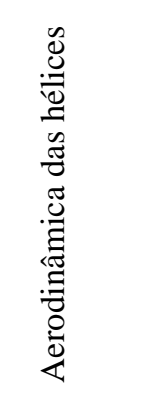 & 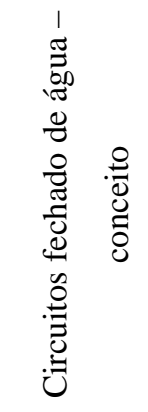 & 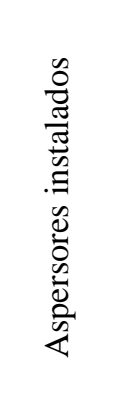 & 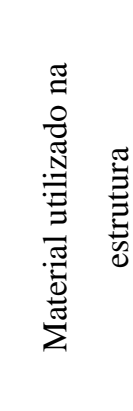 \\
\hline Disponibilidade & $\mathrm{AIT} T$ & BAIXO & BAIXO & MÉDIO & BAIXO \\
\hline Eficiência & ALTO & ALTO & BAIXO & ALTO & BAIXO \\
\hline Qualidade & ALTO & ALTO & ALTO & BAIXO & BAIXO \\
\hline PLEITROPIA & ALTA & MÉDIA & MÉDIA & MÉDIA & BAIXA \\
\hline
\end{tabular}

Quadro 10 - Pleitropia de uma inovação e melhoria em facilidades

Apesar das inúmeras inovações e melhorias conferidas à torre, a equipe não previa que uma das características técnicas-chaves - o layout das torres, possuía alta pleitropia, onde a simples mudança física de uma torre pode afetar todos os atributos do artefato. Como o desempenho de uma torre está ligado às condições climáticas como ventos, umidade, exposição ao sol, impurezas do ar etc, a escolha do posicionamento para a instalação é fundamental e o local, inicialmente utilizado, era demasiadamente fechado por paredes e próximo a árvores, dificultando a troca de calor.

Além do layout físico, há o funcional, ou melhor, como e quando a nova torre operará dentro do sistema. Utilizando o conhecimento da equipe de mecânica da Ford, que havia feito 
inúmeras manobras, modificações e improvisações de posicionamento em outros subsistemas na base de tentativa e erro, conclui-se que o melhor local seria a posição cinco (vide Figura 18), colocando a nova torre como apoio para as mais antigas. Esse arranjo operacional propiciou uma modificação gradual do subsistema, visto que uma mudança radical do layout poderia afetar o sistema, reduzindo ainda mais o OEE.

Não obstante, mesmo com todas as modificações, nas últimas avaliações das saídas de temperatura do subsistema, ainda não se atingiu o delta desejado, como afirmou o especialista da Ford, demonstrando o quão complexo é a inserção tecnológica para artefatos com alta pleitropia::

“[...], porém o equipamento em um sistema misto como o nosso não se mostrou muito bom (talvez devido ao seu conceito de operação), em dias de pico de temperatura tivemos que desligá-lo e trabalhar somente com as torres antigas. Em geral, visando atender a economia de energia, os números mostram que é uma boa opção e que esta primeira aquisição de equipamento mostrou que temos que cercar melhor (o projeto) a para troca de calor e, principalmente, corrigir problemas enfrentados nesta fase por se tratar de uma nova tecnologia".

Com a investigação dos níveis do artefato tecnológico pesquisado (a torre) foi possível ampliar e aprofundar as nuances envolvidas no desenvolvimento de uma inovação em facilidades. Num primeiro momento, analisada superficialmente, a aquisição de uma nova torre poderia ser considerada uma melhoria contínua sem qualquer grau de novidade. Todavia, vista sob camadas hierarquizadas, a inovação torna-se mais complexa, conforme Quadro 11 compilado segundo os relatos da investigação de campo e dados fornecidos pelo entrevistado:

Quadro 11 - Nível, mudança e grau de novidade do estudo de caso

\begin{tabular}{|c|c|c|}
\hline $\begin{array}{c}\text { Nível (granularidade) } \\
\text { do artefato }\end{array}$ & Mudança detectada no caso & $\begin{array}{l}\text { Grau de } \\
\text { novidade }\end{array}$ \\
\hline $\begin{array}{l}\text { Sistema } \\
\text { resfriamento de água de } \\
\text { processo (de toda a } \\
\text { planta) }\end{array}$ & $\begin{array}{l}\text { Melhoria contínua no sistema. Ganhos mínimos de desempenho - } \\
\text { OEE }<85 \% \text {, para o sistema. }\end{array}$ & Mínimo \\
\hline $\begin{array}{l}\text { Subsistema de primeira } \\
\text { ordem (parque 101) }\end{array}$ & $\begin{array}{l}\text { Inovação arquitetural no parque (rearranjo físico das torres para a } \\
\text { busca de eficiência global mínima). Ganhos relativos de desempenho } \\
\text { - OEE (entre } 70 \text { e } 85 \% \text { ) para o parque } 101 \text {. Houve redução no } \\
\text { consumo de água (impacto ambiental) e de material para tratamento }\end{array}$ & Médio \\
\hline
\end{tabular}




\begin{tabular}{|l|l|l|}
\hline & químico. & \\
\hline $\begin{array}{l}\text { Subsistema de segunda } \\
\text { ordem (nova torre) }\end{array}$ & $\begin{array}{l}\text { Inovação radical (nos conhecimentos infraestruturais e de otimização } \\
\text { aplicados na escolha do posicionamento físico da nova torre para o } \\
\text { encaixe operacional da nova tecnologia no sistema antigo). Ganhos } \\
\text { relativos de desempenho - OEE da nova torre, como a melhoria na } \\
\text { manutenabilidade (peças para reposição nacionalizadas). }\end{array}$ & Alto \\
\hline $\begin{array}{l}\text { Componentes internos } \\
\text { da nova torre }\end{array}$ & $\begin{array}{l}\text { Inovação incremental dos componentes internos da torre, passando do } \\
\text { tipo evaporativo para o hidro-cooler. Modernização das hélices } \\
\text { (aerodinâmica mais simples e eficiente), do material da estrutura (em } \\
\text { alumínio), dos aspersores externos (que ajudam a resfriar o sistema } \\
\text { em dias excessivamente quentes) e do circuito interno (fechado com } \\
\text { consumo mínimo de água) }\end{array}$ & Mén \\
\hline
\end{tabular}

A equipe ainda pretende introduzir uma melhoria contínua com a instalação de uma bandeja de captação de água dos aspersores, gerando economia de água. Esses resultados corroboram com as observações de Murmann e Frenken (2006) sobre a dificuldade de mudar, com sucesso, os componentes com alta pleitropia. É por isso que as modificações são direcionadas, quando se trata de projetos dominantes, para os componentes periféricos com baixa pleitropia. A mudança de componentes de alta pleitropia viria com inovações radicais, como por exemplo, a substituição completa de todas as torres de resfriamento, o que implicaria em altos custos e riscos. As barreiras para a inserção de novas tecnologias em infraestruturas dominantes podem ser minimizadas quando as mudanças são efetuadas gradualmente com redundâncias e respeitando as granularidades, as pleitropias e o escopo dos artefatos. Esses achados explicam o porquê uma infraestrutura de facilidades pode ser considerada um sistema tecnológico dominante, local, adaptativo, hierarquizado e com alta pleitropia.

SINOPSE 6a: uma infraestrutura de facilidades pode ser considerada um sistema tecnológico dominante, local, adaptativo, hierarquizado e com alta pleitropia, surgida por decisões técnicas e institucionais que geram isomorfismo e inércia tecnológica.

SINOPSE 6b: os níveis das mudanças nas facilidades são diretamente proporcionais aos impactos no sistema como um todo: quanto mais próximas as mudanças estiverem dos componentes centrais, maiores serão os riscos gerados para a infraestrutura.

SINOPSE 6c: as redundâncias operacionais amortecem os impactos da alta pleitropia em subsistemas considerados centrais, podendo adquirir características periféricas de baixa pleitropia com efeitos sobre os atributos do sistema minimizados. 


\subsubsection{Mecanismos causais e aprendizagem infraestrutural}

Uma das questões que surgiu quando se iniciou a análise do caso foi a razão da escolha por uma tecnologia importada (as primeiras torres eram americanas). Seriam essas antigas torres tecnologias dominantes? O último parque de torres de resfriamento (onde está a nova torre) foi comprado no projeto plataforma FIESTA na década de 1990. Invariavelmente, as automobilísticas americanas possuem suas preferências e acordos contratuais, deixando-as enrijecidas quanto às novidades do mercado nacional, pois muita da tecnologia para infraestrutura não é produzida no país. Tanto a escolha das marcas das torres como o layout operacional, foram trazidos pela equipe de engenheiros americanos responsáveis pela implantação da nova plataforma, dificultando, em tempos mais recentes, novas reposições, modificações ou aquisições. Essas premissas poderiam explicar, em parte, porque dada infraestrutura será dominante. Como lembra Cowan (1990), quando analisou a dominância de certas tecnologias das estações de energia nuclear, a aceitação de uma tecnologia emerge da combinação de escolhas e decisões políticas, sociológicas e organizacionais e não apenas técnicas.

Segundo o entrevistado, durante muito tempo, os técnicos da área de facilidades tiveram que improvisar, por exemplo, a confecção de hélices das torres, com fornecedores locais, porque os fornecedores estrangeiros não mais fabricavam os mesmos modelos. Esse fato reforça a necessidade de tecnologias para infraestruturas intercambiáveis, em função da oferta que, ao longo das décadas, tende a mudar ou deixar de existir. A dominância de uma tecnologia de infraestrutura ocorre não apenas na aquisição da instalação, mas quando a mesma adere à realidade operacional local passando a funcionar com eficiência mínima e dada como certa.

Se por um lado a padronização de uma tecnologia cria isomorfismo no mercado, facilitando a curto e médio prazo a reposição de componentes, a longo prazo a mesma padronização pode prejudicar (pela falta de oferta) o ciclo de renovação dos ativos de uma organização, tornado-a vulnerável. Nesse período de vulnerabilidade, as equipes técnicas podem beneficiar-se buscando soluções locais com o uso da improvisação. Aliás, essa foi uma das estratégias adotadas pela equipe responsável pela implantação da nova torre.

Os técnicos relataram que muitas vezes as especificações do projeto não eram adequadas à realidade do sistema. Para isso, técnicas não usuais como a sensorial (para buscar ajustes por 
meio de vibrações, ruídos e calor emitidos pelos equipamentos) e usuais (manômetros para pressão e fluxo) foram utilizadas. Juntas, permitem a equipe minimizar os efeitos negativos da transposição de um novo artefato para um sistema em funcionamento. Dá-se nesse momento o que Leonard-Barton (1988) aponta como inovação na implantação, isto é, na busca do melhor ajuste entre as especificações e o contexto operacional local, os grupos podem inovar (a inovação passa a ser o meio e não o fim do processo de mudança). No caso da nova torre, a inovação se deu no posicionamento, no ângulo e na interligação com o velho sistema, tornando-o uníssono novamente.

Em relação ao conhecimento utilizado na implantação da nova torre, o especialista entrevistado aponta que experiências passadas, como as em otimizar equipamentos (geralmente em virtude dos superdimensionamentos dos projetos), foram as mais frequentes. A habilidade de otimizar sistemas foi reforçada pela necessidade operacional dos grupos autônomos de manutenção que, muitas vezes, eram ignorados na fase de anteprojeto e na implantação do parque de torres pelos especialistas estrangeiros, herdando sistemas alienados do contexto local (por exemplo, o excesso de torres e a instalação de chillers - equipamentos de apoio utilizados em países extremamente quentes). O parque foi comprado em pacote (caixa preta), não permitindo adaptações locais, que essas só ocorreriam ao longo dos anos, na busca do melhor "encaixe" operacional entre o que foi projetado e a realidade funcional dos parques. O "encaixe" operacional remete ao conceito de adaptação de Holland (1995) como um processo por onde um organismo (no sentido biológico) se ajusta ao ambiente.

Percebe-se que os profissionais se beneficiaram do chamado "aprender usando", em função de sua larga experiência e de contato com os equipamentos e do "aprender fazendo", como não seria a primeira vez que eles rearranjavam as torres, utilizando o termo empregado por Cowan (1990) para análise do caso da dominância dos reatores nucleares.

Bell (1984) trabalha com os termos "aprendizado por operação" e "aprendizado por modificação", ambos perfeitamente aplicáveis ao caso analisado. Para Bell os dois tipos de aprendizado são baseados no fazer, frequentemente adquiridos pela aquisição de capacidade tecnológica, sendo o primeiro em resposta a micro alterações operacionais (pequenas modificações técnicas) e o segundo pelo entendimento da relação causa e efeito que tais modificações podem gerar no desempenho operacional. Entretanto, como observado pelo autor, são aprendizados passivos, de baixo custo e automáticos. Sob outra perspectiva não 
apontada por Bell, a das mudanças técnicas em facilidades, pôde-se notar que apesar de uma planta industrial, aparentemente, sobreviver em inércia sem modificações, a própria inércia seria sustentada por pequenas modificações (melhorias). Somados aos aprendizados de Bell, destacou-se no caso o "aprendizado por simulação", sendo aquele gerado pelas inúmeras manobras e otimizações operacionais realizadas pelos manutentores das torres. As manobras possibilitariam testes em diversas situações reais, inclusive do controle do desempenho dos equipamentos, que, ao longo do tempo, traria conhecimento e aprendizado do funcionamento do sistema (parques de torres) como um todo. Denominar-se-á aprendizagem e conhecimento infraestruturais aqueles que reunem aprendizados por operação, por modificação e por simulação.

Sennet (2009) aponta que esses conhecimentos práticos se originam no ato de fazer reparos. Para ele, os consertos podem ser estáticos ou dinâmicos. Os estáticos é composto pelo ato de isolar alguma coisa, descobrir e reparar o que está errado, recompondo o estado anterior do objeto. Já os dinâmicos implicam em mudar a forma ou função atual do objeto depois de remontado.

Como destacam Murmann e Frenken (2006) entender a causalidade entre inovação e ambiente institucional não é tarefa simples tamanha a quantidade de interesses e atores envolvidos. É válido também para os ganhos esperados da inovação. No caso da nova torre, tinha-se uma expectativa de aumento da eficiência operacional (delta de no mínimo $6^{\circ} \mathrm{C}$ ) e redução do consumo de água. Até o momento da pesquisa, só a redução do impacto ambiental foi o realmente atingido. Enquanto as torres antigas consomem em média de $465 \mathrm{~m}^{3}$ de água por mês, a nova utiliza $13 \mathrm{~m}^{3}$. Independente dos primeiros resultados, o entrevistado afirmou que essa inovação foi só o início:

“[...] nós já começamos a elaborar o próximo projeto para compra de uma nova torre, pois já temos outras duas torres (uma para o compressor e outra para o processo) fora de operação dada a péssima condição das mesmas, deixando nosso sistema sem redundância".

SINOPSE 7a: uma inovação ou melhoria em facilidades pode surgir da improvisação para adequação e encaixe das especificações técnicas à realidade local.

SINOPSE 7b: o conhecimento e aprendizagem infraestruturais utilizados nas inovações e melhorias em facilidades vêm do "aprender usando" (otimização operacional e sensorial dos técnicos ao longo dos anos), do "aprender fazendo" (tentativas e erros) na busca de eficiência mínima e do "aprender simulando" (por meio de manobras operacionais) . 
SINOPSE 7c: a mudança técnica num sistema complexo, como o apresentado, ocorre em partes, pois é necessário que se avalie o impacto de cada passo, num ciclo constante de aperfeiçoamento.

\subsubsection{Seqüência temporal : as etapas de implantação da inovação e melhoria}

Para Utterback e Abernathy (1975), a sequência temporal, dentro do estudo dos artefatos tecnológicos, ajuda a entender a evolução particular dos mesmos. As inovações tradicionais possuem fases marcadas por períodos de descontinuidade tecnológica, era de fermentação (variação), seleção de uma tecnologia dominante, era das inovações incrementais (retenção) e, novamente, uma descontinuidade tecnológica. Para as inovações em facilidades o ciclo se repete, como pode ser visto na Figura 19, mas numa dimensão temporal estendida e peculiar. Estendida porque ela pode demorar décadas e perpassar vários ciclos de inovações dos produtos e processos da mesma organização, dando uma falsa impressão de inércia. Peculiar, pois se esperam das inovações tradicionais ciclos constantes de renovação, o que não ocorre nas em facilidades, dada a dominância e alta pleitropia discutidas na seção anterior. A Figura 19 ilustra as principais inovações em produtos, processos e organizacional, da planta de São Bernardo do Campo, entre os períodos de 1994 e 2009. Essa faixa foi escolhida por ser o período entre o comissionamento do antigo parque de torres de resfriamento e a aquisição da nova torre de resfriamento - objeto de análise.

Adicionalmente, para Utterback e Abernathy (1975), os tipos de inovações estariam relacionados aos estágios das organizações. Empresas maduras, como as montadoras, estariam numa fase chamada sistêmica. Nessa fase a estratégia da empresa é minimizar custos e estimular as mudanças em função dos ganhos de produtividade. Exatamente esse foi o cenário do local onde a inovação analisada ocorreu, como relatado pelo entrevistado:

“[...] se podemos ser bem objetivos: custo operacional e de manutenção e aspecto ambiental foram os ganhos da inovação".

Analisando a linha do tempo da inovação em facilidades (torre) com as demais (produto, processo e organizacional), verifica-se que surgem ciclos distintos se aproximando do modelo dinâmico de Utterback e Abernathy (ibid). A construção do gráfico foi resultado de entrevistas com profissionais antigos e sítio oficial da empresa na internet. As inovações consideradas mais radicais, para efeito de ilustração, receberam uma pontuação alta (10) e as 
inovações incrementais e melhorias contínuas, uma razoável (5). Essa pontuação é apoiada apenas na percepção do entrevistado em relação à complexidade e ao efeito das inovações para os clientes internos ou externos e sua função é meramente ilustrativa.

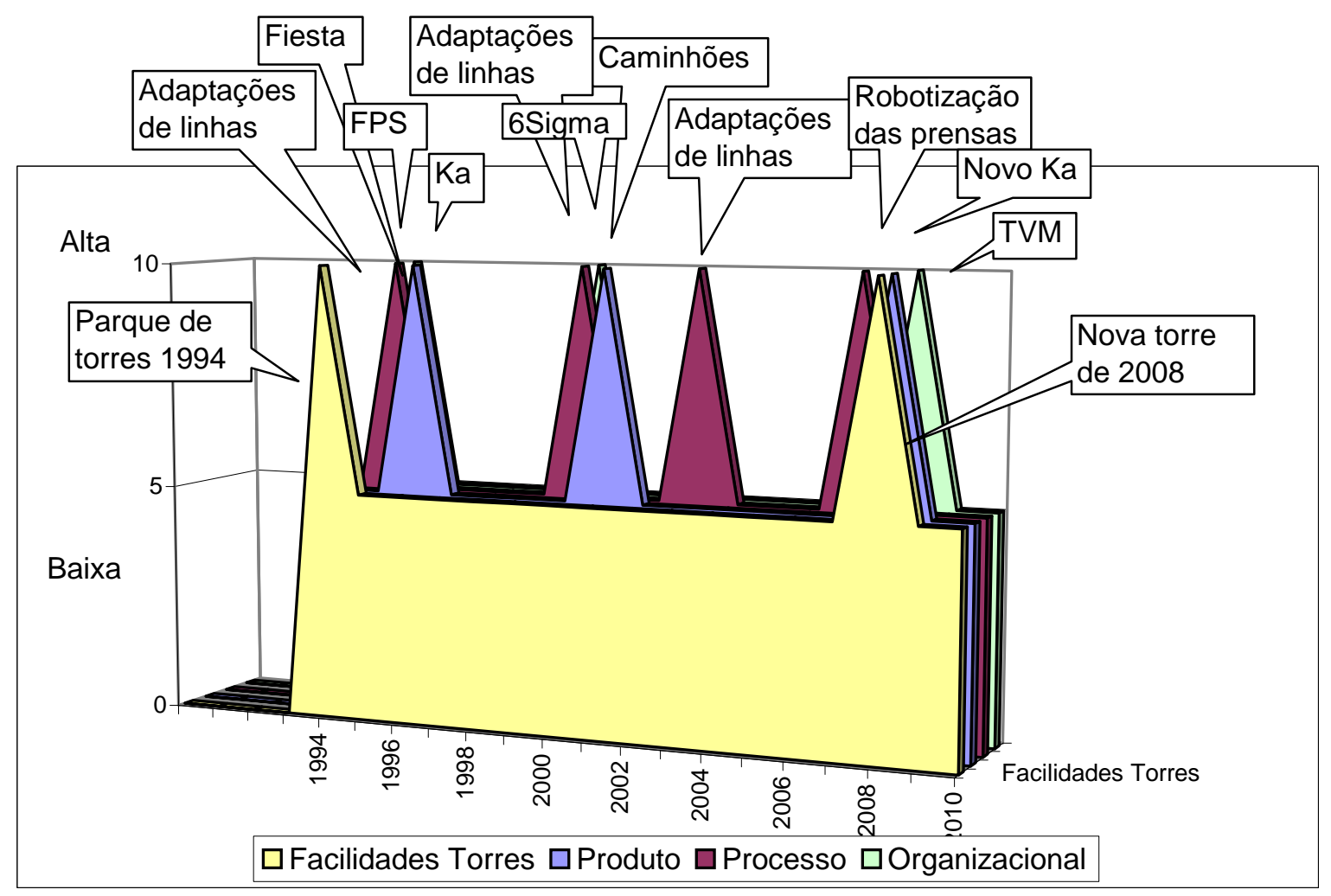

Figura 19 - Principais eventos do caso analisado

A Figura 19 mostra no plano frontal os dois picos de inovação em facilidades ocorridos na aquisição do parque de torres, no ano de 1994, e na última torre instalada em 2009. A lacuna entre as duas datas foi preenchida por pequenas melhorias contínuas oriundas dos grupos autônomos de manutenção, fortalecidos principalmente pela adoção de práticas dos movimentos da qualidade chamadas de FPS - Ford Production System, também na mesma década. As melhorias foram sempre voltadas para pequenas alterações dos equipamentos como a instalação de sensores de níveis, temperaturas e pressões que facilitariam as inspeções de manutenção, a instalação de dosadores automáticos de cloro para a desinfecção das bacias de água, entre outras.

A implantação do parque de torres precederia as mudanças ocorridas nos processos produtivos para receberem as novas plataformas trazidas da Europa (FIESTA em 1996 e KA 
em 1997). Em 2001, a planta de Caminhões do Ipiranga, bairro do município de São Paulo, seria transferida para o complexo industrial de São Bernardo do Campo, no Grande ABC, inaugurando a fabricação de caminhões e pickups na planta. No mesmo ano, outra inovação organizacional, o Seis Sigma, aparece como ferramenta de análise e decisão dos projetos da empresa (a aquisição da nova torre foi objeto de um projeto dessa natureza).

A estamparia, no ano de 2006, faria as mudanças dos processos manuais para automáticos (com o uso de robôs), preparando o último novo modelo - Novo Ka, que muito utilizaria a metodologia TVM - total value management para minimização de custos. É nesse momento de renovação que a nova torre é instalada (ela faz parte de um pacote de renovação tecnológica das infraestruturas na qual a planta industrial passará nos próximos anos). A Figura 20 é uma adaptação do modelo dinâmico das inovações de Utterback e Abernathy (1975), agora com um novo ciclo - o da inovação em facilidades.

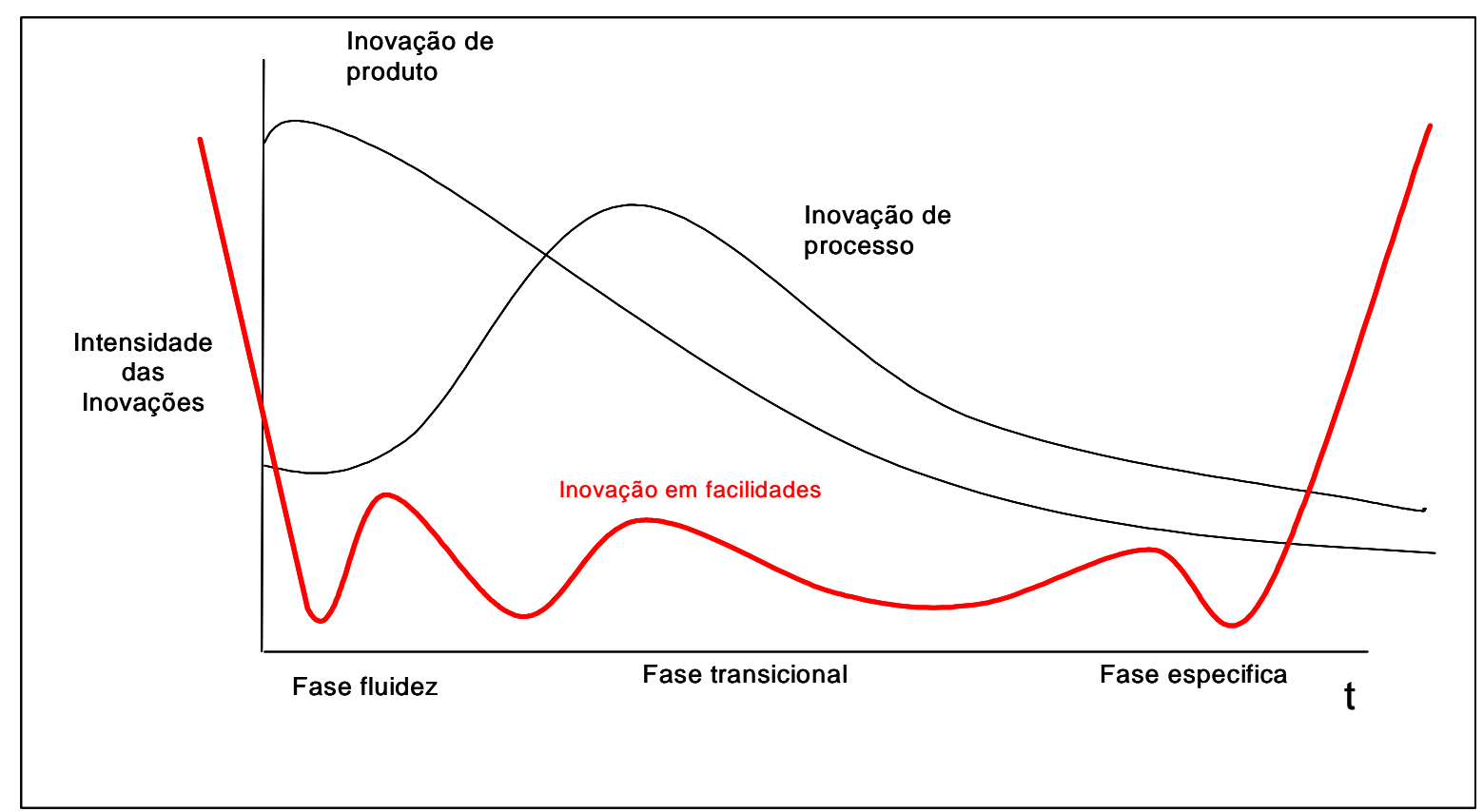

Figura 20 - O modelo da dinâmica das inovações reformulado

Fonte: Adaptado de Utterback (1996)

As inovações em facilidades, Figura 20, parecem surgir antes das em processos, pois ela prepararia as bases tecnológicas para as operações das empresas. Uma vez implantados esses artefatos, eles passam a ser dominantes (ANDERSON e TUSHMAN, 1990), em função da complexidade técnica dos recursos neles alocados, do isomorfismo tecnológico e do encaixe ou ajuste operacional. Essa dominância sedimentará uma determinada trajetória tecnológica de infraestrutura que moldará, ao longo dos anos, as próprias inovações em processos, produtos e organizacionais da empresa. Além dos motivos econômicos, políticos, sociais e 
mercadológicos não explorados em profundidade nesse estudo, a tomada de decisão para a escolha de uma planta industrial para a produção de um produto ou serviço passará pela análise das facilidades (instalações físicas, layout etc), já que as inovações ou melhorias contínuas em facilidades são antecedentes, na linha do tempo, das demais inovações. Da mesma maneira ela é ulterior a todas, pois a fase de descomissionamento de uma instalação fomenta novas inovações e melhorias nas facilidades, no intuito de postergação ou manutenção do ciclo de vida dos ativos e para evitar mitigações futuras causadas por impactos ambientais.

Especificamente no caso das torres, o cronograma da implantação foi marcado por quatro grandes etapas que duraram 300 dias, consumindo 1119 horas de trabalho e incluindo atividades de engenharia:

- Estudo: fase iniciada em 2008 pelas áreas de facilidades e compras da Ford que buscaram, no mercado, fornecedores capazes de instalarem uma nova torre com tecnologia intercambiável com o sistema já em operação. Nessa etapa, as especificações técnicas iniciais foram elaboradas para a norma de concorrência;

- Verbas: para a etapa de aprovações de verbas, o tempo de engenharia gasto foi em função de explicações e argumentações junto ao departamento de finanças. Esse processo não consumiu tempo da engenharia, mas de articulação política para liberação de recursos, uma vez que o foco principal da empresa era reduzir custos operacionais;

- Construção, instalação e adaptação: a etapa de construção da nova torre ocorreu na empresa contratada que trabalhou numa espécie de plataforma de torres, que era a base para as famílias possíveis, dentre elas a de hidro-cooler. A primeira versão construída e instalada não deu certo. Problemas como os posicionamentos da mesma impediram resultados satisfatórios no OEE final. Uma segunda versão, adaptada de acordo com o contexto local, permitiu o encaixe operacional mínimo trazendo desempenho ainda que não dentro das especificações iniciais;

- Entrega/comissionamento. a entrega da torre foi em duas etapas: o chamado tryout, que é o acionamento da torre no local de fabricação junto aos técnicos da contratante e o start-up, o acionamento no local da instalação. Após a entrega, há o serviço de baby-sister por um mês para acompanhamento do sistema e eventuais desajustes. 


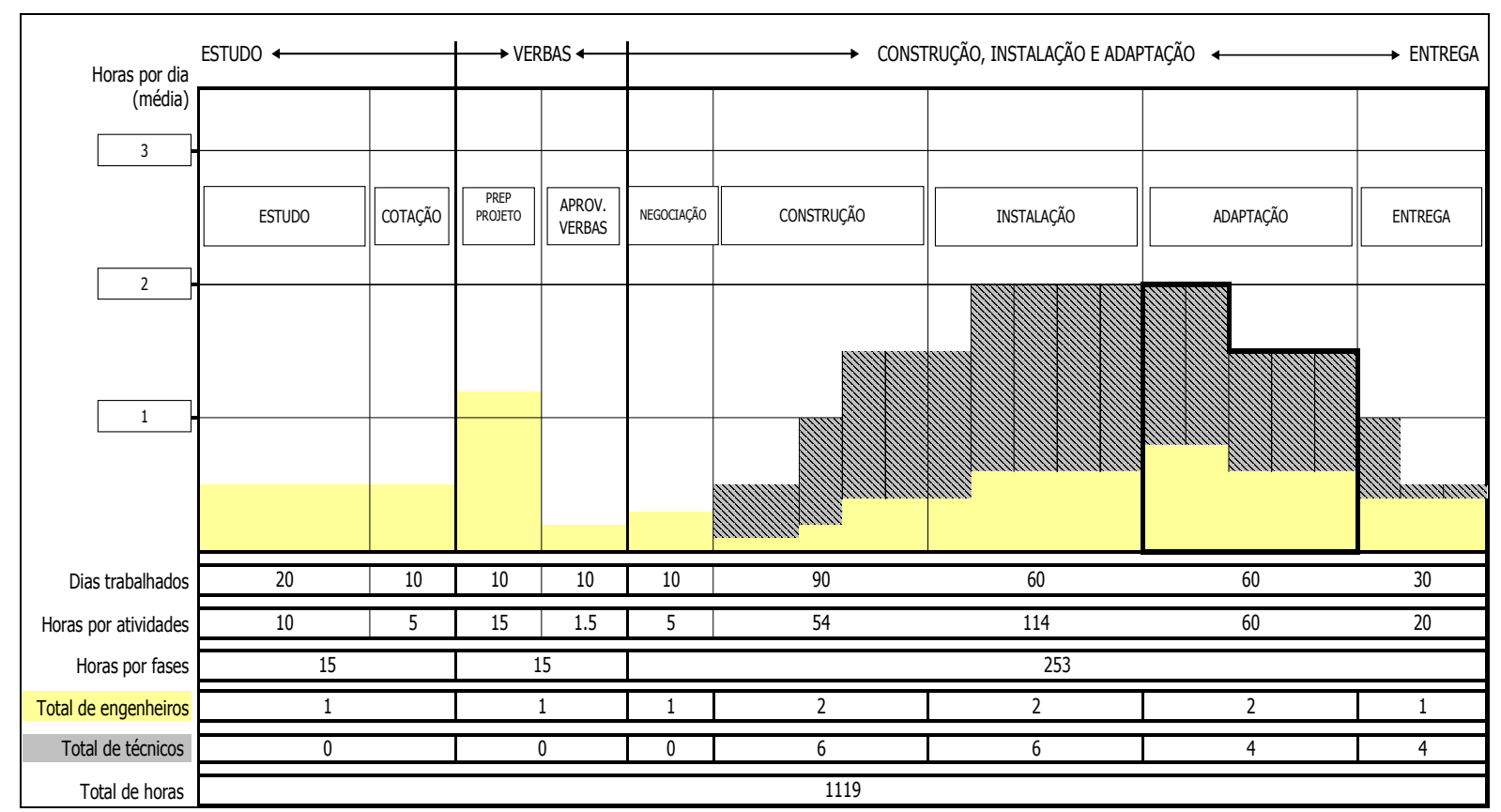

Figura 21 - 0 cronograma da implantação e recursos do caso analisado

A Figura 21 mostra no eixo vertical o tempo (hr) alocado por dia somente para o projeto da torre. No eixo horizontal estão as principais fases da implantação dessa inovação. As cores sinalizam a participação das engenharias e dos técnicos. Observa-se uma etapa bastante peculiar em projetos que é a da adaptação da tecnologia no novo contexto. Aparentemente a inovação não está apenas na nova torre, mas principalmente em como encaixá-la no contexto operacional da empresa. Esse esforço de encaixe é que se daria a inovação na implantação. Curiosamente, o tempo dessa adaptação poderia ser reduzido, segundo o entrevistado, caso os técnicos participassem das fases iniciais do projeto, minimizando erros ou retrabalhos futuros. Constatou-se que o projeto seguiu uma estratégia top-down até a etapa de construção, o que significou dispêndio de recursos nas seguintes. Quando se notaram dificuldades técnicas de ajustes da torre no antigo sistema, ocorreu a inversão de estratégia, agora do tipo bottom-up, com envolvimento direto dos técnicos e operadores do sistema nas melhorias contínuas e inovações.

SINOPSE 8a: uma inovação nas facilidades, frequentemente, é gerada em ciclos longos que perpassam os dos processos e produtos, dando uma falsa idéia de inércia.

SINOPSE 8b: na implantação de uma inovação ou melhorias nas facilidades pode possuir uma etapa de adaptação que será menor à medida que as equipes trabalhem numa estratégia de bottom-up, aumentando a participação dos técnicos nas primeiras etapas do projeto. 


\subsection{Survey}

Nessa seção são discutidas as etapas referentes ao survey realizado entre os meses de abril e dezembro de 2009. Inicialmente, discutir-se-á sobre os pilotos conduzidos antes e depois da banca de qualificação, ocorrida em julho de 2009, permitindo o delineamento e aperfeiçoamento do instrumento de coleta. Em seguida, a aplicação do instrumento no público-alvo, do teste de validação e, por fim, a coleta e a análise dos resultados.

\subsubsection{Fases pilotos para elaboração do survey}

O delineamento do instrumento de coleta aplicado no survey contou com duas etapas: a primeira foi a formatação gerada após as fases empíricas que resultaram num questionário estratificado em 35 questões, sendo 9 assertivas e 26 classificatórias. Esse pré-piloto foi realizado em abril de 2009 com 30 alunos do curso de pós-graduação em gestão de manutenção de uma AES, localizada no Estado de São Paulo (APÊNDICE F). Concluiu-se, após apresentação à banca de qualificação em julho de 2009, ao Consórcio Doutoral do ENANPAD 2009 (QUINELLO, 2009b) em setembro do mesmo ano e análise dos resultados, que as questões assertivas estavam numa escala Likert entre 1 e 5 (em grau de concordância) equivocada e mal posicionada. Além disso, algumas questões classificatórias estavam inadequadas e outras incompletas.

Em relação às questões assertivas, percebeu-se que quando se questionava o respondente em relação a sua concordância sobre o impacto da inovação nos fatores de eficiências e financeiros, possíveis vieses seriam criados caso fossem utilizadas frases imbuídas de verbos quantificadores (reduzir, melhorar e aumentar). Quanto a questão de localização, as questões assertivas (críticas para esta tese) estavam no final do questionário, implicando em uma possível distração dos respondentes, já que teriam respondido anteriormente 26 questões classificatórias. As correções feitas foram na neutralidade das sentenças e na aproximação das assertivas para o início do questionário.

Nas questões classificatórias, verificou-se que algumas características relativas às empresas e a própria inovação estavam mal formuladas e categorizadas, dificultando a estratificação das amostras na fase de análise dos resultados. Utilizando as observações da banca de qualificação, acrescentaram-se questões classificatórias para descrição da empresa, como o setor e perfil; da inovação, como localização e motivação; e do inquirido, como nível 
hierárquico e formação acadêmica. Após essas correções, obteve-se o questionário para o piloto. Também se destacaram algumas dimensões de impacto consideradas importantes como as de produtividade, de satisfação, de eficiência, de qualidade e de custos.

O piloto (APÊNDICE G) realizou-se em setembro de 2009, com uma nova turma do curso de pós-graduação de gestão de manutenção da mesma AES da etapa anterior à qualificação (15 alunos). Nessa fase, além de se testarem as mudanças propostas no pré-piloto, optou-se por verificar a melhor localização das questões assertivas dentro do questionário. Para isso, o grupo de respondentes foi dividido em 4 subgrupos. Um deles foi escolhido como amostra controle com as questões assertivas postadas logo no início do questionário, juntos no mesmo bloco e na seguinte ordem: produtividade, qualidade, custos, entrega, segurança e saúde, meio ambiente, lucros, participação de mercado e vendas. No segundo grupo, essas questões foram misturadas no início do questionário, no mesmo bloco e na seguinte ordem: qualidade, produtividade, vendas, lucros, meio ambiente, segurança e saúde, participação de mercado, entrega e custos. O terceiro grupo teve os fatores de desempenho financeiro colocados à frente dos de eficiência, no início do questionário e no mesmo bloco: lucros, participação de mercado, vendas, produtividade, qualidade, custos, entrega, segurança e saúde, meio ambiente. O último grupo respondeu às assertivas totalmente misturadas entre as questões classificatórias.

A amostra apresentou consistência interna razoável, porém adequada dada a pequena quantidade de respondente $(\mathrm{N}=15)$ com alpha de Cronbach = 0,64 (PESTANA e GAGEIRO, 2008). As repostas seguiram uma distribuição normal sig >0,05 (teste K-S). A escala utilizada foi a Likert (-2 muito negativo, -1 negativo, 0 neutro, 1 positivo, 2 muito positivo). As dispersões das pontuações foram semelhantes em quase todas os fatores analisados (teste Levene com sig >0,05), com exceção dos fatores PRODUTIVIDADE e SEGURANÇA/SAÚDE que variaram mais intensamente. Para analisar as quatro situações de localizações das assertivas no questionário, Pestana e Gageiro (2008) recomendam o uso do teste Kruskall-Wallis, onde foram lançadas as hipóteses:

- H0: Os quatro grupos são iguais em tendência central quando analisadas as pontuações dos fatores;

- H1: Existe ao menos um grupo que difere em tendência central quando analisadas as pontuações dos fatores. 
Tabela 4 - Testes de significância dos fatores de desempenho e financeiro da fase piloto

\begin{tabular}{|l|r|r|r|r|r|r|r|r|r|}
\hline \multicolumn{10}{|c|}{ Test Statistiçs } \\
\hline
\end{tabular}

A Tabela 4 aponta que todos os fatores possuem nível de significância (asymp.sig) maiores que 0,05 , indicando que não há como rejeitar a hipótese nula, isto é, os grupos são iguais em tendência central quando analisadas as pontuações desses fatores. Dessa forma, como não há diferença na localização dos fatores dentro do questionário, optou-se em utilizar o questionário do grupo 1 - controle.

\subsubsection{Aplicação do survey}

O survey foi lançado no dia 4 de novembro de 2009 e encerrado dia 10 de dezembro de 2009 para um público-alvo de aproximadamente 10.000 profissionais da área de facilidades. Para isso, contou-se com um gerenciador on-line chamado SURVEYPRO que enviou, através da internet, o questionário consolidado (APÊNDICE A). O público foi selecionado das seguintes fontes: INFRA - revista especializada de profissionais da área, ABRAFAC - Associação Brasileira de Facilities, PLAXO - rede de relacionamento profissional e UNIFEI - alunos de pós-graduação de manutenção. Alguns contatos foram feitos individualmente através do conhecimento do pesquisador. Ainda foram realizadas duas chamadas e convites direcionadas por meio da ABRAFAC e da revista eletrônica INFRA junto aos seus membros, reforçando a colaboração necessária para a empreitada. Foram obtidas 49 respostas válidas (dentro dos limites esperados de 45 a 500 respondentes), conforme resumo do Apêndice K. Não foi possível coletar mais de uma inovação por empresa, desse modo os resultados representam o ponto de vista dos profissionais e não das empresas.

Para validação das repostas relacionadas aos impactos das inovações nos fatores de desempenho, optou-se por uma segunda coleta com cinco inquiridos sorteados aleatoriamente entre a amostra principal (10\% da amostra, APÊNDICE J). O objetivo desse teste foi verificar se o tempo (intervalo de 30 dias entre a primeira e segunda amostras) influenciaria as 
respostas dos profissionais. Utilizando o Wilcoxon test para amostras emparelhadas com variáveis ordinais (PESTANA e GAGEIRO, 2008), onde H0 (hipótese nula) seria duas amostras apresentando semelhanças estatisticamente significativas e H1 (hipótese alternativa) se as mesmas eram diferentes. Chegou-se a um p-value de 0,808 (com intervalo de confiança de $95 \%$ ), ou seja, não se pode rejeitar a hipótese nula. Desse modo, conclui-se que as duas amostras, apesar do intervalo de tempo, são semelhantes.

Test Statistics

\begin{tabular}{|l|c|}
\hline & $\begin{array}{c}\text { COLETA2 - } \\
\text { COLETA1 }\end{array}$ \\
\hline$Z$ &,$- 243^{\mathrm{a}}$ \\
Asymp. Sig. (2-tailed) &, 808 \\
\hline
\end{tabular}

a. Based on positive ranks.

b. Wilcoxon Signed Ranks Test

Nas próximas seções, analisar-se-ão, individualmente, as dimensões gerais da tese: o perfil das empresas, dos respondentes, das inovações e dos impactos gerados. Em seguida, essas dimensões foram mescladas com análises multivariadas a fim de descobrir padrões ou arranjos peculiares.

\subsubsection{Perfil das empresas}

Em relação aos dados classificatórios, tem-se, na grande maioria, empresas nacionais (53\%), de grande porte $(73 \%)$ e com mais de 20 anos de vida (75\%), sugerindo ambientes organizacionais maduros e com experiência no mercado, de acordo com Gráfico 4. 


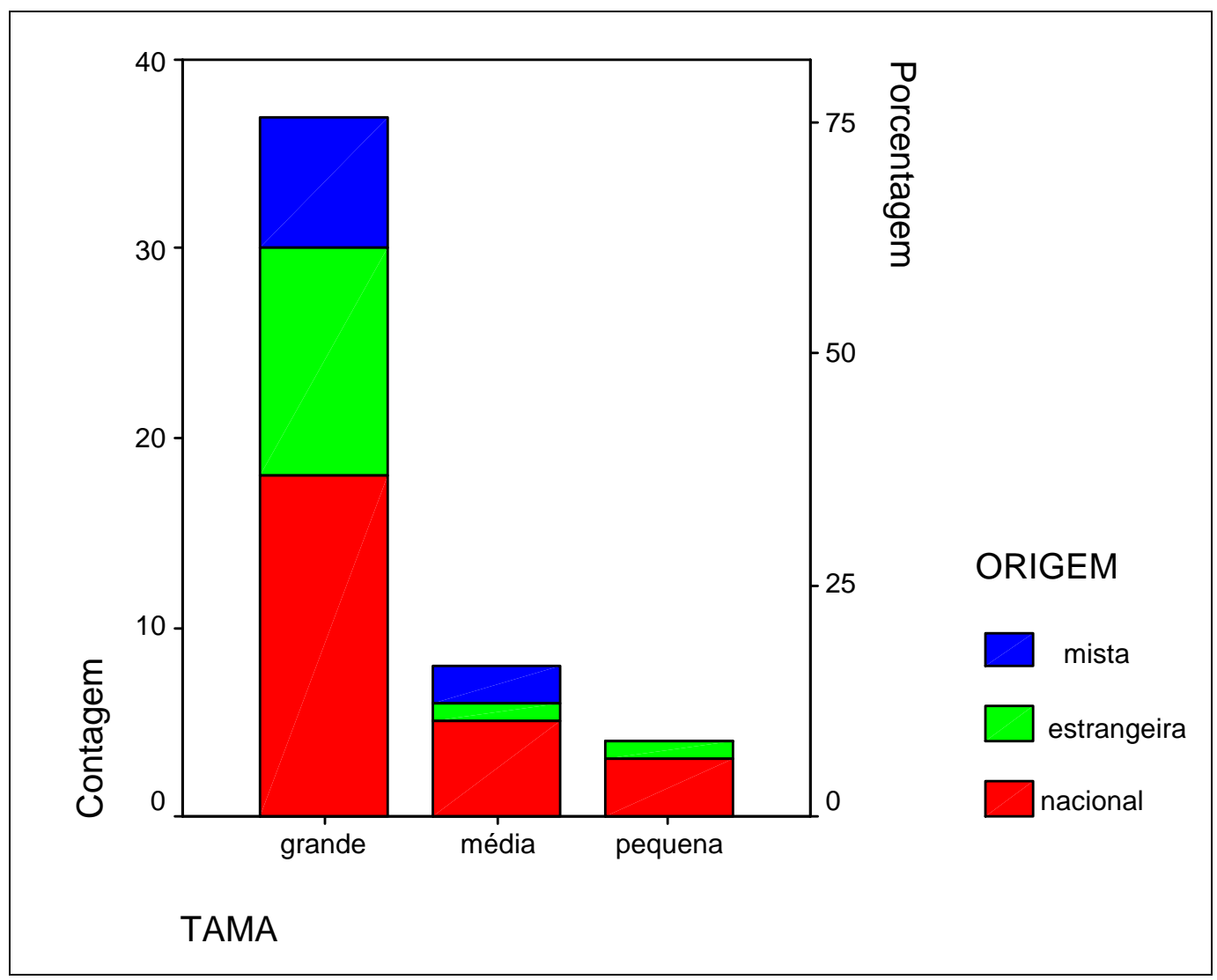

Gráfico 4 -Origem e tamanho das organizações

Segundo o Gráfico 5, a maior parte da amostra (26\%) pertencia ao setor industrial, seguido pelo de atividades administrativas e serviços complementares (16\%) e os financeiros $(10 \%)$. Há também um grupo formado por empresas de informação (8\%) e de construção (6\%). Possivelmente, em ambientes industriais de grande porte, as áreas de facilidades encontrem mais espaços dentro das estruturas organizacionais formais, indicando que nesse setor essa atividade possa estar mais avançada e consolidada do que nas demais. 


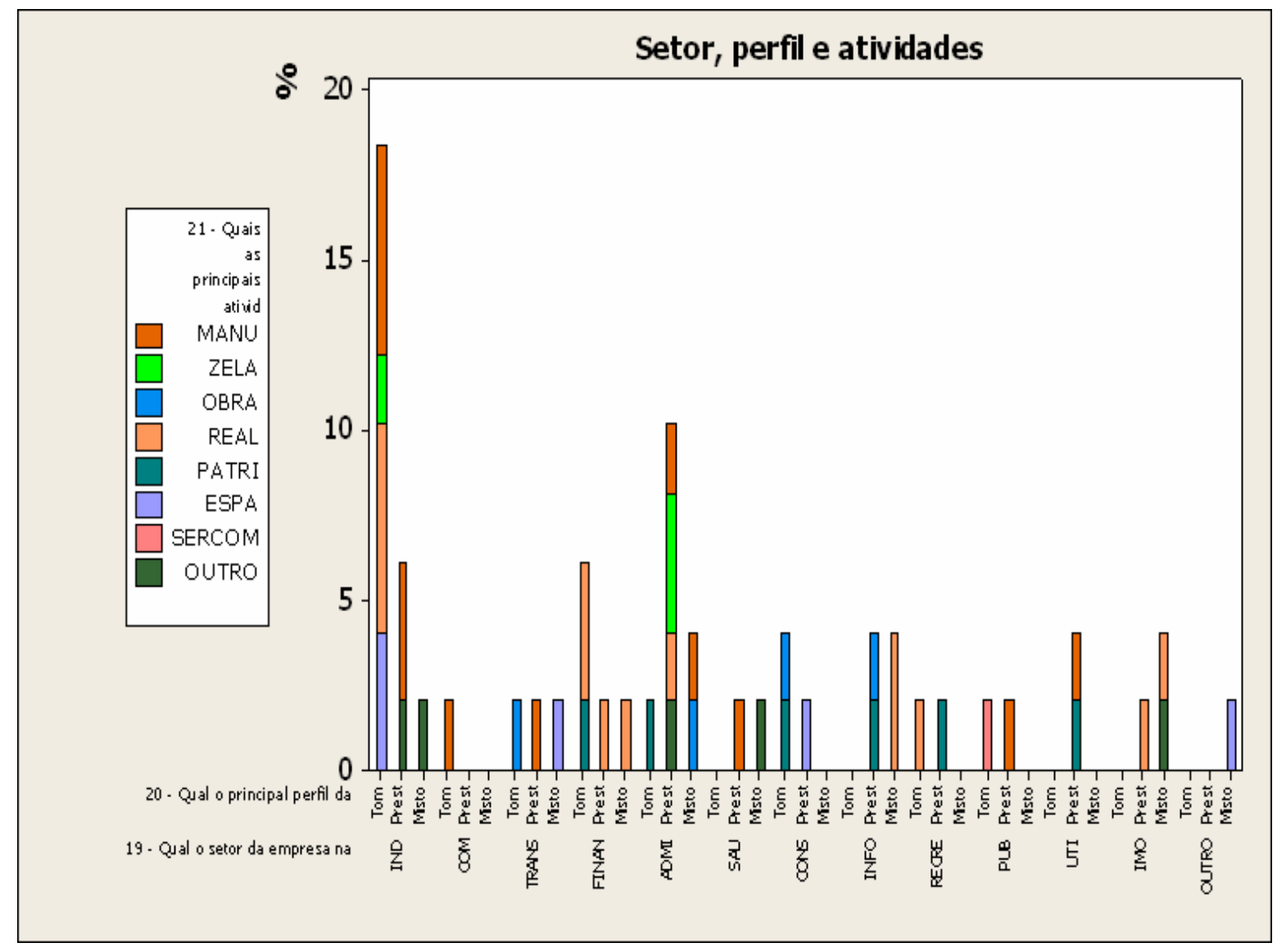

Gráfico 5 - Setor, perfil e atividades das organizações.

Dando continuidade ao perfil das empresas, elas se dividiram igualmente em tomadoras (38\%), com mais ocorrência no setor industrial, e em prestadoras (38\%) de serviços com mais freqüência nas atividades administrativas, provavelmente em função dos fortes movimentos de terceirização após os anos 1980 no Brasil. Para as principais atividades exercidas pelo departamento de facilidades, $22 \%$ exerciam atividades de manutenções em geral, $14 \%$ de obras e reformas, $11 \%$ administração de imóveis, $11 \%$ zeladoria, 9,8\% gerenciamento de espaços e 8,3\% utilidades, ratificando a pesquisa empreendida pela ABRAFAC em 2005 (ABRAFAC, 2006). A área de facilidades é reconhecidamente multidisciplinar e essa condição pôde ser verificada na dispersão quase uniforme das colunas estratificadas do Gráfico 5. 


\subsubsection{Perfil dos respondentes}

Quanto aos respondentes, 63,3\% tinham até quinze anos de experiência e 36,7\%, mais que dezesseis. Eram 49\% com pós-graduação, demonstrando baixa oferta de cursos de pósgraduação na área de facilidades, impedindo a formalização, como ocorre em países desenvolvidos, da profissão. Os dados também apontam que a atividade de facilidades seria aprendida na prática e não nos bancos escolares.

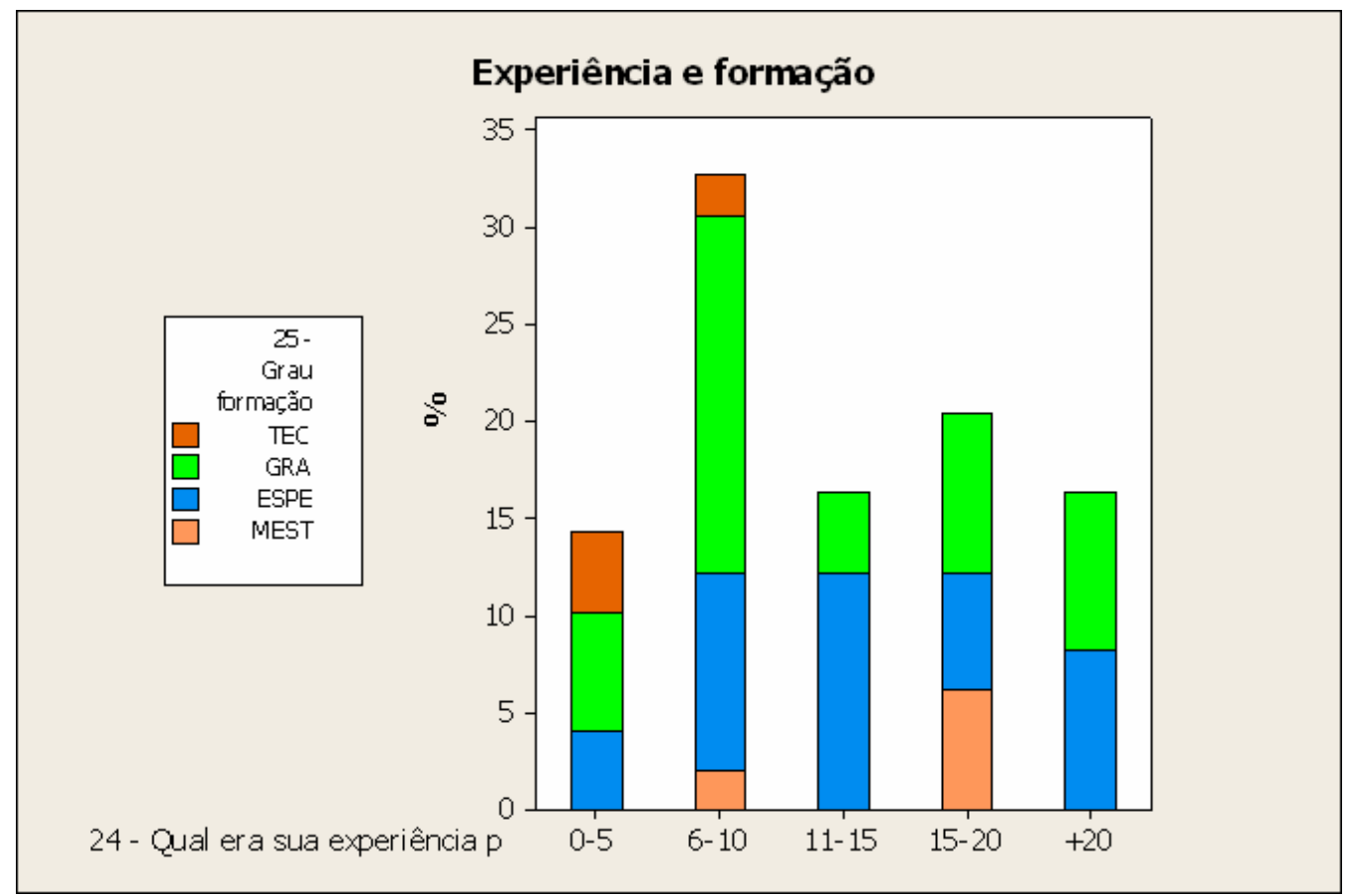

Gráfico 6 - Experiência e formação dos respondentes

Para os cargos ocupados na época da inovação descrita (Gráfico 7), 72\% eram de comando (31\% supervisores, $35 \%$ gerentes e $6 \%$ presidentes) e $28 \%$ analistas. O departamento respondia, no geral, para a diretoria (segundo escalão na hierarquia - 41\%), para a gerência (terceiro escalão - 39\%), para a presidência (primeiro escalão - 12\%) e supervisão (quarto escalão - 8\%). 


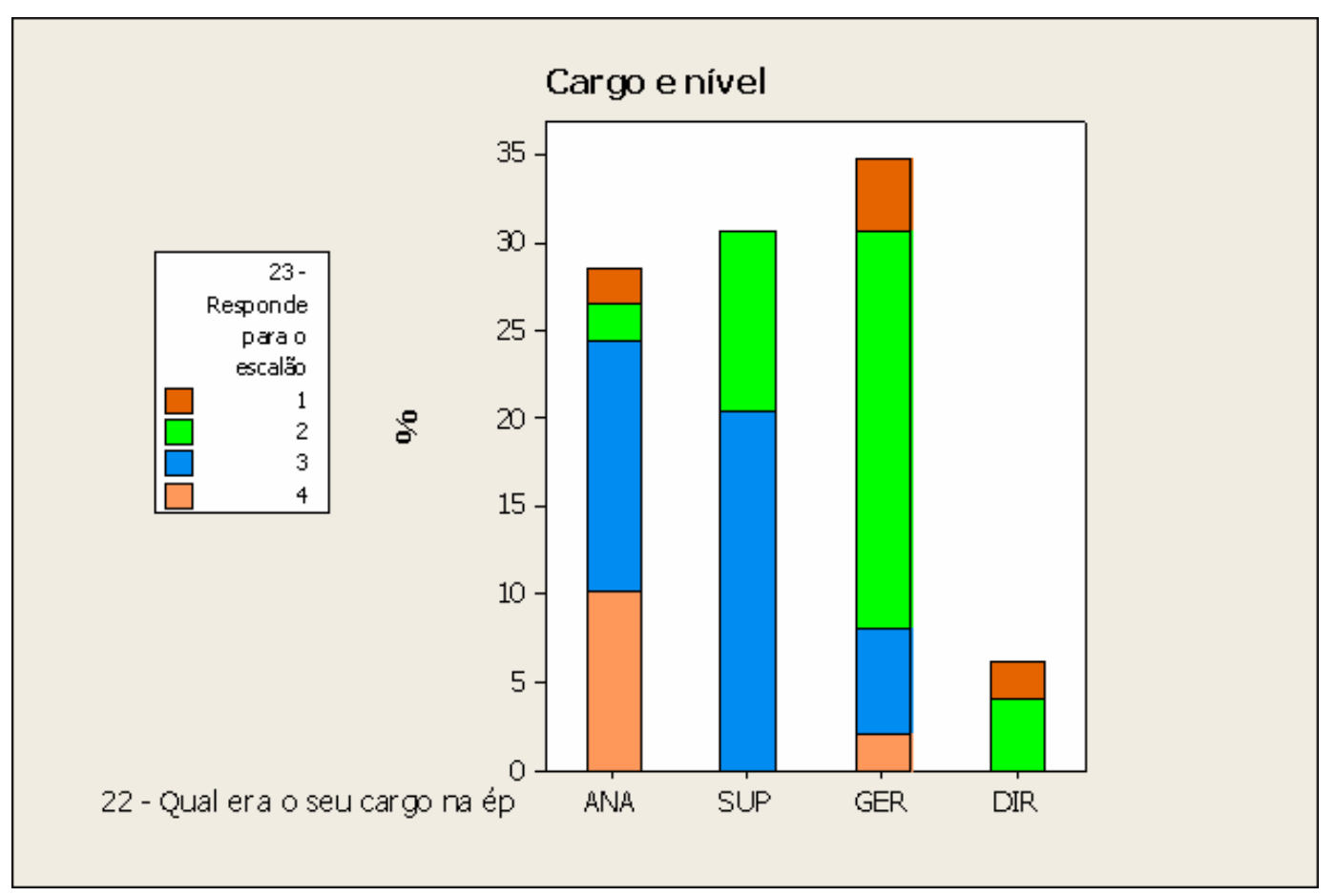

Gráfico 7 - Cargo e nível hierárquico dos respondentes

Resumindo, os respondentes pertenciam e respondiam mais aos níveis estratégicos do que para os operacionais. Entretanto, dada a baixa quantidade de respondentes, não se pode generalizar esse quadro para todo o mercado. De acordo com as observações de Shohet e Lavy (2004) ainda persistem paradoxos na área de facilidades, entre eles: que é uma disciplina estratégica, mas a maioria dos praticantes ainda está nos níveis operacionais das organizações; deseja estar numa posição central das empresas, mas boa parte dos serviços é terceirizada e aspira gerenciar mudanças dentro das organizações, porém ainda seria uma atividade reativa.

SINOPSE 9a: as áreas de facilidades são mais frequentes e formais nas empresas industriais, maduras, de grande porte, exercendo atividades de manutenção, corroborando os achados da etapa de levantamento de dados.

SINOPSE 9b: os gestores de facilidades que responderam o survey eram, em sua maioria, dos níveis estratégicos das organizações, enquanto que os respondentes da etapa de levantamento de dados eram, dos operacionais, indicando alta heterogeneidade das amostras. 


\subsubsection{Características gerais das melhorias e inovações}

Como características gerais das inovações citadas (obtidas pelas modas e desvios-padrão), pode-se dizer que as mesmas estavam focadas sobretudo nos processos industriais das empresas e muito próximas das atividades centrais. Quanto a novidade dessas mudanças, eram majoritariamente melhorias contínuas, de baixo custo e direcionadas para resolução de problemas. Foram obtidas em parcerias em curto período de tempo, utilizando principalmente conhecimentos tácito e informal dos grupos. A seguir, os principais resultados do survey:

Quadro 12 - Características gerais das inovações e melhorias

\begin{tabular}{|c|c|c|c|}
\hline Questões & Moda & $\begin{array}{l}\text { Desvio } \\
\text { padrão }\end{array}$ & Interpretação \\
\hline 6 - Essa inovação ocorreu principalmente: & 2 & 1.77 & $\begin{array}{l}\text { nos processos: equipamentos, } \\
\text { máquinas e dispositivos de apoio às } \\
\text { operações }\end{array}$ \\
\hline 7 - Onde se localiza a inovação: & 1 & 0.48 & principalmente na empresa \\
\hline $\begin{array}{l}8 \text { - Se você pudesse posicionar essa inovação } \\
\text { em relação às atividades centrais da sua } \\
\text { organização, ela estaria:Por exemplo: para uma } \\
\text { automobilística, a atividade central é a } \\
\text { fabricação de veículos. }\end{array}$ & 5 & 1.38 & muito próxima das atividades centrais \\
\hline 9 - Aponte qual a intensidade da inovação: & 2 & 0.66 & $\begin{array}{l}\text { nova para a empresa, mas já existe no } \\
\text { mercado nacional }\end{array}$ \\
\hline $\begin{array}{l}10 \text { - Qual foi o custo para implantação da } \\
\text { inovação }(\mathrm{R} \$) ?\end{array}$ & 1 & 1.99 & até $50 \mathrm{mil}$ \\
\hline $\begin{array}{l}11 \text { - Qual a principal motivação para a } \\
\text { inovação? }\end{array}$ & 1 & 1.66 & resolução de problemas \\
\hline $\begin{array}{l}12 \text { - Qual foi a principal fonte de idéias da } \\
\text { inovação? }\end{array}$ & 4 & 1.26 & mista (interna e externa) \\
\hline $\begin{array}{l}13 \text { - Qual o tempo médio de implantação da } \\
\text { inovação? }\end{array}$ & 2 & 0.94 & 2 a 6 meses \\
\hline $\begin{array}{l}14 \text { - Qual foi o principal obstáculo para a } \\
\text { concretização dessa inovação? }\end{array}$ & 2 & 1.85 & $\begin{array}{l}\text { tempo para desenvolvimento e } \\
\text { implantação }\end{array}$ \\
\hline $\begin{array}{l}15 \text { - Qual foi o principal conhecimento utilizado } \\
\text { pelo grupo na inovação? }\end{array}$ & 2 & 0.76 & informal - experiência profissional \\
\hline
\end{tabular}

Seguiu-se a investigação com uma análise léxica das principais palavras citadas entre os respondentes e se ratificaram os achados da seção anterior onde a inovação em "implantação" foi tipo mais próximo do estudo de caso demonstrado. Esse achado remete aos estudos de Leonard-Barton (1988) quando a autora aponta como inovação o próprio ato de implantar, 
isto é, na busca do melhor ajuste entre as especificações técnicas e o contexto operacional existente, os grupos podem inovar. Nesta fase, com uma amostra maior, pode-se argüir que, no universo de facilidades, as inovações e melhorias surgem durante o ciclo de desenvolvimento da mudança, sejam para ajustes, adequações ou correções ocorridas entre as especificações técnicas iniciais e as expectativas dos clientes (estes em constante contato com o processo de implantação).

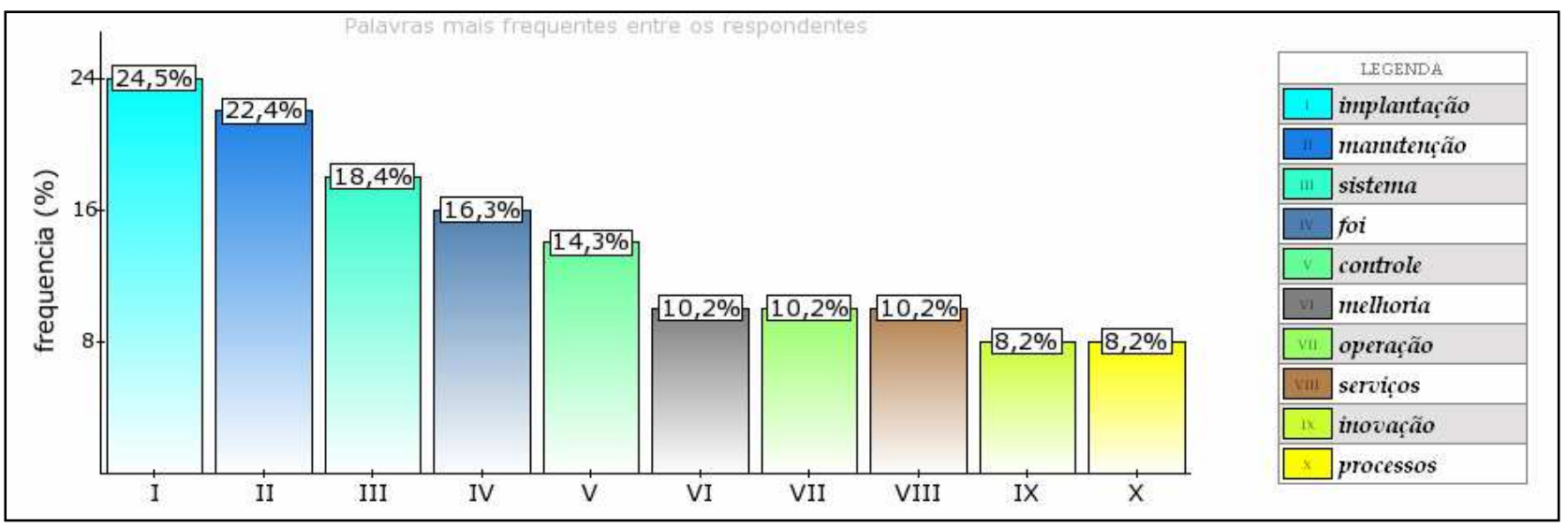

Gráfico 8 - Análise léxica das respostas

Citou-se com regularidade a palavra "manutenção", indicando a área ou atividade que mais produziria as tais inovações e melhorias nas implantações em facilidades. Percebe-se que nos ambientes em constante contato com eventos inesperados, tipicamente os das manutenções, haveria estímulo para a busca de soluções técnicas criativas que minimizariam os efeitos das ocorrências sobre os desempenhos operacionais. Outras palavras como "sistema", "controle", "operação", "serviços" e "processos" apontam para que as melhorias e inovações em facilidades são produzidas. Elas suportariam particularmente os problemas operacionais das organizações, impulsionando os resultados por meio das "melhorias" e "inovações" (palavras citadas em diferentes intensidades).

As mudanças geradas pelas áreas de facilidades (Gráfico 9) foram mais freqüentes nos processos industriais (máquinas, equipamentos, sistemas e dispositivos) com 36,7\%. Elas foram geradas dentro das empresas e apresentaram mínima ou baixa novidade, revelando serem mais do tipo melhorias contínuas do que inovações no sentido tradicional. Porém, as inovações organizacionais, 30,6\% da amostra, apresentaram maiores novidades dentro das organizações. Isso demonstra que para os respondentes, as mudanças organizacionais foram 
mais complexas do que as em processos, possivelmente devido a amplitude da ação e impacto dessas mudanças não técnicas.

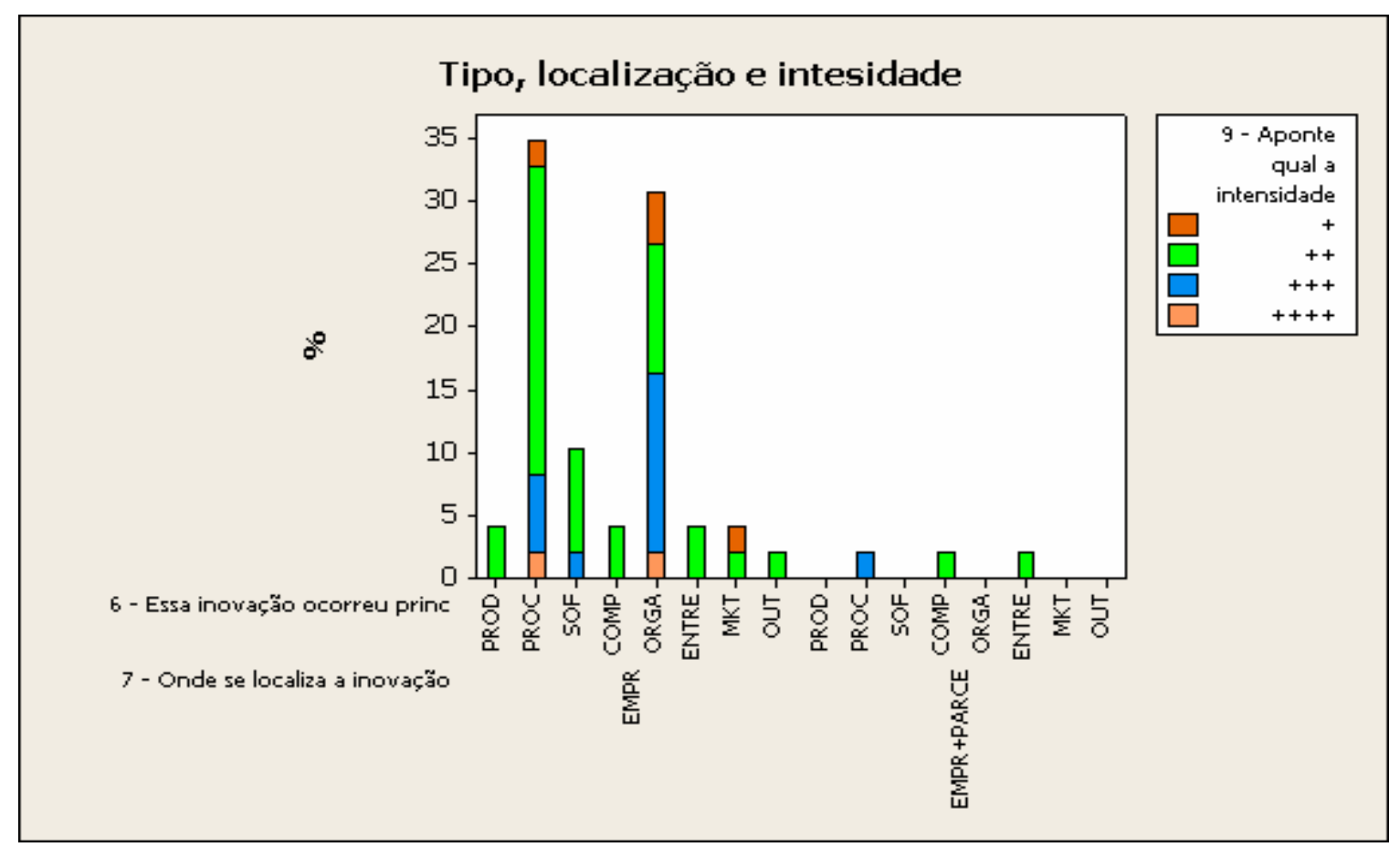

Gráfico 9 - Tipo, localização e intensidade das inovações e melhorias

Quando perguntado sobre a proximidade das mudanças em relação às atividades centrais das organizações (Gráfico 10), os respondentes tomadores de serviços eram diametralmente opostos aos prestadores, esses indicando inovações mais próximas das atividades centrais.

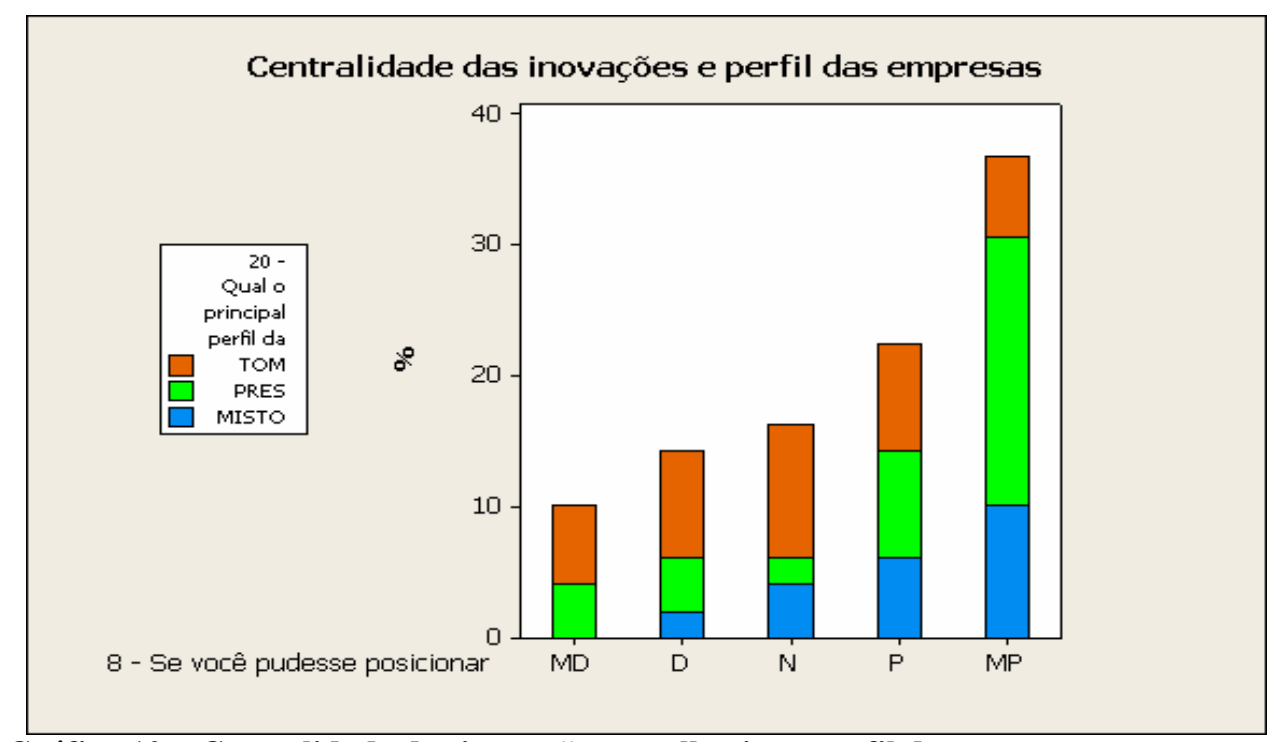

Gráfico 10 - Centralidade das inovações e melhorias e perfil das empresas 
Percebe-se que para os prestadores de serviços de facilidades, as inovações seriam seus "produtos" finais, ou seja, mais próximas das atividades centrais da organização, ao passo que para o tomador, as mudanças propostas orbitariam as atividades menos centrais.

A principal motivação para as mudanças ocorridas, de acordo com Gráfico 11, foi a resolução de problemas com 49\%. Para os profissionais, tempo para implantação $(34,7 \%)$ e rigidez organizacional $(30,6 \%)$ foram as principais barreiras para a implantação da mudança.

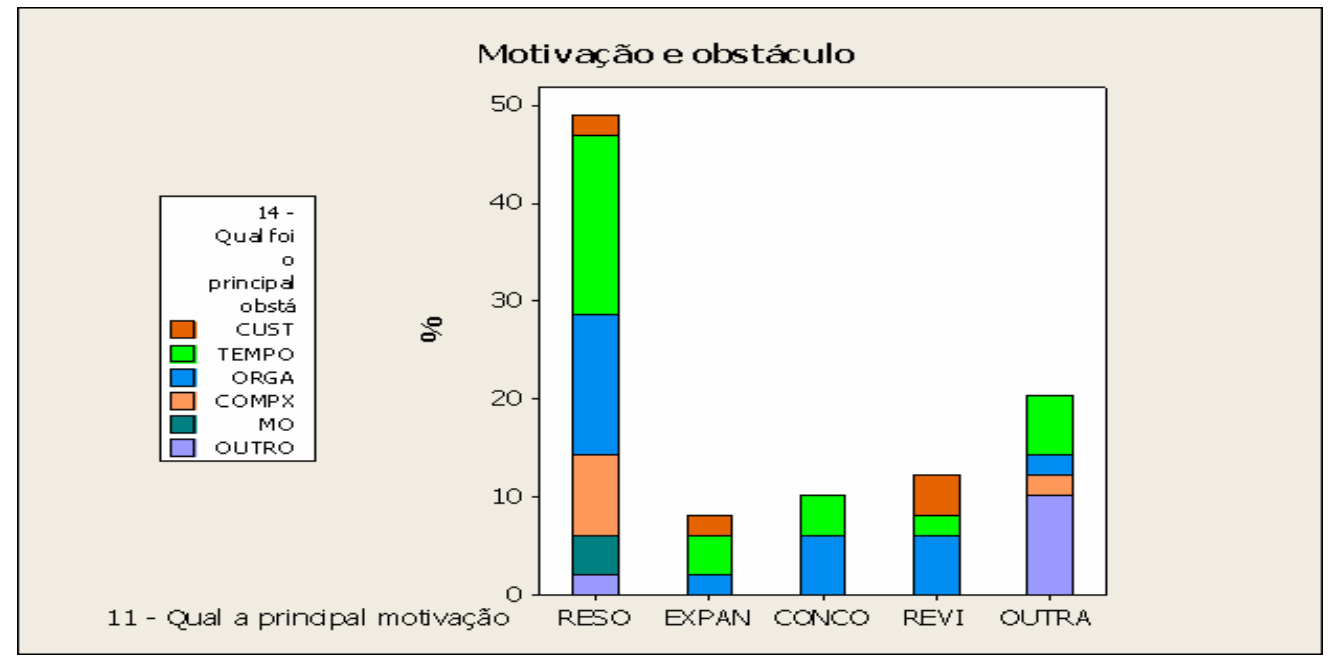

Gráfico 11 - Motivação e obstáculos para as inovações e melhorias

Entretanto, quando analisados os tipos de mudanças em função dos obstáculos percorridos, verifica-se que para as mudanças em processos, as dificuldades pairam (Gráfico 12) no tempo de desenvolvimento e implantação, provavelmente em função da complexidade técnica exigida. Nas mudanças organizacionais, é a própria rigidez das empresas que impediria ou dificultaria a implantação. 


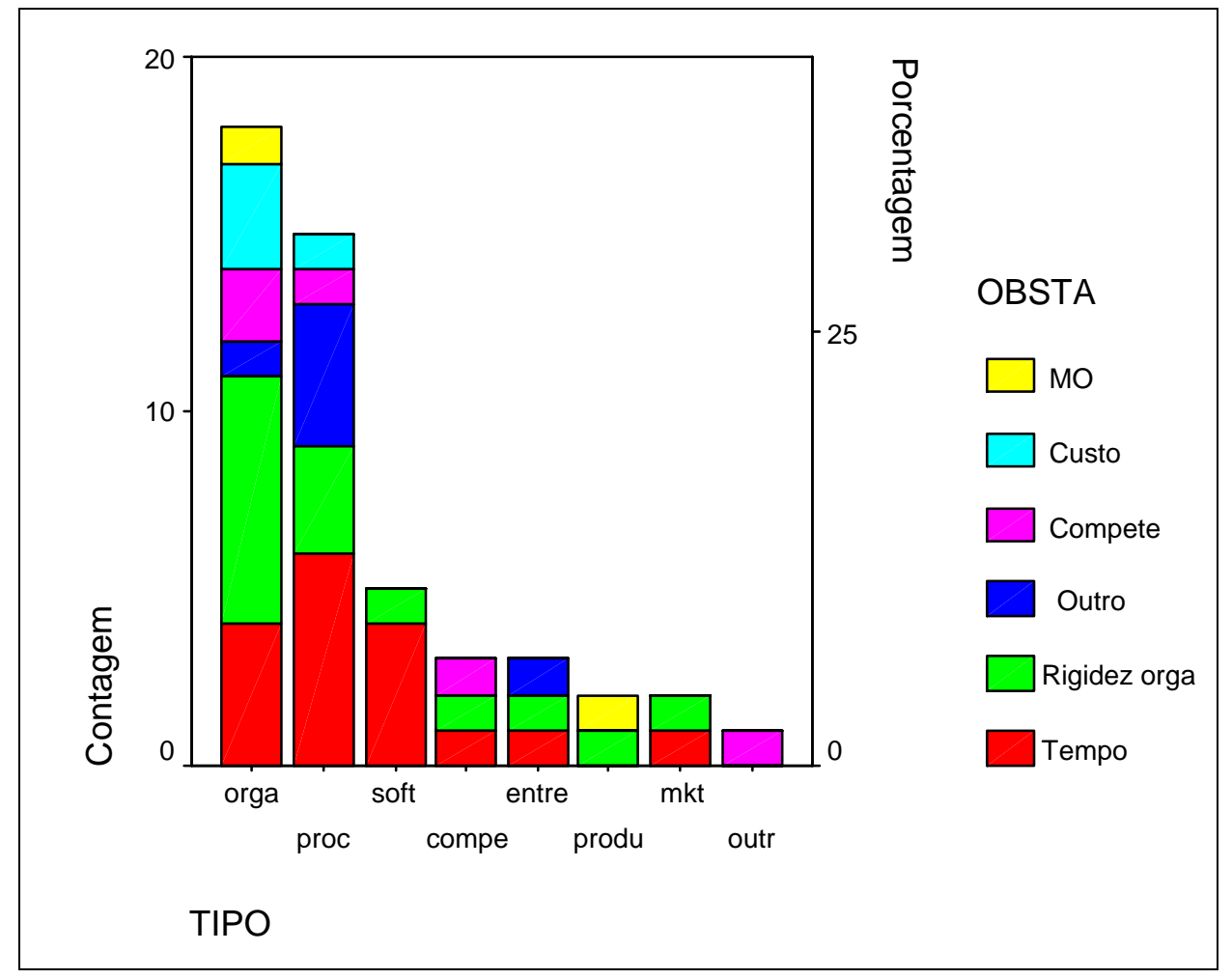

Gráfico 12 - Tipo de inovação e melhorias e os obstáculos

No geral, as mudanças ocorreram em médio espaço de tempo (entre 6 meses e 1 ano), com custos em torno de $\mathrm{R} \$ 50.000,00$, reforçando a indicação de que se tratam, sobretudo, de melhorias contínuas de baixo investimento e rápido retorno (Gráfico 13). À medida que esses custos aumentam, o tempo exigido cresce. As mudanças que exigiram menos investimentos foram as organizacionais.

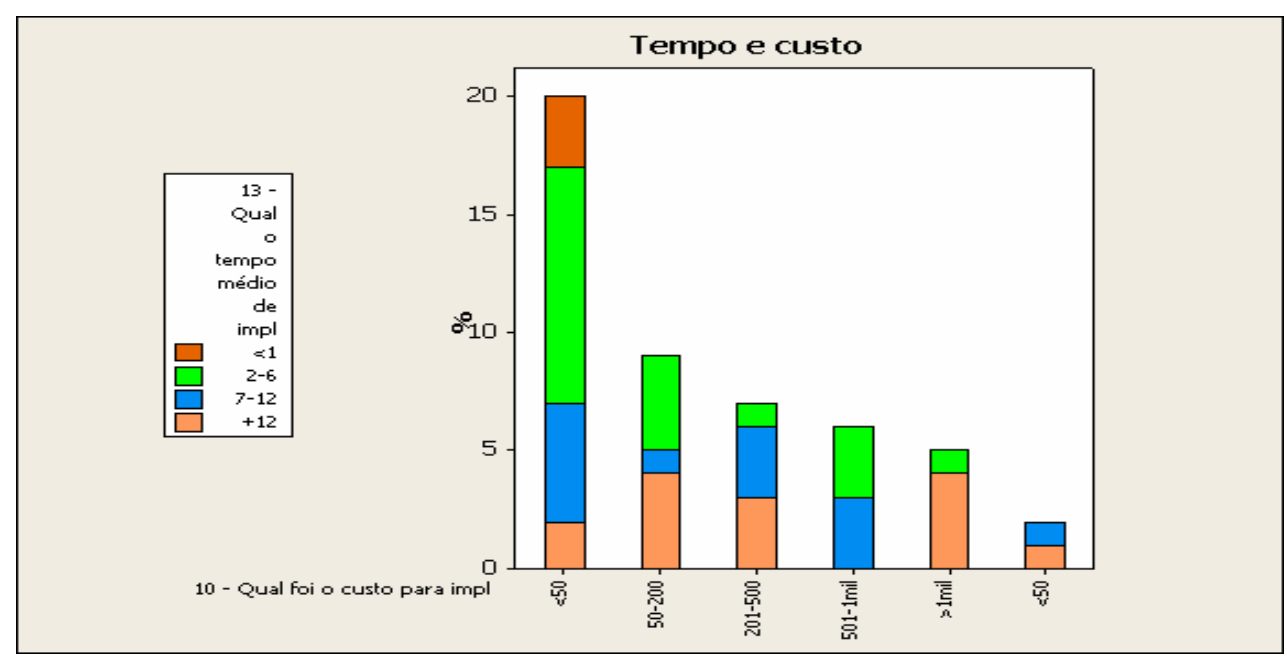

Gráfico 13 - Tempo e custo das inovações e melhorias 
Os inquiridos, de acordo com Gráfico 14, apontaram que a principal fonte de ideias surgiu das parcerias com fornecedores externos $(36,7 \%)$, seguidos dos próprios funcionários $(28,6 \%)$, pela liderança $(24,5 \%)$ e exclusivamente externo $(10,2 \%)$. Os conhecimentos mais utilizados foram aqueles adquiridos por meio das experiências do dia a dia (informais) com 40,8\% da amostra, acompanhados dos mistos (formais e informais - 36,7\%) e, menos acionado, o formal com 22,4\%. A indicação dessas respostas reforça a tese de que as mudanças em facilidades são frutos da informalidade e intensa parceria entre tomador e prestador de serviços.

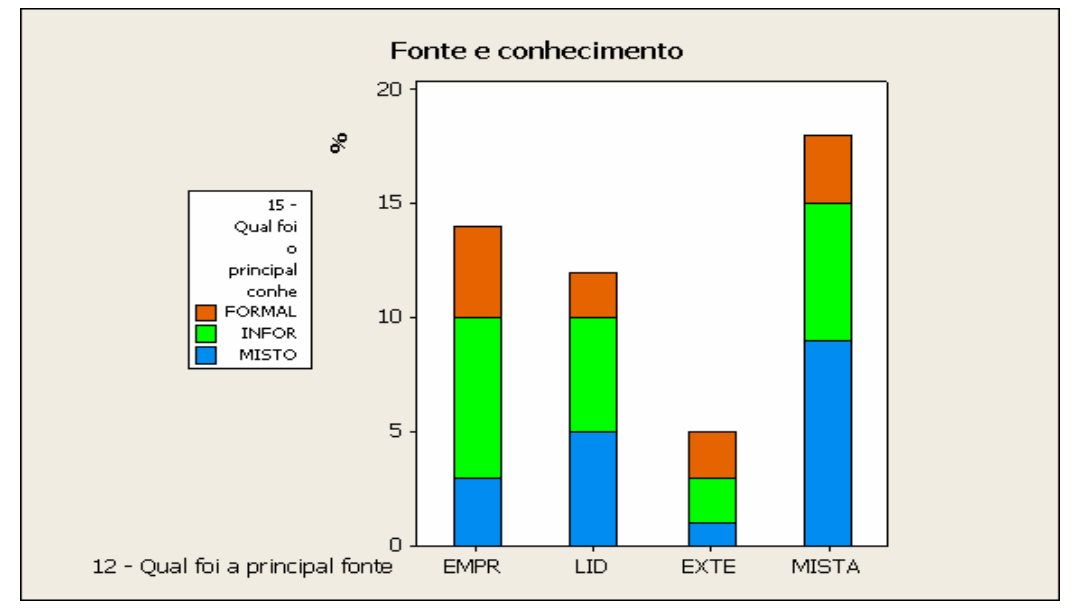

Gráfico 14 - Fonte de idéias e conhecimentos utilizados

Analisando o tipo de mudança com a centralidade da mesma nas atividades das organizações (Gráfico 15), verificou-se que para as mudanças em facilidades nos processos estas estariam muito próximas das atividades centrais das empresas e, em menos intensidade, as mudanças organizacionais. 


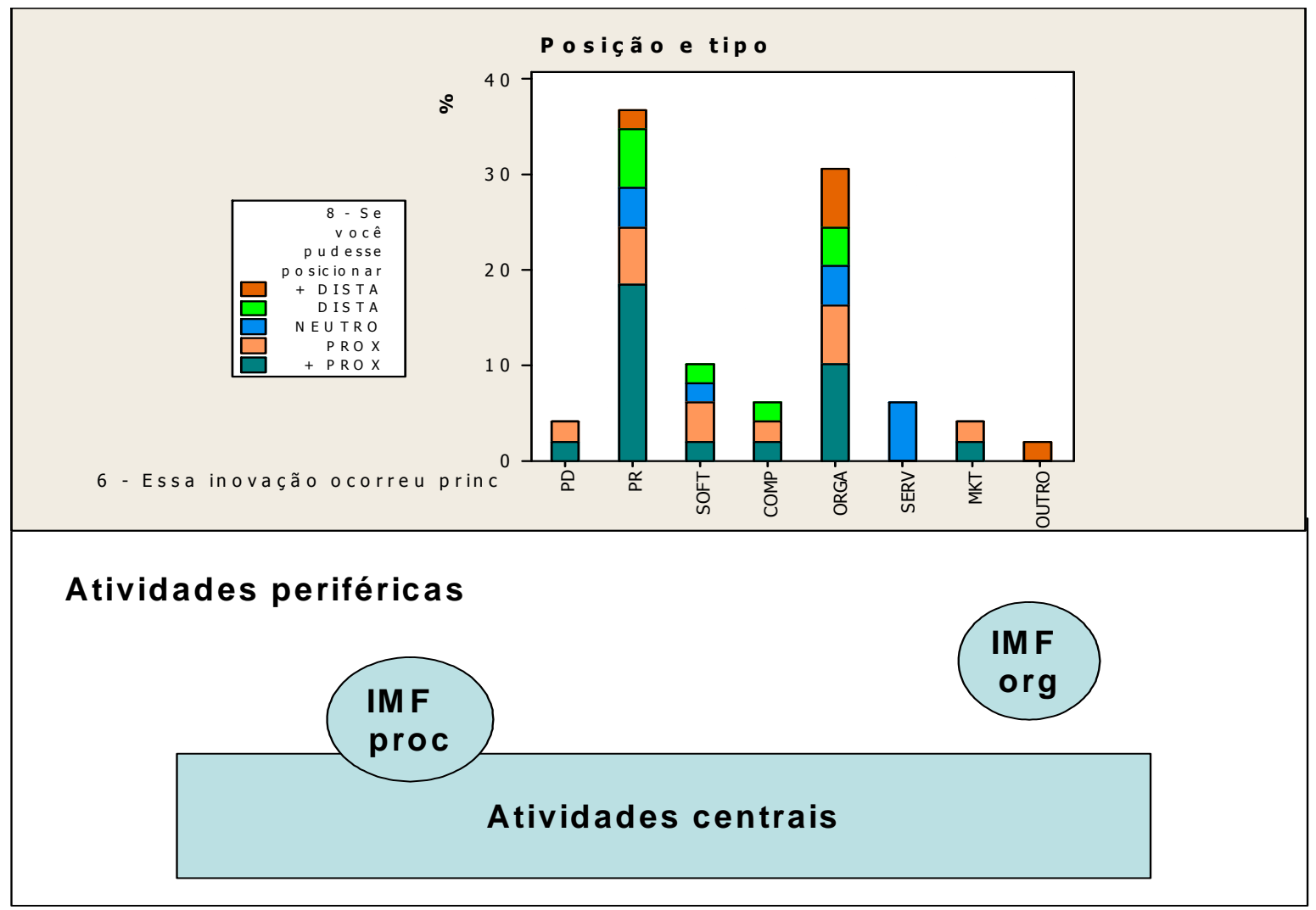

Gráfico 15 - Posição e tipo de inovação e melhoria

SINOPSE 10a: as mudanças técnicas (processos) e não técnicas (organizacionais) produzidas pelas facilidades são, na maioria dos casos, de baixa complexidade, novidade, custos e tempo de desenvolvimento, geradas em parcerias com fornecedores.

SINOPSE 10b: tempo para implantação e rigidez organizacional são os principais obstáculos para as mudanças geradas, principalmente, pelo empirismo dos funcionários das empresas.

SINOPSE 10c: as mudanças mais técnicas estariam mais próximas às atividades centrais das empresas, ao passo que organizacionais, mais distantes.

\subsubsection{Impactos gerados pelas melhorias e inovações}

Pelo Gráfico 16, obtido por meio das modas das respostas, percebe-se que os fatores de eficiência (produtividade e meio ambiente) são os mais afetados positivamente, seguidos pelos de custos, entrega e qualidade. Os desvios-padrão foram baixos, indicando consenso nas respostas. Esses dados apontam que as preocupações das organizações estariam voltadas, principalmente em função do contexto industrial da amostra, para as questões de eficiências 
operacionais internas e, seguindo tendências do mercado, para o meio ambiente (redução de resíduos, consumo de utilidades etc.).

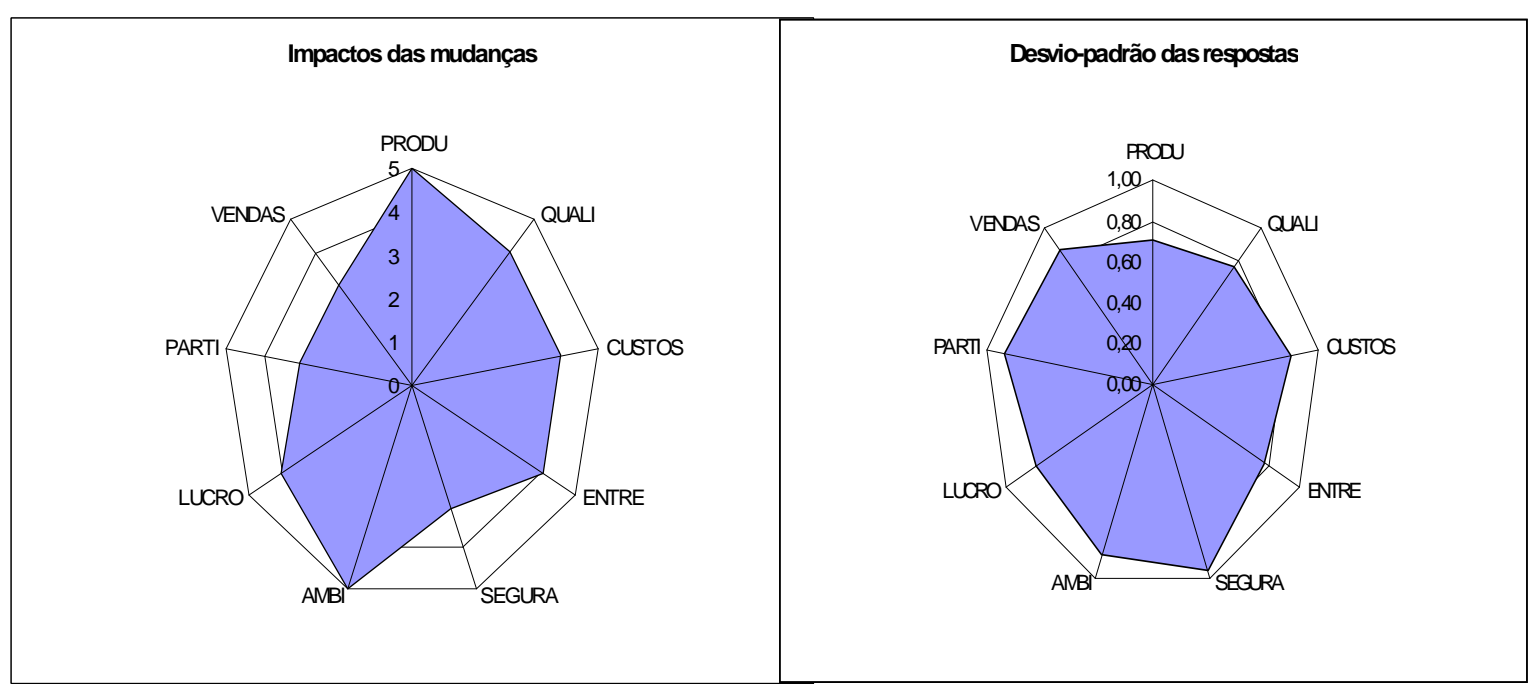

Gráfico 16 - Impactos das mudanças nos desempenhos

Observando-se esses impactos, por meio das somatórias das respostas (Gráfico 17), nota-se que os fatores ligados às eficiências são os mais pontuados que os financeiros, corroborando com as observações preliminares da tese e com as pesquisas de campo na fase de levantamento de dados. Nas primeiras evidências de campo, intuiu-se sobre a dominância dos fatores de eficiência sobre os financeiros, ainda que os últimos sejam tão importantes quanto os primeiros, porém, dada a característica de facilidades como área de apoio às infraestruturas das organizações, imaginou-se que as mudanças operadas nesse ambiente produziriam efeitos mais visíveis para as operações internas que para os agentes externos. 


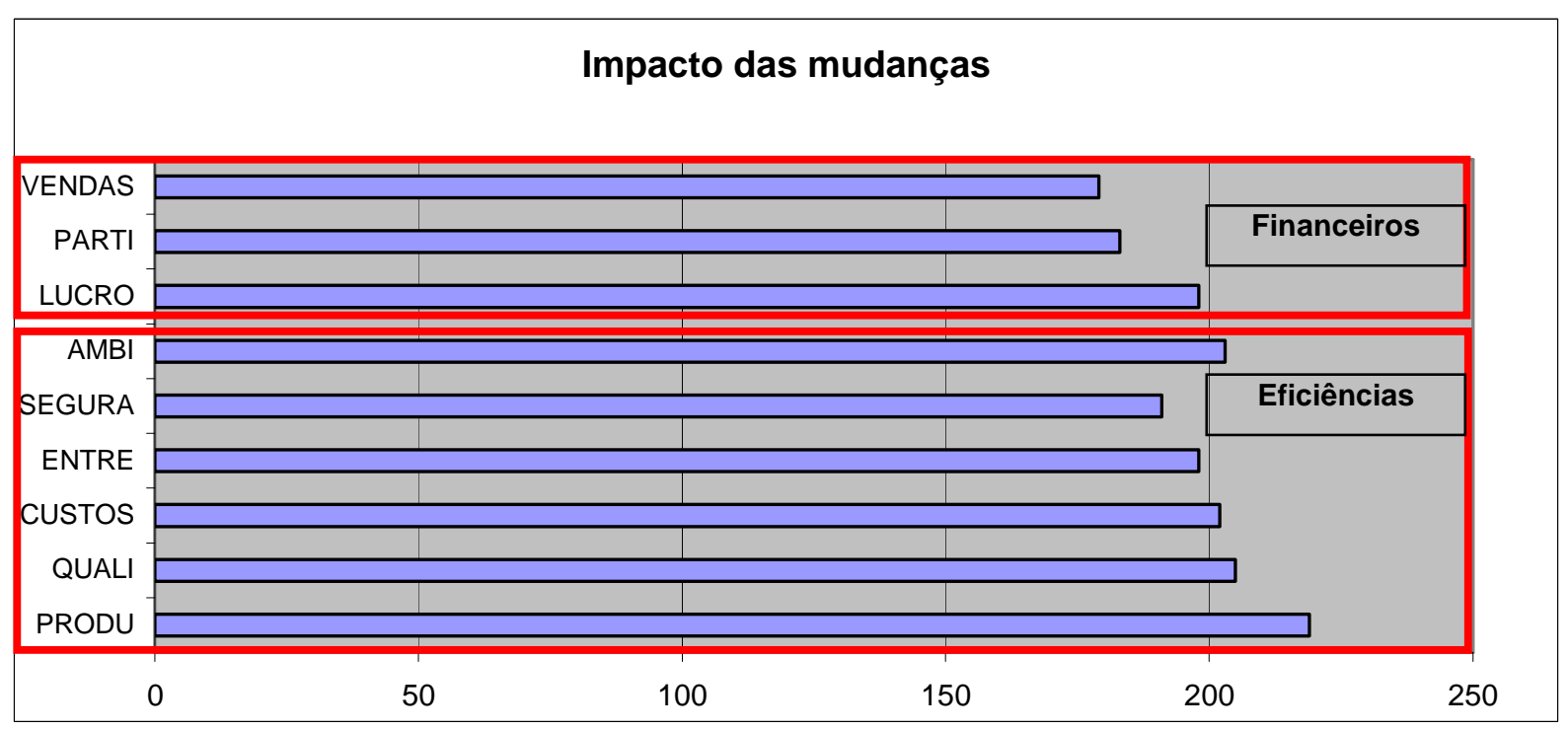

Gráfico 17 - Pesos dos impactos das mudanças

SINOPSE 11: as mudanças técnicas (processos) e não técnicas (organizacionais) produzidas pelas facilidades impactam principalmente os fatores de eficiência das organizações.

A seguir, foram averiguadas as correlações entre as dimensões empresas, respondentes, inovação e impactos.

\subsubsection{Correlações e testes de significância da amostra}

Rodaram-se testes de correlação posicional Kendall (para amostras não paramétricas e correlações com níveis de significância ente 0,01 e 0,05) entre as dimensões empresas, respondestes, inovações e não foram localizadas correlações significativas (acima de 70\%), conforme Apêndice L. Para os impactos nos fatores de eficiência e financeiros, de acordo com a Tabela 5, com confiabilidade interna significativa (Alpha de Cronbach) de 0,74, obtiveramse correlações razoáveis entre os fatores de eficiência - produtividade e custos, entrega e qualidade (todos com 56,3\%) e os financeiros - vendas e participação de mercado $(74,9 \%)$. 


\begin{tabular}{|c|c|c|c|c|c|c|c|c|c|}
\hline $\begin{array}{c}\text { (correlaçẫo posicional de Kendall - Tau- } \\
\text { a) }\end{array}$ & 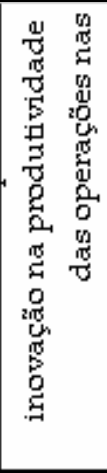 & 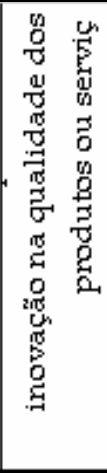 & 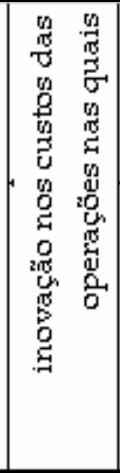 & 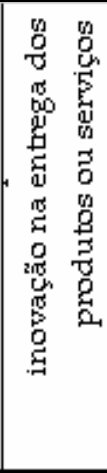 & 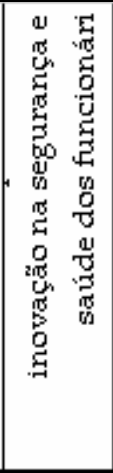 & 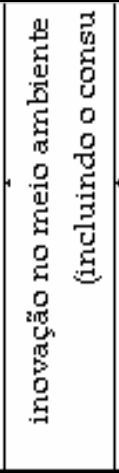 & 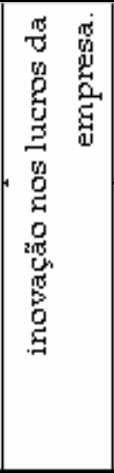 & 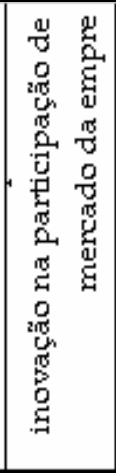 & 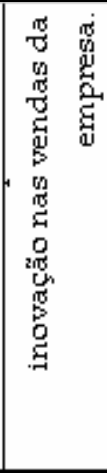 \\
\hline $\begin{array}{l}5.1 \text { - O impacto dessa inovação na } \\
\text { produtividade das operações nas }\end{array}$ & $=$ & $+34,6 \%$ & $+56,3 \%$ & $+30,1 \%$ & $+14,5 \%$ & $+0,4 \%$ & $+28,3 \%$ & $+1,9 \%$ & $+9,4 \%$ \\
\hline $\begin{array}{l}5.2 \text { - O impacto dessa inovação na } \\
\text { qualidade dos produtos ou serviç }\end{array}$ & $+34,6 \%$ & . & $+12,2 \%$ & $+56,3 \%$ & $+25,1 \%$ & $+2,6 \%$ & $+2,2 \%$ & $+16,7 \%$ & $+17,7 \%$ \\
\hline $\begin{array}{l}5.3 \text { - O impacto dessa inovação nos } \\
\text { custos das operações nas quais }\end{array}$ & $+56,3 \%$ & $+12,2 \%$ & = & $+29,2 \%$ & $+9,4 \%$ & $+16,2 \%$ & $+42,1 \%$ & $+10,6 \%$ & \\
\hline $\begin{array}{l}5.4 \text { - O impacto dessa inovação na } \\
\text { entrega dos produtos ou serviços }\end{array}$ & $+30,1 \%$ & $+56,3 \%$ & $+29,20$ & $=$ & $+9,9 \%$ & $-3,6 \%$ & $+16,7^{\circ}$ & $+33,8 \%$ & $+31,6 \%$ \\
\hline $\begin{array}{l}\text { 5.5- O impacto dessa inovação na } \\
\text { segurança e saúde dos funcionári }\end{array}$ & $+14,5 \%$ & $+25,1 \%$ & $+9,4 \%$ & $+9,9 \%$ & & $+32,1 \%$ & $+7,4 \%$ & $+28,8 \%$ & \\
\hline $\begin{array}{l}5.6 \text { - O impacto dessa inovação no meio } \\
\text { ambiente (incluindo o consu }\end{array}$ & $+0,4 \%$ & $+2,6 \%$ & $+16,2 \%$ & $-3,6 \%$ & $+32,1 \%$ & . & $+20,2 \%$ & $+23,0 \%$ & $+10,2^{\circ}$ \\
\hline $\begin{array}{l}5.7 \text { - O impacto dessa inovação nos } \\
\text { lucros da empresa. }\end{array}$ & $+28,3 \%$ & $+2,2 \%$ & $+42,1 \%$ & $+16,7 \%$ & $+7,4 \%$ & $+20,200$ & $=$ & $+40,2 \%$ & $+41,8 \%$ \\
\hline $\begin{array}{l}5.8 \text { - O impacto dessa inovação na } \\
\text { participação de mercado da empre }\end{array}$ & $+1,9 \%$ & $+16,7^{\circ}$ & $+10,6 \%$ & $+33,8 \%$ & $+28,8 \%$ & $+23,0 \%$ & $+40,2 \%$ & 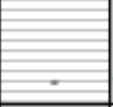 & $+74,9^{\circ}$ \\
\hline $\begin{array}{l}5.9 \text { - O impacto dessa inovação nas } \\
\text { vendas da empresa. }\end{array}$ & $+9,4 \%$ & $+17,7 \%$ & $+4,4 \%$ & $+31,6$ & $+20,5^{\circ}$ & $+10,2 \%$ & $+41,8 \%$ & $+74,9 \%$ & \\
\hline
\end{tabular}

Tabela 5 - Correlações entre os impactos nos fatores de eficiência e financeiro

Outras correlações abaixo de 50\% apontam que, havendo amostras maiores, outras relações poderiam existir, por exemplo, entre os fatores de eficiência e financeiros. Contudo, nessa análise, não foi possível investigar tal possibilidade.

O próximo passo foi constatar se haveriam diferenças estatísticas significativas entre as dimensões empresa, respondente e inovações, com os resultados dos impactos gerados pelas mudanças das facilidades. Para isso testes não paramétricos Kruskal-Wallis verificaram as relações entre as variáveis independentes (empresa, respondente e inovações) com as dependentes (impactos) buscando hipóteses de igualdade entre as amostras (resultados, demonstrados no Quadro 13). 
Quadro 13 - Testes de hipóteses de igualdade entre variáveis dependentes e independentes

\begin{tabular}{|l||l|l|}
\hline Dimensão & Variável & $\begin{array}{l}\text { Fator de desempenho/financeiro com diferenças } \\
\text { estatísticas significativas (p-value < 0,05) }\end{array}$ \\
\hline Inovação & POSICIONAMENTO (questão 8) & $\begin{array}{l}\text { ENTREGA } \\
\text { VENDAS } \\
\text { PARTICIPAÇÃO }\end{array}$ \\
\cline { 2 - 3 } & MOTIVAÇÃO (questão 11) & LUCRO \\
\cline { 2 - 3 } & CONHECIMENTO (questão 15) & CUSTO \\
\hline Empresa & TAMANHO (questão 17) & LUCRO \\
\hline Respondente & CARGO (questão 22) & PARTICIPAÇÃO \\
\cline { 2 - 3 } & EXPERIÊNCIA (questão 24) & SEGURANÇA \\
\hline
\end{tabular}

Para a dimensão inovação, as variáveis relacionadas ao posicionamento da inovação, motivação e conhecimentos, impactaram diferentemente os fatores entrega, vendas e participação de mercado. Para aqueles que posicionaram a inovação ou melhoria próxima as atividades centrais das organizações, os impactos nas entregas, vendas e participação de mercado foram maiores, condizendo com a importância que as mudanças geradas tinham para com os negócios das empresas. Elas, sejam melhorias ou inovações, desempenharam um papel importante nos resultados externos (fatores financeiros) conforme Gráfico 18: 


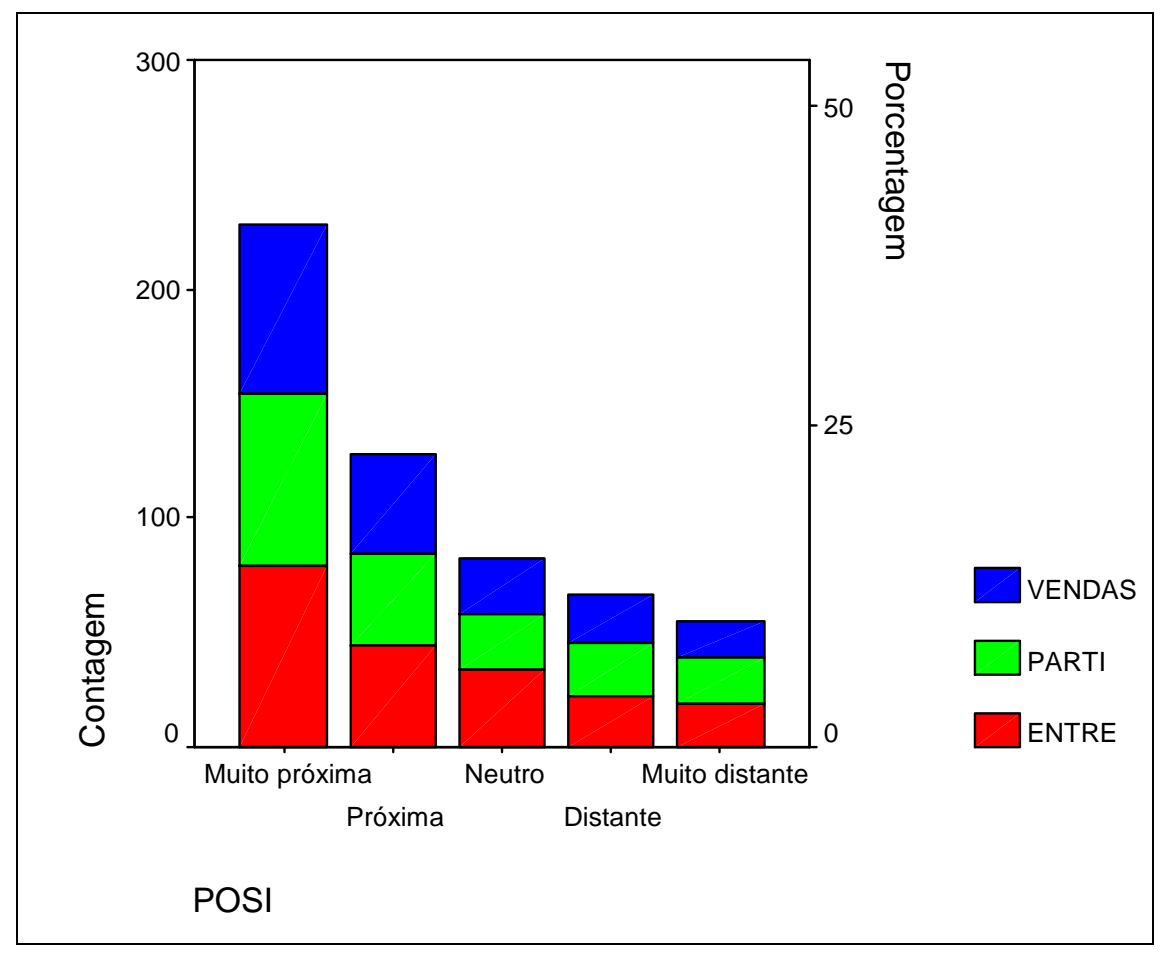

Gráfico 18 - Diferenças entre posicionamento e impactos

Para a variável motivação, de acordo com o Gráfico 19, verificou-se que à proporção que o lucro foi afetado positivamente, a resolução de problemas, como motivador da inovação, foi reduzindo. A revitalização dos ativos e expansão do mercado tornaram-se motivadores mais requisitados quando o lucro foi o fator mais impactado. O Gráfico 19 também aponta que para as empresas mais voltadas para resultados financeiros do que as eficiências operacionais, revitalização de ativos e expansão de mercado são mais motivadoras do que a resolução de problemas, esta possivelmente mais direcionadas para empresas focadas em produtividade e eficiências (por exemplo, as manufatureiras). 


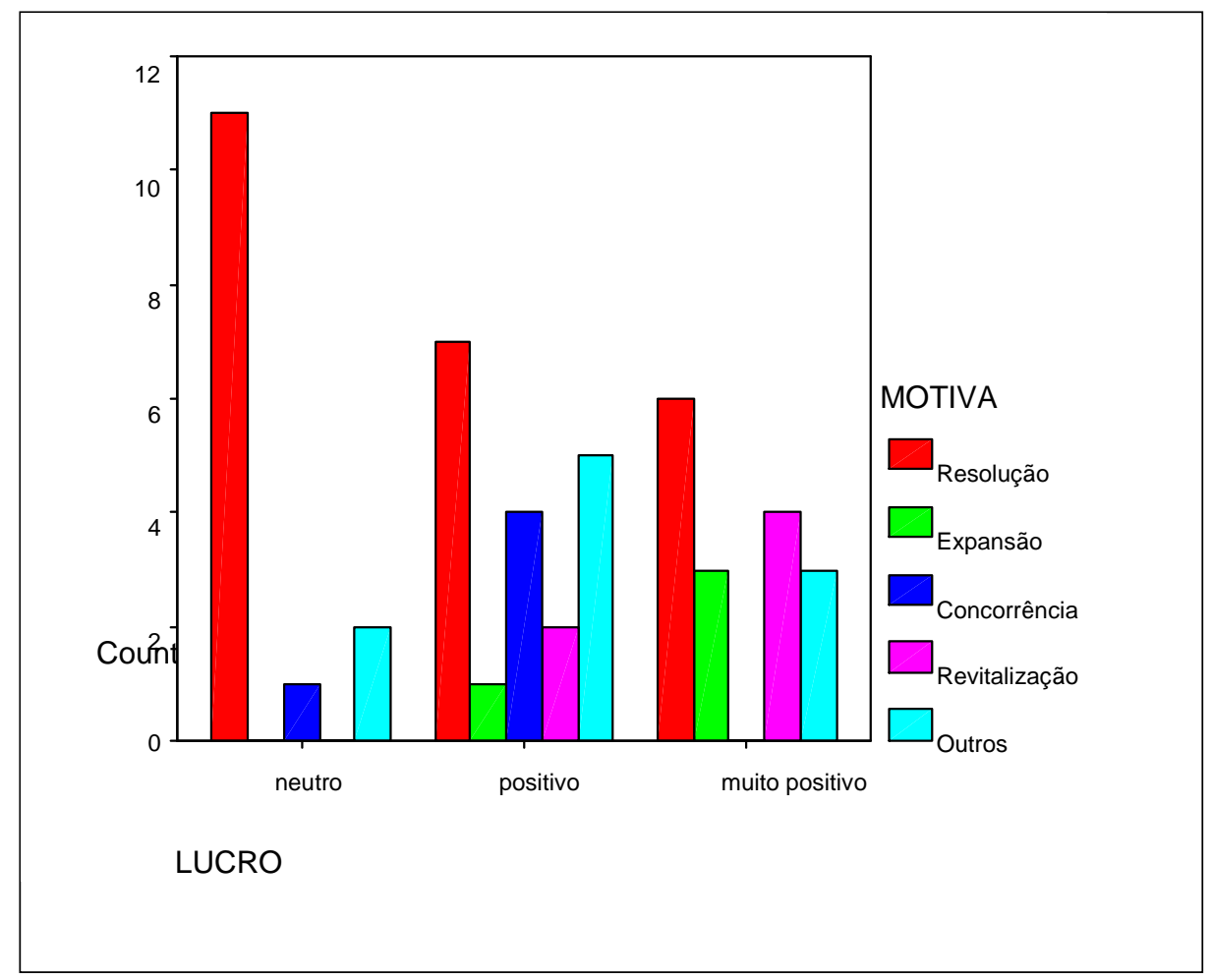

Gráfico 19 - Diferenças entre motivação e impactos

Os conhecimentos utilizados para a mudança apontada no survey, também alteraram em função dos impactos gerados em custos e lucros (Gráfico 20). Para os que apontaram maiores impactos em lucros, os conhecimentos formais foram menores. Porém os adquiridos em parcerias foram maiores, possivelmente para redução dos riscos, utilizaram-se conhecimentos de dentro e fora da empresa. Quando são os custos os fatores mais afetados, os grupos utilizaram menos os conhecimentos formais e mais os informais, corroborando com a literatura da qualidade, quando são apontados esforços internos na busca de eficiências internas, no caso as relacionadas à custos. 


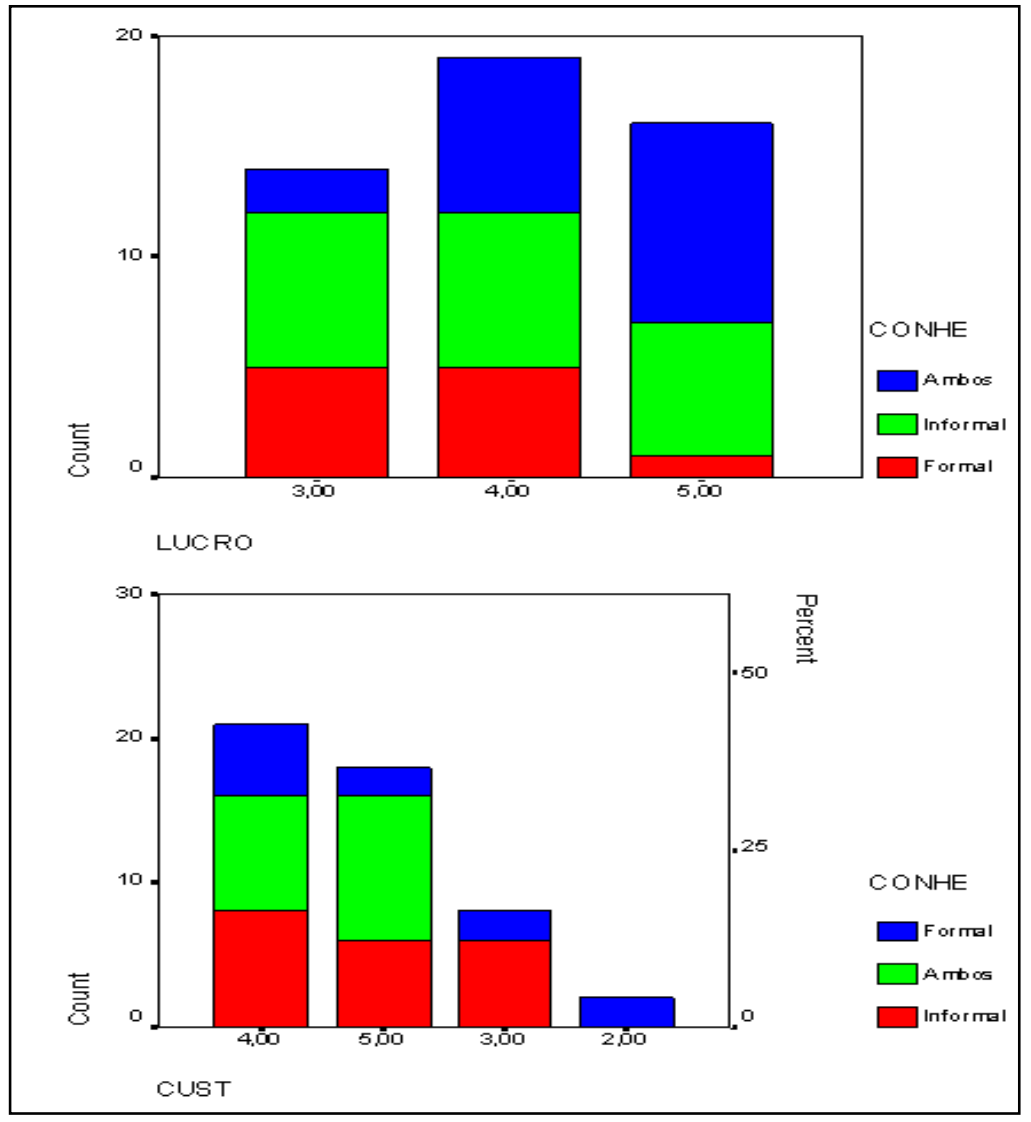

Gráfico 20 - Diferenças entre conhecimentos e impactos.

$\mathrm{Na}$ dimensão empresa, o tamanho foi o que apresentou diferenças estatísticas significativas nos fatores vendas, participação de mercado e produtividade (Gráfico 21). Para as grandes empresas (com mais de 500 funcionários) o principal fator impactado pela mudança realizada foi o de produtividade. Para as pequenas e médias empresas os impactos em vendas, participação e produtividade têm importâncias similares, dado o número de respostas favoráveis. Os dados indicam que para as empresas maiores as mudanças propostas têm papel mais significativo no aumento das eficiências internas. 


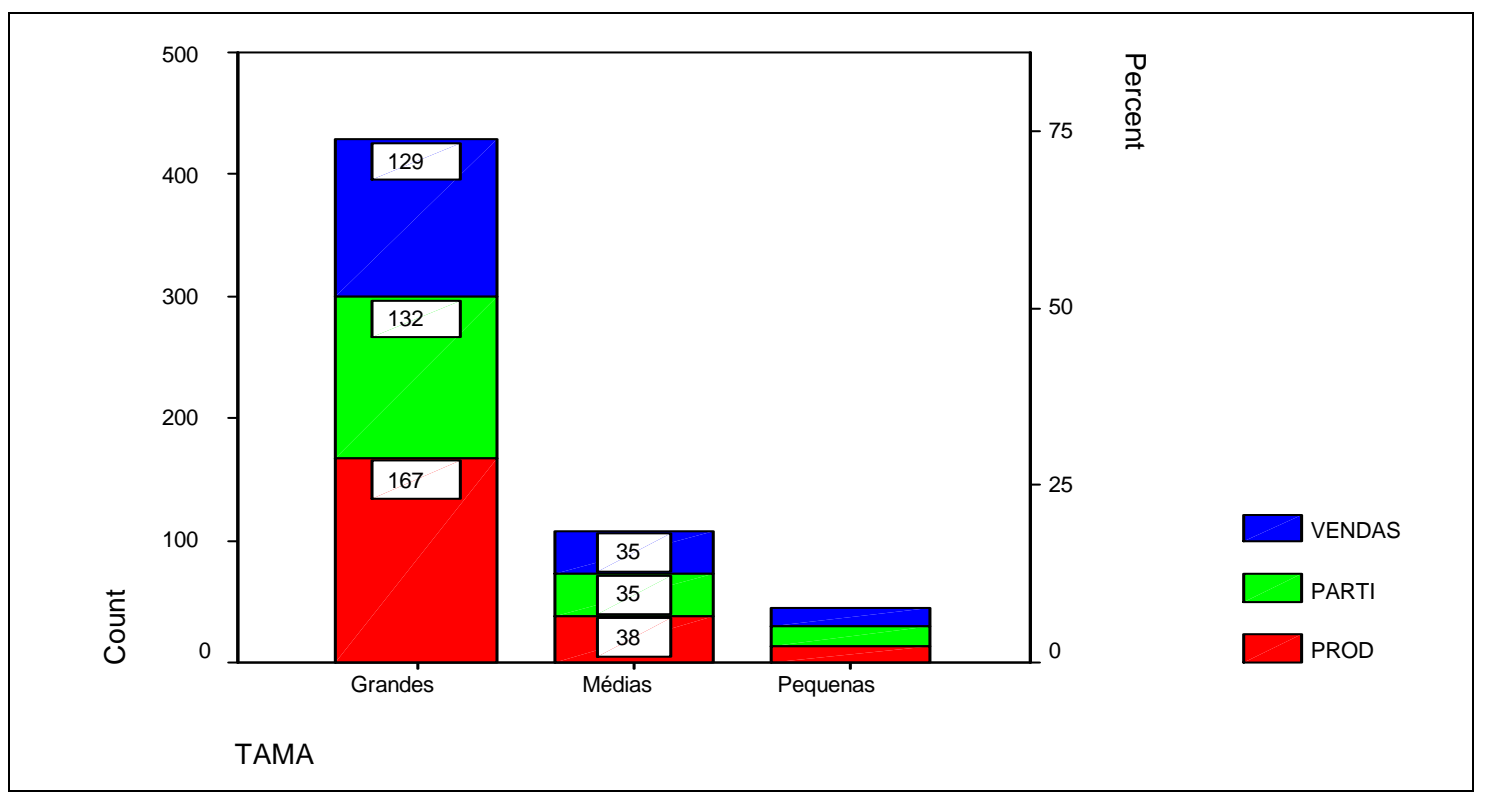

Gráfico 21 - Diferenças entre tamanho e impactos

$\mathrm{Na}$ dimensão respondente, as variáveis cargo e experiência profissional tiveram impactos diferentes nos fatores segurança e qualidade. A percepção para o fator qualidade parece estar mais presente nos cargos estratégicos (supervisores e gerentes) que nos operacionais (analistas), de acordo com Gráfico 22 (a esquerda). Ainda no mesmo gráfico, a direita, os impactos em segurança e saúde gerados pelas mudanças foram apontados pelos funcionários mais experientes.

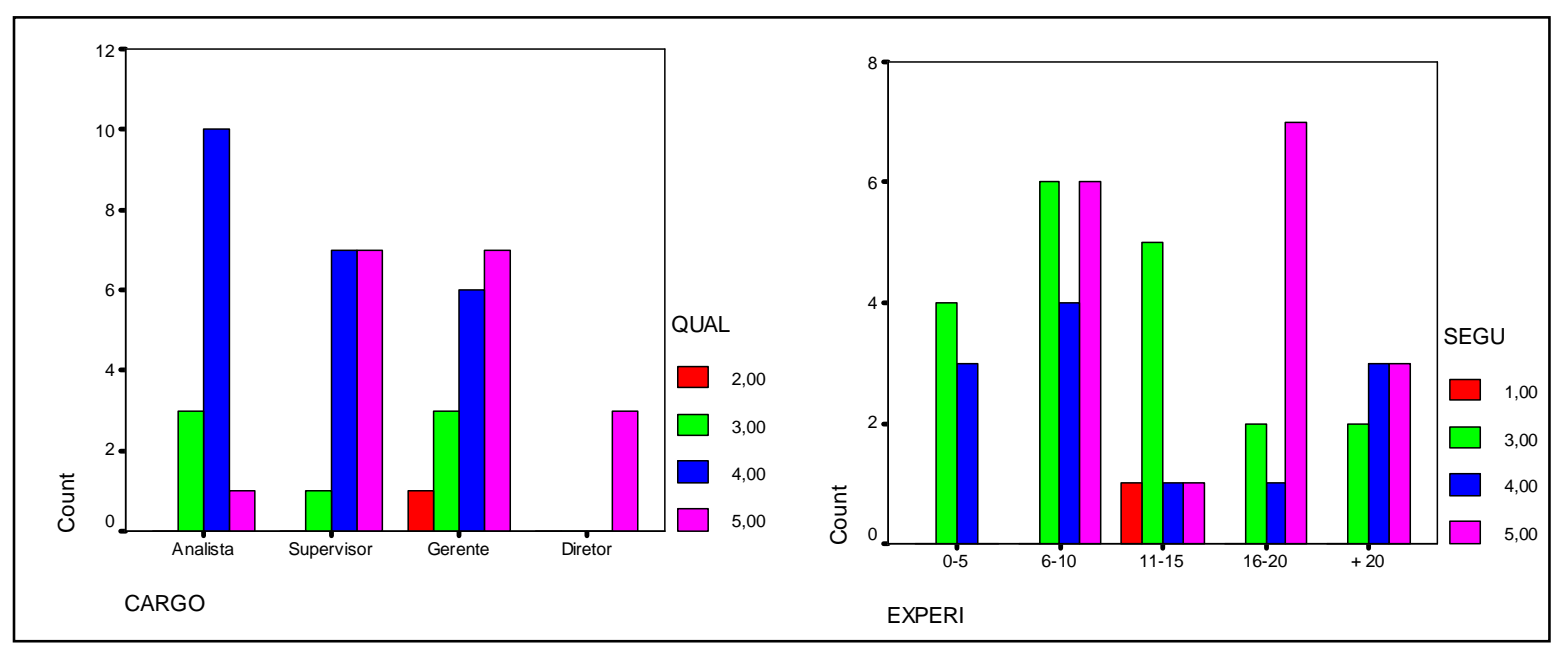

Gráfico 22 - Diferenças entre cargo, experiência e impactos

SINOPSE 12: As mudanças técnicas (processos) e não técnicas (organizacionais) produzidas pelas facilidades podem afetar diferentemente os fatores operacionais, conforme as características da inovação ou melhoria, do respondente e da empresa. 


\subsubsection{Análise fatorial e testes de hipóteses: novas categorias de inovações e melhorias}

O passo seguinte foi identificar se os fatores de desempenho $(\mathrm{H} 1)$ e os financeiros $(\mathrm{H} 2)$ formariam estruturas não identificadas no modelo de hipóteses proposto inicialmente na tese. Hair et al (2005) recomendam, como regra geral, cinco vezes o número de variáveis a serem observadas para uma análise fatorial, sendo assim, com 9 assertivas espera-se, no mínimo, 45 observações (o teste contou com 49 observações válidas). A análise resultou em um KMO (Kaiser-Meyer-Olkin) de 0,60, portanto está acima do nível de 0,50, que é um dos limitadores da aplicação da análise fatorial (CORRAR et al, 2007), pois compara as correlações de ordem zero com as correlações parciais observadas entre as variáveis. O teste de esfericidade Bartlett também ficou abaixo do valor considerado como limite $(0,05)$. Os valores de MAS (matriz antiimagem) individuais na tabela estão na sua maioria acima de 0,500 (APÊNDICE M). As comunalidades estão entre 0,50 e 0,80 (APÊNDICE N). A variância total explicada pelos três fatores (extraídos pelo critério Kaiser) é de quase 70\% (APÊNDICE O). Esses números são considerados satisfatórios, permitindo aprofundar as análises sobre os fatores gerados pela análise fatorial. Os mesmos testes foram realizados nas dimensões categóricas (inovação, empresa e respondente), contudo não responderam adequadamente às exigências estatísticas. A confiabilidade interna (Alpha de Cronbach) foi significativa em 0,74. Após a rotação dos dados pelo método Varimax, necessário para a identificação dos componentes principais do modelo, chegou-se ao seguinte desenho (Figura 22): 


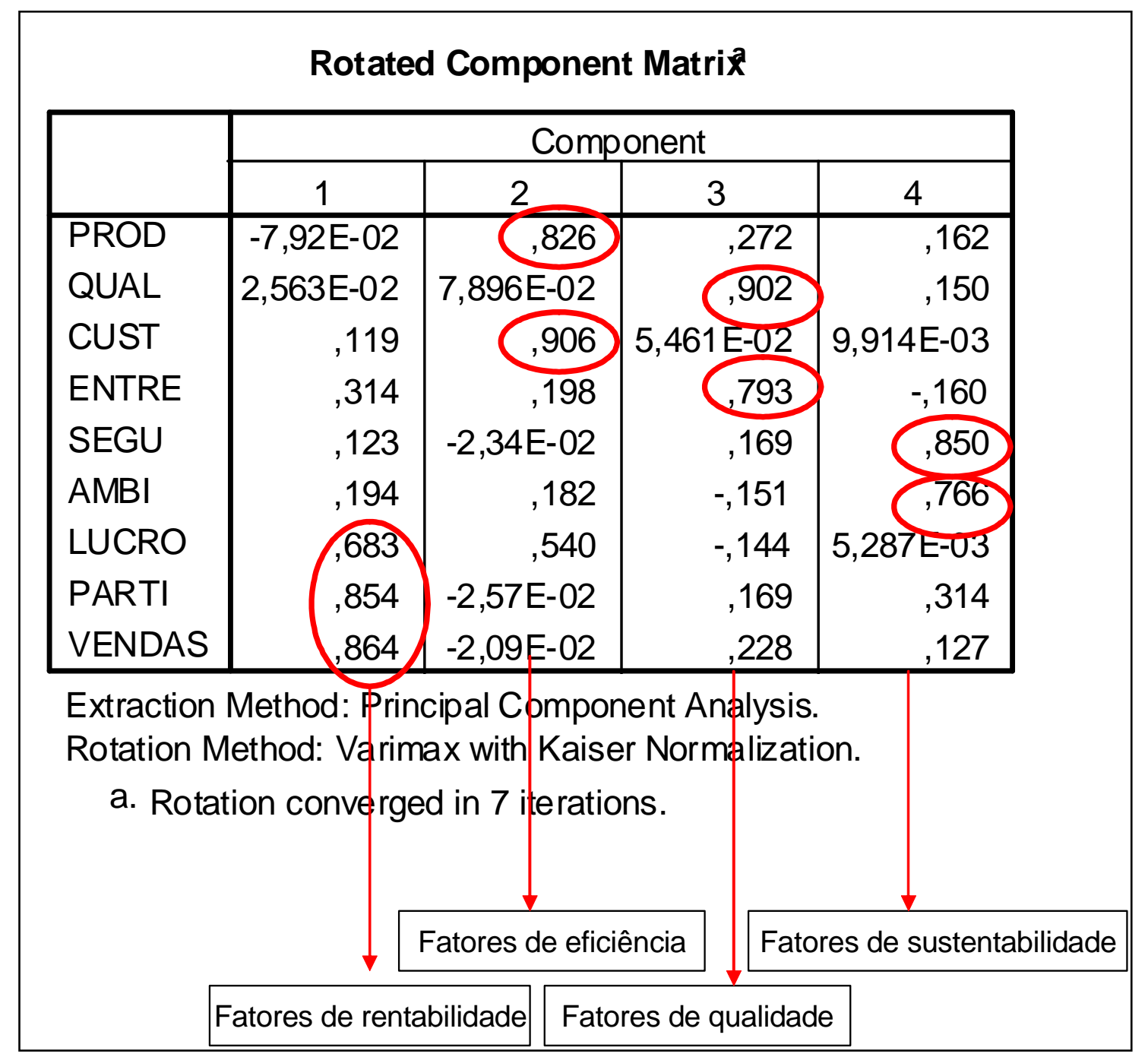

Figura 22 - Resultado da análise fatorial

Os resultados apresentados na Figura 22 indicam que os fatores se agruparam diferentemente do modelo de hipóteses inicial proposto na tese. Hair et al (2005) alertam que para uma amostra pequena (com até 50 observações), as cargas dos fatores devem ser maiores que 0,75.

Nele, alguns fatores se uniram a outros, formando novas composições. Dessa maneira, o modelo de hipóteses inicial foi redesenhado para representar os resultados da análise fatorial. Surgiram quatro novas dimensões que podem indicar taxonomias distintas das tradicionais: as de produtividade, unindo os fatores produtividade e custos; as de qualidade, na junção dos fatores entrega e qualidade; as de sustentabilidade, unindo os fatores de segurança e meioambiente e os de rentabilidade, na união dos fatores de vendas, lucros e participação de mercado. Esses achados possivelmente indicam que as inovações e as melhorias contínuas 
podem ser classificadas pelos impactos que produzem e não pelos antecedentes que as geraram.

A Figura 23, com as novas estratificações, identifica por meio de traços a força do impacto (medido pela moda) que a mudança (inovação ou melhoria contínua) produziu. Os traços mais grossos indicam que o impacto foi significativo (moda 5) os mais estreitos indicam relatividade (modas 3 e 4) e os tracejados, baixa significância (moda 1 e 2).

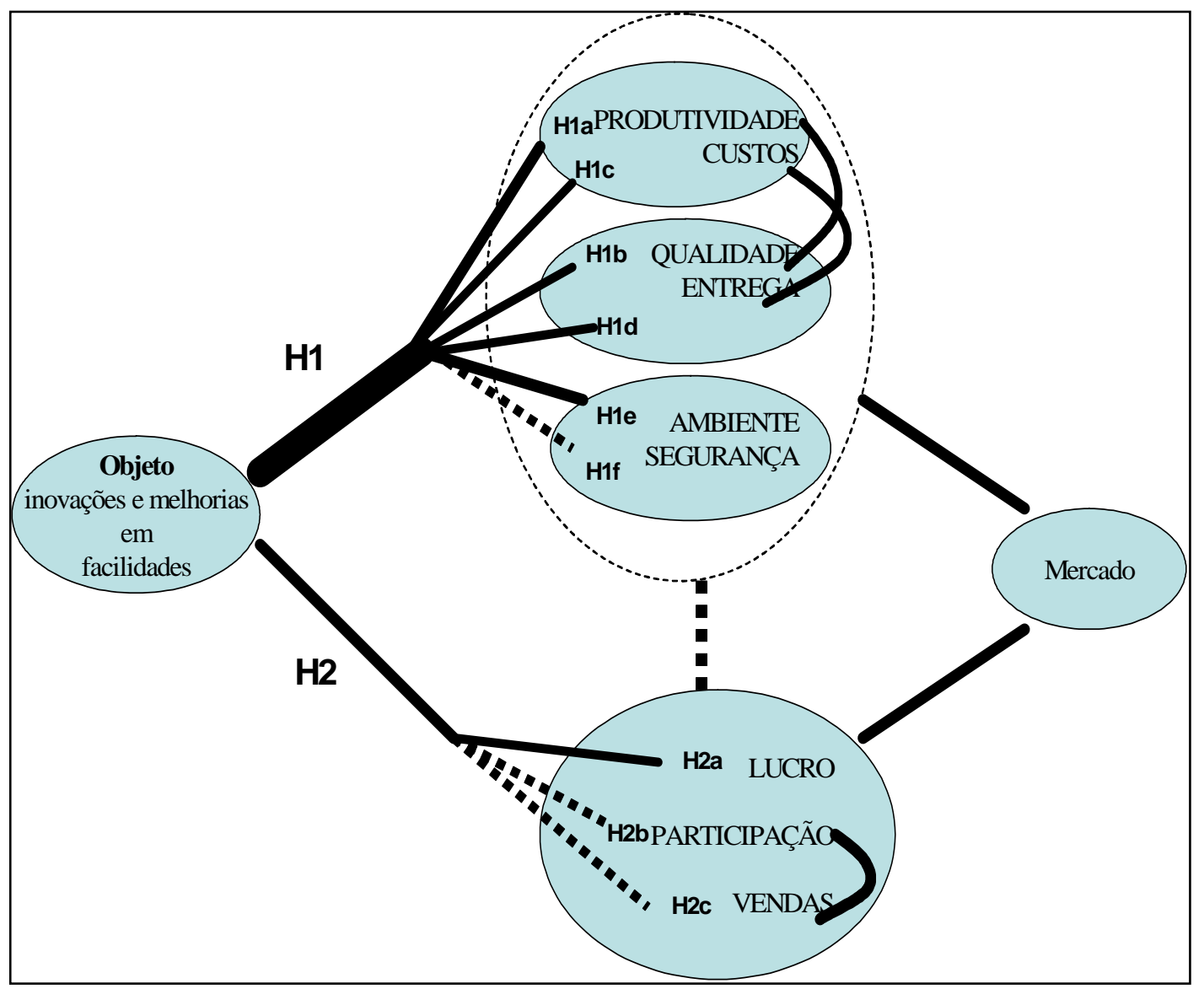

Figura 23-Modelo de hipóteses testado

Nota-se, no Quadro 13, que as hipóteses inicialmente propostas foram testadas, confirmando e refutando algumas afirmações. 
Quadro 14 - Dimensões e hipóteses testadas

\begin{tabular}{|c|c|c|c|}
\hline Dimensão & $\begin{array}{c}\text { Hipóteses } \\
\text { principais de } \\
\text { pesquisa }\end{array}$ & Hipóteses secundárias de pesquisa & Resultados \\
\hline $\begin{array}{l}\text { Inovação e } \\
\text { eficiência } \\
\text { operacional }\end{array}$ & $\begin{array}{l}\text { H1: as inovações e } \\
\text { melhorias em } \\
\text { facilidades } \\
\text { impactam } \\
\text { significativamente } \\
\text { a eficiência } \\
\text { operacional }\end{array}$ & $\begin{array}{l}\text { H1a: as inovações e melhorias em facilidades impactam } \\
\text { significativamente a produtividade das empresas } \\
\text { H1b: as inovações e melhorias em facilidades impactam } \\
\text { significativamente a qualidade das empresas } \\
\text { H1c: as inovações e melhorias em facilidades impactam } \\
\text { significativamente os custos das empresas } \\
\text { H1d: as inovações e melhorias em facilidades impactam } \\
\text { significativamente a entrega das empresas } \\
\text { H1e: as inovações e melhorias em facilidades impactam } \\
\text { significativamente o meio-ambiente das empresas } \\
\text { H1f: as inovações e melhorias em facilidades impactam } \\
\text { significativamente a segurança e saúde das empresas }\end{array}$ & $\begin{array}{l}\text { CONFIRMADA } \\
\text { REJEITADA } \\
\text { REJEITADA } \\
\text { REJEITADA } \\
\text { CONFIRMADA } \\
\text { REJEITADA }\end{array}$ \\
\hline $\begin{array}{l}\text { Inovação e } \\
\text { desempenho } \\
\text { financeiro }\end{array}$ & $\begin{array}{l}\text { H2: as inovações e } \\
\text { melhorias em } \\
\text { facilidades não } \\
\text { impactam } \\
\text { significativamente } \\
\text { o desempenho } \\
\text { financeiro }\end{array}$ & $\begin{array}{l}\text { H2a: as inovações e melhorias em facilidades não } \\
\text { impactam significativamente os lucros das empresas } \\
\text { H2b: as inovações e melhorias em facilidades não } \\
\text { impactam significativamente a participação de mercado } \\
\text { das empresas } \\
\text { H2c: as inovações e melhorias em facilidades não } \\
\text { impactam significativamente as vendas das empresas }\end{array}$ & CONFIRMADA \\
\hline
\end{tabular}

Os resultados das estatísticas descritivas (utilizando a moda) e indutivas (análise fatorial) puderam confirmar algumas hipóteses, como a de que os fatores de eficiência seriam mais afetados pelas melhorias e inovações em facilidades que os financeiros (Figura 23). Contudo, não foi possível apontar que todos os fatores de eficiência teriam os mesmos impactos (Quadro 13). Dentro do fator eficiência, apenas os de produtividade e meio ambiente 
mostraram-se fortemente afetados pelas mudanças. Os demais, custos, qualidade e entrega, foram relativamente impactados. O de segurança, pouco. Entre os próprios fatores de eficiência, mostraram-se muito próximos (por meio da análise fatorial) os de produtividade com qualidade e os de custos com entrega. Isso corrobora com estudos como os de Slack (1993) sobre trade-offs entre os desempenhos, onde a alavancagem de um pode favorecer o outro.

Para os fatores de desempenho financeiros, o mais afetado, ainda que relativamente, foi o de custos, seguido pelo de vendas e participação de mercado. Entre eles, há uma convergência forte entre participação de mercado e vendas, apontando também possíveis trade-offs, pois vendendo mais, espera-se maior participação de mercado e vice-versa. Entre os fatores eficiência e financeiro não foram encontradas relações significativas.

A etapa seguinte foi buscar dentro das quatro novas subcategorias identificadas nas Figuras 22 e 23 quais seriam as principais características que difeririam as novas taxonomias. Assim, separou-se os indivíduos pelas máximas pontuações (moda 5) dadas para cada subgrupo (APÊNDICE P). Verificou-se se haveriam diferenças estatísticas significativas entre as novas amostras. O teste de Kendall indicou que elas eram de fato diferentes ( $\mathrm{p}$-value $<0,05$ ).

\begin{tabular}{r|r}
\hline $\mathrm{N}$ & 4 \\
\hline Kendall's W &, 752 \\
\hline Chi-Square & 57,179 \\
\hline $\mathrm{df}$ & 19 \\
\hline Asymp. & $\mathbf{, 0 0 0}$ \\
Sig. & \\
\hline
\end{tabular}

Em função dos resultados gerados pela análise fatorial, as inovações e melhorias em facilidades, produzidas pelos agentes (sejam eles indivíduos, grupos ou as empresas), poderiam ser divididas nas técnicas e não técnicas (organizacionais) com baixa, média e alta complexidade para a produtividade, qualidade, sustentabilidade e rentabilidade das empresas. A complexidade se deu de acordo com as respostas das intensidades e novidades das mudanças, custos e o período de desenvolvimento e implantação. Essas três dimensões (mudança, complexidade e propósito), ainda que não totalmente validadas e excludentes, gerariam uma matriz com 24 combinações possíveis, conforme Figura 24. Dessas, nessa tese, foram encontradas quatro categorias, indicando a necessidade de futuras investigações nas demais. A construção da Figura 24 remete a Holland (1995) quando o autor, no livro "Hidden 
Order: how adaptation building complexity", propõe que a combinação de diferentes blocos (building blocks) faz surgir diferentes soluções.

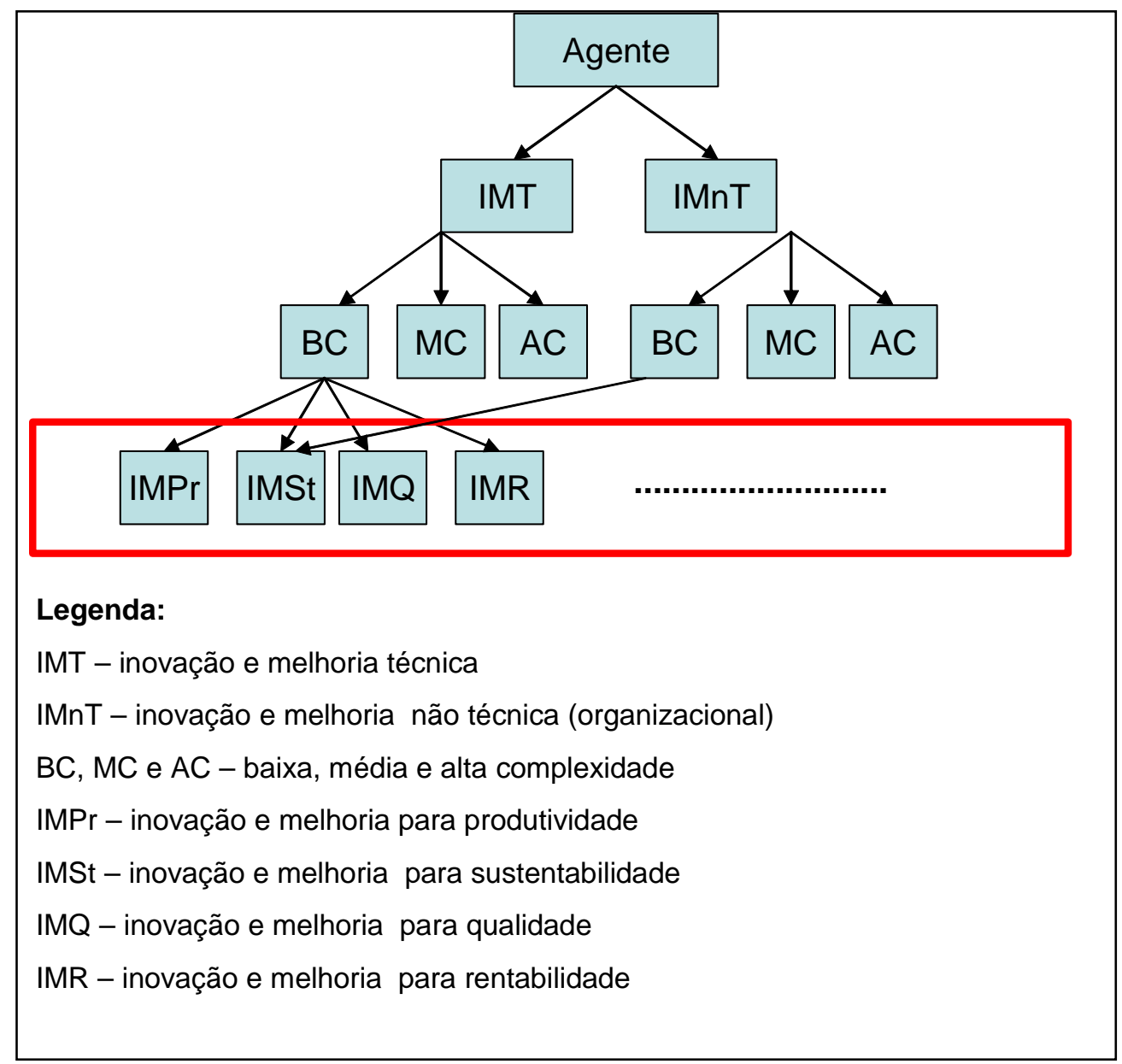

Figura 24 -Combinações possíveis para melhorias em facilidades

Dentre as possíveis combinações, chegaram-se as categorias descritas a seguir, de acordo com as pontuações (moda) dos respondentes para os impactos gerados nos desempenhos das organizações. As características apontadas foram aquelas que mais se destacaram na amostra principal:

- Inovações e melhorias em facilidade para produtividade operacional: segundo os dados obtidos, essa classe seria produzida por prestadores de serviços nacionais direcionados para as mudanças em processos (máquinas, dispositivos, equipamentos), com baixa novidade e oriundas de parcerias com os clientes. São mudanças realizadas em curto período (entre dois e seis meses). Esses resultados foram apontados, na 
maioria das vezes, por supervisores com mais de vinte anos de experiência profissional na área e indicaram que a rigidez organizacional era a principal barreira para a implantação da melhoria. Afetariam os fatores de eficiência para produtividade e custos. Os exemplos que foram citados pelos respondentes do survey foram: instalação de medidores de utilidades remotos para monitoramento e controle dos consumos e sistemas eletrônicos para controle das subestações elétricas em tempo real. Parece que as mudanças são voltadas para o aumento da eficiência no uso dos ativos das empresas.

- Inovações e melhorias em facilidade para qualidade operacional: de acordo com os dados identificados, essa classe seria direcionada para as mudanças em processos (máquinas, dispositivos, equipamentos), com baixa novidade, curto período de desenvolvimento e implantação (entre dois e seis meses), oriundas de fontes externas e implantadas pelas empresas estrangeiras de serviços. Esses resultados foram apontados, majoritariamente, por gerentes com mais de vinte anos de experiência profissional e indicaram que a rigidez organizacional era a principal barreira para a implantação da melhoria. Citou-se, como exemplo, a implantação de grupo gerador de energia elétrica para melhoria na qualidade da utilidade (fontes de energia) entregue aos usuários.

- Inovações e melhorias em facilidade para sustentabilidade operacional: essa categoria seria gerada pelos próprios tomadores de serviços, direcionada para as mudanças organizacionais, com novidade média, longo período de desenvolvimento e implantação, oriunda de parcerias e implantadas pelas empresas estrangeiras do setor industrial. Esses resultados foram relatados frequentemente por supervisores com mais de seis anos de experiência profissional que indicaram o tempo como a principal barreira para a implantação da inovação. Nela, foram exemplificados casos relacionados a normas e regulamentações, como a adoção da NR-10 (normas regulamentadoras para instalações elétricas), NR-33 (inspeções de vasos sob pressão), melhorias no processo de aprovação de faturas dos serviços, padronização de cores de tintas ecológicas para manutenção predial, rearranjo da estrutura de facilidades em nível global para atendimento de normas corporativas. Essa classe parece estar alinhada com a necessidade das facilidades responderem aos novos parâmetros de governança corporativa adotados, principalmente, por empresas multinacionais nos últimos anos, minimizando passivos trabalhistas e ambientais. 
- Inovações e melhorias em facilidade para rentabilidade empresarial: esta seria produzida pelos prestadores de serviços, direcionada para as mudanças em processos (máquinas, dispositivos, equipamentos), com novidade média, longo período de desenvolvimento e implantação (mais de doze meses), oriundas de parcerias e implantadas pelas empresas estrangeiras do setor de utilidades. Esses resultados foram relatados pela maioria dos gerentes com mais de dezesseis anos de experiência profissional que indicaram a rigidez organizacional como a principal barreira para a implantação da inovação. Uma das melhorias citadas nessa categoria foi a atualização tecnológica de máquinas para anestesia e modificações no protocolo do procedimento para anestesia, gerando, para a empresa, utilização máxima dos recursos. Citou-se a automatização de compressores de ar nos horários de ponta de consumo, para redução dos custos com energia elétrica.

Não é descartada a possibilidade de hibridização entre as categorias supracitadas, uma vez que foram encontradas correlações, ainda que discretas, e traços de trade-offs entre as mesmas. Algumas melhorias parecem atender a mais de uma categoria. Por exemplo, a instalação de um gerador de energia, poderia melhorar a produtividade da empresa, por reduzir paradas das operações em situações de emergência, a qualidade do insumo, pois a energia entregue é mais estável; a sustentabilidade dos negócios, pois a redução do consumo de energia nos horários de ponta pode gerar menos desperdício para o sistema elétrico da cidade e, finalmente, rentabilidade para os negócios, porque a energia excedente pode gerar receitas para a empresa.

SINOPSE 13: Após análise fatorial do survey, sob o ponto de vista dos efeitos e não das causas, novas classificações para as inovações e melhorias em facilidades surgiram como às direcionadas para produtividade, qualidade, sustentabilidade e rentabilidade, apontando novas fronteiras de investigação. 


\section{CONTRIBUIÇÕES DO ESTUDO, LIMITAÇÕES E CONCLUSÕES.}

As empresas instaladas no Brasil do século XXI, com produto interno bruto sempre próximo a $5 \%$ aa, necessitam de investimentos crescentes nas suas infraestruturas (instalações, máquinas, equipamentos e mão de obra especializada). Não há como manter o crescimento dos negócios sem passar pelas estratégias de sustentação desses ativos físicos. É nesse âmbito, o do suporte às operações centrais, que a área de facilidades atua por meio de múltiplas atividades como as de gestão da manutenção predial, das utilidades, da administração de propriedades, do meio ambiente, dos layouts e arranjos físicos, das construções e reformas e dos serviços compartilhados (como os de alimentação, estacionamento e limpeza).

O papel dos profissionais de facilidades em organizações localizadas no Brasil, como apontado pela revisão de literatura e pesquisas de campo, ainda é mais operacional do que estratégico, com escassas posições de alto comando. Em contrapartida, nessa posição operacional dentro de um cenário aparentemente pouco dinâmico, no qual está inserida a disciplina de facilidades, foi constatada uma constante busca pela mudança, melhoria contínua e inovações. Todavia, não são mudanças que diferem tanto pela natureza, mas pelo modo operacional em que são implantadas e pelos resultados alcançados. As próximas seções trataram das respostas às questões de pesquisa, implicações gerenciais, limitações da pesquisa, contribuições teóricas e novas pesquisas.

\subsection{Respondendo a questão geral da tese}

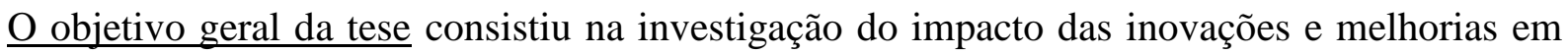
facilidades no desempenho operacional das organizações, obtendo mais informações sobre quais são as características dessa inovação e melhoria, e os fatores de desempenho afetados (eficiência operacional e desempenho financeiro).

A principal maneira em que são implantadas as mudanças é com a gestão informal e em parcerias. Os profissionais não possuem uma metodologia formal para pesquisa e desenvolvimento, mas pelo contato direto com prestadores e tomadores de serviços e fornecedores de máquinas e equipamentos, acabam, sistematicamente, detectando e solucionando problemas do cotidiano nas infraestruturas periféricas. Essas mudanças afetam, principalmente, os fatores ligados a produtividade e meio ambiente. 
Não foi possível isolar completamente a inovação da melhoria. Um dos esforços da teoria da inovação tem sido o de catalogar ou tipificar as inovações, separando-as das melhorias contínuas. Nas investigações de campo dessa tese, observou-se que essas duas classes, inovação e melhoria, não se separam, são interdependentes. Elas representariam uma só dimensão que é a da mudança em facilidades. Para os profissionais inquiridos, a relevância não estava em classificar a mudança, mas no impacto que ela produzia em suas infraestruturas, remetendo às observações de Slappendel (1996) e Zaltman et al (1973) sobre o papel da percepção do adotante sobre a novidade. Diferentemente de uma inovação em produto, quase sempre perceptível aos olhos, uma mudança em facilidades possui alternâncias de elementos tangíveis e intangíveis, discutidos ao longo da tese, que impossibilitaram categorizações separadas. Essa mesma dificuldade em separar inovação incremental e melhoria contínua foi discutida por Tidd et al (2008) quando os autores chegam a propor que ambas, inovação incremental e melhoria contínua, sejam da mesma classe: uma inovação contínua, surgindo ora emergentes, ora deliberadas.

\subsection{Respondendo as questões específicas da tese}

1. A primeira diz respeito à caracterização das inovações e melhorias em facilidades. Constatou-se que as mudanças técnicas e organizacionais produzidas pelos agentes poderiam, na maioria dos casos, ser classificadas como melhorias contínuas e inovações incrementais e não inovações que produzem mudanças drásticas nos bens ou serviços. Poucos foram os casos de inovações radicais. No geral, elas surgem das pressões internas das empresas em busca de eficiências. Essas pressões ocorreram por inércia organizacional, isomorfismo tecnológico, degradação dos ativos, ingerências e restrição de recursos. As mudanças são implantadas em boa parte com o uso da improvisação e do contato entre tomadores, prestadores de serviços e fornecedores de equipamentos, máquinas e sistemas. Analisando as mudanças pela ótica da curva U, percebeu-se que elas seriam mais intensa nas extermidades, próxima do momento de implantação dos mesmos (start up), provavelmente em função dos ajustes técnicos iniciais, e no fim da vida útil, onde as adaptações ocorreram para redução dos desgastes do tempo. As mudanças apontadas ao longo da curva U são menos intensas em novidades, sendo frequentemente melhorias contínuas para aumento da produtividade ou adequação às normas e leis sócio-ambientais. 
Outra constatação foi que uma melhoria técnica pode produzir uma melhoria organizacional, e vice-versa. A implantação da torre de resfriamento propiciou, entre outros ganhos, a especialização da manutenção e o reforço das competências já existentes. Outro achado, no caso da torre de resfriameno, foi que uma mudança em facilidades pode ser complexa, dada as interações dos seus componentes, ser hierarquizada em componentes, subsistemas e sistemas, ser dominante e local, já que a implantação deve respeitar o contexto e as condições físicas e ambientais da planta industrial, ser adaptativa, pois se ajusta aos fatores exógenos como o clima local e as restrições operacionais do parque de torres e, finalmente, com alta pleitropia, pois as modificações nos componentes centrais afetam, em diferentes intensidades, o sistema (e seus atributos) como um todo.

2. O segundo objetivo era analisar como as inovações e melhorias impactam a eficiência operacional das organizações. Os impactos foram maiores nos fatores de meio ambiente e produtividade e menores nos financeiros, demonstrando que os profissionais da área estão direcionados para ações de ordens operacional e sócioambiental. Vale lembrar que o próprio crescimento das áreas de facilidades nas organizações americanas remonta a década de 1960, quando surgem movimentos, ainda que embrionários, de terceirizações em massa nas áreas de serviços e pressões sócio-ambientais nas empresas, criando, nas estruturas organizacionais, a figura do gestor de facilidades.

Notou-se, também, que certos tipos de inovações e melhorias, empresas e agentes afetam determinados fatores. Por exemplo, para as melhorias mais próximas das atividades centrais das empresas, os impactos nos fatores de entrega, vendas e participação de mercado foram maiores, possivelmente por conta do perfil da empresa (prestadora de serviços). Já quando a inovação era motivada para resolução de problemas, o impacto em lucro reduzia, presumindo-se que as melhorias geradas para resolução de problemas afetam mais os fatores de eficiência operacional. Em relação ao tamanho das empresas, para as grandes, o impacto no fator de produtividade foi maior que em vendas e participação de mercado. Houve, também, diferenças entre os níveis hierárquicos e experiência profissional. Para os profissionais em cargos executivos, o fator qualidade foi o menos mencionado, provavelmente por fazer parte das decisões que estão mais no âmbito operacional. $O$ fator segurança, para os profissionais mais experientes, foi o mais significativo. 
A tese apresentou, após verificação dos impactos, novas classificações das inovações e melhorias sob o ponto de vista dos efeitos destas nos desempenhos organizacionais, respondendo a questão suplementar sobre a heterogeneidade das inovações e melhorias. Foram classificadas nessa tese como inovações e melhorias nas facilidades para produtividade, qualidade, sustentabilidade e rentabilidade.

3. O próximo objetivo específico foi demonstrar as diferenças do impacto nas eficiências operacionais e nos fatores de desempenho financeiro. Adicionalmente, buscaram-se possíveis trade-offs entre os fatores impactados pelas mudanças, mas os resultados apontaram que eles foram sempre positivos, padecendo de mais investigações de campo para ratificar os achados. Não foram encontrados trade-offs negativos, possivelmente pela dificuldade de acesso dos respondentes aos métricos reais das organizações. Ainda que as respostas tenham sido revalidadas, é provável que uma mudança gere impactos positivos e negativos ao longo do tempo, por exemplo, a instalação de um novo motor de compressor de ar comprimido com consumo mínimo de energia e partida suavizada. Se esse motor for mantido ao longo dos anos por uma política de manutenção falha, passará a gastar mais energia, ou seja, um efeito contrário do objetivo inicial.

O modelo de hipóteses confirmou que as inovações e melhorias citadas pelos profissionais impactaram mais nos fatores de eficiência operacional (especificamente os de produtividade e meio ambiente). Ainda observou-se uma correlação intensa entre os fatores de produtividade com qualidade e custos com entrega, possivelmente numa espécie de alavancagem mútua. $\mathrm{O}$ fator de segurança foi o menos afetado no grupo de eficiência operacional. Ainda que de maneira menos intensa, os fatores de desempenho financeiro apareceram no modelo de hipóteses com destaque para o lucro, seguido de participação de mercado e vendas (os dois últimos com forte correlação entre si). Esses achados podem estar atrelados ao perfil mais operacional dos profissionais que responderam o survey, mesmo aqueles em posição de comando. Essa hipótese reforça os trabalhos de Ferreira (2005) e Shohet e Lavy (2004) para os quais o reconhecimento da área como disciplina estratégica, na literatura internacional, não condiz com o real papel exercido pelos profissionais no mercado de trabalho (este mais operacional do que estratégico). 
Como complemento, a tese buscou ampliar a discussão da atividade de facilidade dentro das disciplinas de Operações. Passaram-se muitos anos desde que a gestão de facilidades aparece timidamente nos livros de administração de produção como aquela responsável pela localização e layout das plantas industriais. Os papéis e responsabilidades aumentaram e essa participação e crescimento não têm sido devidamente explorados pelos pesquisadores da disciplina, o que reduz em muito a modernização da área enquanto objeto de pesquisa. As atividades de facilidades, dentro das áreas de Operações e Serviços, iriam desde a formação dos ativos, da implantação das instalações e das infraestruturas, passando pela manutenção e monitoramento dos mesmos, até o seu descomissionamento, ou seja, é muito mais sofisticado e profundo do que a literatura científica nacional tem retratado. Esse ciclo, quando em algumas ocasiões dura mais de cinqüenta anos, dificulta o corte longitudinal das pesquisas, por isso, constantemente, a área é tida erroneamente como em constante inércia. A falsa inércia e o isomorfismo também prejudicam os estudos acerca das suas inovações e melhorias, pois estas, classicamente, ocorrem em curtos ou médios períodos de tempo e em grandes intensidades, o que não acontence nas facilidades. Deve-se considerar, para futuros trabalhos, o descompasso temporal do fenômeno e a perspectiva histórica das mudanças analisadas.

\subsection{Implicações gerenciais}

Os achados da tese, principalmente os relacionados às classificações das inovações e melhorias em facilidades, podem, no âmbito empresarial, apontar para os gestores e praticantes os caminhos mais adequados para o desenvolvimento e implantação das mudanças, de acordo com perfis específicos das empresas e dos profissionais dessa área. Não obstante, isso sugere ainda a necessidade de pesquisas profissionais setoriais, pois verificou-se que facilidades têm subespecializações como àquelas focadas em serviços, indústria, hospitais, portos etc., demandando respostas singulares. As inovações e melhorias investigadas na tese demonstram que há um estreito relacionamento entre teoria e prática, porque nota-se que a preocupação com sustentabilidade não está só no debate acadêmico, mas também na ação, visto que algumas mudanças impactaram positivamente os fatores relacionados ao meio ambiente. $\mathrm{O}$ foco em sustentabilidade apontaria uma possível especialização do mercado, como a do reuso das facilidades após o descomissionamento dos ambientes construídos. Isto abriria espaço para empresas interessadas em mitigar impactos ambientais das construções e plantas industriais, em descartar equipamentos e instalações contaminados, em reaproveitar mobiliários, em reutilizar e atualizar máquinas antigas para 
novas funções, em buscar e selecionar normas, leis e regulamentações específicas para facilidades, entre outras.

Sugeriu-se uma análise estratificada das infraestruturas em componentes, subsistemas e sistemas (como a utilizada na seção 5.2), permitindo ao gestor encontrar novas oportunidades de melhorias contínuas e receitas, reduzindo o estigma de área geradora de despesas. Também foi possível notar que as mudanças técnicas produzidas por fornecedores de equipamentos e máquinas propiciam mudanças organizacionais, e vice-versa, indicando futuros negócios para os prestadores e tomadores de serviços de facilidades.

Como boa parte das inovações e melhorias ocorreram durante a implantação, remetendo aos trabalhos de Leonard-Barton, recomenda-se atenção durante essa fase. Nela, para adequação das especificações técnicas ou desejos dos clientes à realidade encontrada no ato da implantação, os gestores poderiam produzir soluções técnicas que futuramente se tornam novos serviços. Um exemplo é o da torre de resfriamento que, durante a implantação, verificou-se a necessidade de adoção de bandejas para captação da água excedente. É uma melhoria que não estava contemplada na instalação e que gerará um novo serviço. Mais um exemplo, ainda na torre, é a do acionamento dos equipamentos, em função da nova configuração, que deverá respeitar uma sequência totalmente nova, demandando um dispositivo sequenciador eletrônico capaz de atendê-la. Para isso, os gestores precisam de um monitoramento sistemático nessa etapa.

Outro dado revelado pelas pesquisas de campo e do survey foi a importância do desenvolvimento de softwares específicos para gestão de facilidades. Apesar de estarmos em pleno século XXI, onde as decisões gerenciais são amplamente suportadas por ferramentas de decisão computadorizadas, muito dos inqueridos apontaram a introdução de um aplicativo como uma melhoria de grande impacto nos fatores de eficiência. Essa constatação indica um amplo campo, o de novas tecnologias da informação para gestão das facilidades, a ser explorado. 


\subsection{Limitações da tese}

- A primeira limitação se deu no objeto da tese: inovação e melhoria em facilidades. As duas classes, dada a proximidade das características no contexto de facilidades, são interdependentes, não sendo possível a separação.

- Pôde-se observar na fundamentação teórica, que inovações e melhorias em processos e as em facilidades estão muito próximas, sendo que a segunda está contida na primeira. Essa linha tênue que separa uma da outra, por vezes, poderia confundir a análise, sendo assim, utilizou-se o conceito de centralidade no escopo para diferenciá-las.

- Uma das limitações metodológicas é que não foram encontrados instrumentos de coleta de dados específicos para o empreendimento dessa tese. O questionário desenhado foi baseado tanto na pesquisa empírica quanto na teórica. O cuidado extra que se teve durante a coleta de dados foi reforçar, em cada questão, o significado da pergunta, evitando erros de interpretação dos conceitos apresentados.

- O que definiu a força das dimensões foi a moda, ou seja, quanto mais alta, maior o impacto. Essa foi a medida estatística adotada, contudo não houve contraprova por meio de indicadores quantitativos reais das organizações. $\mathrm{O}$ indicador foi substituído pela percepção dos respondentes quanto ao grau de importância (escala Likert) de cada dimensão. Para evitar o viés de um determinado nível hierárquico nas respostas, todos foram considerados.

- O instrumento de coleta de dados abordou a inovação ou melhoria mais importante ocorrida no departamento do respondente nos últimos dois anos, não considerando as demais inovações ocorridas neste período.

- A análise fatorial foi gerada com um número baixo de observações, 49 respostas válidas, o que a restringe ao universo aqui estudado.

- Boa parte das melhorias e inovações deu-se em empresas do setor industrial, portanto, convém expandir a amostra para outros setores. 


\subsection{Contribuição teórica e novas pesquisas}

Durante a execução de todas as fases da tese, vários achados poderiam contribuir com as teorias correntes da inovação e de facilidades. Contudo, devidamente aprofundados, eles se tornam pontos de partida para novas pesquisas. Destacam-se nesse grupo:

1. Uma das contribuições da tese foi a adequação do modelo dinâmico das inovações de Utterback e Abernathy (1975), acrescentando-se à curva U as melhorias e inovações das facilidades. Elas têm ciclos e dinâmicas peculiares, pois seriam mais intensas na formação e composição dos ativos e infraestruturas e no final do ciclo de vida dos mesmos. Surgem, geralmente, das tensões exercidas entre as pressões das especificações técnicas e dos requisitos dos clientes, estes presentes em todas as fases de desenvolvimento e implantação, diferentemente das melhorias e inovações tradicionais. Essa constatação demonstra, ainda que por meio de uma pequena amostra, a importância que as mudanças em facilidades têm no prolongamento do ciclo de vida dos ativos das empresas e no desenvolvimento dos produtos e serviços das organizações.

2. Leonard-Barton (1992) advoga que a implantação de uma mudança também gera inovação (na adaptação mútua entre tecnologia e organização). Muitas das inovações e melhorias em facilidades analisadas surgiram durante a implantação de alguma mudança. Essa relação mútua entre as mudanças deliberadas e as emergentes demonstra que novas pesquisas durante a implantação de uma mudança poderia reforçar a teoria de Barton.

3. Nessa tese pode-se constatar que boa parte das mudanças surgiu da improvisão e do "conhecimento infraestrutural" das facilidades. Esse termo, lançado na tese, seria outro campo de pesquisa no âmbito da aprendizagem e do conhecimento nas melhorias e inovações. O "aprender fazendo, operando e simulando" seria uma adição aos achados de Bell (1984) sobre o processo de aprendizagem.

4. Utilizou-se uma nova forma de investigar as infraestruturas das organizações, por meio das definições e estratificações de Murmann e Frenken (2006), que subdividem um artefato em componentes, subsistemas e sistemas, analisando-se a pleitropia dos mesmos e seus efeitos. Não seriam as infraestruturas, sistemas sócio-tecnológicos complexos adaptativos? Contudo, novas investigações poderiam comprovar a eficiência desse tipo de estratificação. 
5. Nakajima (1988) fundamentou os conceitos de TPM, indicando critérios de desempenho que os gestores deveriam focar. Contudo, esses critérios tinham pesos equivalentes. Essa tese pode comprovar a eficácia do uso desses critérios como ferramenta de análise dos impactos das inovações e melhorias, porém ponderados e aglomerados. Com o uso da análise fatorial os gestores e pesquisadores poderiam direcionar as inovações e melhorias para determinados resultados ou estudar os efeitos isoladamente.

6. Percebeu-se uma preocupação com as questões sócio-ambientais nas mudanças geradas nas facilidades. Não seria o caso de examinar as "facilidades reversas" utilizando o mesmo conceito empregado pela logística reversa? Ou seja, após o descomissionamento das instalações, não poderiam essas seguir um fluxo reverso e serem reaproveitadas? As novas plantas industriais, a exemplo das novas gerações de usinas sucroalcooleiras, não poderiam ser limpas, flexíveis e, sobretudo, recicláveis?

7. A relação entre a teoria da inovação e da qualidade ficou no campo da suposição, dada a limitação das informações coletadas. Quiçá a maturidade empresarial adquirida ao longo dos anos pelas empresas instaladas no país contribuiu decisivamente para a busca do "fazer diferente". As teorias da qualidade e a da inovação poderiam, por essa ótica, contribuir com o aprofundamento dos artefatos gerados pelos movimentos da qualidade e não somente da gestão utilizada. Há indícios, nos casos levantados, de que as mudanças geradas pelos agentes foram beneficiadas pelo ambiente organizacional existente. $\mathrm{O}$ ambiente, adotante formal ou informal de políticas ou práticas da qualidade, poderia favorecer o surgimento das mudanças em facilidades, principalmente numa área tipicamente estável.

Por vezes, a Administração, enquanto ciência social aplicada, catalisa as mudanças no mundo dos negócios em três perspectivas históricas: contando um fato já ocorrido; descrevendo um evento no momento da ação ou; por meio de traços, prevendo um fenômeno a ocorrer. Esta tese se encaixaria melhor na segunda opção, ou seja, a de investigar um fenômeno em curso. Estudar um assunto em construção tem desafios como o de não descartar indícios que, num primeiro momento, parecem insignificantes, ou de aprofundar em demasia uma parte desse fenômeno em detrimento de outra. A academia, dentro das áreas de Operações e Serviços, ao longo das últimas décadas, muito se esforçou para ampliar e aprofundar os estudos sobre as 
estratégicas de produção, mas esse trabalho não se esgota na medida em que essas estratégias e dinâmicas organizacionais se alteram continuamente. Uma dessas alterações, que muito se destacou nesse trabalho, foi da ascensão, dentro das tecnoestruturas, das atividades de apoio as infraestruturas e instalações físicas das empresas - chamadas de gestão de facilidades, tradução livre da expressão anglo-saxônica "facilities management". Tema esse em discussão nos países desenvolvidos há mais de dez anos. Por que o assunto tem sido abordado nos últimos tempos tanto pelo mercado como pela academia internacional, além das publicações acadêmicas, formação de associações profissionais, mestrados e doutorados? Por que pouco se discute no Brasil?

A resposta se existe uma, parece encontrar-se justamente nas novas demandas das organizações. Sabiamente, em tempos recentes, as empresas têm tratado as suas infraestruturas e instalações, sejam fábricas ou escritórios, como ativos estratégicos. No passado, as funções de localização ou layout, desempenhadas nas indústrias pela chamada engenharia de instalações, não consideravam todo o ciclo de vida das instalações, pois elas perdurariam várias décadas numa espécie de inércia e enfatizariam os processos operacionais internos. Assim, muitas fábricas foram desenhadas e instaladas em locais e formatos que hoje seriam considerados impróprios. Critérios como passivos ambientais e trabalhistas, custos de descomissionamento, fábricas e tecnologias enxutas e operações limpas, não eram tão aplicados aos processos produtivos. Todavia, pressões sociais e econômicas fizeram os gestores repensarem essas questões e a "olharem" para fora das fronteiras internas. Sejam para empresas em início de formação, que considerarão instalações enxutas, para as intermediárias, que buscarão rearranjos infraestruturais mais adequados, como para as maduras, que necessitarão de respostas tecnológicas para mitigarem os impactos gerados por suas operações. Nessas três fases, retomando o ciclo de Utterback e Abernathy (1975), haverá a participação da gestão das facilidades na apresentação de soluções técnicas ou organizacionais para as infraestruturas e instalações de apoio.

No Brasil, inicia-se um movimento embrionário em direção aos avanços conseguidos pelos países desenvolvidos. O avanço do tema se dá no mercado por meio do crescimento das associações profissionais e da conquista de posições de comando nas empresas, como percebido nas pesquisas de campo e por vias acadêmicas, ainda que tímidas, com artigos, cursos de pós-graduação e dissertações de mestrado. As sinopses apresentadas ao longo da tese demonstram, também, outras nuances desse crescimento, como o direcionamento dos 
esforços das organizações na busca de soluções alinhadas com as novas perspectivas citadas no parágrafo anterior. Algumas (soluções) focadas em sustentabilidade, outras em rentabilidade, produtividade e qualidade. Provavelmente, numa amostra maior, seria possível verificar se esses direcionamentos têm relação com os estágios de vida dessas organizações.

O fato é que a gestão das facilidades representa uma nova fronteira e campo de estudo em Operações, num movimento parecido com o enfrentado pela logística, nos anos de 1970, e pela tecnologia da informação, nos anos de 1990, ambas as áreas de apoio às operações e, nos dias de hoje, amplamente cobertas pelos estudos e pesquisas acadêmicas.

Ao longo dos anos de 2007 a 2010 foi possível não apenas investigar um fenômeno - o das facilidades, suas inovações e melhorias com seus impactos, como também ressaltar a necessidade de novas discussões dentro dos saberes da Administração nas chamadas áreas de operações e serviços, vitais para a sobrevivência de quaisquer organizações. 


\section{REFERÊNCIAS}

ABERNATHY, W. J.; CLARK, K. B. Innovation: mapping the winds of creative destruction. Research Policy. v.14, 1985, pp. 3-22.

ABERNATHY, W. J.; UTTERBACK, J. Patterns of industrial innovation. Technology Review. v.50, 1978, pp.41-47.

ABRAFAC - Associação Brasileira de Facilities - $1^{\text {a }}$ Pesquisa sobre o profissional de facilities no Brasil. Documentos. Disponível em: <http://www.abrafac.com.br >. Acesso em: 20 mai 2006.

ADNER, R.; LEVINTHAL, D. Demand heterogeneity and technology ev.ution: implications for product and process innovation. Management Science. v.47, n.5, ABI/INFORM Global, May 2001, p.611

ALEXANDER, K. Facilities management: theory and practice. Taylor \& Francis: United Kingdom, 1996.

ANDERSON, P.; TUSHMAN, M. L. Technological discontinuities and dominant designs: a cyclical modelo of technological change. Administrative Science Quartely. v.35, n.4, 1990, pp.604-633.

ANDRADE, T. Inovação e ciências sociais: em busca de novos referenciais. RBCS, v.20, n.58, jun 2005, pp. 145-211.

ANDREASSI, T. A gestão da inovação tecnológica. São Paulo: Thomson Pioneira, 2006.

ANFAVEA - Associação Nacional dos Fabricantes de Veículos Automotores. Estatísticas. Disponível em:<http://www.anfavea.com.br>. Acesso em: 20 out 2007.

AVERMAETE, T. et al. Determinants of innovation in small food firms. European Journal of Innovation Management. Bradford, v.6, n.1, 2003, pp. 8-17.

BABA, Y. The dynamics of continuos innovation in scale-intensive industries. Strategic Management Journal. v.10, 1989, pp. 89-100.

BARRAS, R. Towards a theory of innovation in services. Research Policy. v.15, 1986, pp.161-173.

BHASKARAN, S. Incremental innovation and business performance: small and medium-size food enterprises in a concentrated industry environmental. Journal of Small Business Management. v.44, n.1, 2006, pp. 64-80.

BECHEIKH, N.; LANDRY, R.; AMARA, N. Lessons from innovation empirical studies in the manufacturing sector: a systematic review of the literature from 1993-2003. Technovation. v.26, issues 5-6, May/June 2006, pp. 644-664. 
BELL, M. Learning and the accumulation of industrial technology capacity in developing countries. In: FRANSMAN, M.; KING, K. Technological capability in the third world. New York, St. Martin's Press, 1984, pp. 187-209.

BOLWIJN, P. T.; KUMPE, T. Manufacturing in the 1990s - productivity, flexibility and innovation. Long Range Planning. v.23, n.4, 1990, pp. 44-57.

BOND, T. C. The role of performance measurement in continuos improvement. International Journal of Operations \& Production Management. Bradford, v.19, n.12, 1999, p. 1318.

BROWN, S. L.; EISENHARDT, K. M. Product development: past research, present findings, and future directions. The Academy of Management Review. v.20, n. 2, 1995, pp. 343-378.

BURAWOY, M. Revisits: an outline of a theory of reflexive ethnography. American Sociological Review. v.68, n. 5, ABI/INFORM Global, Oct 2003, p. 645.

CARDELLINO, P.; FINCH, E. Evidence of systematic approaches to innovation in facilities management. Journal of Facilities Management. v.4, n.3, 2006, pp. 150-166.

CHEN, J.S.; TSOU, H.T. (2007). Information technology adoption for service innovation practices and competitive advantage: the case of financial firms, Information Research, 12(3) paper 314. [Available at http://nformationR.net/ir/123/paper314.html].

CHURCHMAN, C. W. The systems approach. New York: Dell Pub. Co., 1968.

CLARK, G.; JOHNSTON, R. Administração de Operações de Serviços. São Paulo: Atlas, 2002.

COOBS, R.; NARANDREN, P.; RICHARDS, A. A literature-based innovation output indicator. Research Policy. v.25, 1996, pp. 403-413.

COOPER, R.; EDGETT, S.; KLEINSCHMIDT, E. Portfolio management for new product development: results of a industry practices study. R\&D Management. v.31, n.4, 2001, pp. 361-379.

COOPER, D. R.; SCHINDLER, P. S. Método de Pesquisa em Administração. 7 ed. Porto Alegre: Bookman, 2003.

CORDERO, R. The measurement of innovation performance in the firm: an overview. Research Policy. v.19, 1990, pp. 185-192.

CORRAR, L. J.; PAULO, E.; FILHO, J. M. D. (coordenadores). Análise Multivariada para os cursos de Administração, Ciências Contábeis e Economia. São Paulo: Atlas, 2007. 
CORREIA, H. L.; CORREIA, C. A. Administração de produção e operações: manufatura e serviços, uma abordagem estratégica. São Paulo: Atlas, 2005.

CHOI, T. Conceptualizing continuous improvement: implications for organizational change. International Journal Management Science. v. 23, 1995, pp. 607-624.

DA SILVEIRA, G.; SLACK, N. Exploring the trade-off concept. International Journal of Operations \& Production Management. v.21, n.7, ABI/INFORM Global, 2001, p. 949.

DANNEELS, E. The dynamics of product innovation and firm competendes. Strategic Management Journal. v. 23, 2002, pp. 1095-1121.

DAVENPORT, T. H. Need radical innovation and continuous improvement? Integrete process reengineering on TQM. Planning Review. v.21, n.3, ABI/INFORM Global, May/June1993, p. 6.

DEMING, W. E. Improvement of quality and productivity through action by management. In: TUSHMAN, M. L.; MOORE, W. L. Readings in the management innovation. Cambridge, Massachusetts, 1988, pp.454-465.

DOSI, G. Technological paradigms and technological trajectories: a suggested interpretation of the determinants and directions of technical change. Research Policy. v. 11, 1982, pp. 147-162.

DOUGLAS, T. J.; JUDGE, W. Q. JR. Total quality management implementation and competitive advantage: the role of structural control and exploration. Academy of Management Journal. v. 44, n. 1, Feb 2001, pp. 158-169.

DRUCKER, P. F. Inovação e espírito empreendedor (entrepreneurship): prática e princípios. São Paulo: Pioneira, 1986.

EHIGIE, B. O.; MCANDREW, E. B. Innovation, diffusion and adoption of total quality management (TQM). Management Decision. v. 43, 5/6; ABI/INFORM Global, 2005, p.925.

EASTERBY-SMITH, M.; THORPE, R.; LOWE, A.Pesquisa gerencial em Administração: um guia para monografias, dissertações, pesquisas internas e trabalhos de consultoria. São Paulo: Pioneira, 1999.

FAGERBERG, J. Innovation: a guide to the literature. Centre of Technology, Innovation and Culture. University of Oslo, Oct 2003.

FERREIRA, F. P. Gestão de facilities: estudo exploratório da prática em empresas instaladas na região metropolitana de Porto Alegre. Dissertação de mestrado. Universidade Federal do Rio Grande do Sul. Porto Alegre, maio 2005. Disponível em: < http://www.lume.ufrgs.br/handle/10183/6527> Acesso em: 15 nov 2009. 
FERREIRA, J. J. M.; MARQUES, C. S. E.; BARBOSA, M. J. Relação entre inovação, capacidade inovadora e desempenho: o caso das empresas da região da Beira Interior. Revista de Administração da Inovação - RAI, São Paulo. v.4, n. 3, 2007, pp. 117 132.

FLIKKEMA, M.; JANSEN, P.; VAN DER SLUIS, L. Identifying neo-schumpeterian innovation in service firms: a conceptual essay with a novel classification. Economics of Innovation and New Technology. v. 17, n.7, 2007, pp. 541-558.

FREEMAN, C. The economics of industrial innovation. Pinguim Books: England, 1974.

FREEL, M. S.; ROBSON, P. J. A. Small firm innovation, growth and performance: evidence from Scotland and Northern England. International Small Business Journal. v. 22, 2004, p. 561-575.

FRIEDMAN, M. Externalities: there is a free lunch, 2008. Vídeo disponível em: http://www.youtube.com/watch?v=g-1P6lhe9Wo. Acesso em: 20 Setembro 2009.

GADREY, J.; GALLOUJ, F. New moes of innovation: how services benefit industry. International Journal of Service Industry Management. v.6, n. 3, 1995, pp.4-16.

GALLOUJ, F. Economia da Inovação: um balanço dos debates recentes. In: BERNARDES, R.; ANDREASSI, T. Inovação em Serviços Intensivos em Conhecimento. Saraiva: São Paulo, 2007, pp. 7-10.

GALlOUJ, F.; WEINTEIN, O. Innovation in services. Research Policy. v.26, 1997, pp. 537556.

GATI-WECHSLER, A. M.; NASCIMENTO, P. T. S. Manufacturing role in simple product development at a multi-project environment. PICMET 2008 Proceedings, 27-31 July, Cape Town, South Africa (c), 2008.

GOPALAKRISHNAN, S.; BIERLY, P.; KESSLER, E. H. A reexamination of product and process innovation using a knowledge-based view. The Journal of High Technology Management Research. v.10, n.1, 1999, pp.147-166.

GOYAL, S.; PITT, M. Determining the role of innovation management in facilities management. Facilities. v. 25, n. 1/2, 2007, pp. 48-61.

GUAN, J. Comparasion study of industrial innovation between China and European countries. Production and Inventory Management Journal , v.43, 3/4. ABI/INFORM Global, third quarter 2002, p. 30

HAGE, J. T. Organizational innovation and organizational change. Annu. Rev. Sociol. v.25, 1999, pp. 597-622.

HAIR, J. F. et al. Análise multivariada de dados. 5ed. Porto Alegre: Bookman, 2005. 
HAMEL, G.; PRAHALAD, C. K. Competing for the future. Boston: Harvard Business School Press, 1994.

HAUSTEIN, H. D.; MAIER, H. Basic, improvement and pseudo-innovations and their impact on efficiency. International Institute for Applied Systems Analysis. Aústria, Laxenburg, Sep 1979.

HAYES, R.; PISANO, G.; UPTON, D.; WHEELWRIGHT, S. Produção, Estratégia e Tecnologia: Em busca da vantagem competitiva. Porto Alegre: Bookman, 2008.

HEGARU, S. S. Facilities Design. 3 ed, FL, USA: CRC Press , 2008.

HENDERSON, R. M.; CLARK, K. B. Architectural innovation: the reconfiguration of existing product technologies and the failure of established firms. Administrative Science Quartely. v. 35, 1990, pp. 9-30.

HOANG, D. T.; IGEL, B. The impact of total quality management on innovation: findings from a development. International Journal of Quality and Reliability Management. v. 23, 9, 2006, pp. 1092-1117.

HOLLAND, J. Hidden Order. How adaptation builds complexity. Addison-Wesley Publishing Company. Reading, Mass., etc., USA, 1995.

HUNG, S. C. Explaining the process of innovation: The dynamic reconciliation of action and structure. Human Relations. v. 57, 2004, pp. 1479-1497.

IANSITI, M. Technology integration: managing technological ev.ution in a complex environment. Research Policy. v. 24, 1995, pp. 521-542.

IFMA. World Workplace with Facilities America 2003. Disponível em: <http://www.worldworkplace.org/northamerica/2003>. Acesso em: 8 fev. 2006

IMAI, M. Kaizen: the key to Japan's competitive success. McGrow-Hill, New York, NY, 1987.

ITTNER, C. D.; LARCKER, D. F. Innovations in performance measurement: trends and research implications. Journal of Management Accounting Research. ABI/INFORM Global, v.10, 1998, p. 205.

KAYNAK, H. The relationship between total quality management practices and their effects on firm performance. Journal of Operations Management. v. 21, 2003, pp. 405-435.

KAPLAN, R. S.; NORTON, D. P. Linking the balanced scorecard to strategy. California Management Review. ABI/INFORM Global, v.39, n.1, Fall 1996, p. 53.

KEMP, R. G. M.; et al. Innovation and firm performance. Research Report H200207, Zoetermer, 2003. 
KLEMENTI, C. F. F. Inovação em Serviços: estudo de casos em uma organização da indústria hoteleira brasileira. Tese (doutorado). São Paulo: Universidade de São Paulo, 2007.

KNIGHT, K. A descriptive modelo of the intra-firm innovation process. Journal of Business. v. 40, n.4, Oct 1967, pp. 478.

KOELLINGER, P. The relationship between technology, innovation, and firm performance: empirical evidence from e-business in Europe. Research Policy. v. 37, 2008, pp. 1317-1328.

KOTABE, M.; MURRAY, J. Y. Linking product and process innovations and modes of international sourcing in global competition: a case of foreign multinational firms. Journal of International Business Studies. v.21, n.3. ABI/INFORM Global, third quarter, 1990, p. 383.

LAGER, T.; HORTE, S.-A. Success factor for improvements and innovation process of process technology in process industry. Integrated Manufacturing Systems. v. 13, n.3, 2002, pp. 158-164.

LEONARD-BARTON, D. Implementation as the mutual adptation of technology and organization. Research Policy. v.17, n.5, 1988, pp. 251-267.

. The factory as a learning laboratory. Sloan Management Review. v.34, n.1, ABI/INFORM Global, 1992, p. 23.

LEVIN, J. Estatística Aplicada a Ciências Humanas. 2 ed. São Paulo: Harbra, 1987.

LI, Y.; LIN, Y.; REN, F. Product innovation and process innovation in SOEs: evidence from the Chinese transition. Journal Technol Transfer. v.32, 2007, pp.63-85.

LIN, C. Y.; CHEN, M. Y. Does innovation lead performance? An empirical study of SME's in Taiwan. Management Research News. v. 30, n.2, 2007, pp. 115-132.

LORD, A. L.; PRICE I, S.; STEPHENSON, P. Emergent behavior in a new market: facilities management in the UK. Disponível em:< www.ifm.eng.cam.ac.uk/mcn/pdf_files/part7_1.pdf>. Acesso em: 20 jan. 2006.

MAIA, J. L.; CERRA, A. L.; ALVES, A. G. Inter-relações entre estratégias de operações e gestão da cadeia de suprimentos: estudos de casos no segmento de motores para automóveis. Gestão e Produção. v. 12, n. 3, set-dez, 2005, pp. 377-391.

MCKOBE, K. E.; SCHROEDER, R. G.; CUA, K. O. The impact of total productive maintenance practices on manufacturing performance. Journal of Operations Management. v. 19, 2001, pp. 39-58.

MALHOTRA, N. K. Pesquisa de Marketing: uma orientação aplicada. 3. ed. Porto Alegre: Bookman, 2001 
MANSHARAMANI, V. Towards o theory of services innovation: an inductive case study approach to evaluating the uniquess of services. Master of Science. Massachussets Institute Technology, 2005.

MANUAL DE OSLO - versão 2005. Disponível em: <http://www.mct.gov.br/upd_blob/0005/5068.pdf> Acesso em: 20 out 2007.

MARCUS, G. Kluge: the haphazard construction of the human mind. USA: Houghton Mifflin, 2008.

MARTINS, G. A. Manual para elaboração de monografias e dissertações. 3 ed. São Paulo: Atlas, 2002.

MELNYK, S. A.; STEWART, D. M.; SWINK, M. Metrics and performance measurement in operations management: dealing with the metrics maze. Journal of Operations Management. v.22, 2004, pp. 209-217.

MINTZBERG, H. The structuring of organization. Englewood Cliffs, N.J.: Prentoce Hall, 1979.

Criando organizações eficazes: estruturas em cinco configurações. 2. Ed. São Paulo: Atlas, 2003.

MONACO, F. F.; GUIMARÃES, V. N. Creating and innovation in the context of team-work: an evaluation in the self-management cells and quality control circles of Ambev SC Branch. Brazilian Administration Review. v. 4, n.1, 2007, pp. 21-34.

MORRIS, D.; BRANDON, J. Reengenharia: reestruturando sua empresa. São Paulo: Makron Books, 1994.

MOREIRA, D.; QUEIROZ, A. C. Inovação Organizacional e Tecnológica. Thomson Learning, 2007.

MOTTA, F. C. P.; VASCONCElOS I. F. G. Teoria Geral da Administração. São Paulo: Thomson Pioneira, 3 ed., 2006.

MOUBRAY, J. Reliability-centred maintenance. Great Britain: Butterworth-Heinemann, 1997.

MURMANN, J. P.; FRENKEN, K. Toward a systematic framework for research on dominant design, technological innovation, and industrial change. Research Policy. v.35, 2006, pp. 925-952.

NASCIMENTO, P. T.; YU, A. S. O.; SOBRAL, M. C. Estratégias de Negócios e Inovação em Mercados de Produtos Populares, ALTEC, 2005.

NAKAJIMA, S. Introduction to TPM. Productivity Press, Cambridge: MA, 1988. 
NÄVY, J. Facility Management: grundlagen, computerunterstützung, einführungsstrategie, praxisbeipiele. 4 ed. Berlin, Heidelberg, New York: Springer Verlag, 2006, p.4.

NAVEH, E.; EREZ, M. Innovation and attention to detail in the quality improvement paradigm. Management Science. v. 50, 11, Nov 2004, pp. 1576-1586.

NEELY, A.; GREGORY, M.; PLATTS, K. Performance measurement system design. International Journal of Operations and Production Management. v. 25, 12, 2005, pp. 1228-1263.

NUTT, B. Linking FM practice and research. Facilities. Bradford: Jan/Fev, v. 17, n. 1/2, 1999, p.11.

OECD. OECD Economic Surveys: Canada. cap.3, OECD, 2006, pp. 73-100.

OICA - Organisation Internationale des Constructeurs d'Automobiles. Statistics. Disponível em:< http://www.oica.net/htdocs/Main.htm>. Acesso em: 02 jan 2007.

OMNI Grupo Industrial de Equipamentos. Torres de resfriamento de água: noções gerais. Disponível em <www.omnigrupo.com.br $>$. Acesso em: 12 nov 2009.

PAVITT, K. Sectoral patterns of technical change: towards a taxonomy and a theory. Research Policy. v. 13, 1984, pp. 343-373.

PESTANA, M. H.; GAGEIRO, J. N. Análise de dados para ciências sociais - a complementariedade do SPSS. Lisboa: Edições Silabo, 4 ed, 2005.

PINTEC 2003. Pesquisa Industrial de Inovação Tecnológica. IBGE, Rio de Janeiro, 2005.

PISANO, G. P. Learning-before-doing in the development of new process technology. Research Policy. v. 25, 1996, pp. 1097-1119.

PORTER, M. E. Technology and competitive advantage. Journal of Business Strategy (pre 1986). ABI/INFORM Global, 1985, p. 60.

The competitive advantage of nations. The free press: New York, NY, 1990.

The technological dimension of competitive strategy. Research on Technological Innovation, Management and Policy, v. 1. JAI Press Inc, 1983.

PRAHALAD, C. K.; HAMEL, G. The core competence of the corporation. Harvard Business Review. May-June, 1990, pp.79-91.

PRAJOGO, D. The relationship between TQM practices, quality performance, and innovation performance: an empirical examination. The International Journal of Quality \& Reliability Management. v. 20, 8/9, ABI/INFORM, 2003, p. 901. 
PROCHNIK, V.; ARAUJO, R. D. Uma análise do baixo grau de inovação na indústria brasileira a partir do estudo das firmas menos inovadoras. Grupo de pesquisa em Cadeias Produtivas URFJ -IE, 2005. Disponível em: <www.ie.ufrj.br/cadeiasprodutivas> Acesso em 10 nov 2008.

QUINELlO, R. A teoria institucional aplicada à Administração. São Paulo: Novatec, 2007.

Impacto das Inovações em Facilidades na Eficiência Operacional. Consórcio Doutoral, ENANPAD 2009, banca 10, projeto 11, 2009 b.

QUINELlO, R.; CASTRO, A. E. M. C. O papel da gestão de facilities no processo de inovação: estudo exploratório em uma indústria automobilística do Estado de São Paulo. Revista Tecnologia e Sociedade, v. 5, 2007, pp. 125-149.

QUINELLO, R.; NASCIMENTO, P. T. S. Caracterização preliminar da inovação na gestão de facilidades industriais: novas perspectivas com a aplicação do extended case method. In: XI SIMPOI - Simpósio de Administração da Produção, Logística e Operações Internacionais, 2008, São Paulo, SP. Anais do SIMPOI 2008. São Paulo, SP : Escola de Administração de Empresas de São Paulo da Fundação Getúlio Vargas, 2008.

Repaginando um Elo de Operações: Breve História da Gestão de Facilidades, Prováveis Origens e Desenvolvimento da Atividade no Âmbito Organizacional. In: XI SIMPOI - Simpósio de Administração da Produção, Logística e Operações Internacionais, 2008, São Paulo, SP. Anais do SIMPOI 2008. São Paulo, SP : Escola de Administração de Empresas de São Paulo da Fundação Getúlio Vargas, 2008b.

O processo de inovação sob o enfoque institucionalista: um estudo etnográfico na gestão de facilidades de uma montadora do Estado de São Paulo. Revista de Administração e Inovação, v.6, n.1, 2009.

QUINELLO, R.; NICOLETTI, J.R. Gestão de facilidades. Novatec: São Paulo, 2006.

Inovação Operacional: entenda como atitudes inovadoras aplicadas nos processos industriais podem agregar valor e alavancar a competitividade de sua empresa. Rio de Janeiro: Brasport, 2009.

REICHSTEIN, T.; SALTER, A. Investigating the sources of process innovation among UK manufacturing firms. Industrial and Corporate Change. v. 14, n. 4, 2006, pp. 653682.

ROSENTHAL, S. R.; CAPPER, M. Ethnographies in the Front End: Designing for Enhanced Customer Experiences. Journal of Product Innovation Management. v. 23, May 2006, pp. 215-237.

ROSS, E. A. The location of industries. The Quarterly Journal of Economics, April, 1896, pp. $247-268$ 
SALOMO, S.; TALKE, K.; STRECKER, N. Innovation field orientation and its effect on innovativeness and firm performance. Journal Product Innovation Management. v. 25, 2008, pp. 560-576.

SCHUMPETER. J. A. The theory of economic development. Nova York: Oxford University, 1961.

SEBRAE - Serviço de Apoio às Micro e Pequenas Empresas de São Paulo. Inovação e Competitividade das MPE's paulistas. Observatório das MPE's, jun 2008.

Inovação é muito rara em pequenas empresas brasileiras. Disponível em: $<$ http://www.inovacaotecnologica.com.br/noticias/noticia.php?artigo=inovacao-emuito-rara-em-pequenas-empresas-brasileiras\&id=010175080801> Acesso em 03/08/08.

SELLTIZ, C. Métodos de pesquisa nas relações sociais. São Paulo: Herder, 1974.

SENNET, R. O artifice. Rio de Janeiro: Record, 2 ed, 2009.

SHOHET, I. M.; LAVY, S. Healthcare facilities management: state of art review. Facilties. v.22, n.7, 2004, pp. 210-220.

SHOSTACK, G. L. How to design a service. European Journal of Marketing. v. 16, n. 1, 1982, pp.49-61.

SIEGEL, S. Estatística não paramétrica para as ciências do comportamento. São Paulo: McGraw-Hill, 1975.

SKINNER, W. Manafacturing strategy on the "s" curve. Production and Operations Management. v. 5, n.1, Spring 1996.

SLACK, N. Vantagem competitiva em manufatura : atingindo competitividade nas operações industriais. Sao Paulo: Atlas, 1993

SLAPPENDEL, C. Perspectives on innovation in organizations. Organization Studies, Wntr, 1996.

SMITH, C. O. Introduction to reability in design. Tokyo: McGraw-Hill Kogakusha, 1976.

STORHOLMEN, T.B. Tecnologia finalmente chega aos capacetes de segurança. Foundation for Scientific and Industrial Research. Disponível em: $<$ http://www.inovacaotecnologica.com.br/noticias/noticia.php?artigo=capacete-deseguranca-inteligente\&id=010170080609> . Acesso em 02.Set.2008.

STRAUSS, A.; CORBIN, J. Basics of qualitative research. Thousand Lage Daks: Lage Publications, 1990.

TEECE, D. J.; PISANO, G.; SHUEN, A. Dynamic capabilities and strategic management. Strategic Management Journal. v.18:7, 1997, pp. 509-533. 
THOMPSON, J. D. Dinâmica organizacional: fundamentos sociológicos da teoria administrativa. São Paulo: McGraw-Hill do Brasil, 1976.

TERZIOVSKI, M.; SOHAL, A. S. The adoption of continuous improvement and innovation strategies in Australian manufacturing firms. Tecnovation. v. 20, 2000, pp.539-550.

TIDD, J.; BESSANT, J.; PAVITT, K. Gestão da Inovação. 3 ed, Porto Alegre: Bookman, 2008.

TOMPKINS, J. A.; WHITE, J. A. Facilities Planning. USA: John Wiley \& Sons, 1984, pp. $1-31$.

TORNATZKY, L. G.; FLEISCHER, M. The process of technological innovation. Massachusets, Lexington Books, 1990.

TUSHMAN, M. L.; ANDERSON, P. Technological discontinuites and organizational environments. Administrative Science Quartely. v. 31, 1986, pp. 439-465.

UTTERBACK, J. M. Mastering the dynamics of innovation. Boston, Mass. : Harvard Business School Press, 1996.

UTTERBACK, J. M.; ABERNATHY, W. J. A dynamic model of process and product innovation. The International Journal of Management Science. v. 3, n. 6, 1975, pp. 639-656.

VERMEULEN, P. A. M.; VAN DEN BOSCH, F. A. J.; V.BERDA, H. W. Complex incremental product innovation in established service firms: a micro institutional perspective. Organization Studies. v. 28, 2007, p. 1523.

VICENT, L. H.; BHRADWAJ, S. G.; CHALLAGALLA, G. N. Does innovation mediate firm performance?: A meta-analysis of determinants and consequences of organizational innovation. Georgia Institute of Technology, 2004.

WECHSLER, A. M. -G.; NASCIMENTO, P. T. S. Manufacturing role in simple product development at a multi-project environment. PICMET 2008 proceedings. 27-31 July, Cape Town, South Africa (c), 2008.

WEISE, A. D.; SCHULTZ, C. A.; TRIERWEILLER, A. C. A estratégia, o mercado e as dificuldades do facility management no Brasil. Congresso Internacional de Administração. Gestão Estratégica na Era do Conhecimento, 8 a 12 de setembro de 2008, Ponta Grossa, Paraná, 2008.

WHEELWRIGHT, S.; CLARK, C. Creating project plans to focus product development. Harvard Business Review. Cambridge, Ma., Mar-Apr, 1992, pp.70-82.

WILLIAMS, B. Cost-effective facilities management: a practical approach. MCB University Press. Facilities, v. 14, n. 5/6, 1996 
WOLFF, J. A.; PETT, T. L. Small-firm performance: modeling the role of product and process improvements. Journal of Small Business Management. v. 44, 2, 2006, pp. 268-284.

WOMACK, J. P. A máquina que mudou o mundo. Rio de Janeiro: Campus, 1992.

YIN, R. K. Estudo de caso: planejamento e métodos. Trad Daniel Grassi, 3 ed. Porto Alegre: Bookman, 2005.

YAN, K.; EL-HAIK, B. Projeto para Seis Sigma: um roteiro para o desenvolvimento do produto. São Paulo: QPB, 2008.

YU, A. S. ; FIGUEIREDO, P. S. ; NASCIMENTO, P. T. . Development Resource Planning: The complexity of product development and the capacity to launch new products. Journal of Product Innovation Management, 2008.

ZHANG, Q.M. et al. Large Electrocaloric Effect in Ferroelectric Polymers Near Room Temperature. Science, 8 August 2008, V.: 321, Issue 5890. Disponível em: <http://www.inovacaotecnologica.com> Acesso em: 2 set 2008, pp 821-823. 


\section{LISTA DE APÊNDICES}

APÊNCICE A - Questionário do survey 177

APÊNDICE B - Inovações e melhorias coletadas na fase empírica - etapa I 182

APÊNDICE C - Instrumento de coleta de dados da fase empírica - etapa II 190

APÊNDICE D - Inovações coletadas na fase empírica - etapa II 191

APÊNDICE E - Inovações coletadas na fase empírica - etapa III 201

APÊNDICE F - Inovações coletadas na fase piloto pré-qualificação 203

APÊNDICE G - Inovações coletadas na fase piloto pós-qualificação 206

APÊNDICE H - Convergência das inovações coletadas nas fases empíricas e pilotos 209

APÊNDICE I - Exemplos de inovações em facilidades 215

APÊNDICE J - Teste entre duas amostras do survey 216

APÊNDICE K - Inovações e melhorias levantadas no survey 218

APÊNDICE L - Correlações das variáveis dependentes e independentes 223

APÊNDICE M - Matriz anti-imagem do survey 233

APÊNDICE N - Comunalidades dos dados do survey 235

APÊNDICE O - Variância total dos dados do survey 236

APÊNDICE P - Características das subcategorias encontradas no survey 237 


\section{APÊNDICE A - QUESTIONÁRIO DO SURVEY}

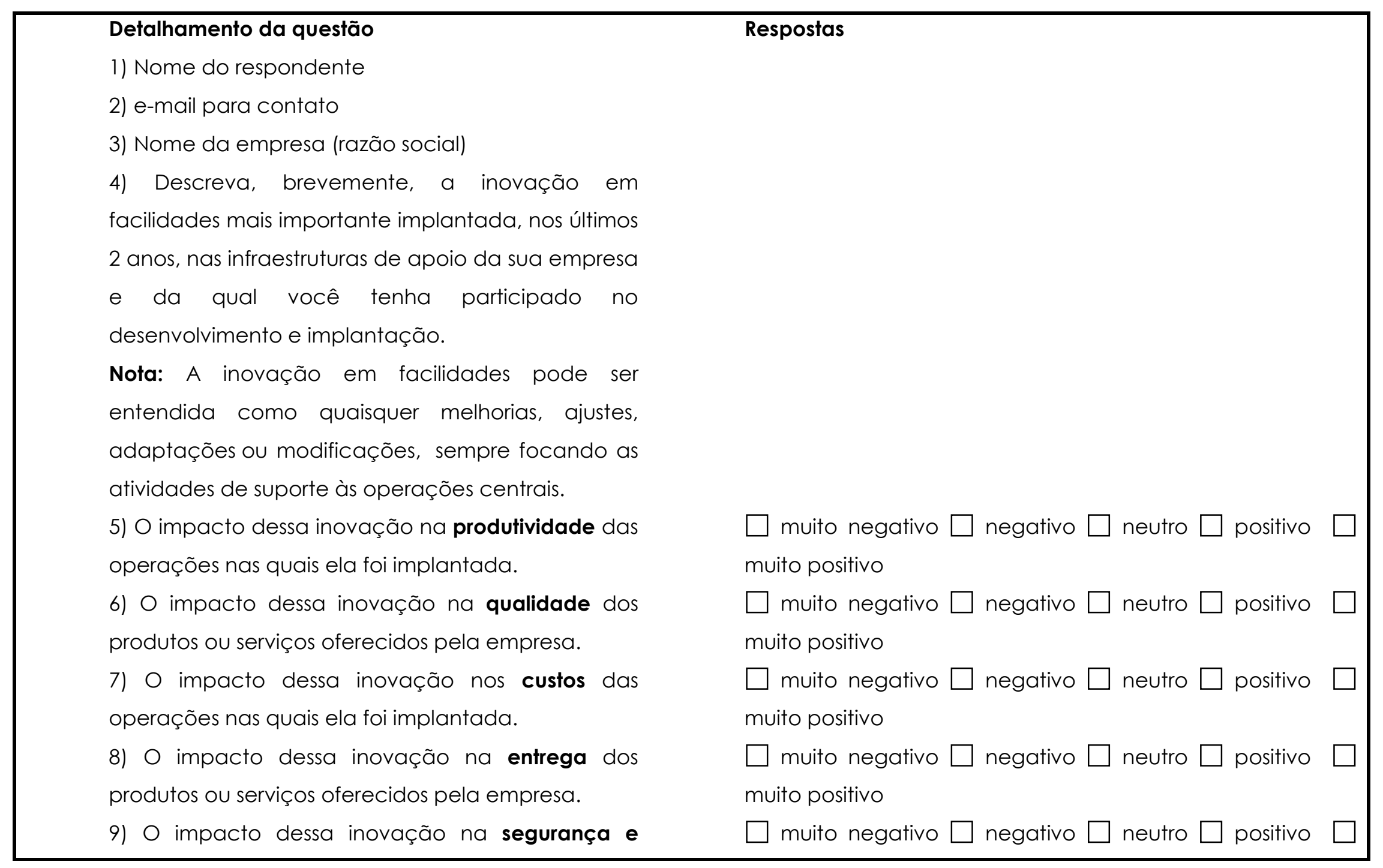


saúde dos funcionários.

10) $O$ impacto dessa inovação no meio ambiente (incluindo o consumo de energia, água, geração de resíduo etc).

11) O impacto dessa inovação nos lucros da empresa.

12) O impacto dessa inovação na participação de mercado da empresa.

13) O impacto dessa inovação nas vendas da empresa.

14) Essa inovação ocorreu principalmente:

15) Onde se localiza a inovação:

16) Se você pudesse posicionar essa inovação em relação às atividades centrais da sua organização, muito positivo

$\square$ muito negativo $\square$ negativo $\square$ neutro $\square$ positivo muito positivo

$\square$ muito negativo $\square$ negativo $\square$ neutro $\square$ positivo $\square$ muito positivo

$\square$ muito negativo $\square$ negativo $\square$ neutro $\square$ positivo muito positivo

$\square$ muito negativo $\square$ negativo $\square$ neutro $\square$ positivo muito positivo

$\square$ nos produtos (bens tangíveis) $\square$ nos processos: equipamentos, máquinas e dispositivos de apoio às operações $\square$ nos software, sistemas e programas $\square$ nas competências e especialização da mão-de-obra $\square$ nos modelo de negócios, estruturas, gestão e práticas de trabalho $\square$ nas formas de entrega ou prestação de serviços $\square$ nas formas de apresentação e marketing dos produtos ou serviços $\square$ outros

$\square$ principalmente na empresa $\square$ principalmente outra empresa do grupo $\square$ principalmente a empresa em cooperação com outras empresas ou institutos principalmente outras empresas ou institutos

$\square$ muito distante das atividades centrais $\square$ distante das atividades centrais $\square$ nem próxima nem distante das 
ela estaria:

Por exemplo: para uma automobilística, a atividade central é a fabricação de veículos.

17) Aponte qual a intensidade da inovação:

18) Qual foi o custo para implantação da inovação $(R \$)$ ?

19) Qual a principal motivação para a inovação?

20) Qual foi a principal fonte de idéias da inovação?

21) Qual o tempo médio de implantação da inovação?

22) Qual foi 0 principal obstáculo para a concretização dessa inovação?

23) Qual foi o principal conhecimento utilizado pelo grupo na inovação?

24) Qual a origem da empresa na qual ocorreu a atividades centrais $\square$ próxima das atividades centrais

muito próxima das atividades centrais

$\square$ nova para o departamento, mas já existe na empresa $\square$ nova para a empresa, mas já existe no mercado nacional $\square$ nova para o mercado nacional, mas já existe no mercado mundial $\square$ nova para o mercado mundial $\square$ até 50 mil $\square 51$ a 200 mil $\square 201$ a 500 mil $\square 501$ a 1 milhão $\square 1$ a 10 milhões $\square$ mais de 10 milhões

$\square$ resolução de problemas $\square$ expansão de mercado concorrência $\square$ revitalização ou atualização dos ativos outra

$\square$ interna - próprios empregados $\square$ interna - liderança externa - fornecedores, clientes, consultoria $\square$ mista (interna e externa)

$\square$ até 1 mês $\square 2$ a 6 meses $\square 7$ a 12 meses $\square$ mais de 12 meses

$\square$ custos da inovação $\square$ tempo para desenvolvimento e implantação $\square$ riscos econômicos $\square$ rigidez organizacional $\square$ complexidade técnica $\square$ falta de pessoal qualificado $\square$ outro

$\square$ formal - cursos e especializações técnicas $\square$ informal experiência profissional $\square$ ambos

$\square$ nacional $\square$ estrangeira $\square$ nacional e estrangeira 
inovação?

25) Qual o tamanho da empresa na qual ocorreu a inovação?

26) Qual a idade da empresa na qual ocorreu a inovação?

27) Qual o setor da empresa na qual ocorreu a inovação?

28) Qual o principal perfil da empresa onde ocorreu a inovação?

29) Quais as principais atividades do seu departamento? $\square$ micro (menos de 10 funcionários) $\square$ pequena (10 a 99) $\square$ média (100 a 499) $\square$ grande (500 ou mais)

$\square$ 0-5 anos $\square$ 6-10 $\square$ 11-15 $\square$ 16- $20 \square$ mais de 20

Indústrias de transformação $\square$ Comércio; reparação de veículos automotores e motocicletas $\square$ Agricultura, pecuária, produção florestal, pesca e aqüicultura Transporte, armazenagem e correio $\square$ Atividades financeiras, de seguros e serviços relacionados Atividades administrativas e serviços complementares $\square$ Saúde humana e serviços sociais $\square$ Construção $\square$ Informação e comunicação $\square$ Atividades profissionais, científicas e técnicas $\square$ Artes, cultura, esporte e recreação $\square$ Educação $\square$ Água, esgoto, atividades de gestão de resíduos e descontaminação $\square$ Administração pública, defesa e seguridade social $\square$ Eletricidade e gás Atividades imobiliárias $\square$ Outro:

$\square$ tomador de serviços (contratante) $\square$ prestador de serviços (contratada) $\square$ ambos

$\square$ manutenção em geral $\square$ zeladoria (limpezas, conservação, coleta de resíduos) $\square$ obras e reformas real estate (administração de propriedades) $\square$ segurança patrimonial $\square$ gerenciamento de espaços, escritórios e 
30) Qual era o seu cargo na época em que ocorreu a inovação?

31) O seu departamento, na época da implantação da inovação, respondia para que nível da hierarquia organizacional?

32) Qual era sua experiência profissional (em anos) na época em que ocorreu a inovação?

33) Qual era o seu grau de formação acadêmica na época em que ocorreu a inovação?

34) Você teria algo a acrescentar ou comentários sobre o assunto tratado nessa pesquisa?"

35) O que você achou da iniciativa dessa pesquisa? O questionário foi suficientemente claro e abrangente? Houve dificuldade no preenchimento? Faltou algo a indagar? mobílias $\square$ utilidades $\square$ gestão ambiental $\square$ serviços compartilhados (alimentação, transporte, correio e outras conveniências) $\square$ outra

$\square$ analista/engenheiro/técnico $\square$ coordenador/supervisor $\square$ gerente $\square$ diretor $\square$ presidente

$\square 1^{\circ}$ escalão (presidência) $\square 2^{\circ}$ escalão (diretoria) $\square 3^{\circ}$ escalão (gerência) $\square 4^{\circ}$ escalão (supervisão)

$\square$ 0-5 $\square$ 6-10 $\square$ 11-15 $\square$ 16- $20 \square$ mais de 20

$\square$ técnico $\square$ graduação $\square$ pós-graduação (especialização) $\square$ mestrado $\square$ doutorado 


\section{APÊNDICE B -INOVAÇÕES E MELHORIAS COLETADAS NA FASE EMPÍRICA (ETAPA I)}

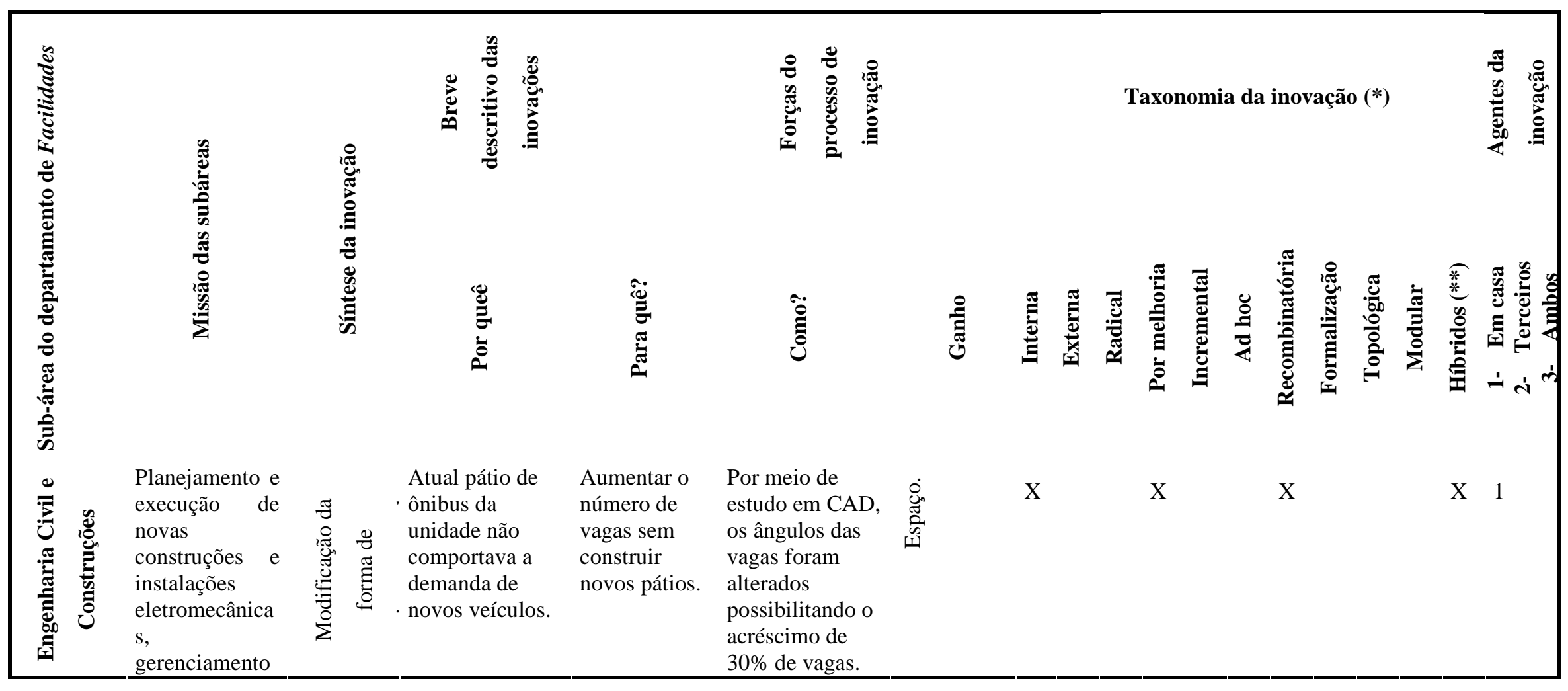




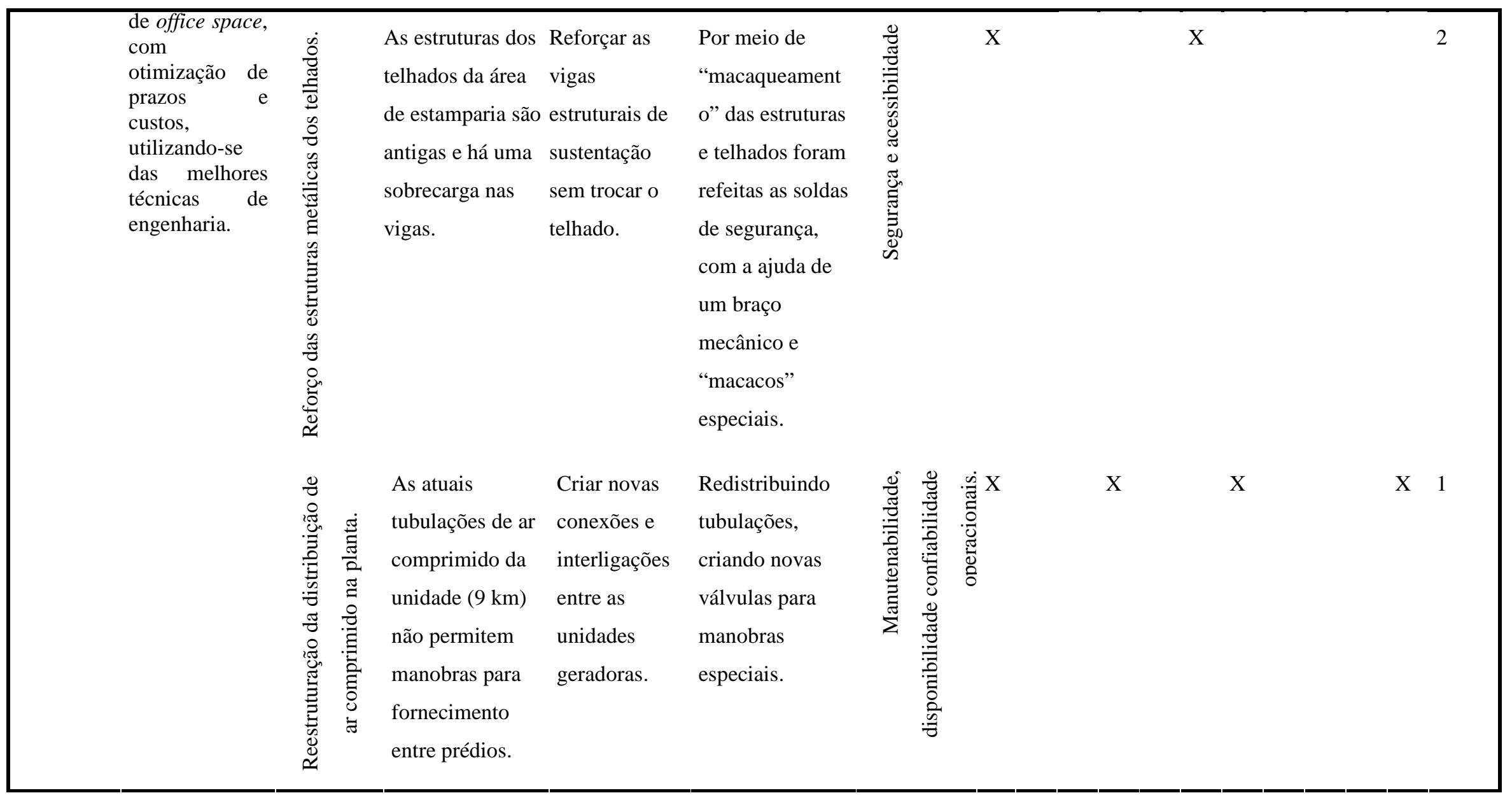




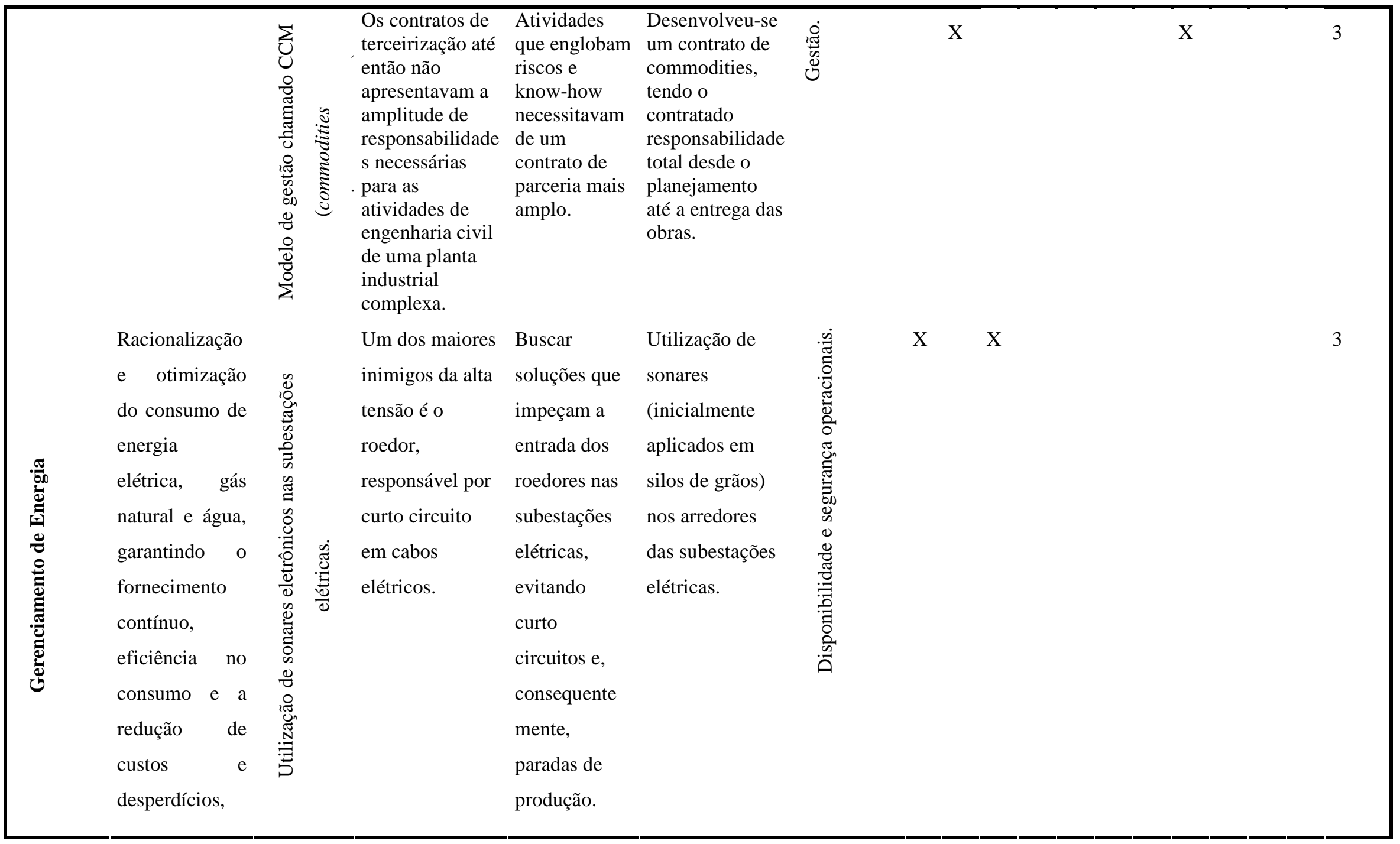




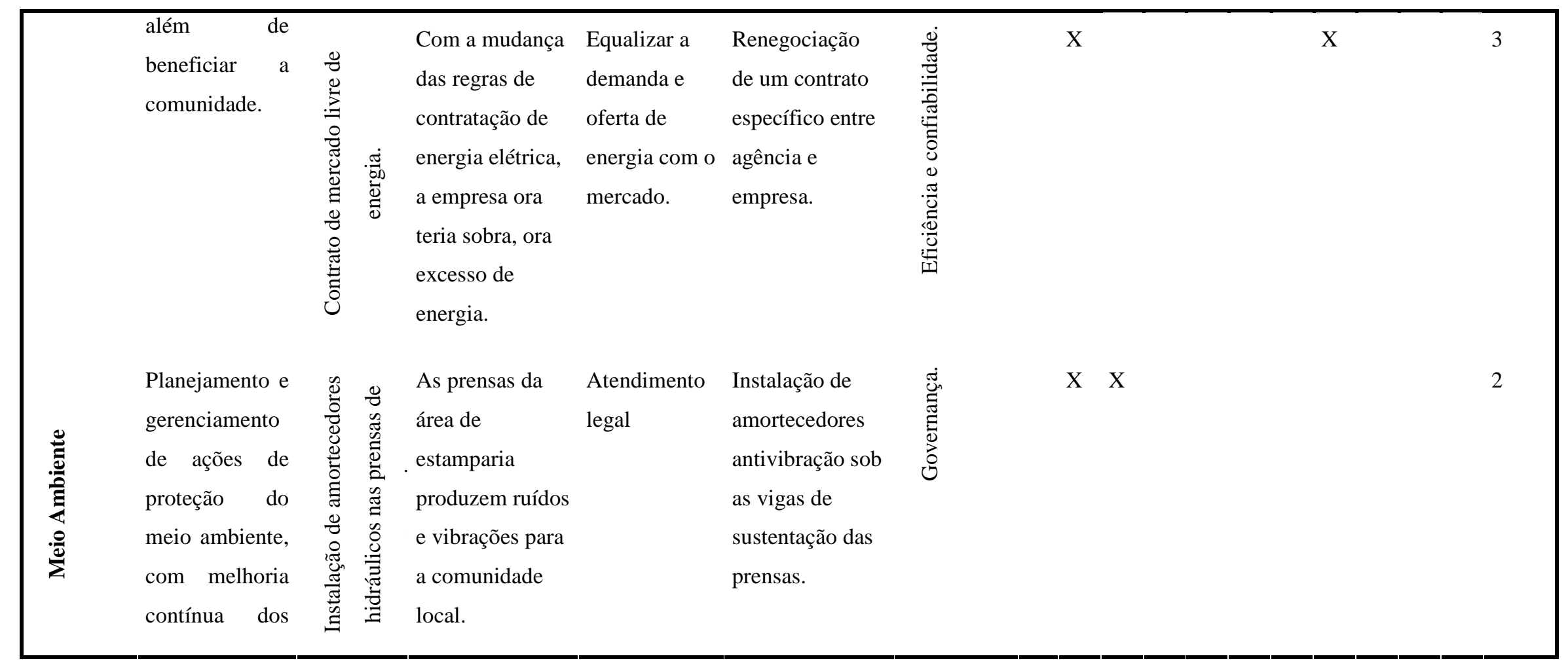




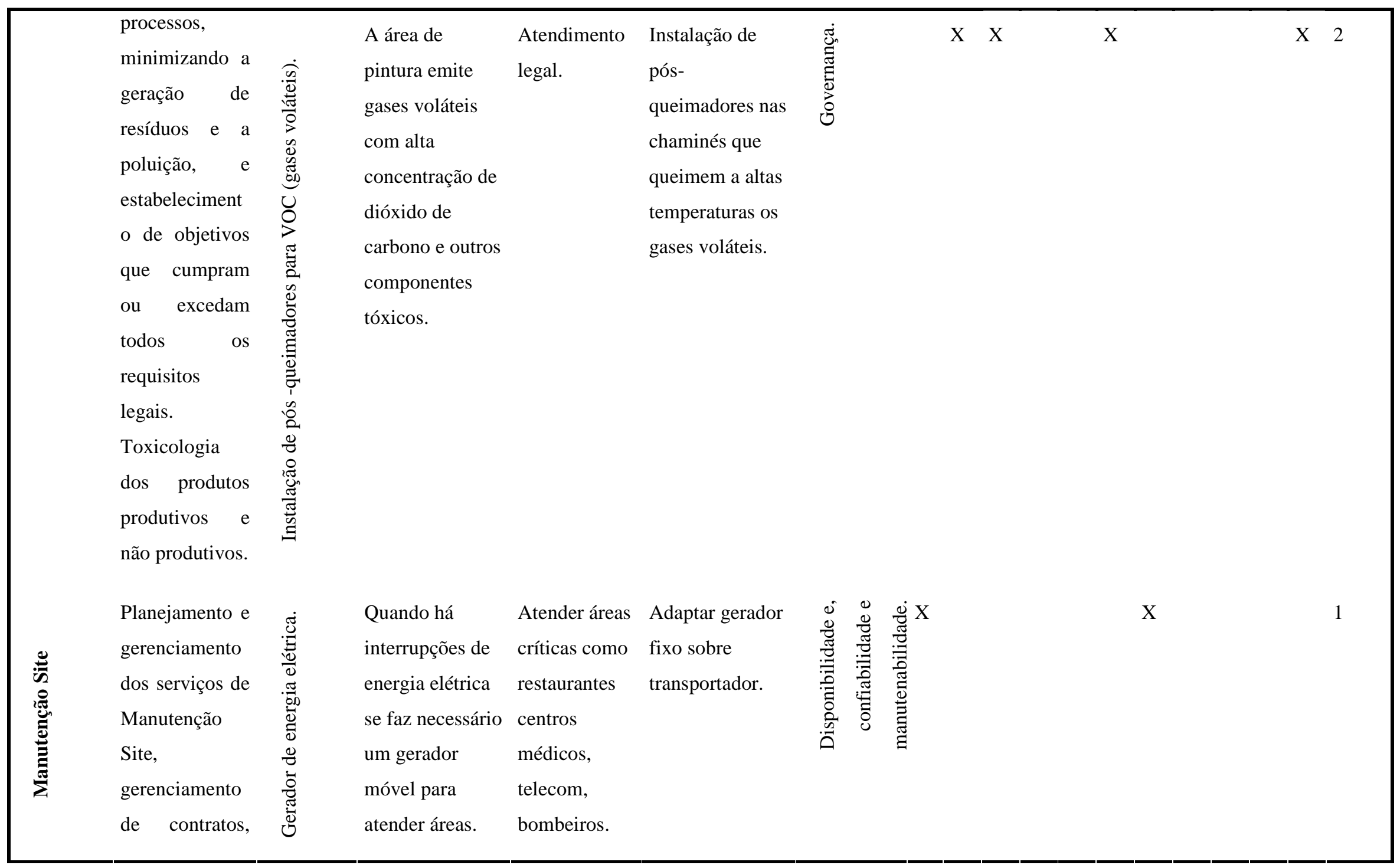




\begin{tabular}{|c|c|c|c|c|c|c|c|c|c|c|c|}
\hline $\begin{array}{l}\text { manutenção de } \\
\text { veículos } \\
\text { industriais, } \\
\text { manutenção } \\
\text { elétrica, } \\
\text { mecânica e } \\
\text { ventilação, } \\
\text { fontes de } \\
\text { abastecimento } \\
\text { e escritórios. }\end{array}$ & 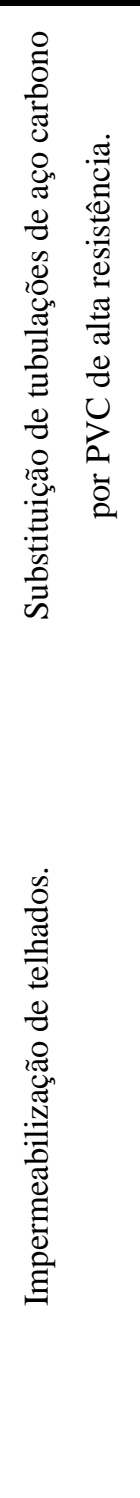 & $\begin{array}{l}\text { As tubulações } \\
\text { de água potável } \\
\text { são velhas e } \\
\text { apresentam } \\
\text { corrosões que } \\
\text { comprometem a } \\
\text { qualidade da } \\
\text { água e exigem } \\
\text { constantes } \\
\text { manutenções. } \\
\text { As telhas de } \\
\text { fibro-cimento da } \\
\text { área de pintura } \\
\text { são antigas, } \\
\text { provocando } \\
\text { vazamentos em } \\
\text { dias de chuvas } \\
\text { (afetando a } \\
\text { qualidade dos } \\
\text { veículos) e não } \\
\text { há como } \\
\text { substituí-las } \\
\text { durante a } \\
\text { produção. }\end{array}$ & $\begin{array}{l}\text { Melhorar a } \\
\text { qualidade da } \\
\text { água potável } \\
\text { e reduzir } \\
\text { manutenção. }\end{array}$ & $\begin{array}{l}\text { Substituição das } \\
\text { tubulações } \\
\text { antigas por } \\
\text { soluções em } \\
\text { PVC de alta } \\
\text { resistência. }\end{array}$ & 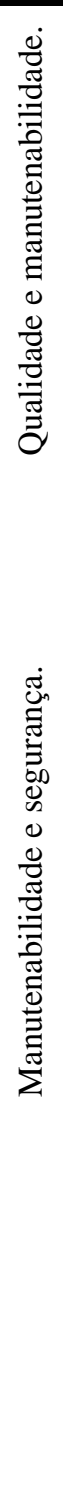 & $X$ & $X$ & $X$ & $\mathrm{X}$ & $X$ & 3 \\
\hline
\end{tabular}




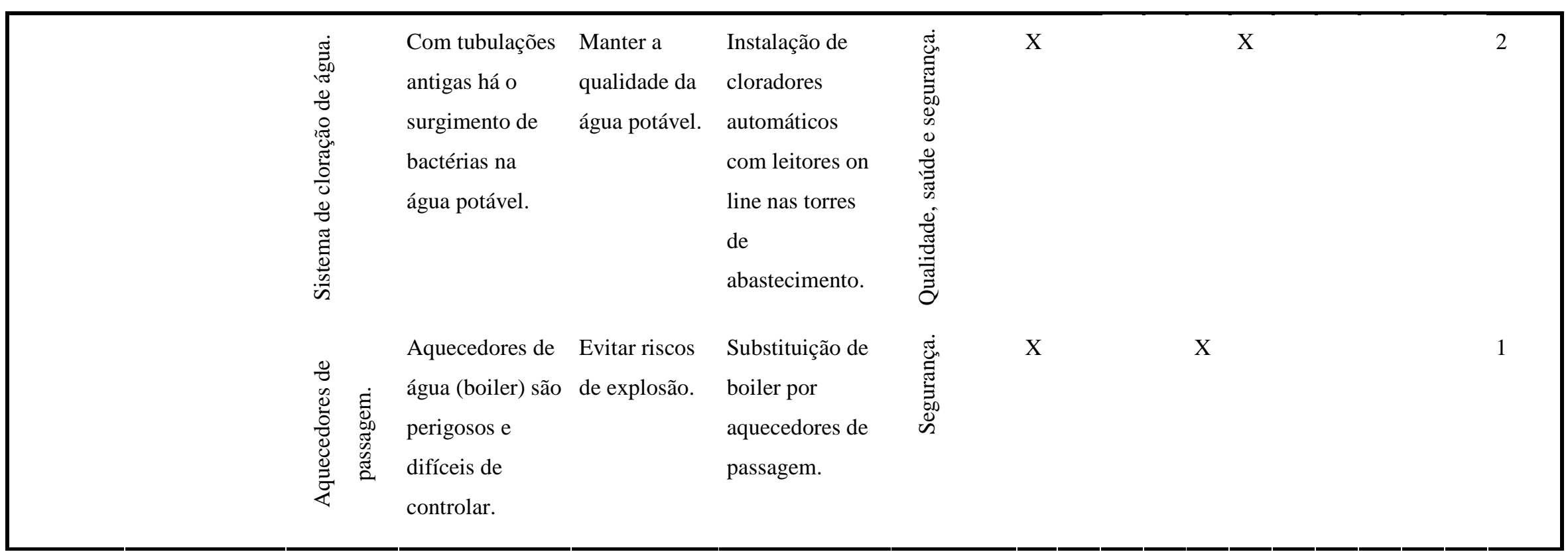




\begin{tabular}{|c|c|c|c|c|c|c|c|c|c|}
\hline 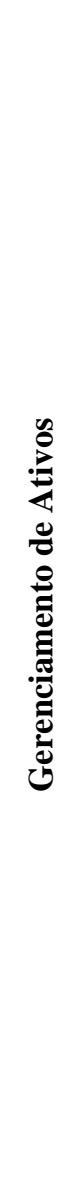 & $\begin{array}{l}\text { Prover serviços } \\
\text { de } \\
\text { gerenciamento } \\
\text { dos imóveis e } \\
\text { outros ativos, } \\
\text { incluindo } \\
\text { seleção de } \\
\text { novos terrenos } \\
\text { para } \\
\text { construções, } \\
\text { avaliação de } \\
\text { imóveis e } \\
\text { venda de ativos } \\
\text { sem previsão } \\
\text { de futura } \\
\text { utilização, } \\
\text { buscando uma } \\
\text { otimização de } \\
\text { custos e novos } \\
\text { negócios. }\end{array}$ & 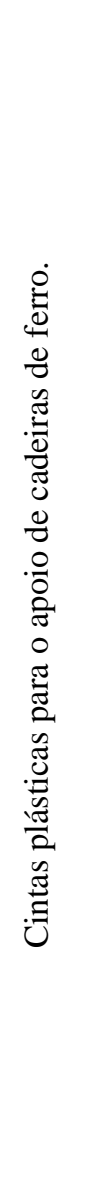 & $\begin{array}{l}\text { Com a troca de } \\
\text { pisos paviflex } \\
\text { livres de } \\
\text { chumbo, o } \\
\text { material perdeu } \\
\text { flexibilidade a } \\
\text { impactos. Os } \\
\text { móveis atuais } \\
\text { riscam o piso. }\end{array}$ & $\begin{array}{l}\text { Evitar riscos } \\
\text { no piso } \\
\text { paviflex. }\end{array}$ & $\begin{array}{l}\text { Colocação de } \\
\text { cintas plásticas } \\
\text { nas bases das } \\
\text { cadeiras e } \\
\text { mesas. }\end{array}$ & 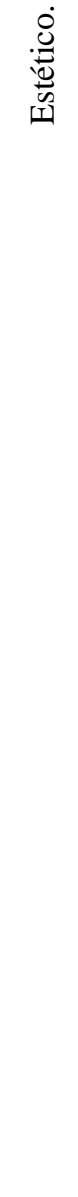 & $X$ & $X$ & 1 \\
\hline
\end{tabular}




\section{APÊNDICE C - INSTRUMENTO DE COLETA DE DADOS DA FASE EMPÍRICA (ETAPA II)}

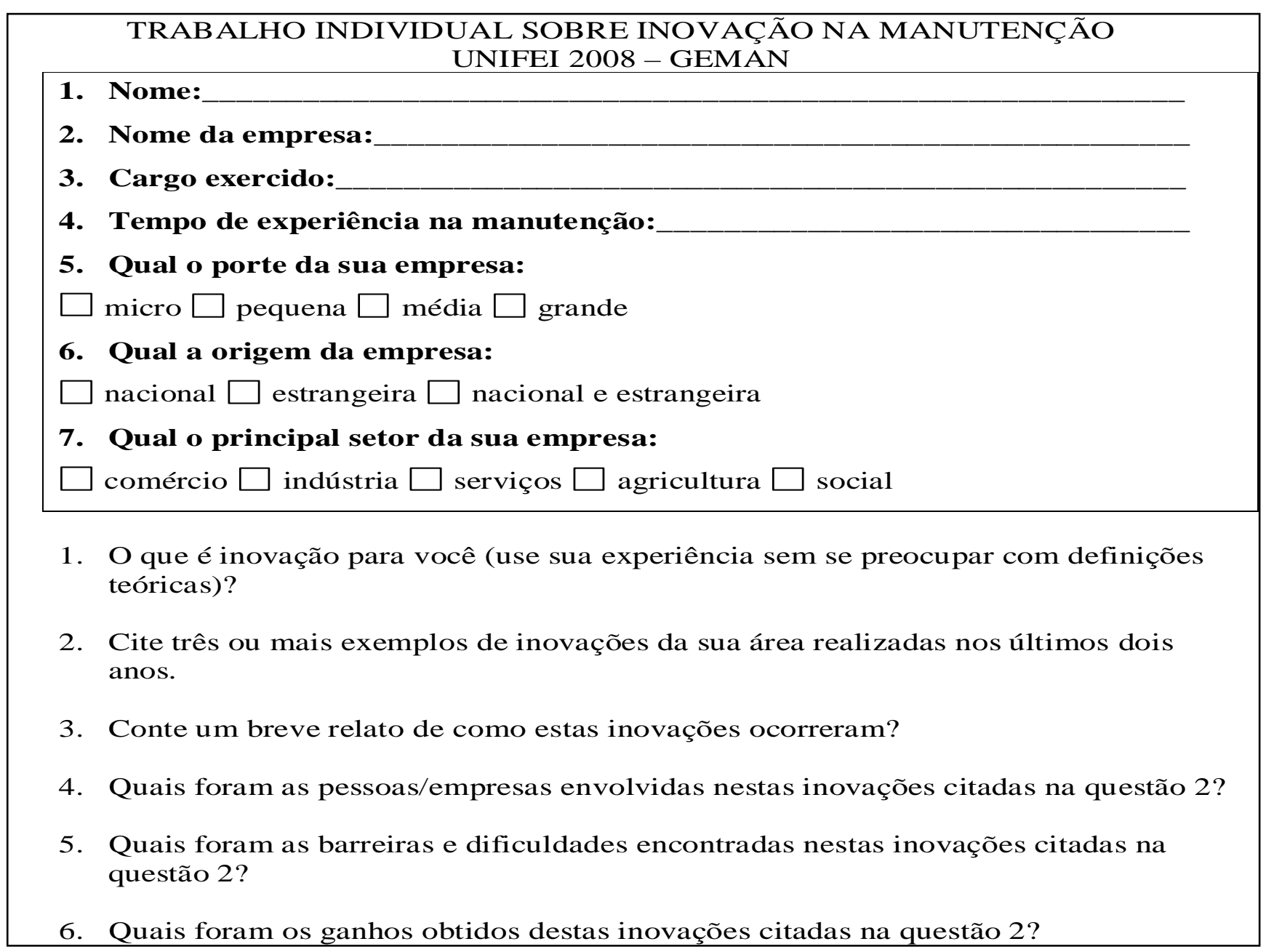




\section{APÊNDICE D -INOVAÇÕES COLETADAS NA FASE EMPÍRICA (ETAPA II)}

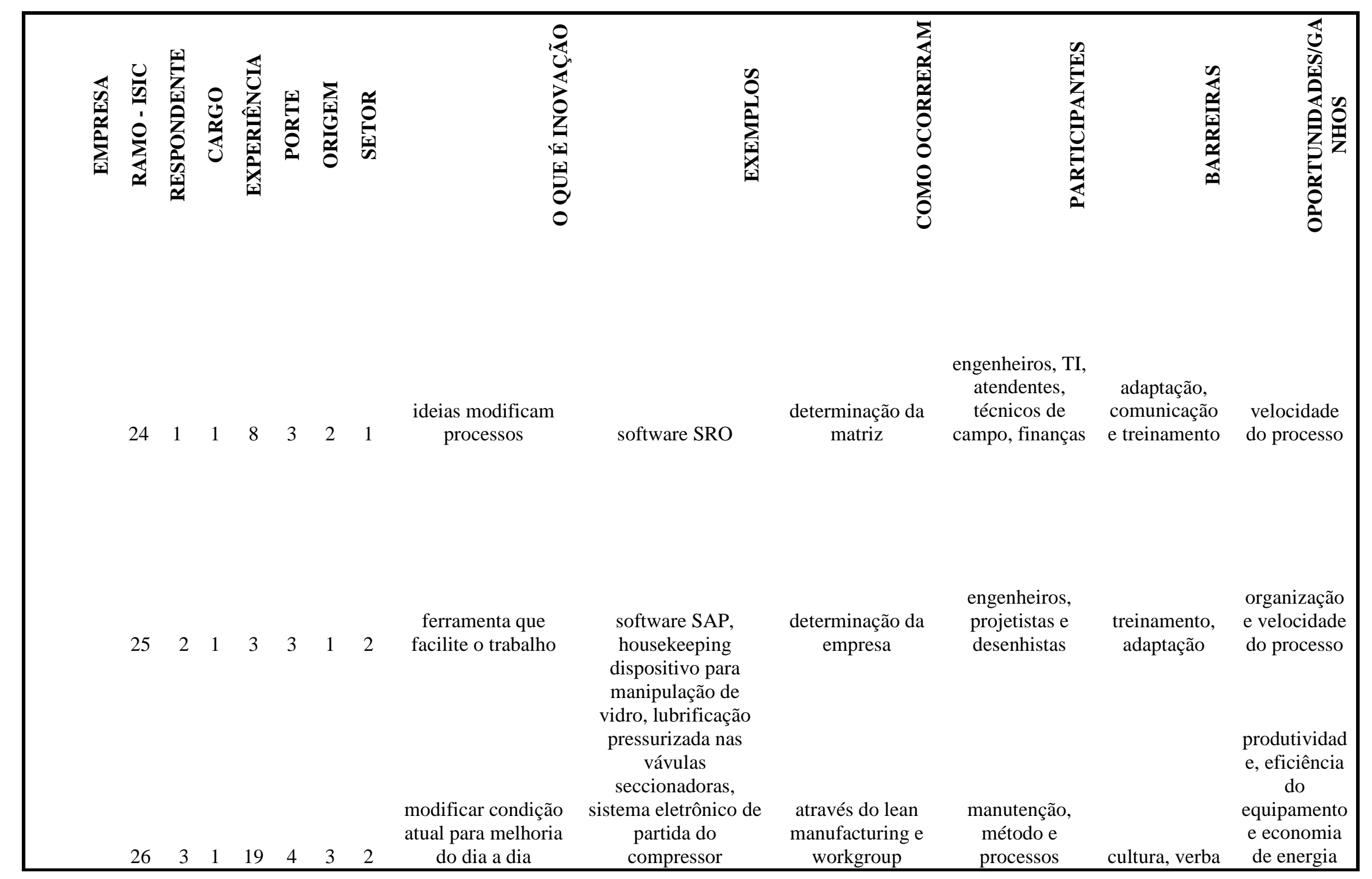


sair da rotina, dar

salto de qualidade e estrutura, máquinas,

15 $\begin{array}{lllllll}4 & 2 & 18 & 3 & 1 & 2 & \text { eficiência }\end{array}$

$$
\text { eficiência }
$$

visão

fazer algo diferente

mesmo simples sem

complicação ou

26

$\begin{array}{lllllll}5 & 2 & 13 & 4 & 2 & 2 & \begin{array}{l}\text { engenhosidade } \\ \text { engen }\end{array}\end{array}$

\section{RCM - reliability}

centered

maintenance computadores,

disponibilização de novos recursos

físicos ou

$\begin{array}{llllllll}36 & 6 & 1 & 7 & 4 & 1 & 1 & \text { administrativos }\end{array}$ software de

produção/manutençã

o BPCS/EAM e

análises preditivas

fazer algo diferente,

central de pedidos,

certificação de

chapas, retrofit de

gás refrigerante $\mathrm{CFC}$

contratação de

especialista com

nova estrutura

organizacional,

visão corretiva

para preventiva

com time de melhoria continua

que trabalhava

corretivamente e

passou a utilizar

novas formas de

organização mudança da

cultura

organizacion

$$
\text { al e }
$$

resistências

sistematizaçã

operadores e iniciais para

o dos

liderança mudanças

trabalhos

melhorou o

falta de

treinamento e

conheciment

o dos

operadores,

processo, green

belts,

conhecimento processos por

das meio das

supervisores

ferramentas

estatísticas

ferramentas e

estatísticas

agilidade,

controle,

tomada de

decisão

apoiada em

resistências, softwares,

supervisor, falta de uniformidade

fábrica e colaboração e e otimização

manutenção boicote de recursos

supervisor

montagem de

equipe de

atendimento,

necessidade de

manutenção

preditiva nas

chapas e

consciência

ambiental redução de

despesas de

manutenção

e utilidades,

redução do

manutenção,

engenharia e

fornecedores adaptação dos usuários impacto

ambiental 


\begin{tabular}{|c|c|c|c|c|c|c|c|c|c|c|c|c|}
\hline 24 & 8 & 1 & 10 & 4 & 2 & 3 & $\begin{array}{l}\text { processo realcionado } \\
\text { a novas ideias e } \\
\text { introdução de } \\
\text { melhorias }\end{array}$ & $\begin{array}{l}\text { canalização de gases } \\
\text { de exaustão das } \\
\text { caldeiras a gás } \\
\text { natural até o lavador } \\
\text { de gases } \mathrm{CO} 2, \\
\text { tubulações para } \\
\text { descarte de NH3 do } \\
\text { sistema de } \\
\text { refrigeração, } \\
\text { equipamento } \\
\text { eletrônico para } \\
\text { controle automático } \\
\text { de combustão nos } \\
\text { motogeradores EPC } \\
100\end{array}$ & $\begin{array}{l}\text { por meio do } \\
\text { "innovation day" } \\
\text { programa interno } \\
\text { da empresa } \\
\text { formado por } \\
\text { grupos de } 4 \\
\text { pessoas }\end{array}$ & $\begin{array}{l}\text { operadores, } \\
\text { engenheiros, } \\
\text { terceiros, } \\
\text { mecânicos, } \\
\text { eletricistas e } \\
\text { instrumentistas }\end{array}$ & $\begin{array}{l}\text { verba, } \\
\text { empresa } \\
\text { especializada, } \\
\text { convenciment } \\
\text { o da gerência. }\end{array}$ & $\begin{array}{c}\text { reconhecime } \\
\text { nto, } \\
\text { premiação, } \\
\text { autoestima, } \\
\text { eficiência e } \\
\text { meio- } \\
\text { ambiente }\end{array}$ \\
\hline 74 & 10 & 1 & 12 & 4 & 1 & 2 & $\begin{array}{l}\text { algo diferente, novo } \\
\text { produto, ferramenta } \\
\text { de gestão, nova } \\
\text { forma de atuar de } \\
\text { uma equipe }\end{array}$ & $\begin{array}{l} \\
\\
\text { contratação de } \\
\text { empresas } \\
\text { especializadas para } \\
\text { preditivas, } \\
\text { descentralização da } \\
\text { forma de atuar, } \\
\text { gestão com } \\
\text { indicadores, } \\
\text { manutenção world } \\
\text { class }\end{array}$ & $\begin{array}{l}\text { gestor trouxe } \\
\text { conhecimentos de } \\
\text { outras empresas, } \\
\text { mudanças de } \\
\text { layout dos } \\
\text { processos, } \\
\text { contratação de } \\
\text { consultoria e } \\
\text { multiplicador. }\end{array}$ & $\begin{array}{c}\text { dirretoria, corpo } \\
\text { clínico, } \\
\text { enfermagem, } \\
\text { fornecedores, } \\
\text { compras, } \\
\text { importação e } \\
\text { logística }\end{array}$ & $\begin{array}{c}\text { custos } \\
\text { verbas, falta } \\
\text { de } \\
\text { conscientizaçã } \\
\text { o da alta } \\
\text { gerência, } \\
\text { ceticismo do } \\
\text { pessoal } \\
\text { operacional, } \\
\text { falta de } \\
\text { experiência, } \\
\text { desconfiança, } \\
\text { falta de } \\
\text { harmonia, } \\
\text { convenciment } \\
\text { o, aversão ao }\end{array}$ & $\begin{array}{c}\text { aumento de } \\
\text { disponibilida } \\
\text { de (MTTR e } \\
\text { MTBF), } \\
\text { redução de } \\
\text { HE, redução } \\
\text { de quebra e } \\
\text { corretivas }\end{array}$ \\
\hline
\end{tabular}




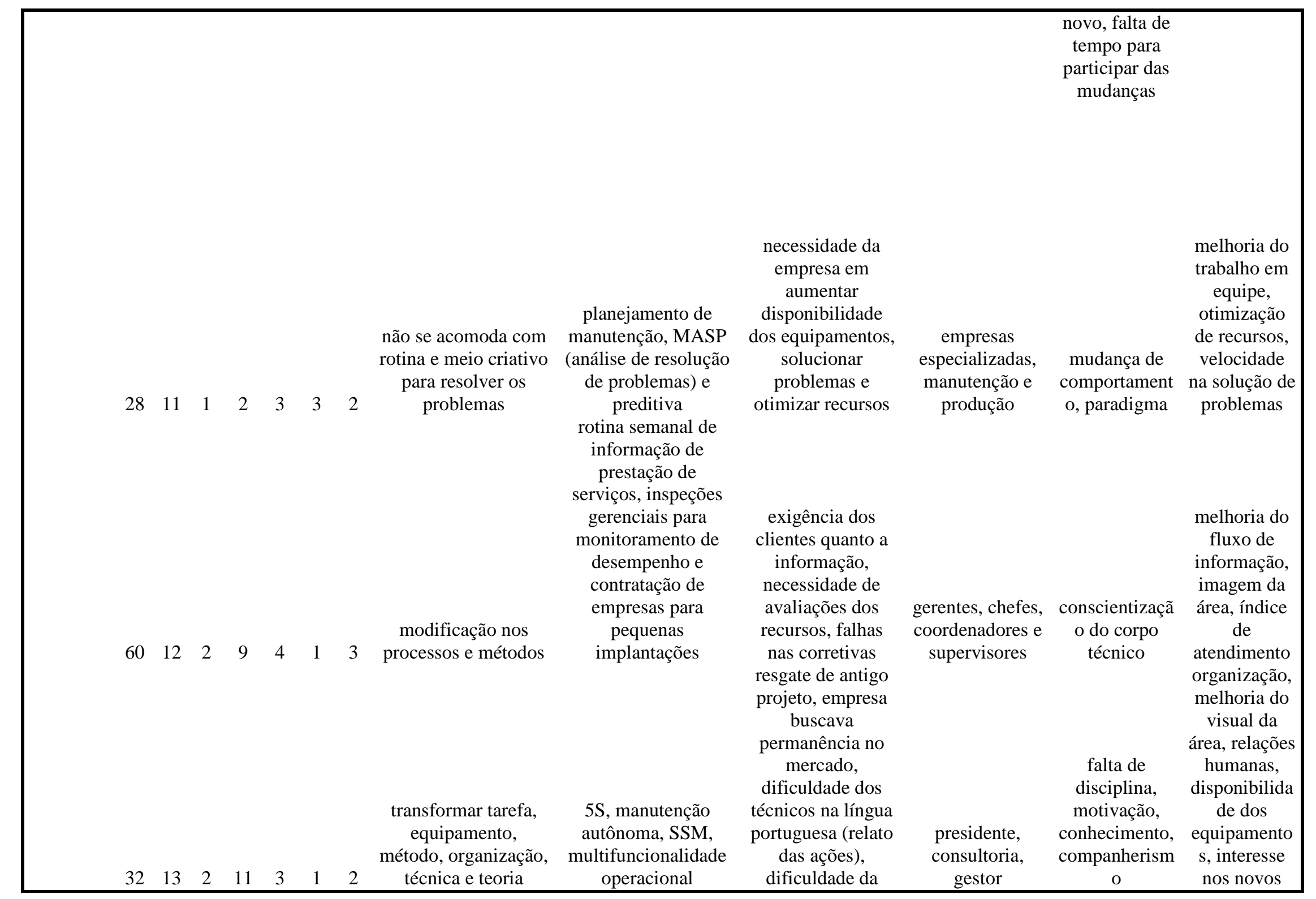




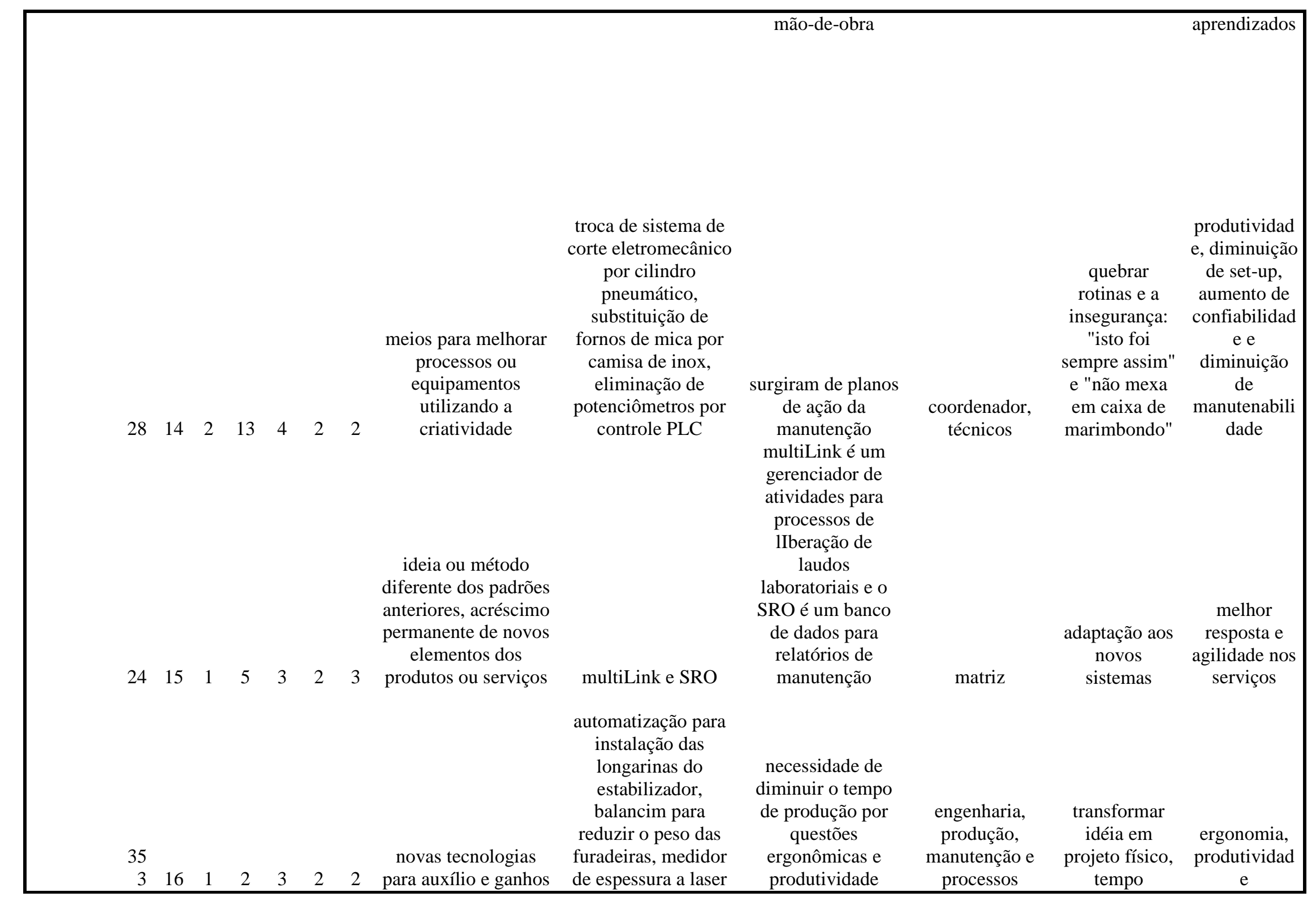




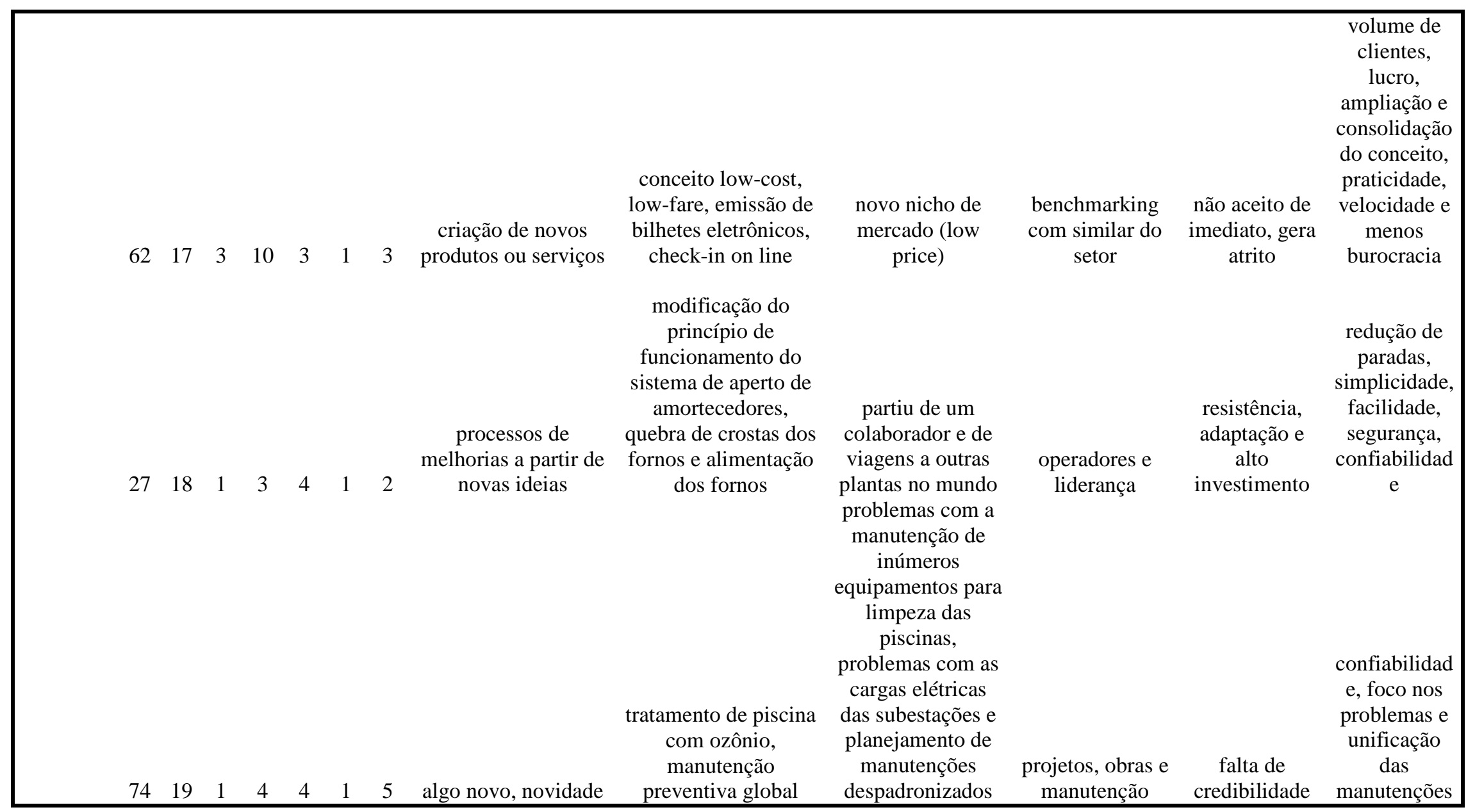




\begin{tabular}{|c|c|c|c|c|c|c|c|c|c|c|c|c|}
\hline 30 & 20 & 2 & 16 & 4 & 3 & 2 & $\begin{array}{c}\text { novas ideias, } \\
\text { conceitos para } \\
\text { organizar, estruturar } \\
\text { ou mudar tecnologia }\end{array}$ & $\begin{array}{l}\text { estruturação do } \\
\text { departamento, } \\
\text { melhorias } \\
\text { tecnológicas no } \\
\text { parque gráfico, } \\
\text { implantação de } \\
\text { treinamento no } \\
\text { exterior }\end{array}$ & $\begin{array}{l}\text { partiu da visão da } \\
\text { área de } \\
\text { manutenção em } \\
\text { obter uma posição } \\
\text { estratégica na } \\
\text { empresa, da } \\
\text { própria } \\
\text { reestruturação do } \\
\text { departamento e } \\
\text { parcerias externas }\end{array}$ & $\begin{array}{l}\text { manutenção, } \\
\text { gerência, } \\
\text { coordenação e } \\
\text { analistas }\end{array}$ & custos & $\begin{array}{c}\text { eficiência, } \\
\text { redução de } \\
\text { quebras e } \\
\text { manutenção } \\
\text { corretiva, } \\
\text { motivação e } \\
\text { agregação } \\
\text { aos } \\
\text { conheciment } \\
\text { os }\end{array}$ \\
\hline 15 & 22 & 2 & 10 & 4 & 2 & 4 & $\begin{array}{l}\text { implementação de } \\
\text { um produto ou } \\
\text { serviço que gere } \\
\text { valor agregado }\end{array}$ & $\begin{array}{l}\text { prensa hidráulica } \\
\text { com uma mesa } \\
\text { giratória de } 6 \\
\text { posič̃os e sistema de } \\
\text { visão } 100 \% \text { para } \\
\text { controle de qualidade } \\
\text { por fotografia }\end{array}$ & $\begin{array}{l}\text { necessidade } \\
\text { interna da } \\
\text { produção e } \\
\text { segurança aliada a } \\
\text { reclamações } \\
\text { externas }\end{array}$ & $\begin{array}{l}\text { empresas do } \\
\text { setor } \\
\text { engeharia do } \\
\text { produto, do } \\
\text { processo, de } \\
\text { projeto, de } \\
\text { manutenção, de } \\
\text { segurança, } \\
\text { departamento de } \\
\text { automoção, } \\
\text { empresas } \\
\text { parceiras }\end{array}$ & $\begin{array}{c}\text { complexidade, } \\
\text { busca de } \\
\text { parcerias }\end{array}$ & $\begin{array}{c}\text { qualidade na } \\
\text { aplicação, } \\
\text { aumento de } \\
\text { safra e menor } \\
\text { custo de } \\
\text { produção }\end{array}$ \\
\hline 29 & 23 & 2 & 3 & 2 & 3 & 3 & $\begin{array}{l}\text { implementar algum } \\
\text { tipo de mudança para } \\
\text { melhorar processo }\end{array}$ & $\begin{array}{c}\text { priorização de } \\
\text { atendimento a } \\
\text { clientes em } 24 \text { horas, } \\
\text { treinamento contínuo } \\
\text { para manutentores }\end{array}$ & $\begin{array}{l}\text { surgiu de } \\
\text { reclamações de } \\
\text { clientes e falta de } \\
\text { conhecimento } \\
\text { técnico dos } \\
\text { manutentores }\end{array}$ & $\begin{array}{l}\text { coordenadores, } \\
\text { diretor }\end{array}$ & $\begin{array}{l}\text { falta de } \\
\text { materiais e } \\
\text { resistência dos } \\
\text { técnicos }\end{array}$ & $\begin{array}{c}\text { redução de } \\
\text { reclamações, } \\
\text { disponibilida } \\
\text { de e } \\
\text { mudança de } \\
\text { postura }\end{array}$ \\
\hline
\end{tabular}




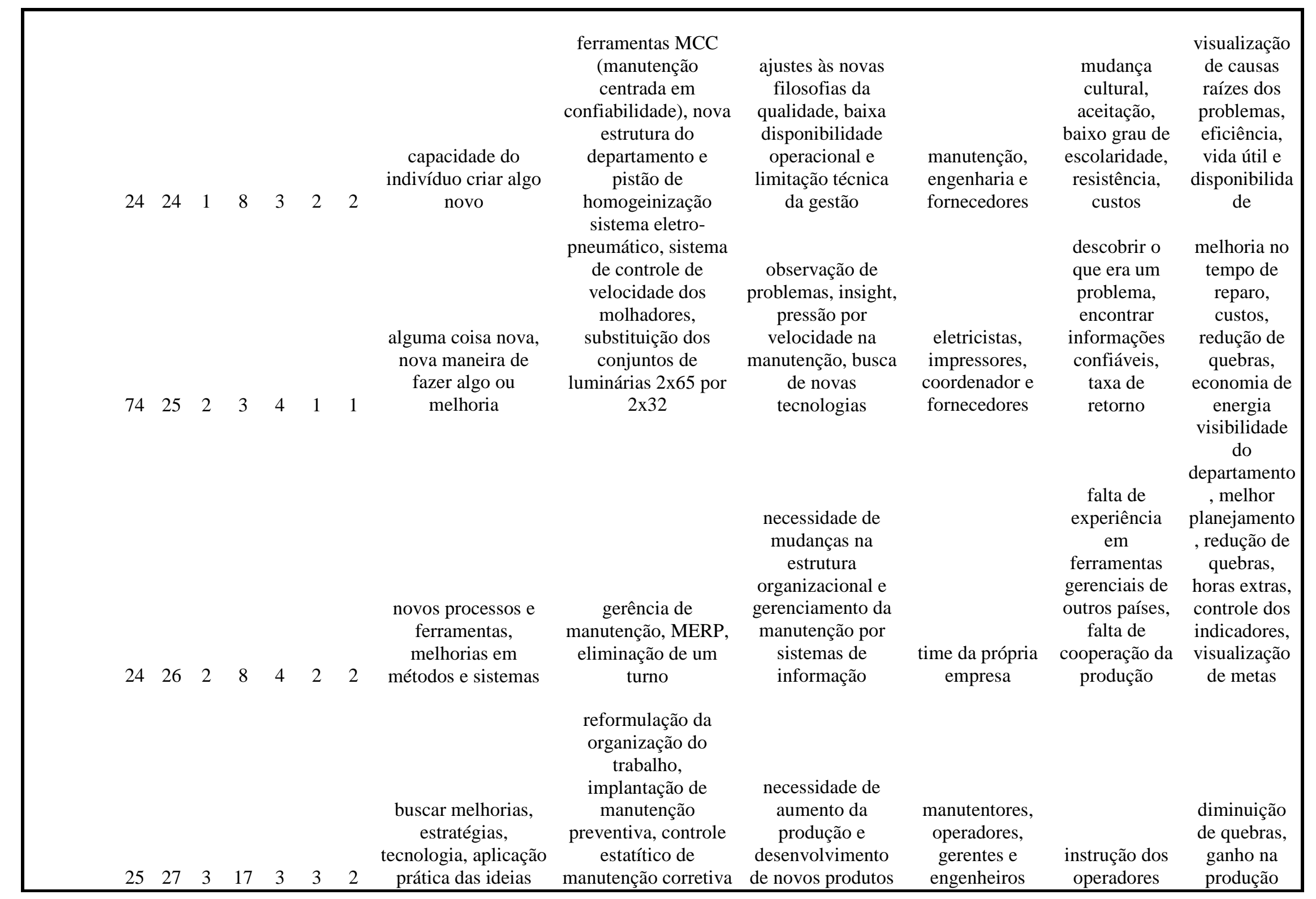




\begin{tabular}{|c|c|c|c|c|c|c|c|c|c|c|c|c|}
\hline 25 & 28 & 1 & 5 & 4 & 2 & 2 & $\begin{array}{l}\text { novidade no sistema, } \\
\text { processo ou produto }\end{array}$ & $\begin{array}{l}\text { implantação de ERP } \\
\text { (SAP) sistemas de } \\
\text { manutenção preditiva }\end{array}$ & $\begin{array}{l}\text { necessidade de } \\
\text { melhorias no } \\
\text { controle e } \\
\text { monitoramento } \\
\text { dos processos }\end{array}$ & $\begin{array}{l}\text { diretoria, } \\
\text { gerência }\end{array}$ & $\begin{array}{c}\text { catalogação } \\
\text { dos } \\
\text { equipamentos, } \\
\text { mostrar } \\
\text { benefícios, } \\
\text { treinamentos }\end{array}$ & $\begin{array}{c}\text { melhorou os } \\
\text { sistemas de } \\
\text { gerenciamen } \\
\text { o dos } \\
\text { processos }\end{array}$ \\
\hline $\begin{array}{r}74 \\
2\end{array}$ & 29 & 2 & 5 & 3 & 2 & 3 & $\begin{array}{c}\text { reinventar algo que } \\
\text { já existe com novas } \\
\text { tecnologias, } \\
\text { ferramentas e } \\
\text { pesquisas }\end{array}$ & $\begin{array}{l}\text { SIACO (sistema } \\
\text { integrado de } \\
\text { automação) e CCO } \\
\text { (sistema de controle } \\
\text { operacional) }\end{array}$ & $\begin{array}{c}\text { aumentar a } \\
\text { produção e } \\
\text { transporte de } \\
\text { cargas da empresa }\end{array}$ & $\begin{array}{l}\text { time da própria } \\
\text { empresa, } \\
\text { parceiros e } \\
\text { terceirizados }\end{array}$ & $\begin{array}{l}\text { mudanças, } \\
\text { custos iniciais } \\
\text { mudança de } \\
\text { cultura, } \\
\text { adaptação, } \\
\text { transição de } \\
\text { sistemas, } \\
\text { teinamentos e } \\
\text { cronogramas } \\
\text { físicos- } \\
\text { financeiros }\end{array}$ & $\begin{array}{c}\text { padronização } \\
\text { produtividad } \\
\text { e, segurança } \\
\text { e economia } \\
\text { produção, } \\
\text { confiabilidad } \\
\text { e, lucro, } \\
\text { monitoramen } \\
\text { to, } \\
\text { comunicação } \\
\text {, segurança, } \\
\text { eficiência, } \\
\text { agilidade }\end{array}$ \\
\hline 15 & 31 & 2 & 4 & 4 & 1 & 2 & $\begin{array}{l}\text { novas idéias ou } \\
\text { conceitos }\end{array}$ & $\begin{array}{l}\text { nova ferramenta para } \\
\text { gerenciamento SAP, } \\
\text { modulação dos } \\
\text { maquinários e } \\
\text { reestruturação do } \\
\text { departamento }\end{array}$ & $\begin{array}{c}\text { nasceu de projeto } \\
\text { maior SAP-PM da } \\
\text { IBM, falta de } \\
\text { capacidade dos } \\
\text { maquinários e } \\
\text { necessidade de } \\
\text { visualizar as falhas } \\
\text { rapidamente }\end{array}$ & $\begin{array}{l}\text { time todo (da } \\
\text { diretoria aos } \\
\text { operadores) }\end{array}$ & $\begin{array}{l}\text { resistência dos } \\
\text { usuários }\end{array}$ & $\begin{array}{c}\text { gerenciamen } \\
\text { o da } \\
\text { manutenção, } \\
\text { eficiência do } \\
\text { trabalho, } \\
\text { lucratividade }\end{array}$ \\
\hline
\end{tabular}




\begin{tabular}{|c|c|c|c|c|c|c|c|c|c|c|c|c|}
\hline 74 & 32 & 1 & 18 & 4 & 1 & 3 & $\begin{array}{l}\text { aquilo que provoca } \\
\text { mudança em algo } \\
\text { estabelecido }\end{array}$ & $\begin{array}{l}\text { cursos regulares de } \\
\text { mecânico de plantas } \\
\text { de processo, } \\
\text { operador de } \\
\text { processos } \\
\text { siderúrgicos e } \\
\text { técnico de } \\
\text { manutenção } \\
\text { eletromecânica }\end{array}$ & $\begin{array}{c}\text { devido a } \\
\text { transformação } \\
\text { tecnológica do } \\
\text { segmento de bens } \\
\text { e capital }\end{array}$ & $\begin{array}{l}\text { coordenadores, } \\
\text { corpo docente, } \\
\text { supervisores, } \\
\text { analistas e } \\
\text { empresa } \\
\text { contratante }\end{array}$ & $\begin{array}{l}\text { tempo para } \\
\text { implantação }\end{array}$ & $\begin{array}{l}\text { qualificação } \\
\text { da mão-de- } \\
\text { obra }\end{array}$ \\
\hline 74 & 33 & 1 & 7 & 4 & 1 & 3 & $\begin{array}{c} \\
\\
\text { melhorias aplicadas } \\
\text { em projetos, } \\
\text { processos, } \\
\text { procedimentos, } \\
\text { layout, segurança }\end{array}$ & $\begin{array}{c}\text { geradores com } \\
\text { tranferência } \\
\text { automática e } \\
\text { farmárcias robôs } \\
\text { (dose unitária de } \\
\text { medicação) } \\
\text { material refratário } \\
\text { nos cadinhos, } \\
\text { refrigeração dos } \\
\text { sistema hidráulica } \\
\text { dos veículos } \\
\text { especiais e oléo } \\
\text { lubrificante resistente } \\
\text { a fogo e alta pressão } \\
\text { com eletro- } \\
\text { ventiladores }\end{array}$ & $\begin{array}{c}\text { necessidade de } \\
\text { abastecimento de } \\
\text { energia e multas e } \\
\text { confiabilidade das } \\
\text { dosagens de } \\
\text { medicação }\end{array}$ & $\begin{array}{l}\text { time da empresa } \\
\text { e vários } \\
\text { parceiros }\end{array}$ & $\begin{array}{c}\text { tempo de } \\
\text { desenvolvime } \\
\text { nto }\end{array}$ & $\begin{array}{c}\text { disponibilida } \\
\text { de, } \\
\text { manutenabili } \\
\text { dade, vida } \\
\text { útil, redução } \\
\text { de corretivas } \\
\text { e eficiência }\end{array}$ \\
\hline
\end{tabular}




\section{APÊNDICE E -INOVAÇÕES COLETADAS NA FASE EMPÍRICA (ETAPA III)}

\begin{tabular}{|c|c|c|c|c|c|c|c|c|c|c|c|c|c|c|c|c|}
\hline 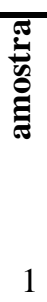 & Ogusku & ) & 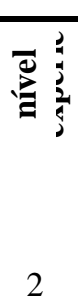 & $=$ & 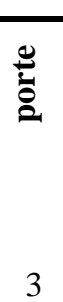 & 莺 & 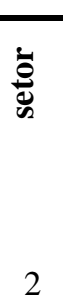 & CALDEIRAS & $\begin{array}{l} \\
\text { MAQUINA }\end{array}$ & 墨 & $\frac{0}{0.0}$ & 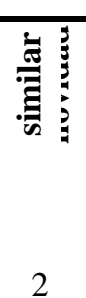 & 0 & 苞 & $\stackrel{2}{:}$ & 量詹 \\
\hline 2 & Renato & & 3 & 3 & 3 & 1 & 1 & CHOPP & ESTRUTURA ORG & RECURSOS & 5 & 3 & 2 & 2 & 4 & 1000 \\
\hline 3 & Mauricio & & 2 & 3 & 3 & 1 & 5 & EDUCAÇÃO & $\begin{array}{l}\text { CAPACITAÇÃO } \\
\text { TÉCNICA }\end{array}$ & RECURSOS & 4 & 3 & 1 & 1 & 4 & 0 \\
\hline 4 & Fernando & & 2 & 2 & 3 & 3 & 2 & PARAFUSOS & HARDWARE CLP & EQUIPAMENTO & 4 & 3 & 2 & 1 & 3 & 170000 \\
\hline 5 & Luis & & 2 & 1 & 2 & 2 & 3 & EQTO HOSPITALAR & ESTRUTURA ORG & RECURSOS & 3 & 2 & 2 & 1 & 4 & 0 \\
\hline 6 & Andre & & 2 & 1 & 3 & 1 & 2 & USINAGEM & SOFTWARE LOGIX & SOFTWARE & 2 & 5 & 1 & 1 & 3 & 5000 \\
\hline 7 & Afonso & & 1 & 1 & 3 & 2 & 2 & LAMINADOS & SOFTWARE ERP & SOFTWARE & 4 & 3 & 2 & 1 & 4 & 0 \\
\hline 8 & Alberto & & 2 & 1 & 3 & 1 & 3 & ARMAZENAMENTO & $\begin{array}{l}\text { SOFTWARE } \\
\text { ESTOQUE }\end{array}$ & SOFTWARE & 5 & 5 & 1 & 1 & 3 & 0 \\
\hline 9 & Cleber & & 2 & 3 & 4 & 1 & 2 & COBRE & ULTRAFILTRAGEM & EQUIPAMENTO & 4 & 3 & 2 & 2 & 3 & 200000 \\
\hline 10 & Altemar & & 2 & 5 & 4 & 2 & 2 & ESTRUTURA MET & $\begin{array}{l}\text { AUTOMOTIZAÇÃO } \\
\text { LINHA }\end{array}$ & EQUIPAMENTO & 5 & 3 & 2 & 1 & 3 & 600000 \\
\hline 11 & Nelson & & 2 & 4 & 4 & 2 & 1 & HOTELARIA & $\begin{array}{l}\text { TÉCNICA DE } \\
\text { MANUTENÇÃO }\end{array}$ & RECURSOS & 4 & 3 & 2 & 1 & 3 & 5000 \\
\hline
\end{tabular}




\begin{tabular}{|c|c|c|c|c|c|c|c|c|c|c|c|c|c|c|c|}
\hline 12 & Ricardo & 2 & 3 & 2 & 1 & 3 & VIDROS & $\begin{array}{l}\text { HARDWARE } \\
\text { TELEMETRIA }\end{array}$ & EQUIPAMENTO & 5 & 3 & 2 & 1 & 4 & 10000 \\
\hline 13 & Luciano & 3 & 4 & 4 & 1 & 3 & SANEAMENTO & $\begin{array}{l}\text { EQUIPAMENTO DE } \\
\text { FURAÇÃOO }\end{array}$ & EQUIPAMENTO & 4 & 3 & 1 & 1 & 3 & 13500 \\
\hline 14 & Fabiano & 2 & 4 & 3 & 1 & 2 & FARÓIS & SENSOR NA LINHA & EQUIPAMENTO & 5 & 3 & 2 & 2 & 3 & 400 \\
\hline 15 & Haroldo & 2 & 4 & 4 & 1 & 2 & PAPEL & $\begin{array}{l}\text { REATOR DE } \\
\text { OXIGÊNIO }\end{array}$ & EQUIPAMENTO & 5 & 3 & 3 & 1 & 3 & 0 \\
\hline 16 & Hildemar & 1 & 4 & 4 & 2 & 2 & SUSPENSÃO & VSM & RECURSOS & 5 & 3 & 2 & 2 & 3 & 80000 \\
\hline 17 & José & 2 & 2 & 4 & 1 & 2 & EMBALAGENS & $\begin{array}{l}\text { SISTEMA } \\
\text { HIDRÁULICO }\end{array}$ & EQUIPAMENTO & 5 & 3 & 1 & 1 & 3 & 30000 \\
\hline 18 & $\begin{array}{l}\text { André } \\
\text { Tav }\end{array}$ & 1 & 2 & 3 & 2 & 1 & INSTRUMENTAÇÃO & ESTRUTURA ORG & RECURSOS & 3 & 5 & 2 & 2 & 1 & 0 \\
\hline 19 & Giancarlo & 2 & 1 & 3 & 2 & 2 & ESPELHOS & ESTRUTURA ORG & RECURSOS & 4 & 3 & 1 & 1 & 3 & 0 \\
\hline 20 & Fabio & 2 & 2 & 4 & 1 & 2 & MEDICAMENTO & NOVO SITE & EQUIPAMENTO & 3 & 3 & 3 & 2 & 3 & $8 \mathrm{E}+08$ \\
\hline 21 & Candido & 2 & 2 & 4 & 2 & 3 & ELEVADORES & NOVA POLÍTICA & RECURSOS & 3 & 3 & 2 & 2 & 4 & 0 \\
\hline 22 & Thiago & 2 & 2 & 4 & 1 & 2 & $\mathrm{AÇO}$ & $\begin{array}{l}\text { MODELO DE } \\
\text { GESTÃO }\end{array}$ & RECURSOS & 4 & 3 & 1 & 1 & 4 & 0 \\
\hline 23 & Marcio & 3 & 4 & 4 & 2 & 2 & PNEUS & AUTOMATIZAÇÃO & EQUIPAMENTO & 5 & 2 & 2 & 1 & 3 & 2000000 \\
\hline 24 & Andre & 2 & 3 & 4 & 1 & 3 & CALL & CHAVE ESTÁTICA & EQUIPAMENTO & 5 & 3 & 2 & 1 & 3 & 55000 \\
\hline
\end{tabular}




\section{APÊNDICE F - INOVAÇÕES COLETADAS NA FASE PILOTO PRÉ-QUALIFICAÇÃO}

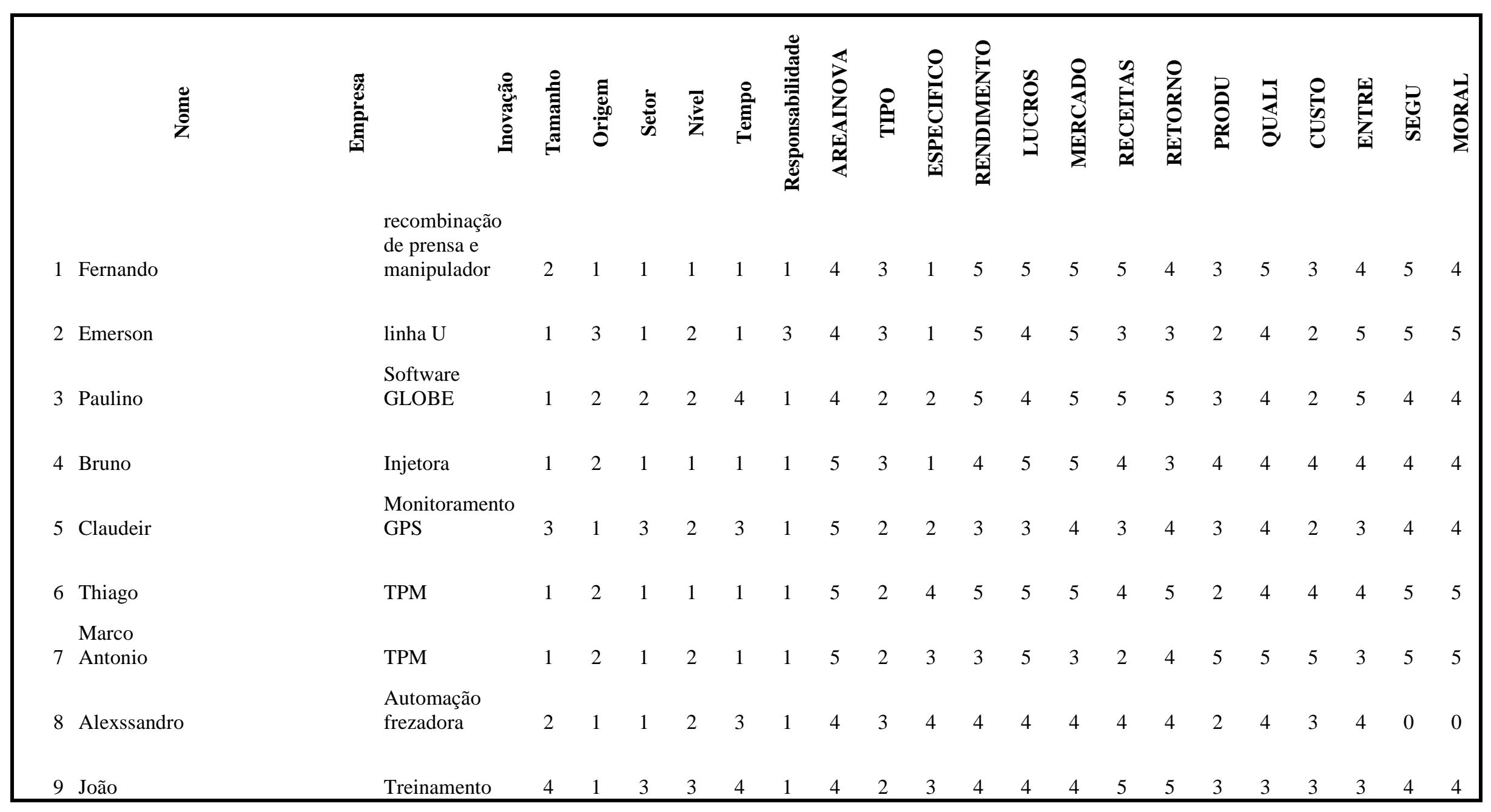




\begin{tabular}{|c|c|c|c|c|c|c|c|c|c|c|c|c|c|c|c|c|c|c|c|c|c|c|}
\hline 10 & Antonio & Estrutura orga & 2 & 1 & 2 & 2 & 4 & 1 & 5 & 3 & 4 & 5 & 5 & 5 & 5 & 5 & 4 & 5 & 1 & 5 & 5 & 5 \\
\hline 11 & Roberto & $\begin{array}{l}\text { WFE Air } \\
\text { blowing }\end{array}$ & 1 & 2 & 1 & 3 & 4 & 1 & 5 & 1 & 1 & 5 & 5 & 5 & 5 & 3 & 5 & 5 & 5 & 5 & 5 & 5 \\
\hline 12 & $\begin{array}{l}\text { Luis } \\
\text { Henrique }\end{array}$ & Estrutura orga & 2 & 3 & 3 & 3 & 3 & 2 & 4 & 4 & 4 & 5 & 3 & 3 & 3 & 3 & 5 & 5 & 2 & 5 & 4 & 5 \\
\hline 13 & Rogério & Software & 2 & 3 & 3 & 3 & 2 & 2 & 4 & 3 & 4 & 4 & 3 & 3 & 3 & 5 & 5 & 4 & 5 & 4 & 4 & 4 \\
\hline 14 & $\begin{array}{l}\text { Marco } \\
\text { Antonio }\end{array}$ & Software SM & 1 & 1 & 1 & 1 & 3 & 1 & 4 & 2 & 2 & 4 & 3 & 4 & 3 & 4 & 3 & 2 & 2 & 3 & 3 & 4 \\
\hline 15 & Valdir & Modelo EAM & 2 & 1 & 1 & 2 & 4 & 1 & 5 & 2 & 2 & 5 & 4 & 5 & 4 & 4 & 2 & 4 & 4 & 4 & 4 & 4 \\
\hline 16 & Rafael & $\begin{array}{l}\text { Software WEB } \\
\text { Automatização } \\
\text { endireitadeira }\end{array}$ & 2 & 1 & 3 & 3 & 3 & 2 & 4 & 3 & 2 & 5 & 3 & 5 & 3 & 4 & 5 & 4 & 4 & 4 & 5 & 5 \\
\hline 17 & Álvaro & de barras & 1 & 1 & 1 & 1 & 3 & 1 & 5 & 3 & 1 & 5 & 4 & 5 & 4 & 5 & 1 & 5 & 5 & 4 & 0 & 0 \\
\hline 18 & Reginaldo & Lean System & 1 & 1 & 3 & 1 & 1 & 1 & 4 & 4 & 4 & 5 & 5 & 4 & 5 & 4 & 0 & 0 & 0 & 0 & 0 & 0 \\
\hline 19 & Marcelo & Estrutura orga & 1 & 1 & 3 & 2 & 3 & 5 & 4 & 4 & 3 & 5 & 5 & 5 & 4 & 5 & 4 & 4 & 4 & 4 & 4 & 5 \\
\hline 20 & Rodrigo & Novo mercado & 2 & 1 & 3 & 2 & 2 & 2 & 4 & 2 & 3 & 4 & 5 & 5 & 5 & 4 & 2 & 4 & 4 & 4 & 5 & 4 \\
\hline 21 & Eduardo & Prensa satélite & 2 & 1 & 1 & 1 & 2 & 1 & 4 & 3 & 1 & 4 & 4 & 4 & 4 & 4 & 2 & 4 & 4 & 3 & 4 & 3 \\
\hline 22 & Ederson & $\begin{array}{l}\text { Automação de } \\
\text { torno }\end{array}$ & 2 & 3 & 1 & 3 & 3 & 5 & 5 & 3 & 1 & 4 & 5 & 5 & 5 & 4 & 0 & 0 & 0 & 0 & 0 & 0 \\
\hline 23 & Carlos & Software OS & 2 & 1 & 1 & 2 & 1 & 1 & 5 & 3 & 2 & 4 & 4 & 4 & 4 & 4 & 3 & 4 & 4 & 4 & 2 & 4 \\
\hline
\end{tabular}




\begin{tabular}{|c|c|c|c|c|c|c|c|c|c|c|c|c|c|c|c|c|c|c|c|c|c|c|}
\hline 24 & Waiton & $\begin{array}{l}\text { Almoxarifado } \\
\text { automotizado }\end{array}$ & 2 & 3 & 3 & 1 & 1 & 3 & 3 & 4 & 4 & 1 & 1 & 1 & 1 & 1 & 1 & 2 & 1 & 1 & 3 & 4 \\
\hline 25 & Rodrigo & $\begin{array}{l}\text { Moinho de } \\
\text { carvão }\end{array}$ & 1 & 2 & 1 & 1 & 2 & 1 & 4 & 3 & 1 & 4 & 5 & 5 & 4 & 4 & 1 & 4 & 4 & 3 & 5 & 5 \\
\hline 26 & Wilson & $\begin{array}{l}\text { Automotização } \\
\text { de caldeira }\end{array}$ & 2 & 1 & 1 & 1 & 1 & 1 & 5 & 3 & 1 & 5 & 4 & 3 & 3 & 4 & 2 & 5 & 3 & 3 & 4 & 5 \\
\hline 27 & José Pivato & TPM & 1 & 3 & 1 & 1 & 1 & 1 & 5 & 3 & 4 & 4 & 5 & 5 & 4 & 4 & 0 & 0 & 0 & 0 & 0 & 0 \\
\hline 28 & Carlos & Software & 1 & 1 & 3 & 2 & 4 & 1 & 5 & 2 & 4 & 5 & 5 & 5 & 5 & 5 & 2 & 5 & 4 & 4 & 5 & 5 \\
\hline 29 & Olismar & Software SAP & 1 & 1 & 1 & 2 & 1 & 1 & 4 & 4 & 2 & 5 & 5 & 5 & 5 & 5 & 5 & 5 & 5 & 5 & 4 & 5 \\
\hline 30 & Cleber & $\begin{array}{l}\text { Manutenção } \\
\text { preventiva }\end{array}$ & 2 & 1 & 1 & 1 & 1 & 1 & 4 & 2 & 3 & 5 & 5 & 4 & 4 & 5 & 2 & 5 & 4 & 2 & 3 & 4 \\
\hline
\end{tabular}




\section{APÊNDICE G - INOVAÇÕES COLETADAS NA FASE PILOTO PÓS-QUALIFICAÇÃO}

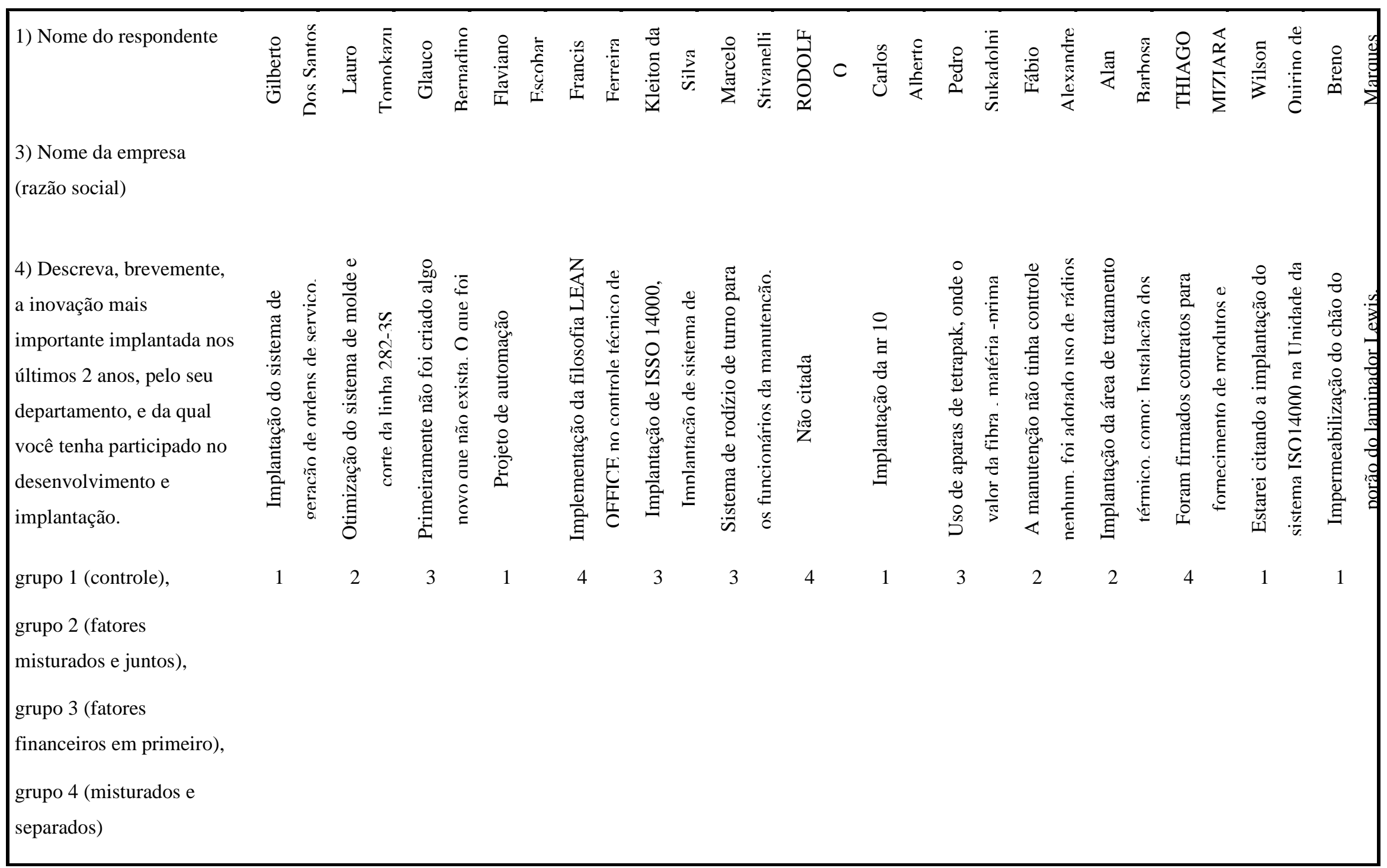




\begin{tabular}{|c|c|c|c|c|c|c|c|c|c|c|c|c|c|c|c|}
\hline $\begin{array}{l}\text { 5) O impacto dessa } \\
\text { inovação na produtividade } \\
\text { das operações nas quais } \\
\text { ela foi implantada. }\end{array}$ & 2 & 1 & 0 & 2 & 2 & 2 & 1 & 2 & 1 & 0 & 1 & 1 & 1 & 2 & 0 \\
\hline $\begin{array}{l}\text { 6) O impacto dessa } \\
\text { inovação na qualidade dos } \\
\text { produtos ou serviços } \\
\text { oferecidos pela empresa. }\end{array}$ & 0 & 0 & 0 & 1 & 0 & 2 & 1 & 1 & 1 & 1 & 0 & 1 & 1 & 1 & 1 \\
\hline $\begin{array}{l}\text { 7) O impacto dessa } \\
\text { inovação nos custos das } \\
\text { operações nas quais ela } \\
\text { foi implantada. }\end{array}$ & 0 & 1 & 0 & 1 & 1 & 1 & 0 & 1 & 2 & 2 & 1 & 1 & 1 & 1 & 1 \\
\hline $\begin{array}{l}\text { 8) O impacto dessa } \\
\text { inovação na entrega dos } \\
\text { produtos ou serviços } \\
\text { oferecidos pela empresa. }\end{array}$ & 0 & 1 & 0 & 1 & 2 & 0 & 1 & 0 & 2 & 1 & 1 & 2 & 2 & 1 & 0 \\
\hline $\begin{array}{l}\text { 9) O impacto dessa } \\
\text { inovação na segurança e } \\
\text { saúde dos funcionários. }\end{array}$ & 2 & 0 & 0 & 1 & 1 & 2 & 2 & 1 & 2 & 0 & 0 & 0 & 1 & 2 & 2 \\
\hline
\end{tabular}




\begin{tabular}{|c|c|c|c|c|c|c|c|c|c|c|c|c|c|c|c|}
\hline $\begin{array}{l}\text { 10) O impacto dessa } \\
\text { inovação no meio } \\
\text { ambiente (incluindo o } \\
\text { consumo de energia, água, } \\
\text { geração de resíduos etc). }\end{array}$ & 0 & 0 & 0 & 1 & 0 & 2 & 1 & 1 & 1 & 1 & 0 & 0 & 0 & 2 & 2 \\
\hline $\begin{array}{l}\text { 11) O impacto dessa } \\
\text { inovação nos lucros da } \\
\text { empresa. }\end{array}$ & 0 & 1 & 0 & 1 & 0 & 1 & 0 & 1 & 1 & 1 & 1 & 2 & 1 & 1 & 0 \\
\hline $\begin{array}{l}\text { 12) O impacto dessa } \\
\text { inovação na participação } \\
\text { de mercado da empresa. }\end{array}$ & 2 & 0 & 0 & 1 & 1 & 1 & 0 & 1 & 2 & 1 & 1 & 2 & 0 & 1 & 0 \\
\hline $\begin{array}{l}\text { 13) O impacto dessa } \\
\text { inovação nas vendas da } \\
\text { empresa. }\end{array}$ & 2 & 1 & 0 & 1 & 0 & 0 & 0 & 1 & 1 & 1 & 0 & 2 & 0 & 1 & 0 \\
\hline
\end{tabular}




\section{APÊNDICE H - CONVERGÊNCIA DAS INOVAÇÕES COLETADAS NAS FASES EMPÍRICAS E PILOTOS}

\begin{tabular}{|c|c|c|c|c|c|}
\hline \multirow[t]{25}{*}{ EMPRESA } & PORTE & ORIGEM & SETOR & BREVE DESCRIÇÃO DO TIPO DE INOVAÇÃO & TIPO \\
\hline & 3 & 2 & 1 & software SRO & 6 \\
\hline & 3 & 1 & 2 & software SAP & 6 \\
\hline & 3 & 1 & 2 & housekeeping & 4 \\
\hline & 4 & 3 & 2 & dispositivo para manipulação de vidro & 3 \\
\hline & 4 & 3 & 2 & lubrificação pressurizada nas válvulas seccionadoras & 3 \\
\hline & 4 & 3 & 2 & sistema eletrônico de partida do compressor & 6 \\
\hline & 3 & 1 & 2 & estrutura & 4 \\
\hline & 3 & 1 & 2 & máquinas & 3 \\
\hline & 3 & 1 & 2 & visão & 4 \\
\hline & 4 & 2 & 2 & RCM - reliability centered maintenance & 4 \\
\hline & 4 & 1 & 1 & computadores & 3 \\
\hline & 4 & 1 & 1 & software de produção/manutenção BPCS/EAM & 6 \\
\hline & 4 & 1 & 1 & análises preditivas & 4 \\
\hline & 4 & 2 & 2 & central de pedidos & 6 \\
\hline & 4 & 2 & 2 & certificação de chapas & 3 \\
\hline & 4 & 2 & 2 & $\begin{array}{l}\text { retrofit de gás refrigerante CFC } \\
\text { canalização de gases de exaustão das caldeiras a gás natural até o lavador de gases }\end{array}$ & 3 \\
\hline & 4 & 2 & 3 & $\mathrm{CO} 2$ & 3 \\
\hline & 4 & 2 & 3 & $\begin{array}{l}\text { tubulações para descarte de NH3 do sistema de refrigeração } \\
\text { equipamento eletrônico para controle automático de combustão nos moto- }\end{array}$ & 3 \\
\hline & 4 & 2 & 3 & geradores EPC 100 & 3 \\
\hline & 4 & 1 & 2 & novas tecnologias PET-CT & 6 \\
\hline & 4 & 1 & 2 & Rádio-cirurgia & 3 \\
\hline & 3 & 2 & 2 & contratação de empresas especializadas para preditivas & 2 \\
\hline & 3 & 2 & 2 & descentralização da forma de atuar & 4 \\
\hline & 3 & 2 & 2 & manutenção world class & 4 \\
\hline
\end{tabular}


MASP (análise de resolução de problemas)

preditiva

rotina semanal de informação de prestação de serviços

inspeções gerenciais para monitoramento de desempenho

contratação de empresas para pequenas implantações

manutenção autônoma

SSM

multifuncionalidade operacional

troca de sistema de corte eletro-mecânico por cilindro pneumático

substituição de fornos de mica por camisa de inox

eliminação de potenciômetros por controle PLC

multiLink

SRO

automatização para instalação das longarinas do estabilizador

balancim para reduzir o peso das furadeiras

medidor de espessura a laser

conceito low-cost, low-fare

emissão de bilhetes eletrônicos

check-in on line

modificação do princípio de funcionamento do sistema de aperto de amortecedores

quebra de crostas dos fornos

alimentação dos fornos

tratamento de piscina com ozônio

manutenção preventiva global

estruturação do departamento

melhorias tecnológicas no parque gráfico

implantação de treinamento no exterior

NPK no grão 
fontes de micronutrientes

embalagens 1000t

prensa hidráulica com uma mesa giratória de 6 posições

sistema de visão $100 \%$ para controle de qualidade por fotografia

priorização de atendimento a clientes em 24 horas

treinamento contínuo para manutentores

ferramentas MCC (manutenção centrada em confiabilidade)

nova estrutura do departamento

pistão de homogeinização

sistema eletro-pneumático

sistema de controle de velocidade dos molhadores

substituição dos conjuntos de luminárias 2x65 por 2x32

gerência de manutenção

MERP

eliminação de um turno

reformulação da organização do trabalho

implantação de manutenção preventiva

controle estatístico de manutenção corretiva

implantação de ERP (SAP) sistemas de manutenção preditiva

busca de ferramentas de qualidade de serviços

SIACO (sistema integrado de automação)

CCO (sistema de controle operacional)

nova ferramenta para gerenciamento SAP

modulação dos maquinários

reestruturação do departamento

cursos regulares de mecânico de plantas de processo

operador de processos siderúrgicos

técnico de manutenção eletromecânica

geradores com transferência automática

farmácias robôs (dose unitária de medicação) 
material refratário nos cadinhos

refrigeração dos sistema hidráulica dos veículos especiais

oléo lubrificante resistente a fogo e alta pressão com eletro-ventiladores

MAQUINA AUTOMÁTICA PARA SOLDAR MULTITUBULARES

ESTRUTURA ORG

CAPACITAÇÃO TÉCNICA

HARDWARE CLP

ESTRUTURA ORG

SOFTWARE LOGIX

SOFTWARE ERP

SOFTWARE ESTOQUE

ULTRAFILTRAGEM

AUTOMOTIZAÇÃO LINHA

TÉCNICA DE MANUTENÇÃO

HARDWARE TELEMETRIA

EQUIPAMENTO DE FURAÇÃO

SENSOR NA LINHA

REATOR DE OXIGÊNIO

VSM

SISTEMA HIDRÁULICO

ESTRUTURA ORG

ESTRUTURA ORG

NOVO SITE

NOVA POLÍTICA

MODELO DE GESTÃO

AUTOMATIZAÇÃO

CHAVE ESTÁTICA

recombinação de prensa e manipulador

linha U

Software GLOBE 


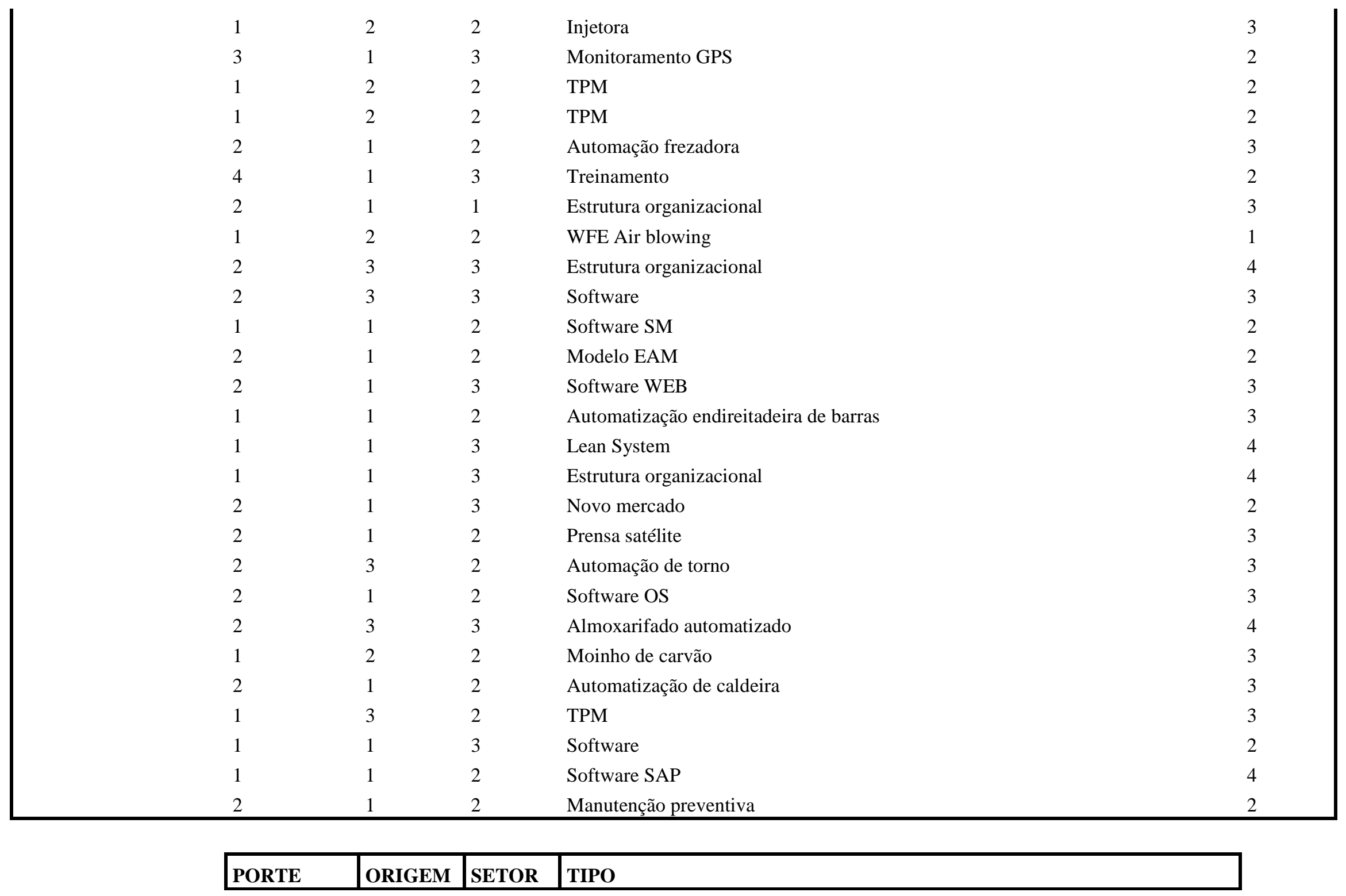




\begin{tabular}{|l|l|l|l|}
\hline 1 MICRO & 1 NAC & 1 COM & 1 PRODUTO \\
\hline 2 PEQUENO & 2 ESTR & 2 IND & 2 SERVICO \\
\hline 3 MEDIO & 3 MISTA & 3 SERV & 3 PROC HARD \\
\hline 4 GRANDE & & 4 AGR & 4 ORGA \\
\hline & & 5 PEC & 5 COMP \\
\hline & & & 6 PROC SOFT \\
\hline & & & 7 MKT \\
\hline
\end{tabular}


APÊNDICE I - EXEMPLO DE INOVAÇÕES EM FACILIDADES

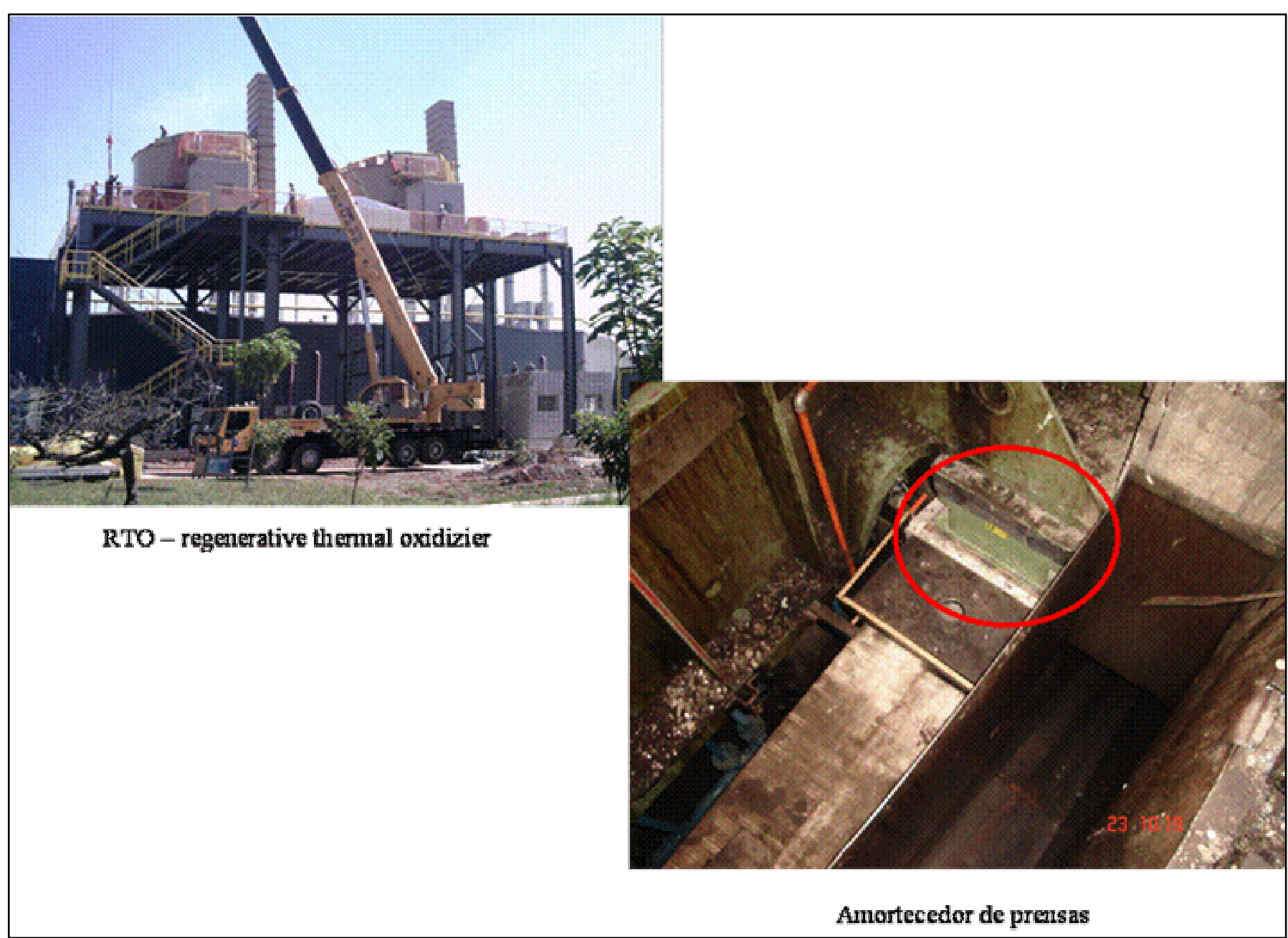


216

APÊNDICE J - TESTE ENTRE DUAS AMOSTRAS DO SURVEY

\begin{tabular}{|ccc|}
\hline respondente & coleta & coleta \\
1 & 5 & 5 \\
1 & 5 & 5 \\
1 & 4 & 4 \\
1 & 4 & 5 \\
1 & 5 & 5 \\
1 & 4 & 5 \\
1 & 4 & 3 \\
1 & 3 & 5 \\
1 & 3 & 4 \\
2 & 4 & 3 \\
2 & 5 & 4 \\
2 & 2 & 2 \\
2 & 4 & 4 \\
2 & 5 & 4 \\
2 & 4 & 4 \\
2 & 3 & 3 \\
2 & 3 & 3 \\
2 & 3 & 3 \\
3 & 4 & 4 \\
3 & 3 & 3 \\
3 & 4 & 4 \\
3 & 3 & 3 \\
3 & 5 & 5 \\
3 & 3 & 4 \\
3 & 4 & 4 \\
3 & 3 & 3 \\
3 & 3 & 3 \\
4 & 3 & 3 \\
4 & 3 & 3 \\
4 & 3 & 3 \\
4 & 3 & 3 \\
4 & 3 & 3 \\
\hline
\end{tabular}




\begin{tabular}{|lll|}
\hline 4 & 3 & 3 \\
4 & 3 & 3 \\
4 & 3 & 3 \\
4 & 3 & 3 \\
5 & 5 & 4 \\
5 & 4 & 3 \\
5 & 5 & 5 \\
5 & 4 & 3 \\
5 & 3 & 3 \\
5 & 5 & 4 \\
5 & 5 & 5 \\
5 & 3 & 4 \\
5 & 3 & 3 \\
\hline
\end{tabular}




\section{APÊNDICE K - INOVAÇÕES E MELHORIAS LEVANTADAS NO SURVEY}

\section{INOVAÇÕES E MELHORIAS CITADAS PELOS RESPONDENTES DO SURVEY}

1 Contrato de Fornecimento com fornecedores de insumos para a nossa operação.

Citarei a implantação do sistema ISO14000 na Unidade da Gerdau em Guarulhos, a qual trabalhei até Nov/2008. A certificação foi alcançada em set/2007 e fui responsável pelo controle e apresentação dos Impactos e Aspectos Ambientais do setor de Manutenção, a certificação foi conquistada sem nenhuma anormalidade na 2 Auditoria.

Individualização e Medições Remotas de Agua, Gás e Energia, desenvolvido por Empresas conceituadas, como a WGE Solutions nossa parceira para Brasília, com 3 a participação do IPT de SP.

Implantação de novo modelo de rack para acomodar novos servidores no data center da empresa: o rack tem algumas características padronizadas como largura (19"), altura de (44 U's)e profundidade de $910 \mathrm{~mm}$, porém com "chaminé" para direcionamento do ar quente diretamente para o plenum de retorno do ar condicionado, melhorando a performance geral do sistema. Os novos servidores de 1 U coletam o ar refrigerado pela frente e descarregam na parte traseira, onde esse ar é puxado por 4 ventoinhas instaladas no teto do rack. Os racks antigos eram totalmente abertos e havia mistura de ar quente com ar frio ocasionando muitas

4 perdas.

5 O inovação implantada foi a adaptação na função de facilities incluído as funções de uma concierge na prestação de serviço.

\section{6 - INTRODUÇÃO DE SISTEMA DE CONTROLE DE ENERGIA E MODERNIZAÇÃO DE SUB ESTAÇÕES ELÉTRICAS}

A criação de um cavalete para organizar e guardar os materiais em bruto para posterior usinagem. Esse cavalete conseguiu reunir em único local esses materiais que 7 antes ficavam em locais diferentes. Essa inovação impulsionou a reorganização de todo o setor resultando em grandes ganhos para a eficiência da área.

Implantação de sitema de Manutenção Preventiva de todas as instalações das Unidades. Consistindo em avaliação das instalações, por meio de inspeções e tomada 8 de ações corretivas.

Sem dúvida foi o desenvolvimento e implantação de um modelo de gestão de serviços corporativos, baseado em gestão por processos. Chegamos a apresentá-lo no IFMA de San Diego, pela Conbras. É um modelo extremamente simples, em PDCA, que contempla a gestão sobre toda e qualquer atividade exercida em uma

infraestrutura predial, modelo esse que por sua metodologia de controle/medição/análise de tendências, promove proatividade e visão sistêmica ao gestor, agregando

9 valor ao serviço contratado e ao negócio do cliente.

Primeiramente não foi criado algo que não exista. O que foi criado como inovação - tomando como algo diferente que nunca foi feito - a implantação de indicadores 10 de manutenção para o setor de Manutenção Industrial. 
IMPLEMENTAÇÃO DE GESTÃO DE CUSTOS EM TELEFONIA, REPROGRAMAÇÃO DE ESCALAS E EQUIPES DE TRABALHO; REGIME

11 REDISTRIBUIDO DE HORAS EXTRAS

Implantação serviço facilities/suprimentos em 06 unidades de Negócios - nov/2008 (Pronto! Imóveis) através de apoio administrativo: recepção, mensageria, serv expresso, reprografia, arquivos inativos, mobiliário, serv gráficos, mat escritório, central de atendimento. Gestão de contratos prestação de serviços, com destaque no desenvolvimento e qualificação de fornecedores e cumprimento serviços contratados: Seg Patrimonial, Monitoramento, Manutenção, Obras, Controle de ativo imobilizado, Frota de veículos próprios e terceiros, Conservação e limpeza, Lay-outs, Adm Contratos, Gerenciamento da área de suprimentos (SAP MM aprovador e requisitante), em atendimento as expectativas quanto à contratação de terceiros, desenvolvimento de parcerias, aquisição de bens e materiais, em consonância com

12 os objetivos estratégicos definidos pela empresa, assegurando os melhores preços através de contratos de longo prazo e follow-up.

ATUALIZAÇÃO TECNOLOGICA DE MÁQUINAS PARA ANESTESIA, ALÉM DE QUEBRA DE PARADIGMA NA NOVA FORMA DE UTILIZAÇÃO, COMO NA PREPARAÇÃO DA INFRA PARA UTILIZAÇÃO MÁXIMA DO POTENCIAL DESTA NOVA TECNOLOGIA. HOUVE UM ENORME ENGAJAMENTO PARA A MUDANÇA DE COSTUME, DEVIDO A RESISTENCIA À MUDANÇA DO PROCEDIMENTO VINCULADO AO PORTOCOLO

13 DE UTILIZAÇÃO DO ANESTÉSICO.

14 implantação de cronograma de paradas de energias para execução de manutenção preventivas,corretivas e preditivas nas agências bancarias do Banco Citibank.

Implantação de fornecimento de água para banho com temperatura pré-ajustada em função da temperatura do ar ambiente. (Aqueciemtno solar, complementado por

15 e'létrico)

Implantamos um sistema de quadro operacional, relatório preenchido diariamente pela equipe operacional, onde temos as seguintes informações reais: - Coberturas

16 de ausências e apoio, reforços, mutirões, quem fez a cobertura e como foi o desenvolvimento deste profissional.

17 Automação nas unidades

18 Implantação de software de manutenção.

$19 \quad$ NR 10 e NR 33

Implementação da filosofia LEAN OFFICE no controle técnico de manutenção no decorrer de 2008. Buscou-se reduzir os longos processos de abertura e

20 fechamento (registro) das ordens de serviço para se ter uma melhor eficiência do processo.

Participei no projeto de canalização dos gases de exaustão das caldeiras a gás natural, até o lavador de gases da planta de $\mathrm{CO}$, alinhando através de dampers até a tubulação já existente, o lance da tubulação aprox. 400mts de tubo de 16 "de diâmetro todo em Inox, As Vantagens ou benefícios: aumento da produção de CO2 em 21 aproximadamente duas toneladas por hora, minimizando a Liberação de gases poluentes p/ atmosfera (meio ambiente).

22 INTRODUÇÃO DE SISTEMA DE DESPOEIRAMENTO EM INSTALAÇÃO DE MOVIMENTAÇÃO DE TRIGO NO PORTO DE SANTOS 


\section{Mobilidade}

24 Alteração do Sistema (software) de Gerenciamento de Manutenção da empresa.

Customizamos um Compressor a Diesel para trabalhar em horário de ponta, totalmente automatizado, entrando em operação na falta de energia, sortindo falta de ar em casos de grande consumo e gerando Pay-Back, pois no horário de ponta a energia elétrica é mais cara. A Atlas-Copco através de nossa idéia passou a

25 comercializar este produto no mercado

26 Aquisição de uma prensa hidráulica de 4000Ton, juntamente com um manipulador de peças cuja capacidade de carga é de 15 Ton.

Criação, implantação e gestão de uma Central de Atendimento a todas as demandas de Real Estate para toda a rede do banco no Brasil. O processo gerou melhoria no atendimento, agilidade, redução de custos e foi considerada a melhor área de atendimento do banco. Inédito no Brasil, despertou o interesse de varias instituições 27 financeiras de grande porte alem de ter sido visitada por funcionários do banco de 5 paises fora LAT.

28 Neste ano iniciamos a informatização da manutenção, nos trouxe muitos benefícios, dentre eles, o maior controle de tudo o que acontece na manutenção.

A Igaratiba está implantando o projeto Sigma. São cinco pilares que englobam: Set Up Rápido, Zero Defeito ,Pessoas, Melhoria Contínua e Quebra Zero. É um

29 programa onde serão detalhados cada etapa para mudanças e gerenciamento da fábrica.

Foram diversas: Modernização dos elevadores, automação do sistema de controle de temperatura dos ambientes climatizados, automação dos chiller's, instalação de torneiras automáticas e reforma dos mecanismos de descarga das cx acopladas, uso de água de chuva nas torres de resfriamento, instalação de plataforma elevatória

30 para deficientes, troca da iluminação fluorescente das 2 garagens por lâmpada fria;

Na realidade, trata-se da melhoria no processo de contratação das atividades de Operação e Manutenção em um importante edifício comercial corporativo. Nesta revisão, foram alterados os contratos, incluindo a redefinição do escopo e suas limitações, a redefinição das posições chaves (interfaces) em ambas as estruturas, a elaboração de manuais de operação e o estabelecimento de uma reciclagem obrigatória e periódica da equipe e a transformação de um contrato "obsoleto" em um

31 contrato de performance, baseado em métricas e resultados.

A padronização da atividade de reforma de equipamentos hospitalares. Nossos clientes são muito exigentes, seja no perfeito funcionamento do equipamento, seja na aparência estética, ou seja todo equipamento que deve ser reformado, tem que apresentar a mesma condição de funcionamento e a mesma condição estética, pois mesmo o cliente sabendo que está adquirindo um equipamento usado e reformado, quer que este tenha a mesma aparência de um novo. Por tanto hoje a única 32 diferença dos equipamento após as reformas são os números de série.

33 Desenvolvimento interno de equipamentos para a produção de produtos dedicados. 
34 Melhoria no processo de aprovação das faturas de prestação de serviços e obras.

35 Padronização/ racionalização de cores de tintas (IMP - Isentas de Metais Pesados) para manutenção

O problema era a elevação de parte do telhado da fábrica de caminhões para possibilitar a modificação da linha para inclusão de um novo produto, sendo que só haveria 2 semanas com interrupção da atividade produtiva. A solução adotada foi a construção de uma nova cobertura por cima da existente, retirando a cobertura 36 antiga somente nas duas semanas de parada. O restante dos serviços de relocação de utilidades e proteção contra incêndio foi completado em finais de semana.

37 Melhoria no sistema de gerenciamento online, em suas interfaces financeira, cliente, e processos.

Revisões de políticas, principalmente na área de transportes (de pessoal, táxi e malotes), em conjunto com implantação de sistemática de controle, resultando em

38 otimização de processos e redução de custos.

39 Em desenvolvimento para implementação em 2010: Travel Management Software (TMS); RH \& Folha Software; CAFM

40 Implementação do Grupo Gerador

41 - Implantação de planilhas de rondas diárias e acompanhamento de equipamentos

A maior inovação foi com relação a sustentabilidade, onde os cestos de lixo sob as mesas fossem eliminados, fazendo com que os usuários levantassem de suas

42 mesas e realizassem o descarte correto.

Inovação: Mudança da estrutura organizacional da empresa. Facility Management passou a ser uma estrutura global com um vice presidente e 5 Diretores 43 Regionais. A partir daí estão sendo criadas e desenvolvidas todas as políticas, ferramentas e estruturas para suportar essa iniciativa

Centralização da gestão de facilities através de um Shared de Serviços da Unilever e contratação de uma empresa para gestão da operação e dos fornecedores de 44 serviços diversos.

45 Sistema de re-uso água edifício Citi Center Av. Paulista

46 Possibilidade de adequar os custos envolvidos na operação com a disponibilidade de orçamento previsto. POR GENTILEZA, ACESSEM O LINK PARA INFORMAÇÕES DETALHADAS E ILUSTRADAS:

47 http://www.4shared.com/file/164173448/f7c9dc76/Jornal_02.html 
48 REFORMA DE PARTE ESTRUTURAL DE PARTE DA EMPRESA (MOBILIARIO, CABLING, LAY OUT)

49 Gráfico de desempenho de reduções de custo por funcionário 


\section{APÊNDICE L - CORRELAÇÕES DAS VARIÁVEIS DEPENDENTES E INDEPENDENTES DO SURVEY}

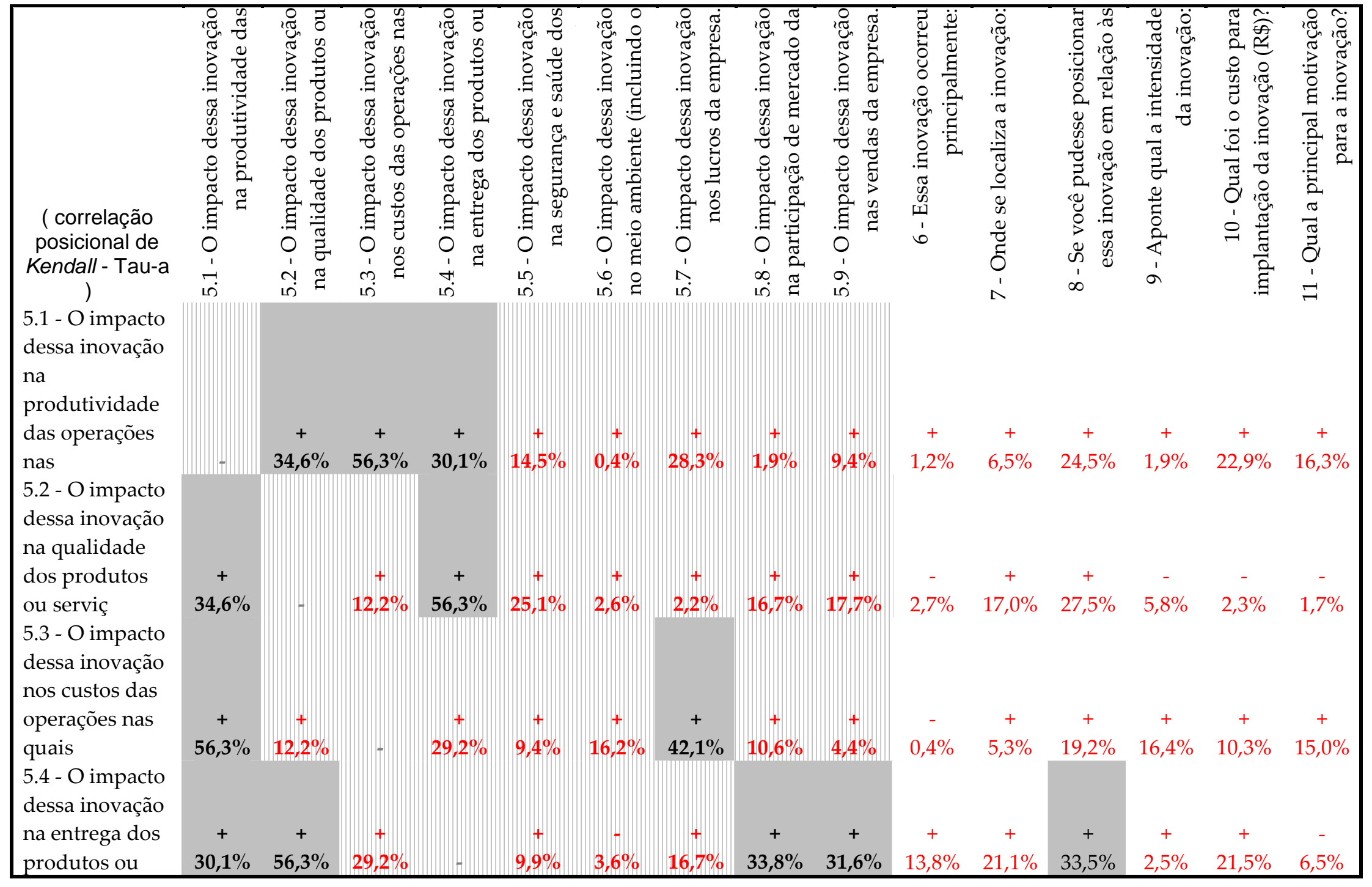




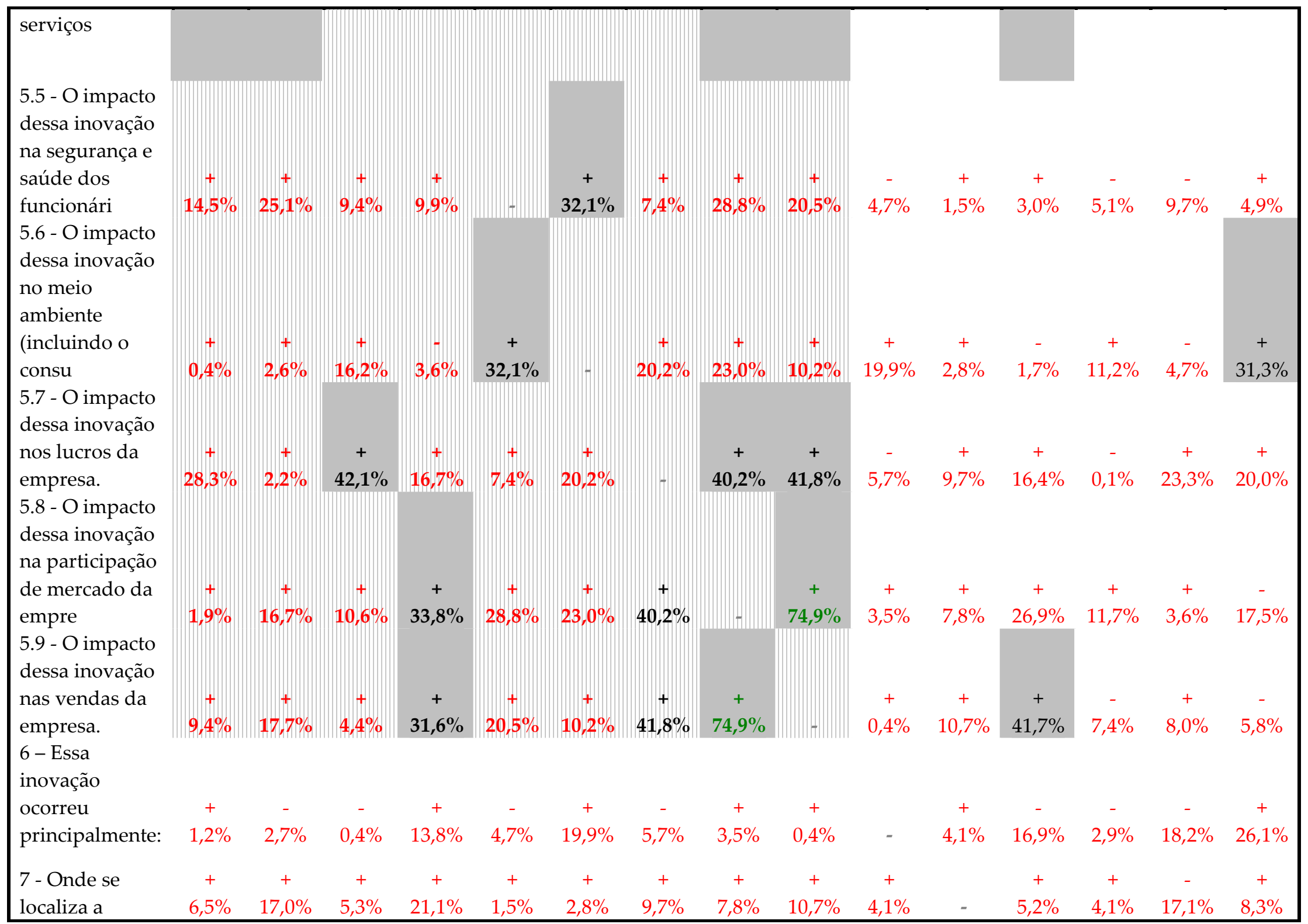




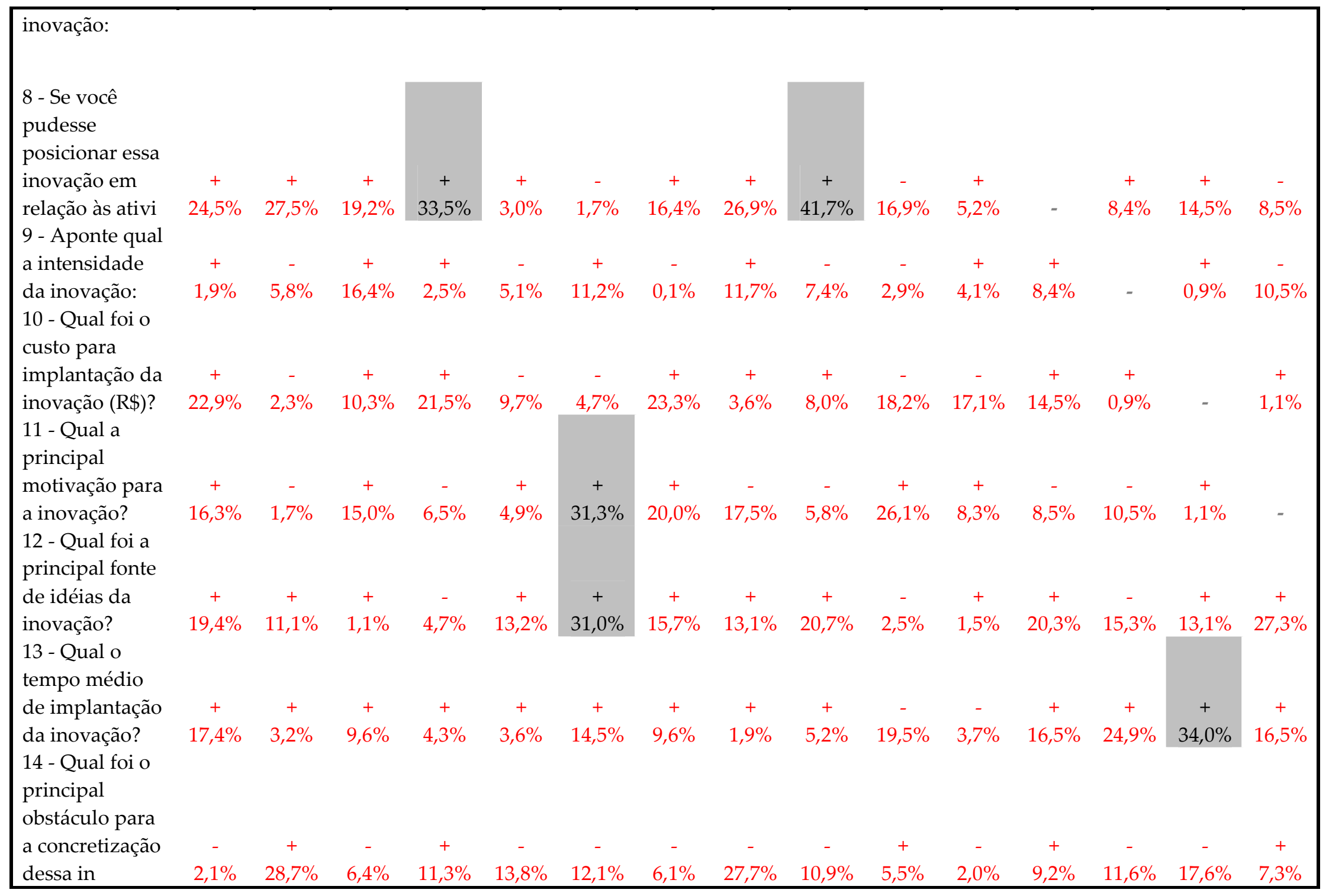




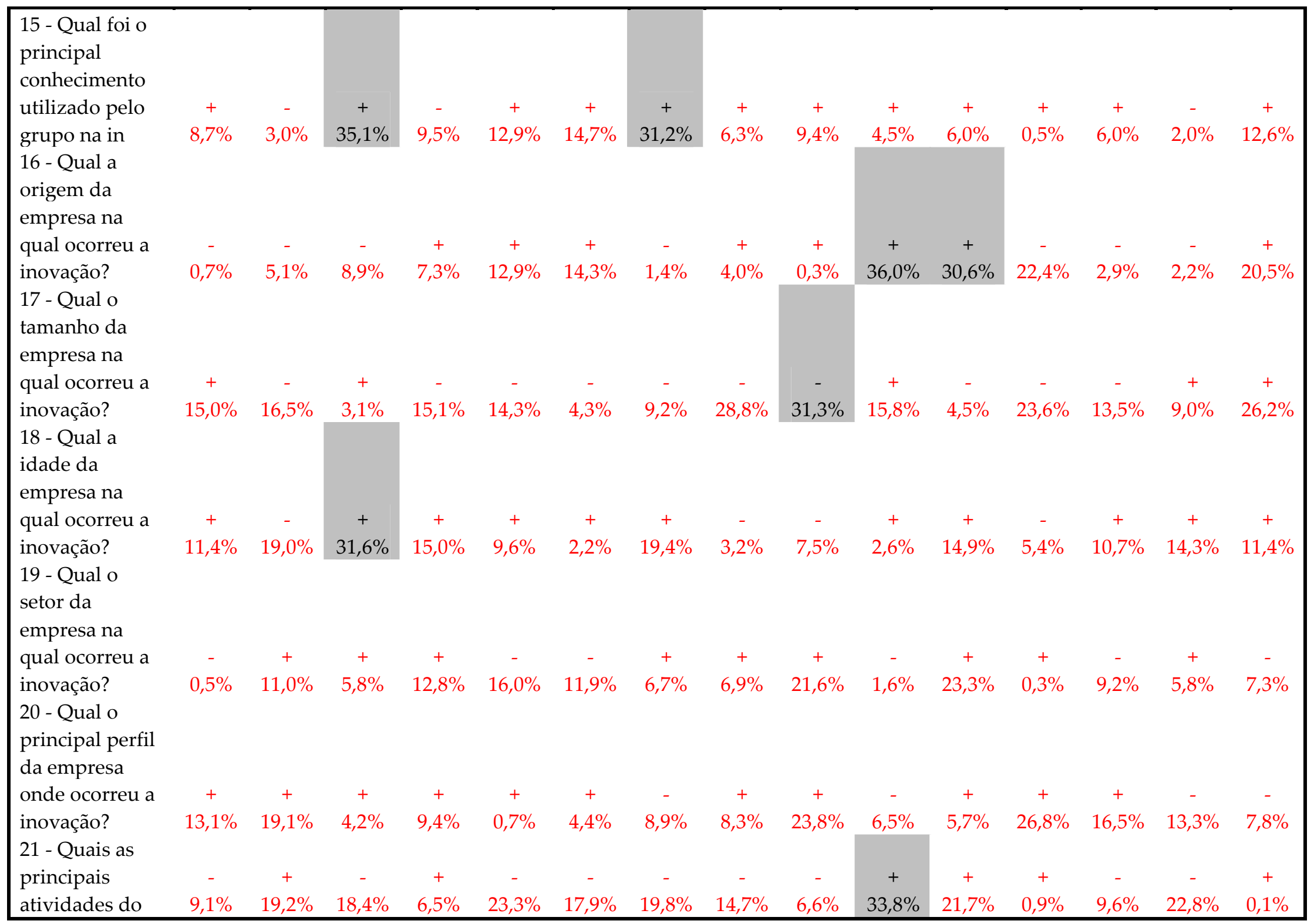




\begin{tabular}{|c|c|c|c|c|c|c|c|c|c|c|c|c|c|c|c|}
\hline $\begin{array}{l}\text { seu } \\
\text { departamento? }\end{array}$ & & & & & & & & & & & & & & & \\
\hline $\begin{array}{l}22 \text { - Qual era o } \\
\text { seu cargo na } \\
\text { época em que }\end{array}$ & & & & & & & & & & & & & & & \\
\hline ocorreu a & + & + & + & + & - & + & + & - & - & + & + & + & + & - & + \\
\hline inovação? & $8,9 \%$ & $26,7 \%$ & $20,9 \%$ & $10,3 \%$ & $0,5 \%$ & $14,2 \%$ & $17,6 \%$ & $2,4 \%$ & $4,6 \%$ & $11,9 \%$ & $10,0 \%$ & $1,8 \%$ & $6,8 \%$ & $5,4 \%$ & $16,1 \%$ \\
\hline $\begin{array}{l}23 \text { - O seu } \\
\text { departamento, } \\
\text { na época da }\end{array}$ & & & & & & & & & & & & & & & \\
\hline implantação da & - & - & - & - & + & - & - & + & + & + & - & - & - & - & - \\
\hline inovação, res & $17,3 \%$ & $26,3 \%$ & $28,1 \%$ & $19,9 \%$ & $4,0 \%$ & $6,9 \%$ & $23,2 \%$ & $7,6 \%$ & $13,2 \%$ & $11,3 \%$ & $7,8 \%$ & $17,6 \%$ & $15,7 \%$ & $14,5 \%$ & $11,0 \%$ \\
\hline $\begin{array}{l}24 \text { - Qual era } \\
\text { sua experiência } \\
\text { profissional }\end{array}$ & & & & & & & & & & & & & & & \\
\hline (em anos) na & + & + & + & + & + & + & + & - & - & + & + & - & + & + & + \\
\hline época em & $13,6 \%$ & $6,7 \%$ & $19,6 \%$ & $0,7 \%$ & $20,5 \%$ & $7,7 \%$ & $7,2 \%$ & $2,7 \%$ & $0,6 \%$ & $3,3 \%$ & $11,2 \%$ & $2,3 \%$ & $15,7 \%$ & $0,3 \%$ & $11,1 \%$ \\
\hline $\begin{array}{l}25 \text { - Qual era o } \\
\text { seu grau de } \\
\text { formação } \\
\text { acadêmica na }\end{array}$ & & & & & & & & & & & & & & & \\
\hline época em que & - & + & - & - & - & - & - & - & - & - & + & - & + & - & - \\
\hline oc & $5,9 \%$ & $19,8 \%$ & $0,5 \%$ & $10,5 \%$ & $3,6 \%$ & $14,2 \%$ & $17,6 \%$ & $15,2 \%$ & $31,3 \%$ & $15,9 \%$ & $7,1 \%$ & $10,3 \%$ & $6,4 \%$ & $9,0 \%$ & $15,4 \%$ \\
\hline
\end{tabular}




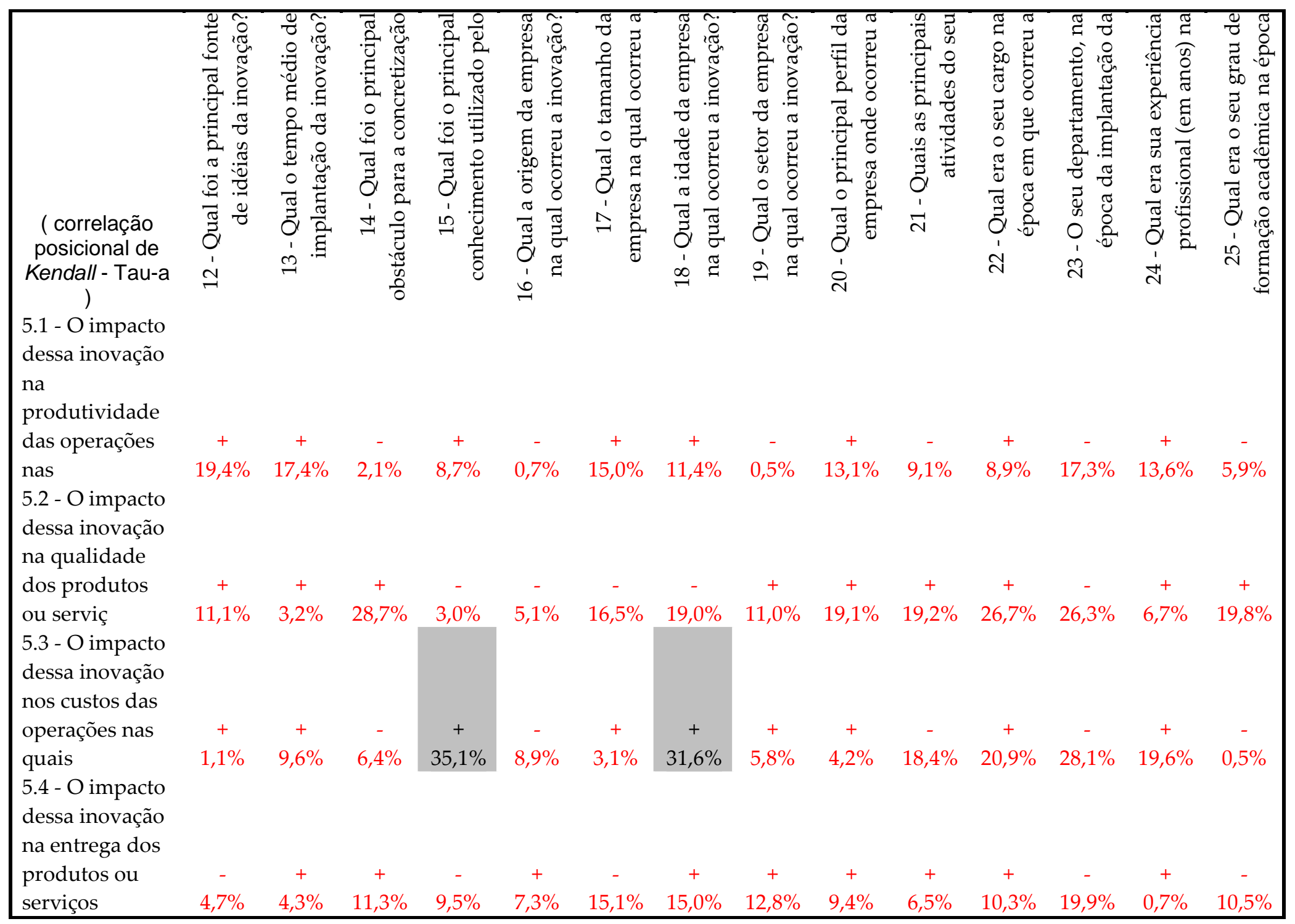




\begin{tabular}{|c|c|c|c|c|c|c|c|c|c|c|c|c|c|c|}
\hline \multicolumn{15}{|l|}{$\begin{array}{l}5.5 \text { - O impacto } \\
\text { dessa inovação }\end{array}$} \\
\hline funcionári & $13,2 \%$ & $3,6 \%$ & $13,8 \%$ & $12,9 \%$ & $12,9 \%$ & $14,3 \%$ & $9,6 \%$ & $16,0 \%$ & $0,7 \%$ & $23,3 \%$ & $0,5 \%$ & $4,0 \%$ & $20,5 \%$ & $3,6 \%$ \\
\hline $\begin{array}{l}5.6 \text { - O impacto } \\
\text { dessa inovação } \\
\text { no meio } \\
\text { ambiente }\end{array}$ & & & & & & & & & & & & & & \\
\hline (incluindo o & + & + & - & + & + & - & + & - & + & - & + & - & + & - \\
\hline consu & $31,0 \%$ & $14,5 \%$ & $12,1 \%$ & $14,7 \%$ & $14,3 \%$ & $4,3 \%$ & $2,2 \%$ & $11,9 \%$ & $4,4 \%$ & $17,9 \%$ & $14,2 \%$ & $6,9 \%$ & $7,7 \%$ & $14,2 \%$ \\
\hline $\begin{array}{l}5.7 \text { - O impacto } \\
\text { dessa inovação }\end{array}$ & & & & & & & & & & & & & & \\
\hline nos lucros da & + & + & - & + & - & - & + & + & - & - & + & - & + & - \\
\hline empresa. & $15,7 \%$ & $9,6 \%$ & $6,1 \%$ & $31,2 \%$ & $1,4 \%$ & $9,2 \%$ & $19,4 \%$ & $6,7 \%$ & $8,9 \%$ & $19,8 \%$ & $17,6 \%$ & $23,2 \%$ & $7,2 \%$ & $17,6 \%$ \\
\hline $\begin{array}{l}5.8 \text { - O impacto } \\
\text { dessa inovação } \\
\text { na participação }\end{array}$ & & & & & & & & & & & & & & \\
\hline de mercado da & + & + & - & + & + & - & - & + & + & - & - & + & - & - \\
\hline empre & $13,1 \%$ & $1,9 \%$ & $27,7 \%$ & $6,3 \%$ & $4,0 \%$ & $28,8 \%$ & $3,2 \%$ & $6,9 \%$ & $8,3 \%$ & $14,7 \%$ & $2,4 \%$ & $7,6 \%$ & $2,7 \%$ & $15,2 \%$ \\
\hline $\begin{array}{l}5.9 \text { - O impacto } \\
\text { dessa inovação }\end{array}$ & & & & & & & & & & & & & & \\
\hline nas vendas da & + & + & - & + & + & - & - & + & + & - & - & + & - & - \\
\hline empresa. & $20,7 \%$ & $5,2 \%$ & $10,9 \%$ & $9,4 \%$ & $0,3 \%$ & $31,3 \%$ & $7,5 \%$ & $21,6 \%$ & $23,8 \%$ & $6,6 \%$ & $4,6 \%$ & $13,2 \%$ & $0,6 \%$ & $31,3 \%$ \\
\hline $\begin{array}{l}6 \text { - Essa } \\
\text { inovação }\end{array}$ & & & & & & & & & & & & & & \\
\hline ocorreu & - & - & + & + & + & + & + & - & - & + & + & + & + & - \\
\hline $\begin{array}{l}\text { principalmente: } \\
7 \text { - Onde se }\end{array}$ & $2,5 \%$ & $19,5 \%$ & $5,5 \%$ & $4,5 \%$ & $36,0 \%$ & $15,8 \%$ & $2,6 \%$ & $1,6 \%$ & $6,5 \%$ & $33,8 \%$ & $11,9 \%$ & $11,3 \%$ & $3,3 \%$ & $15,9 \%$ \\
\hline localiza a & + & - & - & + & + & - & + & + & + & + & + & - & + & + \\
\hline inovação: & $1,5 \%$ & $3,7 \%$ & $2,0 \%$ & $6,0 \%$ & $30,6 \%$ & $4,5 \%$ & $14,9 \%$ & $23,3 \%$ & $5,7 \%$ & $21,7 \%$ & $10,0 \%$ & $7,8 \%$ & $11,2 \%$ & $7,1 \%$ \\
\hline
\end{tabular}




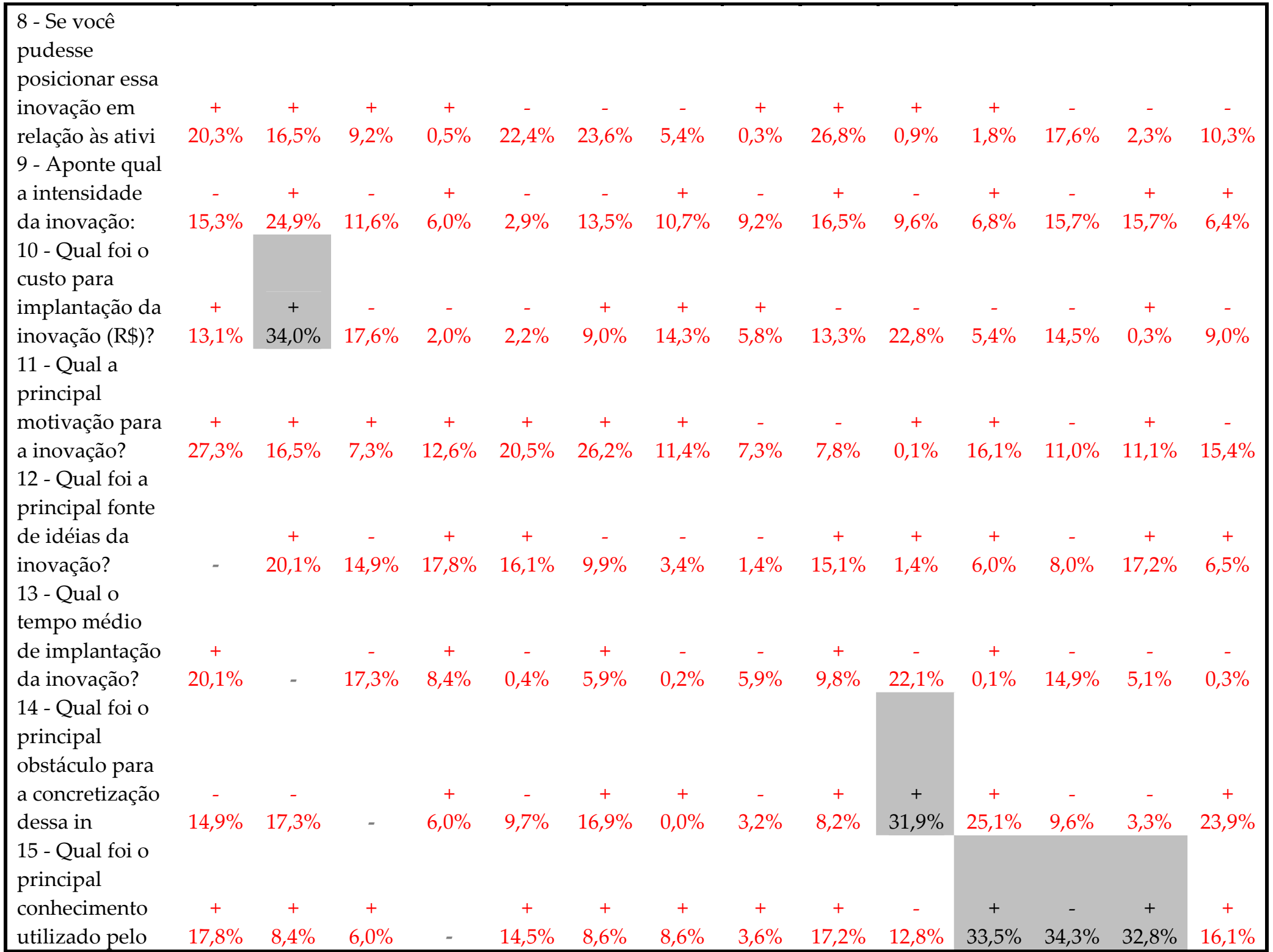




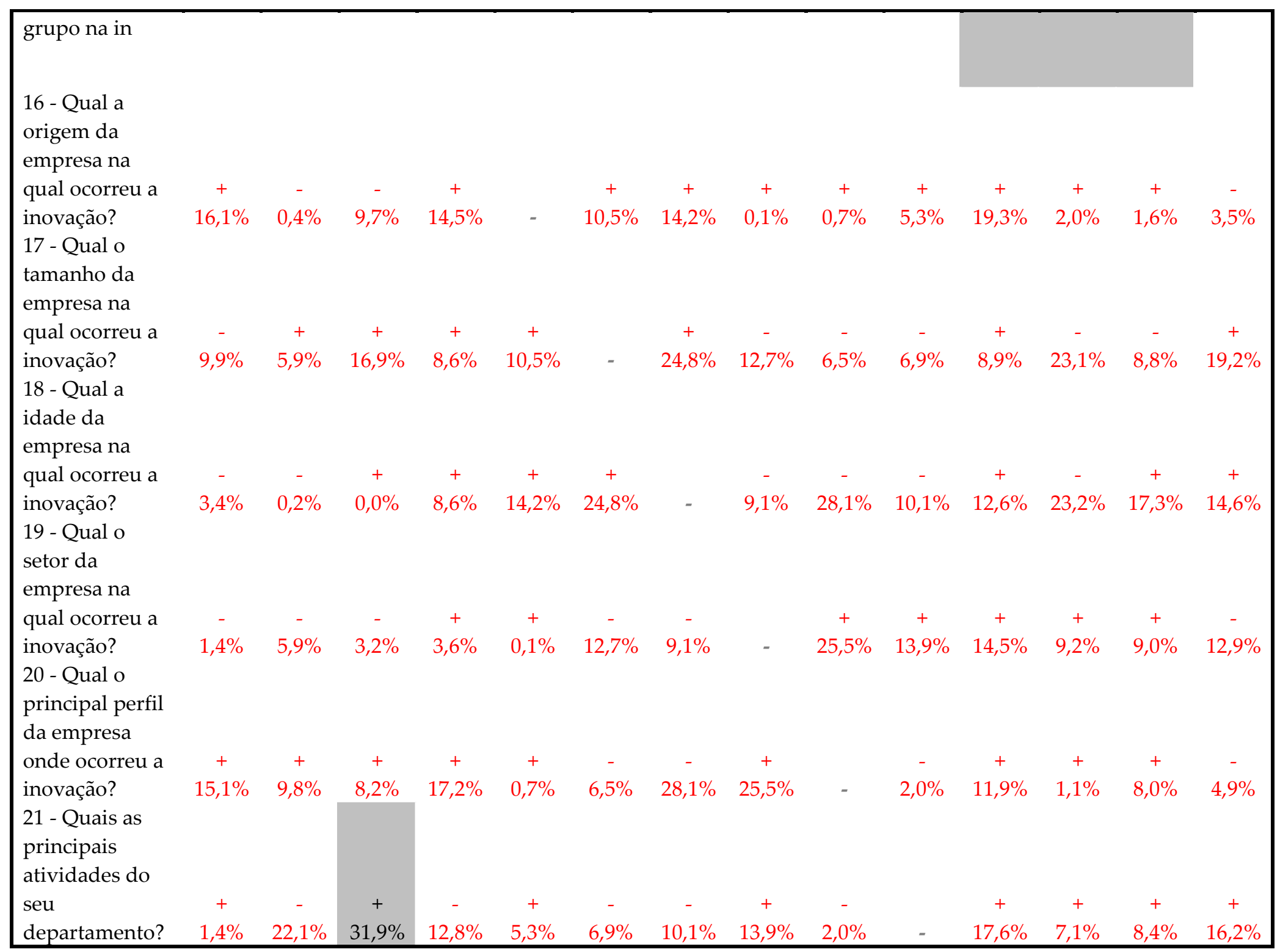




\begin{tabular}{|c|c|c|c|c|c|c|c|c|c|c|c|c|c|c|}
\hline \multicolumn{15}{|l|}{$\begin{array}{l}22 \text { - Qual era o } \\
\text { seu cargo na } \\
\text { época em que }\end{array}$} \\
\hline ocorreu a & + & + & + & + & + & + & + & + & + & + & & - & + & $\stackrel{+}{+}$ \\
\hline $\begin{array}{l}\text { inovação? } \\
23 \text { - O seu } \\
\text { departamento, } \\
\text { na época da }\end{array}$ & $6,0 \%$ & $0,1 \%$ & $25,1 \%$ & $33,5 \%$ & $19,3 \%$ & $8,9 \%$ & $12,6 \%$ & $14,5 \%$ & $11,9 \%$ & $17,6 \%$ & - & $52,6 \%$ & $22,9 \%$ & $27,7 \%$ \\
\hline implantação da & - & - & - & - & + & - & - & + & + & + & - & & - & - \\
\hline $\begin{array}{l}\text { inovação, res } \\
24 \text { - Qual era } \\
\text { sua experiência } \\
\text { profissional }\end{array}$ & $8,0 \%$ & $14,9 \%$ & $9,6 \%$ & $34,3 \%$ & $2,0 \%$ & $23,1 \%$ & $23,2 \%$ & $9,2 \%$ & $1,1 \%$ & $7,1 \%$ & $52,6 \%$ & - & $18,3 \%$ & $27,3 \%$ \\
\hline (em anos) na & + & - & - & + & + & - & + & + & + & + & + & - & & + \\
\hline $\begin{array}{l}\text { época em } \\
25 \text { - Qual era o } \\
\text { seu grau de } \\
\text { formação } \\
\text { acadêmica na }\end{array}$ & $17,2 \%$ & $5,1 \%$ & $3,3 \%$ & $32,8 \%$ & $1,6 \%$ & $8,8 \%$ & $17,3 \%$ & $9,0 \%$ & $8,0 \%$ & $8,4 \%$ & $22,9 \%$ & $18,3 \%$ & - & $23,2 \%$ \\
\hline época em que & + & - & + & + & - & + & + & - & - & + & + & - & + & \\
\hline oc & $6,5 \%$ & $0,3 \%$ & $23,9 \%$ & $16,1 \%$ & $3,5 \%$ & $19,2 \%$ & $14,6 \%$ & $12,9 \%$ & $4,9 \%$ & $16,2 \%$ & $27,7 \%$ & $27,3 \%$ & $23,2 \%$ & - \\
\hline
\end{tabular}




\section{APÊNDICE M - MATRIZ ANTIIMAGEM DO SURVEY}

Anti-image Matrices

\begin{tabular}{|c|c|c|c|c|c|c|c|c|c|c|c|c|c|c|c|}
\hline & & \multicolumn{2}{|c|}{ POSIMOTIVA } & CONHE & TAMA & CARGO & EXPERI & PROD & QUAL & CUST & ENTRE & SEGU & LUCRO & PARTI & VENDAS \\
\hline Anti-image & \multirow[t]{2}{*}{ POSI } & \multirow[t]{2}{*}{, 577} & $4,189 \mathrm{E}-$ & $2,310 \mathrm{E}-$ & ,132 & $1,956 \mathrm{E}-$ & $4,677 \mathrm{E}-$ & $-6,522 \mathrm{E}-$ & $-5,378 \mathrm{E}-$ & $-4,120 \mathrm{E}-$ & $-5,842 \mathrm{E}-$ & $6,758 \mathrm{E}-$ & $1,003 \mathrm{E}-$ & $7,867 \mathrm{E}-$ &,- 175 \\
\hline \multirow{27}{*}{ Covariance } & & & 02 & 02 & & 02 & 02 & 02 & 02 & 02 & 02 & 02 & 02 & 02 & \\
\hline & \multirow[t]{2}{*}{ MOTIVA } & $4,189 \mathrm{E}-$ & ,776 & $4,172 \mathrm{E}-$ &,- 121 & $-4,948 \mathrm{E}-$ &,- 104 & $-1,500 \mathrm{E}-$ & $-1,669 \mathrm{E}-$ & $-2,943 \mathrm{E}-$ & $3,864 \mathrm{E}-$ & $-5,433 \mathrm{E}-$ &,- 156 & $8,510 \mathrm{E}-$ & $-1,947 \mathrm{E}-$ \\
\hline & & 02 & & 02 & & 02 & & 02 & 02 & 02 & 02 & 02 & & 02 & 02 \\
\hline & \multirow[t]{2}{*}{ CONHE } & $2,310 \mathrm{E}-$ & $4,172 \mathrm{E}-$ & ,551 & $-7,471 \mathrm{E}-$ &,- 124 &,- 186 & $8,876 \mathrm{E}-$ & $-6,239 \mathrm{E}-$ &,- 165 & , 153 & $-1,054 \mathrm{E}-$ & $-9,962 \mathrm{E}-$ & $9,310 \mathrm{E}-$ & $-4,936 \mathrm{E}-$ \\
\hline & & 02 & 02 & & 02 & & & 02 & 02 & & & 02 & 02 & 03 & 02 \\
\hline & \multirow[t]{2}{*}{ TAMA } & ,132 &,- 121 & $-7,471 \mathrm{E}-$ & ,671 &,- 126 & ,110 &,- 190 & ,139 & $5,545 \mathrm{E}-$ & $-6,563 \mathrm{E}-$ & $-1,657 \mathrm{E}-$ & ,103 & $2,201 \mathrm{E}-$ & $3,840 \mathrm{E}-$ \\
\hline & & & & 02 & & & & & & 02 & 02 & 03 & & 02 & 03 \\
\hline & \multirow[t]{2}{*}{ CARGO } & $1,956 \mathrm{E}-$ & $-4,948 \mathrm{E}-$ &,- 124 &,- 126 & ,687 &,- 120 & $9,269 \mathrm{E}-$ & - & $-5,371 \mathrm{E}-$ & $1,525 \mathrm{E}-$ & $8,300 \mathrm{E}-$ & $-7,461 \mathrm{E}-$ & $4,695 \mathrm{E}-$ & $-2,114 \mathrm{E}-$ \\
\hline & & 02 & 02 & & & & & 02 & & 02 & 02 & 02 & 02 & 02 & 02 \\
\hline & \multirow[t]{2}{*}{ EXPERI } & $4,677 \mathrm{E}-$ &,- 104 &,- 186 & ,110 &,- 120 & ,731 & $-3,976 \mathrm{E}-$ & $3,684 \mathrm{E}-$ & $5,273 \mathrm{E}-$ & $-6,291 \mathrm{E}-$ &,- 167 & $6,861 \mathrm{E}-$ & $5,032 \mathrm{E}-$ & $\overline{-2,762 \mathrm{E}-}$ \\
\hline & & 02 & & & & & & 02 & 02 & 03 & 02 & & 02 & 02 & 02 \\
\hline & \multirow[t]{2}{*}{ PROD } & $-6,522 \mathrm{E}-$ & $-1,500 \mathrm{E}-$ & $8,876 \mathrm{E}-$ &,- 190 & $9,269 \mathrm{E}-$ & $-3,976 \mathrm{E}-$ & 389 &,- 163 &,- 223 & $8,355 \mathrm{E}-$ & $-7,700 \mathrm{E}-$ & $-6,743 \mathrm{E}-$ & $6,066 \mathrm{E}-$ & $-3,814 \mathrm{E}-$ \\
\hline & & 02 & 02 & 02 & & 02 & 02 & & & & 02 & 02 & 02 & 02 & 02 \\
\hline & \multirow[t]{2}{*}{ QUAL } & $-5,378 \mathrm{E}-$ & $-1,669 \mathrm{E}-$ & $-6,239 \mathrm{E}-$ & ,139 &,- 170 & $3,684 \mathrm{E}-$ &,- 163 & ,431 &, 123 &,- 248 & $-9,553 \mathrm{E}-$ & $9,159 \mathrm{E}-$ & $-2,152 \mathrm{E}-$ & $2,890 \mathrm{E}-$ \\
\hline & & 02 & 02 & 02 & & & 02 & & & & & 02 & 02 & 02 & 02 \\
\hline & \multirow[t]{2}{*}{ CUST } & $-4,120 \mathrm{E}-$ & $-2,943 \mathrm{E}-$ & -.165 & $5,545 \mathrm{E}-$ & $-5,371 \mathrm{E}-$ & $5,273 \mathrm{E}-$ & -.223 & .123 & .352 &,- 142 & $2.549 \mathrm{E}-$ & $-6,721 \mathrm{E}-$ & $-4,739 \mathrm{E}-$ & $8.615 \mathrm{E}-$ \\
\hline & & 02 & 02 & & 02 & 02 & 03 & & & & & 02 & 02 & 02 & 02 \\
\hline & \multirow[t]{2}{*}{ ENTRE } & $-5,842 \mathrm{E}-$ & $3,864 \mathrm{E}-$ & ,153 & $-6,563 \mathrm{E}-$ & $1,525 \mathrm{E}-$ & $-6,291 \mathrm{E}-$ & $8,355 \mathrm{E}-$ &,- 248 &,- 142 & ,445 & $8,868 \mathrm{E}-$ & $-3,391 \mathrm{E}-$ & $-3,766 \mathrm{E}-$ & $-3,469 \mathrm{E}-$ \\
\hline & & 02 & 02 & & 02 & 02 & 02 & 02 & & & & 02 & 02 & 02 & 02 \\
\hline & \multirow[t]{2}{*}{ SEGU } & $6,758 \mathrm{E}-$ & $-5,433 \mathrm{E}-$ & $-1,054 \mathrm{E}-$ & $-1,657 \mathrm{E}-$ & $8,300 \mathrm{E}-$ &,- 167 & $-7,700 \mathrm{E}-$ & $-9,553 \mathrm{E}-$ & $2,549 \mathrm{E}-$ & $8,868 \mathrm{E}-$ & .688 & $6,032 \mathrm{E}-$ &,- 157 & $4,506 \mathrm{E}-$ \\
\hline & & 02 & 02 & 02 & 03 & 02 & & 02 & 02 & 02 & 02 & & 02 & & 03 \\
\hline & \multirow[t]{2}{*}{ LUCRO } & $1,003 \mathrm{E}-$ &,- 156 & $-9,962 \mathrm{E}-$ & , 103 & $-7,461 \mathrm{E}-$ & $6,861 \mathrm{E}-$ & $-6,743 \mathrm{E}-$ & $9,159 \mathrm{E}-$ & $-6,721 \mathrm{E}-$ & $-3,391 \mathrm{E}-$ & $6,032 \mathrm{E}-$ & ,489 & $-9,815 \mathrm{E}-$ & $-5,628 \mathrm{E}-$ \\
\hline & & 02 & & 02 & & 02 & 02 & 02 & 02 & 02 & 02 & 02 & & 02 & 02 \\
\hline & \multirow[t]{2}{*}{ PARTI } & $7,867 \mathrm{E}-$ & $8,510 \mathrm{E}-$ & $9,310 \mathrm{E}-$ & $2,201 \mathrm{E}-$ & $4,695 \mathrm{E}-$ & $5,032 \mathrm{E}-$ & $6,066 \mathrm{E}-$ & $-2,152 \mathrm{E}-$ & $-4,739 \mathrm{E}-$ & $-3,766 \mathrm{E}-$ &,- 157 & $-9,815 \mathrm{E}-$ & ,307 & $\overline{-, 194}$ \\
\hline & & 02 & 02 & 03 & 02 & 02 & 02 & 02 & 02 & 02 & 02 & & 02 & & \\
\hline & \multirow[t]{2}{*}{ VENDAS } & \multirow[t]{2}{*}{,- 175} & $-1,947 \mathrm{E}-$ & $-4,936 \mathrm{E}-$ & $3,840 \mathrm{E}-$ & $-2,114 \mathrm{E}-$ & $-2,762 \mathrm{E}-$ & $-3,814 \mathrm{E}-$ & $2,890 \mathrm{E}-$ & $8,615 \mathrm{E}-$ & $-3,469 \mathrm{E}-$ & $4,506 \mathrm{E}-$ & $-5,628 \mathrm{E}-$ &,- 194 &, 310 \\
\hline & & & 02 & 02 & 03 & 02 & 02 & 02 & 02 & 02 & 02 & 03 & 02 & & \\
\hline Anti-image & \multirow[t]{2}{*}{ POSI } & \multirow[t]{2}{*}{,719 } & $6,260 \mathrm{E}-$ & $4,097 \mathrm{E}-$ & ,213 & $3,107 \mathrm{E}-$ & $7,201 \mathrm{E}-$ &,- 138 &,- 108 & $-9,148 \mathrm{E}-$ &,- 115 & , 107 & $1,889 \mathrm{E}-$ & , 187 &,- 415 \\
\hline \multirow{5}{*}{ Correlation } & & & 02 & 02 & & 02 & 02 & & & 02 & & & 02 & & \\
\hline & \multirow[t]{2}{*}{ MOTIVA } & $6,260 \mathrm{E}-$ & ,686 & $6,381 \mathrm{E}-$ &,- 168 & $-6,779 \mathrm{E}-$ &,- 139 & $-2,729 \mathrm{E}-$ & $-2,887 \mathrm{E}-$ & $-5,634 \mathrm{E}-$ & $6,574 \mathrm{E}-$ & $-7,436 \mathrm{E}-$ &,- 254 & ,174 & $-3,973 \mathrm{E}-$ \\
\hline & & 02 & & 02 & & 02 & & 02 & 02 & 02 & 02 & 02 & & & 02 \\
\hline & CONHE & $4,097 \mathrm{E}-$ & $6,381 \mathrm{E}-$ & ,600 &,- 123 &,- 201 &,- 293 & , 192 &,- 128 &,- 375 & ,309 & $-1,712 \mathrm{E}-$ &,- 192 & $2,263 \mathrm{E}-$ &,- 120 \\
\hline & & 02 & 02 & & & & & & & & & & & & \\
\hline
\end{tabular}




\begin{tabular}{|c|c|c|c|c|c|c|c|c|c|c|c|c|c|c|}
\hline TAMA & ,213 &,- 168 &,- 123 & ,522 &,- 186 & ,156 &,- 371 & ,258 & ,114 &,- 120 & $\begin{array}{r}-2,438 \mathrm{E}- \\
03\end{array}$ & ,181 & $\begin{array}{r}4,849 \mathrm{E}- \\
02\end{array}$ & $\begin{array}{r}8,424 \mathrm{E}- \\
03\end{array}$ \\
\hline CARGO & $\begin{array}{r}3,107 \mathrm{E}- \\
02\end{array}$ & $\begin{array}{r}-6,779 \mathrm{E}- \\
02\end{array}$ &,- 201 &,- 186 & ,614 &,- 170 & , 179 &,- 313 &,- 109 & $\begin{array}{r}2,758 \mathrm{E}- \\
02\end{array}$ &, 121 &,- 129 & , 102 & $\begin{array}{r}-4,585 \mathrm{E}- \\
02\end{array}$ \\
\hline EXPERI & $\begin{array}{r}7,201 \mathrm{E}- \\
02 \\
\end{array}$ &,- 139 &,- 293 & ,156 &,- 170 & ,600 & $\begin{array}{r}-7,455 \mathrm{E}- \\
02\end{array}$ & $\begin{array}{r}6,565 \mathrm{E}- \\
02\end{array}$ & $\begin{array}{r}1,040 \mathrm{E}- \\
02\end{array}$ &,- 110 &,- 235 & ,115 & ,106 & $\begin{array}{r}-5,806 \mathrm{E}- \\
02\end{array}$ \\
\hline PROD &,- 138 & $\begin{array}{r}-2,729 \mathrm{E}- \\
02\end{array}$ & ,192 &,- 371 & , 179 & $\begin{array}{r}-7,455 \mathrm{E}- \\
02 \\
\end{array}$ &, 516 &,- 398 &,- 602 & ,201 &,- 149 &,- 155 & , 175 &,- 110 \\
\hline QUAL &,- 108 & $\begin{array}{r}-2,887 \mathrm{E}- \\
02\end{array}$ &,- 128 & ,258 &,- 313 & $\begin{array}{r}6,565 \mathrm{E}- \\
02\end{array}$ &,- 398 & ,489 & ,316 &,- 567 &,- 175 & ,200 & $\begin{array}{r}-5,915 \mathrm{E}- \\
02\end{array}$ & $\begin{array}{r}7,913 \mathrm{E}- \\
02\end{array}$ \\
\hline CUST & $\begin{array}{r}-9,148 \mathrm{E}- \\
02 \\
\end{array}$ & $\begin{array}{r}-5,634 \mathrm{E}- \\
02 \\
\end{array}$ &,- 375 & ,114 &,- 109 & $\begin{array}{r}1,040 \mathrm{E}- \\
02 \\
\end{array}$ &,- 602 & ,316 & ,562 &,- 359 & $\begin{array}{r}5,184 \mathrm{E}- \\
02 \\
\end{array}$ &,- 162 &,- 144 & $\overline{261}$ \\
\hline ENTRE &,- 115 & $\begin{array}{r}6,574 \mathrm{E}- \\
02\end{array}$ & ,309 &,- 120 & $\begin{array}{r}2,758 \mathrm{E}- \\
02\end{array}$ &,- 110 & ,201 &,- 567 &,- 359 & ,592 & , 160 & $\begin{array}{r}-7,269 \mathrm{E}- \\
02 \\
\end{array}$ &,- 102 & $\begin{array}{r}-9,343 \mathrm{E}- \\
02 \\
\end{array}$ \\
\hline SEGU & ,107 & $\begin{array}{r}-7,436 \mathrm{E}- \\
02\end{array}$ & $\begin{array}{r}-1,712 \mathrm{E}- \\
02\end{array}$ & $\begin{array}{r}-2,438 \mathrm{E}- \\
03\end{array}$ & ,121 &,- 235 &,- 149 &,- 175 & $\begin{array}{r}5,184 \mathrm{E}- \\
02\end{array}$ & , 160 & ,553 & ,104 &,- 341 & $\begin{array}{r}9,762 \mathrm{E}- \\
03\end{array}$ \\
\hline LUCRO & $\begin{array}{r}1,889 \mathrm{E}- \\
02 \\
\end{array}$ &,- 254 &,- 192 &, 181 &,- 129 & ,115 &,- 155 & ,200 &,- 162 & $\begin{array}{r}-7,269 \mathrm{E}- \\
02 \\
\end{array}$ & ,104 & ,751 &,- 253 &,- 145 \\
\hline PARTI & , 187 & ,174 & $\begin{array}{r}2,263 \mathrm{E}- \\
02 \\
\end{array}$ & $\begin{array}{r}4,849 \mathrm{E}- \\
02 \\
\end{array}$ & ,102 & , 106 & , 175 & $\begin{array}{r}-5,915 \mathrm{E}- \\
02\end{array}$ &,- 144 &,- 102 &,- 341 &,- 253 & ,637 &,- 630 \\
\hline VENDAS &,- 415 & $\begin{array}{r}-3,973 \mathrm{E}- \\
02\end{array}$ &,- 120 & $\begin{array}{r}8,424 \mathrm{E}- \\
03\end{array}$ & $\begin{array}{r}-4,585 \mathrm{E}- \\
02\end{array}$ & $\begin{array}{r}-5,806 \mathrm{E}- \\
02 \\
\end{array}$ &,- 110 & $\begin{array}{r}7,913 \mathrm{E}- \\
02\end{array}$ & ,261 & $\begin{array}{r}-9,343 \mathrm{E}- \\
02\end{array}$ & $\begin{array}{r}9,762 \mathrm{E}- \\
03\end{array}$ &,- 145 &,- 630 & ,658 \\
\hline
\end{tabular}

a Measures of Sampling Adequacy(MSA) 
APÊNDICE N - COMUNALIDADES DOS DADOS DO SURVEY

Communalities

\begin{tabular}{r|r|r}
\hline & Initial & Extraction \\
\hline POSI & 1,000 &, 576 \\
\hline MOTIVA & 1,000 &, 380 \\
\hline CONHE & 1,000 &, 690 \\
\hline TAMA & 1,000 &, 527 \\
\hline CARGO & 1,000 &, 680 \\
\hline EXPERI & 1,000 &, 641 \\
\hline PROD & 1,000 &, 805 \\
\hline QUAL & 1,000 &, 806 \\
\hline CUST & 1,000 &, 729 \\
\hline ENTRE & 1,000 &, 706 \\
\hline SEGU & 1,000 &, 855 \\
\hline LUCRO & 1,000 &, 751 \\
\hline PARTI & 1,000 &, 808 \\
\hline VENDAS & 1,000 &, 766 \\
\hline
\end{tabular}

Extraction Method: Principal Component Analysis. 


\section{APÊNDICE O - VARIÂNCIA TOTAL DOS DADOS DO SURVEY}

Total Variance Explained

\begin{tabular}{|c|c|c|c|c|c|c|c|c|c|}
\hline & $\begin{array}{r}\text { Initial } \\
\text { Eigenvalue } \\
\mathrm{s}\end{array}$ & & & $\begin{array}{r}\text { Extraction } \\
\text { Sums of } \\
\text { Squared } \\
\text { Loadings }\end{array}$ & & & $\begin{array}{l}\text { Rotation } \\
\text { Sums of } \\
\text { Squared } \\
\text { Loadings }\end{array}$ & & \\
\hline $\begin{array}{r}\text { Componen } \\
\mathrm{t}\end{array}$ & Total & $\begin{array}{r}\% \text { of } \\
\text { Variance }\end{array}$ & $\begin{array}{r}\text { Cumulativ } \\
\mathrm{e} \%\end{array}$ & Total & $\begin{array}{r}\% \text { of } \\
\text { Variance }\end{array}$ & $\begin{array}{r}\text { Cumulativ } \\
\mathrm{e} \% \\
\end{array}$ & Total & $\begin{array}{r}\% \text { of } \\
\text { Variance }\end{array}$ & $\begin{array}{r}\text { Cumulativ } \\
\text { e \% } \\
\end{array}$ \\
\hline 1 & 3,449 & 24,638 & 24,638 & 3,449 & 24,638 & 24,638 & 2,488 & 17,774 & 17,774 \\
\hline 2 & 2,387 & 17,047 & 41,686 & 2,387 & 17,047 & 41,686 & 2,161 & 15,437 & 33,211 \\
\hline 3 & 1,525 & 10,890 & 52,576 & 1,525 & 10,890 & 52,576 & 2,040 & 14,570 & 47,781 \\
\hline 4 & 1,251 & 8,934 & 61,510 & 1,251 & 8,934 & 61,510 & 1,774 & 12,672 & 60,453 \\
\hline 5 & 1,110 & 7,926 & 69,436 & 1,110 & 7,926 & 69,436 & 1,258 & 8,984 & 69,436 \\
\hline 6 & ,836 & 5,974 & 75,411 & & & & & & \\
\hline 7 & ,786 & 5,617 & 81,028 & & & & & & \\
\hline 8 & ,639 & 4,563 & 85,591 & & & & & & \\
\hline 9 & ,561 & 4,004 & 89,595 & & & & & & \\
\hline 10 & ,433 & 3,094 & 92,690 & & & & & & \\
\hline 11 & ,369 & 2,636 & 95,326 & & & & & & \\
\hline 12 & ,315 & 2,250 & 97,576 & & & & & & \\
\hline 13 & , 195 & 1,389 & 98,965 & & & & & & \\
\hline 14 & , 145 & 1,035 & 100,000 & & & & & & \\
\hline
\end{tabular}

Extraction Method: Principal Component Analysis. 


\section{APÊNDICE P - CARACTERÍSTICAS DAS SUBCATEGORIAS ENCONTRADAS NO SURVEY}

\begin{tabular}{|c|c|c|c|c|c|c|c|c|c|c|c|}
\hline & $\begin{array}{l}6 \text { - Essa } \\
\text { inovação } \\
\text { ocorreu } \\
\text { principalmente: }\end{array}$ & $\begin{array}{l}9 \text { - Aponte } \\
\text { qual a } \\
\text { intensidade } \\
\text { da } \\
\text { inovação: }\end{array}$ & $\begin{array}{l}12-\text { Qual } \\
\text { foi a } \\
\text { principal } \\
\text { fonte de } \\
\text { ideias da } \\
\text { inovação? }\end{array}$ & $\begin{array}{l}13 \text { - Qual o } \\
\text { tempo } \\
\text { médio de } \\
\text { implantação } \\
\text { da } \\
\text { inovação? }\end{array}$ & $\begin{array}{l}14 \text { - Qual foi } \\
\text { o principal } \\
\text { obstáculo } \\
\text { para a } \\
\text { concretização } \\
\text { dessa } \\
\text { inovação? }\end{array}$ & $\begin{array}{l}16 \text { - Qual a } \\
\text { origem da } \\
\text { empresa } \\
\text { onde } \\
\text { ocorreu a } \\
\text { inovação? }\end{array}$ & $\begin{array}{l}19 \text { - Qual o } \\
\text { setor da } \\
\text { empresa onde } \\
\text { ocorreu a } \\
\text { inovação? }\end{array}$ & $\begin{array}{l}20 \text { - Qual } \\
\text { o } \\
\text { principal } \\
\text { perfil da } \\
\text { empresa } \\
\text { onde } \\
\text { ocorreu a } \\
\text { inovação? }\end{array}$ & $\begin{array}{l}21 \text { - Quais as } \\
\text { principais } \\
\text { atividades do } \\
\text { seu } \\
\text { departamento? }\end{array}$ & $\begin{array}{l}22 \text { - Qual } \\
\text { era o seu } \\
\text { cargo na } \\
\text { época em } \\
\text { que } \\
\text { ocorreu a } \\
\text { inovação? }\end{array}$ & $\begin{array}{l}24 \text { - Qual } \\
\text { era sua } \\
\text { experiência } \\
\text { profissional } \\
\text { (em anos) } \\
\text { na época } \\
\text { em que } \\
\text { ocorreu a } \\
\text { inovação? }\end{array}$ \\
\hline EFICI & Processo & Baixa & Parcerias & 2-6 meses & \begin{tabular}{|l|}
$\begin{array}{l}\text { Rigidez } \\
\text { organ }\end{array}$ \\
\end{tabular} & Nacional & Ativ. Administ & Prestador & Real estate & Supervisor & +20 anos \\
\hline QUALITA & Processo & Baixa & Externa & 2-6 meses & \begin{tabular}{|l|}
$\begin{array}{l}\text { Rigidez } \\
\text { organ }\end{array}$ \\
\end{tabular} & Estrangeira & \begin{tabular}{|l|} 
Ativ. \\
Financeiras \\
\end{tabular} & Ambos & Real estate & Gerente & +20 anos \\
\hline SUSTE & Organizacional & Média & Parcerias & +12 meses & Tempo & Estrangeira & Indústria & Tomador & Real estate & Supervisor & 6-10 anos \\
\hline FINAN & Processo & Média & Parcerias & +12 meses & \begin{tabular}{|l}
$\begin{array}{l}\text { Rigidez } \\
\text { organ }\end{array}$ \\
\end{tabular} & Estrangeira & Utilidades & Prestador & $\begin{array}{l}\text { Obras e } \\
\text { reformas }\end{array}$ & Gerente & 16-20 anos \\
\hline
\end{tabular}

